\title{
Sustainable Product Development and its Effect on Performance in High-Technology Firms
}

\author{
By \\ HANUV MANN, BA (Hons.); MBA
}

A thesis submitted to the Faculty of Graduate and Post Doctoral Affairs in partial fulfillment of the requirements

for the degree of Doctor of Philosophy in Management

Eric Sprott School of Business

Carleton University

Ottawa, Canada

Summer 2016

(C) Copyright 2016 Hanuv Mann 


\begin{abstract}
The widely acknowledged need for sustainable development has impacted not only countries and society but also organizations and how they conduct business. While literature has focussed on the environmental impact of organizations and people, as well as how to model the design of products to be environmentally sustainable; not many have focussed on how to develop products that are sustainable for the organization. This study endeavours to understand how organizations can aim their sustainable-product development processes so as to create sustainable products. It is posited that the strategic orientation of an organization influences the sustainable-product development processes that take place, which in turn impact the attributes of the product(s) being developed as well as the performance of the organization. This study consists of two parts; the first is exploratory in nature. Most of the research originates from the field of new product development and is tested in the context of sustainable products. In the second part, the study conducts an empirical survey to confirm the learning from the exploratory study. Thisresearch is important since it provides essential insights into how organizations develop products that are sustainable in nature by incorporating changes at the strategic level.
\end{abstract}




\section{Acknowledgements}

A very wise lady has often been quoted to me, who said "A good thesis is a finished thesis." I believe that the thesis that follows is definitely a most excellent thesis (if I do say so myself), but only because of the people who made it possible for me to finish it.

First and foremost, I wish to express my gratitude to my supervisor, Dr. Uma Kumar. With her unerring instincts and vast experience, she always knew when to gently nudge and when to shove. Everything I know about myself as a scholar is because of her guidance and understanding. I don't think I would have ever found anyone else who is as concerned about the pursuit of excellence as I am.

I am grateful to my fantastic committee, who, despite their incredibly busy schedules managed to provide all the advice and feedback I requested from them so many times. Dr. Cai, Dr. Nsakanda and Dr. Vinod Kumar have especially been so kind in lending me their expertise and critical evaluations when I needed them.

My friends, Ved and Aareni, thank you for being there when it matters the most; for listening to endless opinions, theories, complaints and questions over coffee; and for sometimes dropping everything to help with the crises of the moment. I cannot thank you enough.

I would like to dedicate this thesis to my family:

My Mother: My Chief Sufferer. Thank you for going above and beyond the call of duty (if a ceiling ever did exist for motherhood). Let the record show that you "told me so" and that you were right. From the start, every single time.

My Father: $\quad$ Parent, Mentor, Colleague, Friend, Sense-Maker, Advisor, Confidant, Devil's Advocate, Mediator, Guide, Emergency Babysitter. The list is endless. Thank you.

My Husband: My Modern-Day Saint and Personal Barista rolled into one. Thank you for not flinching at our annual "this-is-taking-longer-than-I-expected" talks. I am very lucky.

My Brother: My Practical Pragmatist. Thank you for your refreshing doses of reality, they really help keep things in perspective.

My Daughter: My Little General. Thank you for keeping everyone in line. 


\section{Table of Contents}

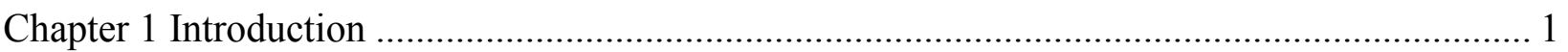

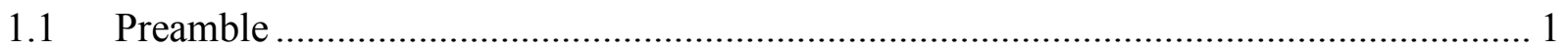

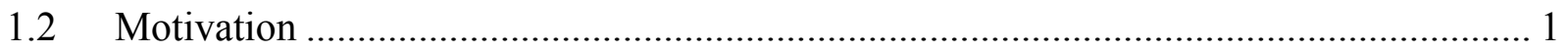

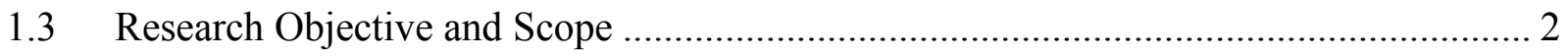

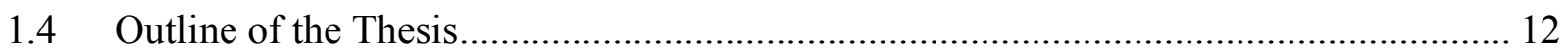

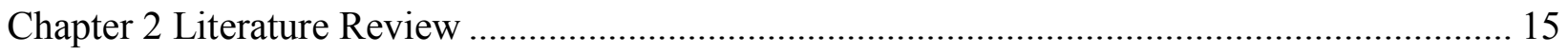

2.1 Antecedents of (Sustainable) Product Development ................................................... 15

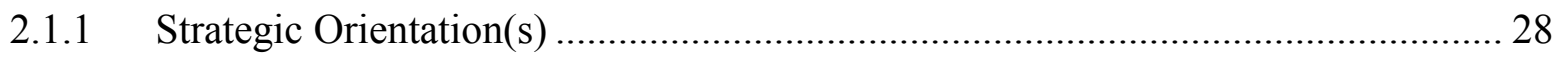

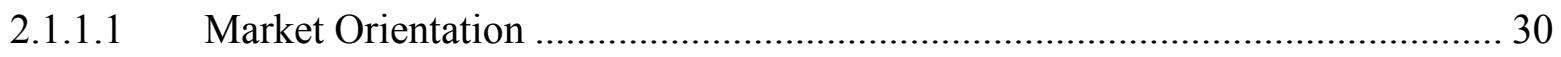

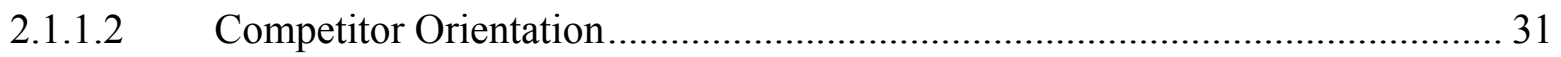

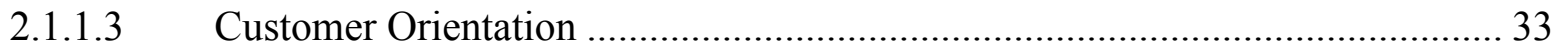

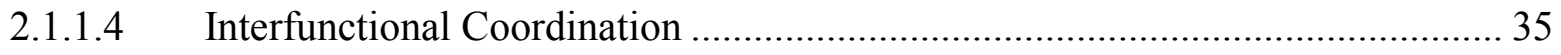

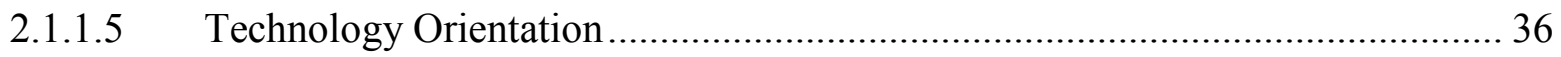

2.1.1.6 Sustainability Orientation ................................................................................ 39

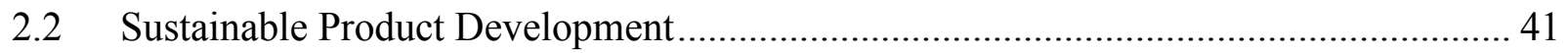

2.2.1 Domain-specific knowledge integration. ......................................................... 42 
2.2.2 Procedural knowledge integration.

2.2.3 Flexible Strategic Decision-making..... 47

2.3 Attributes of Sustainable Products 48

2.3.1 Product Fecundity 50

2.3.2 Product Fidelity 51

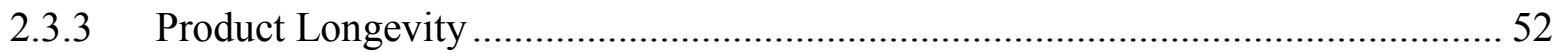

2.4 Product Attributes and Characteristics of Sustainable Products ............................. 53

2.4.1 Customer Satisfaction and Fecundity/Fidelity ............................................. 54

2.4.2 Dual Focus and Fidelity/Longevity ........................................................ 55

2.4.3 Life-cycle Orientation and Longevity/Fecundity ........................................ 56

2.4.4 Significant Improvements, Continuous Improvement and Fidelity/Longevity/

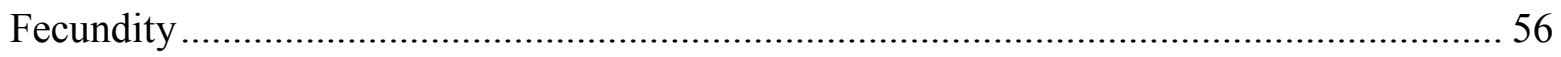

2.4.5 Competing Offers and Fecundity/ Fidelity/ Longevity ...................................... 57

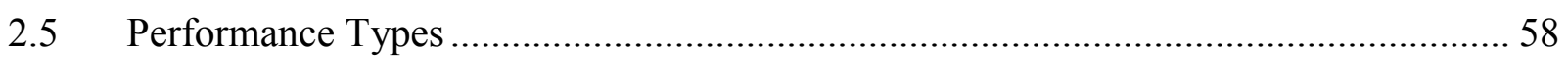

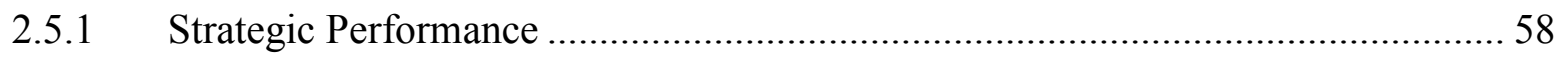

2.5.2 The Triple Bottom Line: Economic, Social and Environmental Performance ...... 60

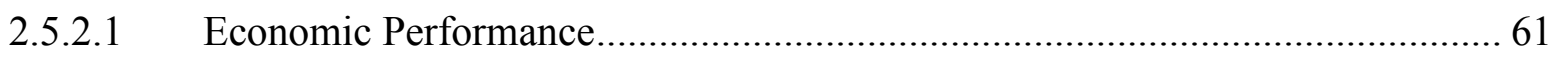

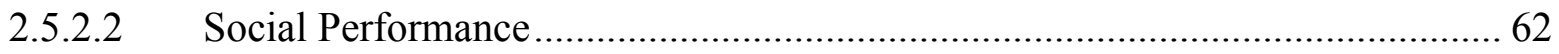


Chapter 3 Theoretical Framework. 66

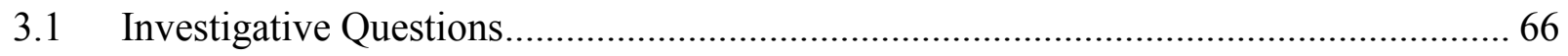

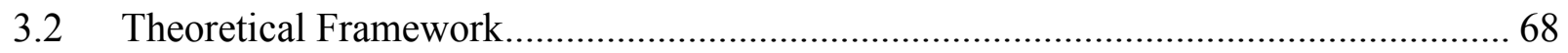

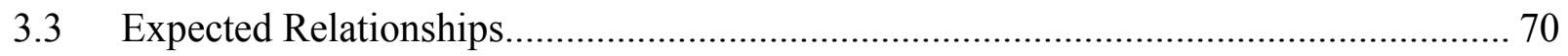

3.3.1 Strategic Orientation and S-PD processes (SPDP) .................................... 71

3.3.2 S-PD processes (SPDP) and performance............................................... 74

3.3.3 S-PD processes (SPDP) and Product Attributes ............................................. 78

Product Attributes and Performance ............................................................. 79

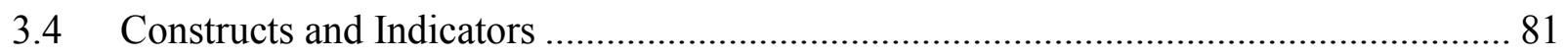

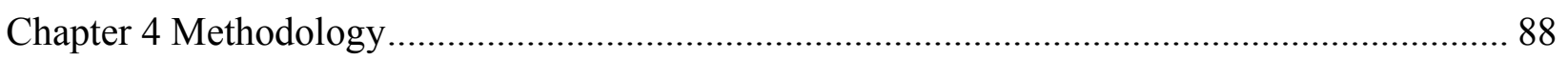

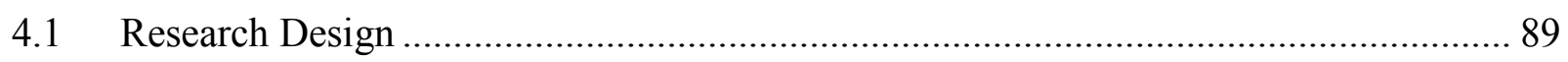

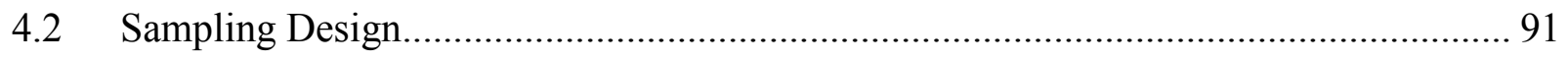

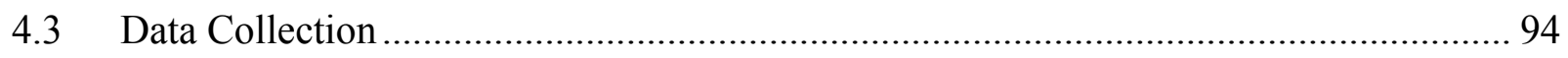

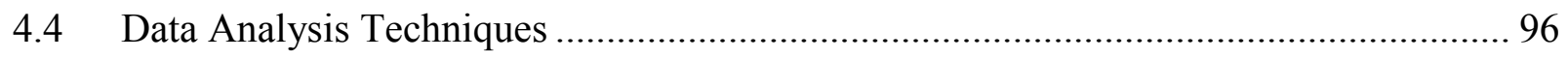

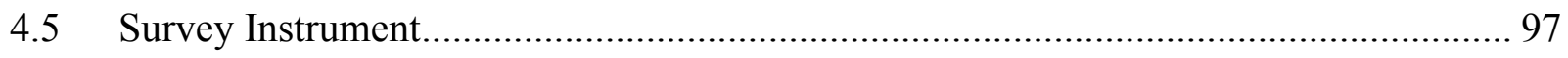

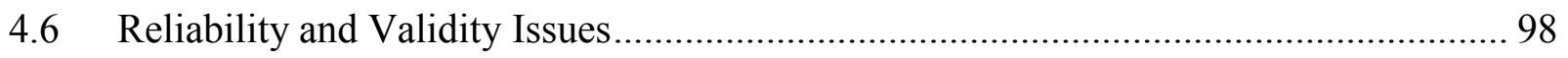


Chapter 5 Stage 1 Results. 102

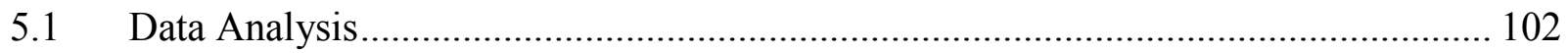

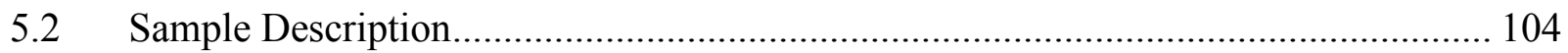

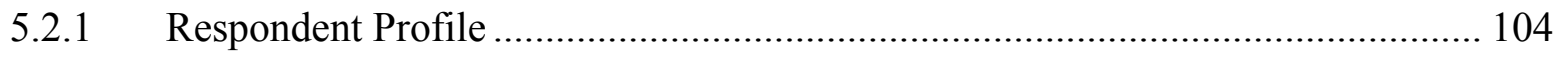

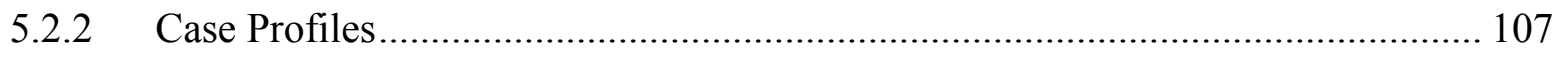

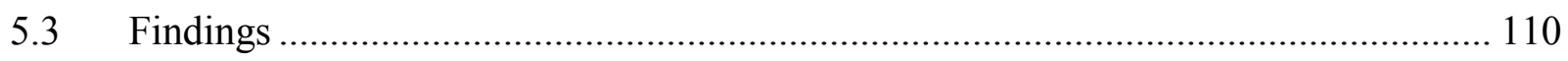

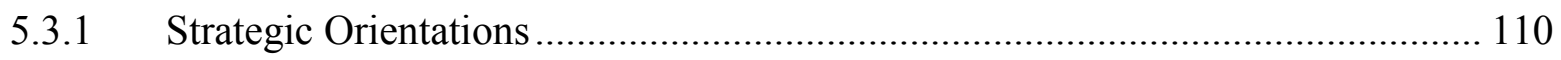

5.3.2 Sustainable Product Development Processes ................................................. 116

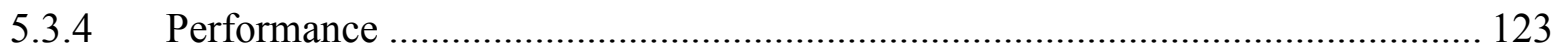

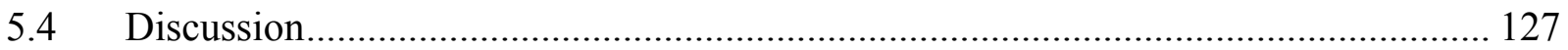

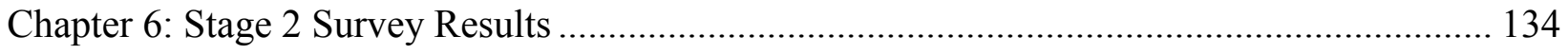

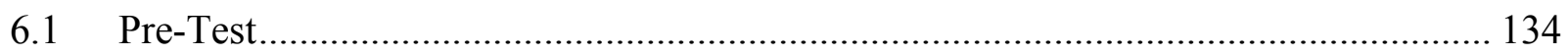

6.2 Administration of Survey and Response Rate ............................................... 138

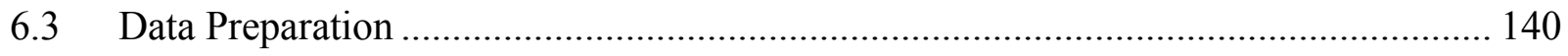

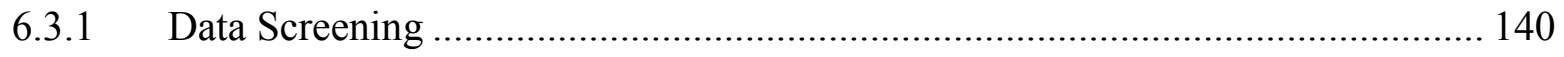

6.3.1.1 Data Cleanup and Missing Values........................................................ 140

6.3.1.2 Checking Response Abnormality: Outliers and Unengaged Responses .......... 144 
6.3.1.3 Data Normality 145

6.4 Common Method Variance 147

Chapter 7: Preliminary Data Analysis.

7.1 Sample Characteristics 149

7.1.1 Respondent Profiles.

7.1.2 Organizational Characteristics 152

7.1.3 Product Characteristics....................................................................... 158

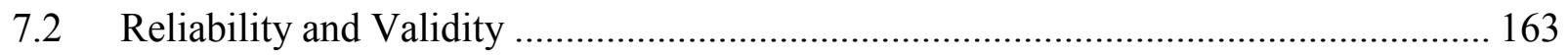

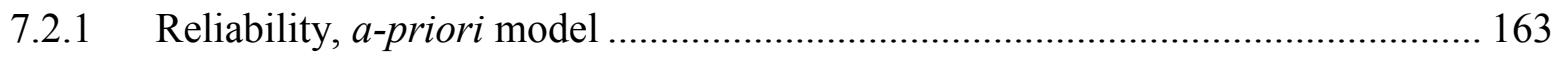

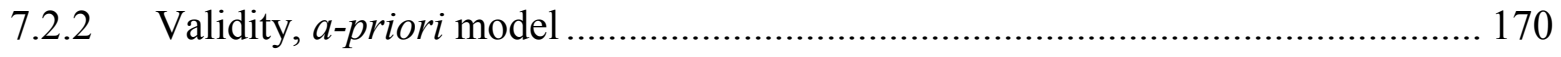

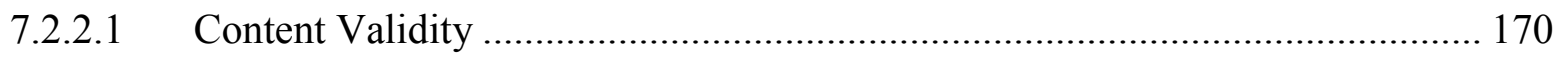

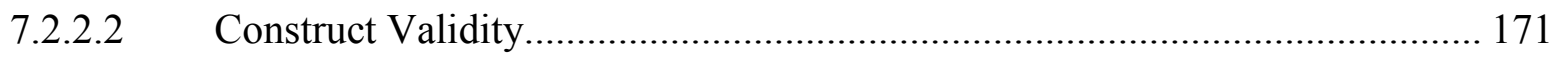

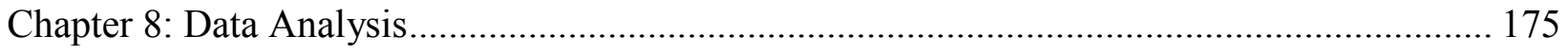

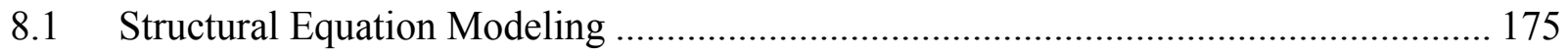

8.1.1 Confirmatory Factor Analysis (CFA) and Measurement Models ...................... 176

8.1.2 Fitting constructs with theory: Second Order Modeling ................................ 191

8.2 The Complete Structural Model: Testing Posited Hypotheses.................................. 205 
8.3 Assessing Total Indirect Effects, Strategic Orientation and Performance

Chapter 9: Discussion

9.1 Interpretation of the a-priori model and model variations.......................................... 222

9.2 Revisiting the Research Question and Objectives .................................................. 227

9.2.1 Strategic Orientation and Sustainable Product Development Processes............... 228

9.2.2 Strategic Orientation and Product Attributes ...................................................... 230

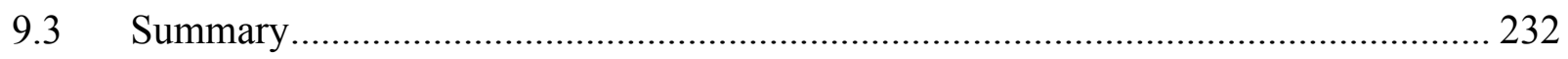

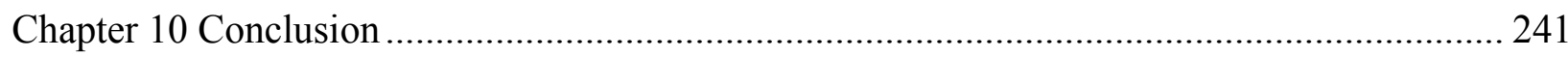

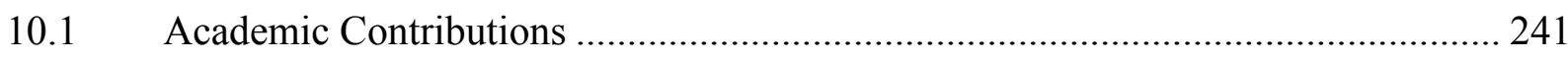

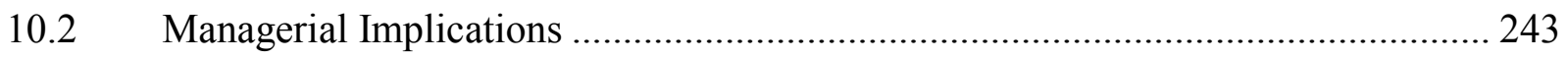

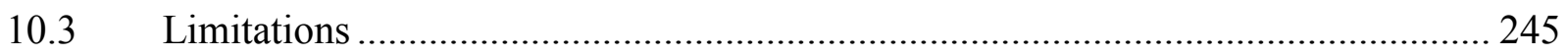

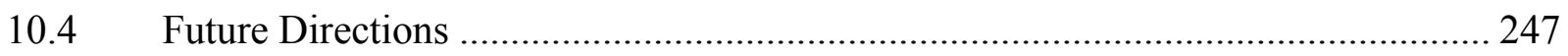

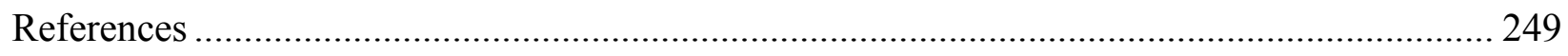

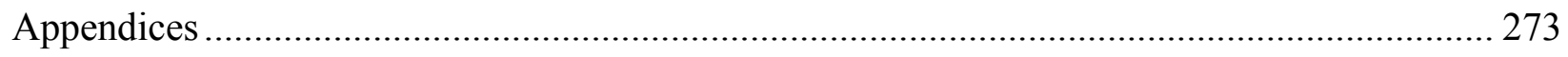




\section{List of Tables, Figures and Appendices}

\section{List of Tables}

Table 1.1 Definitions on sustainability aspects available in the literature

Table $3.1 \quad$ Constructs and their Indicators

Table 4.1 Organizational Size Categories as accounted by the number of employees

Table 5.1 Respondent Profiles $\quad$...106

Table 5.2 Ranking of Strategic Orientations $\quad$..112

Table 5.3 Ranking of Sustainable Product Development Processes $\quad$...117

Table 5.4 Ranking of Product Attributes $\quad$...121

Table 5.5 Ranking of Performance $\quad \ldots 124$

Table 5.6 Respondent Focus on Hypothesized Themes $\quad . .129$

Table 6.1 Test Respondent: JK $\quad \ldots 135$

Table 6.2 Test Respondent: MIJ $\quad \ldots 135$

Table 6.3 Test Respondent: GN $\quad \ldots 136$

Table $6.4 \quad$ Test Respondent: $M S \quad \ldots 137$

Table 6.5 Test Respondent: SV $\quad$...137

Table 6.6 Coding of the Categorical Data $\quad$..142

Table 6.7 Descriptive Statistics of Dependent and Independent Variables $\quad . .147$

Table 7.1 Composite Reliability $\quad \ldots 170$

Table 7.2 Average Variance Extracted $\quad . .173$

Table 7.3 Construct Correlations with AVE on the diagonal $\quad . .174$

Table 8.1 Statistics for Alternate Models for Strategic Orientation $\quad$...193

Table 8.2 Statistics for Alternate Models for Sustainable Product Development Processes

Table 8.3 Statistics for Alternate Models for Product Attributes $\quad$...200

Table 8.4 Statistics for Alternate Models for Performance ‥202

Table 8.5 Composite Reliability for Second Order Constructs $\quad$ C.205

Table 9.1 Subset Models to Determine the Cause of Sign Reversal $\quad$..226

Table 9.2 Summary of the Tested Hypotheses _..238 


\section{List of Figures}

Figure 2.1 Cradle to Cradle life-cycle $\quad . .21$

Figure 2.2 Interactivity and coherence between hierarchical corporate levels for environmental management $\quad . .24$

Figure 2.3 A systemic model for product development function in the organization $\quad \ldots 25$

Figure 2.4 A modified systemic model showing the gradations of focus and consequent impact of an organization. $\quad . .26$

Figure $3.1 \quad$ General Framework $\quad$...68

Figure 3.2 Theoretical Framework $\quad$..69

Figure 7.1 Locations of Respondents $\quad$..150

Figure 7.2 Designations/Titles of Respondents $\quad \ldots 151$

Figure 7.3 Industries Represented $\quad \ldots 153$

Figure 7.4 Area(s) of Operations $\quad \ldots 155$

Figure 7.5 ISO 14000 Certification Status $\quad \ldots 156$

Figure 7.6 Ownership Type $\quad \ldots 157$

Figure $7.7 \quad$ Product Offering $\quad$...159

Figure 7.8 Product Novelty (Newness) $\quad$..160

Figure $7.9 \quad$ Product Version $\quad$...161

Figure 7.10 Number of Years since Product Version was Introduced
in the Market.

Figure 8.1 Measurement model of Technology Orientation (TECH) _..178

Figure 8.2 Measurement model of Competitor Orientation (COMP) _..179

Figure 8.3 Measurement model of Sustainability Orientation (SUSO) _..180

Figure 8.4 Measurement model of Interfunctional Coordination (IFC) $\quad . .180$

Figure 8.5 Measurement model of Customer Orientation (CUST) _..181

Figure 8.6 Measurement model of Domain Specific Knowledge

Integration (DSKI) $\quad \ldots 182$

Figure 8.7 Measurement model of Procedural Knowledge Integration (PKI) ...183

Figure 8.8 Measurement model of Flexible Decision Making (FDM) _..184

Figure 8.9 Measurement model of Product Fecundity (FEC)

Figure 8.10 Measurement model of Product Fidelity (FID) $\quad . .185$

Figure 8.11 Measurement model of Product Longevity (LONG) _..187

Figure 8.12 Measurement model of Economic Performance (ECPERF) _..188

Figure 8.13 Measurement model of Social Performance (SOCPERF) _..189

Figure 8.14 Measurement model of Environmental Performance (ENVPERF) ...190

Figure 8.15 Measurement model of Strategic Performance (STRPERF) _..191

Figure 8.16 Measurement model of Strategic Orientation (MKTO) _..195

$\begin{array}{ll}\text { Figure 8.17 } & \begin{array}{l}\text { Measurement model of Sustainable Product Development } \\ \text { Processes (SPDP) }\end{array}\end{array}$

Figure 8.18 Measurement model of Product Attributes (ATTR) …201

Figure 8.19 Measurement model of Performance (PERF) _..204

Figure 8.20 Conceptual Hypothesized Structural Model $\quad$..206

Figure 8.21 Structural Model (with the standardized solution path coefficients) ...207 


\section{List of Appendices}

Appendix $1 \quad$ List of Abbreviations Used $\quad$..267

Appendix 2 Draft Questions prepared for semi-structured interviews _..268

Appendix 3 Cover Letter for Survey Draft $\quad$..271

Appendix 4 Ethics Statement Draft $\quad$...274

Appendix $5 \quad$ Letter of Information Draft $\quad$...279

Appendix $6 \quad$ Follow-Up Letter (Email) for Survey Draft $\quad$...282

Appendix $7 \quad$ Script for Interview Phonecall /Initial Email $\quad$..284

Appendix $8 \quad$ Conceptual Primer for Interviewees $\quad . .285$

Appendix 9 Survey Questionnaire $\quad . .288$

Appendix 10 Survey Data Response Trend $\quad$...302

Appendix 11 Skewness and Kurtosis Values for all Items $\quad$...303

Appendix 12 Models A to D for the Second Order Constructs $\quad$...305

Appendix 13 LISREL Output for X on Eta Total and Indirect Effects $\quad$...320

Appendix 14 SUB AEffect of Product Attributes on Performance $\quad \ldots 325$

Appendix 14 SUB BEffect of Strategic Orientation on Product Attributes and the effect on Performance $\quad . .326$

Appendix 14 SUB CEffect of Strategic Orientation on Sustainable product development processes and Performance $\quad$...327

Appendix 14 SUB DEffect of Sustainable product development processes on Product attributes and Performance $\quad$...328

Appendix 15 SIMPLIS code for a-priori model $\quad$..329

Appendix 16 Items Removed from Analysis $\quad$...331

Appendix 17 Modification Indices Applied and Reasons $\quad$..335

Appendix 18 Full Correlation Matrix from Data _..337 


\section{Chapter 1 Introduction}

\subsection{Preamble}

This research explores the connection between the strategic orientations of an organization and the product development processes, the attributes of sustainable products and organizational performance.

\subsection{Motivation}

After the dual economic crises in 2008 and 2010, organizations, as well as economies are realising that they must re-prioritise their strategic planning to introduce operations that truly incorporate aspects of sustainability ${ }^{1}$ (Boons et al., 2013). The need to widen the scope of operations to survive the post-crises business and regulatory world is an urgent long-term planning goal (Boons et al., 2013; Dissanayake et al., 2016; Higgins \& Coffey, 2016; Mann et al., 2010; Montalvo et al., 2011). include

For survival in the long term, organizations should consider orienting themselves toward sustainability at the strategic level. Yet, more than this, the focus should now be on introducing processes that support the design and development of sustainable products that improve the performance of the organization without negatively impacting society and the environment at

\footnotetext{
${ }^{1}$ These aspects comprise of a spectrum of operational (short term) and strategic (long term) actions, not limited to, but including reducing waste and toxic emissions, building products and services with a more useful lifecycle, more durability and creating an overall "cleaner" organizational impact on the environment.
} 
large (Boons and Leudeke-Freund, 2013; Gaziulusoy et al., 2013; Zhang et al., 2013). This stream of thought might be sound at the conceptual level, but is as yet untested in the literature. This study empirically tests whether the connections between strategic product and process sustainability and triple bottom line performance hold true in the real world.

\subsection{Research Objective and Scope}

Since research on sustainable development has evolved and found enthusiastic researchers within the field of management, questions have been raised as to what exactly differentiates the sustainable system, the sustainable organization, the sustainable supply chain and so on from the regular varieties of the same (Boons and Leudeke-Freund, 2013; Boons et al., 2013; Franceschini et al., 2016; Jaehn, 2016; Linton et al., 2007; Mann et al., 2010; Tibben-Lembke, 2002).

The research question of interest can be stated as follows: What strategic orientations and product development processes lead to the development of sustainable products in hightechnology organizations and what is their effect on performance?

Hence, this study has two objectives:

1. To test whether the relationships mentioned in the research question above, as adopted from the NPD literature, similarly exist within the context of the development of sustainable products.

2. To study how strong these abovementioned relationships are within the context of development of sustainable products. 
The importance of researching these objectives is discussed systematically in detail below.

Interestingly, operations management and technology management researchers have been working on the concepts like reverse logistics, recycling, reuse, lean operations, and end-ofproduct-life issues for long, some of which are now considered to be core topics of sustainable management (Boons et al., 2013; Bereketli and Genevois, 2013; Bansal and Roth, 2000). At a higher level, apart from the sustainability topics of conservation and environmental consciousness, research is also being conducted on sustainable organizations and how sustainability can be incorporated within everyday functioning so that not only is the firm sustainable in nature, but its offerings are sustainable from social, financial and environmental perspectives.

Previous studies have researched the meaning and consequences of product life-cycles and arrived at the conclusion that social and environmental responsibility mandates closing life-cycle loops either by strengthening reverse logistics or by redesigning products that are more amenable to disassembly and reuse at multiple fronts, using strategies such as life-cycle assessment (LCA) (Fleischmann et al., 1997; Manda et al., 2016; Metta and Badurdeen, 2013; Rubio et al., 2008; Tibben-Lembke, 2002). With the addition of sustainability concerns, the concept of the closed life-cycle loop has advanced in research to reflect social, environmental and financial needs of the system each product exists within. This includes the organization handling its product conceptualisation, modification, development, production and marketing in a more sustainable way. All this has to take into account the consumer who uses it, the reverse logistics that allows the product to be disassembled and reworked into a new product or raw material; and lastly the 
environment and society in which the product exists and travels, and which it can potentially impact.

\subsubsection{A Sustainable Product}

This proposed research is the study of how, from an organizational perspective, products can be aimed toward being sustainable. From the above discussion and current research, it is possible to derive that the concept of a 'sustainable' product would be relative (Boons et al., 2013; Carrillo-Hermosilla et al., 2010; Hallstedt et al., 2015; Mascle, 2013) and not absolute. The degree to which a product is amenable to reworking or recycling is likely to make it that much more sustainable. However, the 'scale' along which this relative sustainability can be measured is as yet not researched, and is outside the scope of this study. In fact, various authors have used various descriptions of how a sustainable product or its components may be reused. Mascle (2013) calls this concept 'rebirth' (of the product) and provides a number of previous authors' views on what the term rebirth may constitute:

“1. Re-use, maintenance, reconditioning, recycling of materials with or without separation and disposal (Rose et al.,2000).

2. Resale, reconditioning, upgrading, material or part recycling and disposal (Low et al., 1996, 1998).

3. Reusing, reconditioning, remanufacturing, material recycling (Staffiere, 1995). 
4. Reusing, refurbishing, reconditioning, material recycling and waste exchange (Gertsakis et al., 1997).”

(Mascle, 2013, p. 235)

For the purposes of this research, the concept of rebirth includes the design and redesign of products that may either be in the early stages of development, undergoing the process of conceptualization and development; or may even be in the process of being manufactured and sold in the market.

At this stage, it is incumbent on this discussion to delineate the definition of what constitutes a 'sustainable product'. Since the literature on sustainability can be described as formative at best and somewhat nebulous at present, a precise and standardized definition of a 'sustainable product' has not, at the time of this research, been widely agreed upon in research published in peer-reviewed journals. The following table (Table 1.1) provides an account of the literature that has posited various definitions relating to sustainability:

\begin{tabular}{|l|l|l|l|}
\hline \multicolumn{1}{|c|}{ Author/s } & \multicolumn{1}{|c|}{ Definition or Concept } & Papers Cited & \multicolumn{1}{|c|}{$\begin{array}{c}\text { Development of } \\
\text { concept }\end{array}$} \\
\hline $\begin{array}{l}\text { Boons } \text { et al., } \\
2013\end{array}$ & $\begin{array}{l}\text { sustainable innovation defined as "innovation that } \\
\text { improves sustainability performance", where such } \\
\text { performance includes ecological, economic, and }\end{array}$ & Boons, 2009 & $\begin{array}{l}\text { From sustainable } \\
\text { development to } \\
\text { systemic sustainable } \\
\text { innovation }\end{array}$ \\
\hline
\end{tabular}




\begin{tabular}{|c|c|c|c|}
\hline & social criteria & & \\
\hline $\begin{array}{l}\text { Govindanet } \\
\text { al., } 2013\end{array}$ & $\begin{array}{l}\text { Sustainability is "design and operation of human } \\
\text { and industrial systems to ensure that humankind's } \\
\text { use of natural resources and cycles do not lead to } \\
\text { diminished quality oflife due either to losses in } \\
\text { future economic opportunities or toadverse impacts } \\
\text { on social conditions, human health and the } \\
\text { environment }\end{array}$ & $\begin{array}{l}\text { Hutchins and } \\
\text { Sutherland, } \\
2008\end{array}$ & $\begin{array}{l}\text { From sustainable } \\
\text { development to } \\
\text { sustainability in } \\
\text { supplier selection and } \\
\text { performance measures } \\
\text { in supply chains }\end{array}$ \\
\hline $\begin{array}{l}\text { Gunasekaran } \\
\text { and Gallear, } \\
2012\end{array}$ & $\begin{array}{l}\text { Sustainable business development "This can be } \\
\text { defined as the development and management of a } \\
\text { business (either in manufacturing or services)so } \\
\text { that itnot only satisfies the current needs of the } \\
\text { market and society, butalso the future needs of } \\
\text { them." }\end{array}$ & NA & $\begin{array}{l}\text { From sustainable } \\
\text { development to } \\
\text { sustainable business } \\
\text { development }\end{array}$ \\
\hline $\begin{array}{l}\text { Pagell and } \\
\text { Gobeli, } 2009\end{array}$ & $\begin{array}{l}\text { Environmentally sustainable organizations "create } \\
\text { production systems that maximize resource } \\
\text { efficiency and minimize harmful ecological } \\
\text { impacts" }\end{array}$ & $\begin{array}{l}\text { Starik and } \\
\text { Rands, 1995; } \\
\text { Kleindorfer et } \\
\text { al., } 2005\end{array}$ & $\begin{array}{l}\text { To the triple bottom } \\
\text { line impacts of being } \\
\text { an environmentally } \\
\text { sustainable } \\
\text { organization }\end{array}$ \\
\hline $\begin{array}{l}\text { Pagell and } \\
\mathrm{Wu}, 2009\end{array}$ & $\begin{array}{l}\text { A sustainable supply chain is then one that } \\
\text { performs well on both traditional measures of profit } \\
\text { and loss as well as on an expanded } \\
\text { conceptualization of performance } \\
\text { that includes social and natural dimensions }\end{array}$ & $\begin{array}{l}\text { Gladwin, } \\
\text { Kennelly and } \\
\text { Krause 1995; } \\
\text { Starik and } \\
\text { Rands 1995; } \\
\text { Jennings and } \\
\text { Zandbergen } \\
\text { 2005; } \\
\text { Kleindorfer et } \\
\text { al., } 2005\end{array}$ & $\begin{array}{l}\text { To what constitutes a } \\
\text { sustainable supply } \\
\text { chain }\end{array}$ \\
\hline $\begin{array}{l}\text { Seuring and } \\
\text { Müller, } 2008\end{array}$ & $\begin{array}{l}\text { Sustainable supply chain management as "the } \\
\text { management of material, information and capital } \\
\text { flows as well as cooperation among companies } \\
\text { along the supply chain while taking goals from all } \\
\text { threedimensions of sustainable development, i.e., } \\
\text { economic, environmental and social, into account }\end{array}$ & $\begin{array}{l}\text { Dyllick and } \\
\text { Hockerts, } \\
2002 ; \\
\text { Elkington, } \\
1997 ; \\
\text { Brundtland }\end{array}$ & $\begin{array}{l}\text { From sustainable } \\
\text { development to } \\
\text { sustainable supply } \\
\text { chain management }\end{array}$ \\
\hline
\end{tabular}




\begin{tabular}{|l|l|l|l|}
\hline & $\begin{array}{l}\text { which are derived from customer and stakeholder } \\
\text { requirements." }\end{array}$ & $\begin{array}{l}\text { Commission, } \\
1987\end{array}$ & $\begin{array}{l}\text { al., 2005 } \\
\text { Kleindorfer } e t\end{array}$ \\
$\begin{array}{l}\text { sustainable OM [operations management] as 'the } \\
\text { structure and manageits business processes to } \\
\text { obtain competitive returns on its capital assets } \\
\text { without sacrificing the legitimate needs of internal } \\
\text { and external stakeholders and with due regard for } \\
\text { the impact of its operations on people and the } \\
\text { environment.' }\end{array}$ & $\begin{array}{l}\text { Brundtland } \\
\text { Commission, } \\
1987\end{array}$ & $\begin{array}{l}\text { From sustainable } \\
\text { development to } \\
\text { sustainable operations } \\
\text { management }\end{array}$ \\
\hline $\begin{array}{l}\text { Original } \\
\text { Brundtland } \\
\text { Commission } \\
\text { Definition, } \\
1987\end{array}$ & $\begin{array}{l}\text { development that meetsthe needs of the present } \\
\text { without compromising theability of future } \\
\text { generations to meet their own needs }\end{array}$ & NA & $\begin{array}{l}\text { Original definition of } \\
\text { sustainable } \\
\text { development from the } \\
\text { World Commission on } \\
\text { Environment and } \\
\text { Development }\end{array}$ \\
\hline
\end{tabular}

Table 1.1:

Definitions on sustainability aspects available in the literature (sources: various)

However, perhaps the most comprehensive delineation of what a sustainable product should offer comes from the book Sustainability Marketing: A Global Perspective by FrankMartin Belz and Ken Peattie (2009). The authors propound a list of six characteristics that are vital in differentiating sustainable products from others, which also form the basis of our understanding of such products:

1. Customer Satisfaction. Belz and Peattie (2009) find that this is the most important criterion for a product's survival in the market. In this research, customer satisfaction is 
duly considered an important consideration, part of an organization's strategic orientation and thus inherent in the development of products.

2. Dual Focus. The second characteristic put forth by the authors is that a product should have a social as well as an ecological focus. As discussed in Sections 2.1.1.6., 2.3. and 2.4., sustainable products are envisaged to possess attributes that positively and significantly impact the social as well as environmental performance in an organization, with implications that are as valid outside the organization as within it.

3. Life-cycle orientation. The authors posit that the entire life-cycle from the cradle (sourcing and raw materials) to the grave (post-use) should be considered. In this research, as previously discussed (and further considered in Section 2.1), the life-cycle of the product is essential to the degree of its 'sustainability'. One of the most prominent differences between other products and sustainable products is clearly outlined as the management of the product life-cycle to minimise waste and premature disposal.

4. Significant improvements. Belz and Peattie (2009) also posit that a product should contribute either on a global socio-ecological scale or at the very least provide some indication of its socio-ecological performance throughout its life-cycle. In this study, this issue has been addressed not only via incorporating a strategic sustainability orientation at the organizational level (Section 2.1.1.6.), but also at the performance end, where social as well as environmental performance (Section 2.4) is seen to be an accountable measure of the impact of the sustainable product in its complete life-cycle.

5. Continuous improvement. The fifth point that the authors provide deals with the changing nature of the market and hence the requirement of products to change with time. In this study, the focus is on making products 'more' sustainable, since the concept is not a static 
absolute (Belz and Peattie, 2009; Mascle, 2013). The idea of improving products as per changing requirements and differing levels of what is sustainable is also internalised in this research (Section 2.1).

6. Competing offers. The last characteristic mentioned by the authors is that a sustainable product may sometimes lag behind in providing competing offers since it has to incorporate costs associated with socio-ecological impacts. Therefore, the authors suggest considering performance at the social, environmental and economic levels. This research also incorporates this self-same concept by considering these three levels of performance for measurement (Section 2.4.2).

For the purposes of this research, a 'sustainable product' (or service) as defined by Belz and Peattie (2009, p. 154) satisfies "customer needs and significantly improve[s] the social and environmental performance along the whole life cycle in comparison to conventional or competing offers."

In addition to these six characteristics, the authors also refer to other important aspects that are incorporated in this study. The first aspect that is elucidated is that of cleaner production (Belz and Peattie, 2009). As part of developing sustainable products, the process of production itself should be a consideration if the impact of the entire life-cycle is to be considered, as discussed further in Section 2.1. Related to this, is the second aspect of providing safe and healthy products for the customers (Belz and Peattie , 2009). A product offering is expected to not only work in a manner expected of it by the customer, but also not cause severe harm or 
damage when misused (Langley et al., 2012; Rogers, 2003; Heylighen, 1998). This is further dealt with as a part of sustainable product attributes in Section 2.3.

Another (third) aspect the authors mention is that a sustainable product needs to be durable, not just energy efficient. This is yet another important point as related to this research. The authors state that most products in the current market are deliberately planned for early obsolescence that is either built-in, psychological or technological (Belz and Peattie, 2009). Such an attitude is not conducive to developing or modifying products for sustainability. The position of this research is similar to the above-mentioned authors (discussed in the latter Section 2.3) where it is found that the extension of a product's life-cycle via one form or another actually leads toward greater sustainability and a more positive overall social and environmental impact (Belz and Peattie, 2009; Langley et al., 2012; Manda et al., 2016; Metta and Badurdeen, 2013). To assist in such an endeavour, the authors suggest services that complement sustainability aspects of products, such as product-related services or use-oriented services which would help in customers realising and optimising the application of the product being sold to them. They further go on to suggest that developers and organizations should not fall prey to "sustainability marketing myopia", an outlook that ignores broader expectations and customer needs for a myopic focus on socio-ecological attributes, which are ultimately of the most optimal strategic use in their auxiliary capacity (Belz and Peattie , 2009). This study attempts to incorporate these basic conceptual points into its view of how sustainable products can be developed in a manner which is viable for an organization in the long-term as well as the short-term.

While the extant literature covers mainly new product development (wherein it focuses on the systems approach (e.g. Boons and Lüdeke-Freund, 2013;Gaziulusoy and Boyle, 2013; Lockrey and Johnson, 2013; Manda et al., 2016), the scope of this study includes products that 
have been developed, and those that are to be redesigned or improved to render them more sustainable. So, the term 'product development' is being used in this study, rather than specifically 'new product development'.

Moreover, prior research has yet to exhaustively discover what product development processes are optimal or even required for the development of sustainable products and when. This study, therefore, functions under the assumption of the quintessential 'black box'. In other words, the objective of this study does not involve identifying each and every one of those processes that assist the creation of sustainable products but acknowledges their rightful existence. This research only requires a part of those processes that are operating at a strategic level. The scope therefore mandates that the other processes, at all management levels, be assigned the status of residing in the black-box - active yet unidentified and not being assessed as a part of the relationships hypothesized.

To summarize, the purpose of this research is to understand how the strategic orientations of a firm can affect the sustainable product development processes and assist in the creation of sustainable products, which in turn leads to improved strategic performance, and the now generally discussed "triple bottom line" (Elkington, 1997) of social performance, environmental performance and financial performance. Based on a study conducted by Lambert and Davidson (2013) the type of business most prone to change and innovation was related to high-technology, which included information technology firms, biotechnology firms and others. Also, the research of Derk Loorbach and Katinka Wijsman (2013) finds a shift of businesses towards sustainabilityis gaining momentum and is also driven by use of technology, a phenomenon also noted previously by David Teece (2010). Therefore, high-technology firms are seen to be more 
involved with the development of sustainable (new or otherwise) products, which makes these firms our primary focus.

The study documented here was conducted in two parts. The first part is a qualitative exploration of whether the constructs that are empirically verified in the NPD and product adoption literature are applicable in the case of sustainable products. The second part of the study is a quantitative analysis of the strength and impact of these constructs, testing their nature in a sustainability context.

\subsection{Outline of the Thesis}

This thesis is divided into twelve parts, or ten chapters. The first Chapter forms the Introduction of the document that is the doctoral thesis. The Introduction includes a preamble, which is a summary statement of the research; an outline of the motivation of this research endeavour;an exploration and definition of what constitutes a sustainable product;a detailed explanation of the research objective of the proposed thesis; a statement of the research question and an outline of the structure of the document.

Chapter Two constitutes the detailed Literature Review for the proposed study. The literature review consists of (a) the antecedents and research gaps that lead to the literature review of the current study, (b) the strategic orientations of the organization discussed in the literature till date (c) the product development processes themselves (d) the attributes of sustainable products and, (e) the dimensions of performance of an organization that may be affected. 
Chapter Three is an explanation of the specific theoretical framework that has been proposed for study. The chapter includes the questions under investigation, the a-priori model as well as the relationships proposed by this study.

Chapter Four covers the methodology proposed for this study. The chapter includes an overview of the approach as well as specific delineations of the suggested research design, the research sample, the proposed data collection techniques and the anticipated data analysis techniques that would be employed by this study.

Chapter Five describes the first stage of the data collection and results of the study, that of the interviews. The chapter details the profiles of the interviewees and the methodology used to conduct the interview then moves on to discuss the results of the same.

Chapter Six forms the first part of the results of the second stage of this study's data collection. The survey instrument pre-test is described, along with data cleaning and preliminary analysis of the dataset to ensure its usability.

Chapter Seven constitutes the descriptive analysis conducted on the dataset from stage two of the research. The chapter also provides preliminary content and construct validity results. 
Chapter Eight covers the data analysis that forms the core of the second stage results for this study. Confirmatory factor analysis of all the constructs is conducted and structural equation modeling is used to test the a-priori model and posited hypotheses. Results are detailed.

Chapter Nine offers a detailed discussion of both stages of the study and the interpretation of the results outlined in the previous chapters. The chapter also conducts an evaluation of an alternate model as well as a comparative analysis of the main learnings of the two stages of this research.

Chapter Ten, the last chapter closes the research with an outline of the academic contributions and managerial implications of this study, and offers a summary of the limitations as well as potential for future research resulting from this study.

The last two parts of this document include the complete bibliography of the thesis presented forthwith and detailed appendices for convenient reference. 


\section{Chapter 2 Literature Review}

\subsection{Antecedents of (Sustainable) Product Development}

\section{Antecedents and Challenges}

After the 2008 world-wide economic upheaval, it has been a growing concern worldwide that business organizations, or even national economies, must re-focus their strategic planning to ensure that are truly sustainable (Boons et al., 2013; Küçüksayraç, 2015). Innovating sustainably to ensure financial well-being is now the standard modus operandi (Boons et al., 2013; Genç \& Benedetto, 2015; Montalvo et al., 2011; Nishant et al., 2016).

New product development and innovation is now conjoined with the need to be sustainable, a necessity arising not only from an environmental perspective, but also emerging from social and economic grounds (Hopkins, 2010; Inigo \& Albareda, 2016; Kuhl et al., 2016; Petala et al., 2010). Because of this emerging trend, development of sustainable products is now an important area that calls for attention. This requires not only additional R\&D resources, new analyses and activities within the new product development (NPD) process, but also development of new functionalities and organizational networks to help overhaul of the existing products and their life-cycles (Dangelico et al., 2013; Genç \& Benedetto, 2015). Further, the process of NPD itself is liable to undergo significant change as well, at least to sufficiently deal with changing product development and its requisite processes. Previous studies have noted that NPD is no longer about creating or improving a product, but about the entire product life-cycle, related impacts and externalities and how they are managed (Boons et al., 2013; Dangelico et al., 2013; Hallstedt et al., 2013; Manda et al., 2016). While it may lead to potentially lucrative market opportunities, overhauling and realigning product development processes and related operations 
has its own risks. Various environmental and social impacts may be a given for current product development operations, but how these impacts will change with change in these processes needs to be studied closely.

A more important consideration is how newer and sustainable NPD and innovation processes affect not only environmental and social performance, but also the financial performance of organizations (Hallstedt et al., 2013; Hallstedt et al., 2015; Inigo \& Albareda, 2016; Kuhl et al., 2016; Montalvo et al., 2011). Previously a relatively peripheral function, conceiving sustainable NPD and its subsequent processes gains primary importance in the creation of a sustainable business model, and the consequent changes are likely to affect organizational performance (Boons \&Lüdeke-Freund, 2013).

Along with acquiring new business functions and skills, organizations are required to satisfy increasingly complex and sometimes conflicting demands from multiple stakeholders (Dangelico et al., 2013). Spurred by societal incentives and stakeholder pressures, organizational sustainability has been considered a focal area for change. Via a percolation effect, products themselves are targeted for change toward sustainability (Küçüksayraç, 2015; Genç \& Benedetto, 2015; Tukker and Jansen, 2006; Tukkeret al., 2008; Petalaet al., 2010; Santamaria et al., 2016).

So studying the link between the sustainability orientation of organizations and the integration of sustainability issues into their NPD functions would be incomplete till it includes the investigation of the relevant dimensions of performance. This exploration gains some complexity from the fact that the nature of sustainability objectives and consequently the measures of performance change when viewed from various levels of analysis, such as the product level, the project level, the organizational level, the societal level and so on. As the field 
of interest expands, its components also expand, and hence the variables under scrutiny rise in number. From a product development and manufacturing perspective, long-term business success can only be ensured when an awareness of activities at a global level is reached, regardless of the actual scope of operations. This is because that any failure of a supply chain member may affect the sustainability performance of the firm. This was very glaringly evident in the infamous Nike case, when low wages paid by one of its suppliers snowballed into a major public relations

catastrophe for the company (Locke, 2003).In reaching a global awareness, the risks and opportunities related to the resources of a firm (from labour to the raw materials) become more relevant to its processes of product development and its contingent performance (Hallstedt et al., 2013; Kuhl et al., 2016). This suggests that sustainable product development processes, tools and related methods are required to change in a mutually compatible way. It is also essential that these processes and methods be rigorous and flexible enough to effectively retain their utility and relevance with changing requirements

\section{Development of Research Area and Gaps}

In the earlier stages of the development of the construct of sustainability, a strong emphasis was laid on the minimal use of resources so that enough resources are left for coming generations (UNECE, 2004; van Weenen, 1995) Increasingly, there is now an awareness that a purely conservationist approach such as the minimisation of resource use, or the reduction of sources is not the key to sustainability (Boons et al., 2013; Franceschini et al., 2016; Glavic\&Lukman, 2007; Hallstedtet al., 2013). This is because sustainability as related to society is very much different than the sustainability of a business. Both of these are fundamentally 
different when the level of their operations; their impact as well as their scope is considered (Dyllick\&Hockerts, 2002; Wang \& Wu, 2016). The requisite re-prioritisation then, draws its power from concepts such as corporate social responsibility (CSR) and the original triple bottom line (3BL) (Elkington, 1997)by supplementing their use with the systematic redefinition of business sustainability. Whereas previous approaches focussed only on the reduction of the "symptoms" of social and ecological unsustainability, these approaches focus on the root causes of the same to analyse how to create sustainable systems. One of the best examples perhaps, is the Framework for Strategic Sustainable Development (FSSD) or the Natural Step Framework which uses root-cause analysis in a non-prescriptive, open-ended manner so as to arrive at solutions that are not biased against or toward specific sustainability aspects (Azaret al., 1996; Johnston et al., 2007; Küçüksayraç, 2015; Hallstedt et al., 2015; Hallstedtet al., 2013; Hallstedtet al., 2010; Matsushita, 2002; Nattrass \& Altomare, 2002). Supported by the core ideologies of CSR and 3BL, such systems not only offer support for strategic decision-making at an organizational level, but also lead to system innovations or transitions to attain inherent sustainability within production as well as consumption ecosystems (Boons, 2009; Boons et al., 2013; Grin et al., 2010).

The development ofthe research interest elucidated above is relatively recent in its formation. This is not because there was a vacuum of thought in this area, but because research streams evolving separately over time have only recently coalesced as a field of study leading to potentially holistic solutions to issues with far-reaching implications, even though the constructs in themselves perhaps are not completely understood as yet (Franceschini et al., 2016; Glavic \& Lukman, 2007; Grin et al., 2010; Holmberg \& Robèrt, 2000; Johnston et al., 2007). It develops from the above research that holistic approaches in both product development and manufacturing 
process need to be adopted at various levels of an organization to truly aim toward sustainability. This is because the socio-ecological and financial impact of any product throughout its life-cycle, be it positive or negative, is substantially determined by the decisions taken at the time of product development (Manda et al., 2016; McAloone and Tan, 2005; Petala et al., 2010; van Weenen, 1995).

As the evolution of this research field continues, a review of extant research aids in the identification of gaps which need special attention. There are four research gaps that have been broadly identified by this study, and the following paragraphs (till the beginning of Section 2.1.1.) explain in detail what these research gaps pertain to and how the proposed study aims to remedy the apparent discrepancies.

The first identified research gap relates to how the sustainability aspect is only incorporated into production process engineering during product development. While technical aspects are receiving serious reconsideration, there remains a disconnect between the strategies being explored and the need of the hour. Concepts such as design for environment (DfE: primarily an environmental-consciousness perspective), design for sustainability (D4S: mostly used for product innovation breakthroughs) and life-cycle analysis (also primarily used to analyse the environmental impact of the product till the end of a product's life-cycle) are required explorations. These explorations, such as the pedagogical approach taken by Lockrey and Johnson (2013) or the cases undertaken by Keskin, Diehl and Molenaarbut (2013)may differ in their scope by their very nature. The idea of 'environment' and its central role in sustainability is not a limiter, though most present research and its applications such as the work by Moon et al., (2016); Manda et al., (2016); Küçüksayraç, 2015; Keskinet al. (2013); Rashid et al., (2013) or 
Bereketli and Genevois (2013), is in the area of societal sustainability via energy transformations, resource conservation, the applications and engineering particulars thereof. However, the tools or methods put forth by this type of research tend to be applicable for very specific relationships or circumstances, or as in some cases more prevention-focussed than proactive solution-seeking (Bullard and Manchanda, 2013; Zhang et al., 2013).

Two emergent streams of thought: sustainability rooted in the systems approach, aided by the Design for Rebirth (DFRb) paradigm can provide a more integrated strategic insight into organizational sustainability (Gaziulusoy and Boyle, 2013; Gaziulusoy et al., 2013; Hallstedtet al., 2013 Hallstedt et al., 2010; Küçüksayraç, 2015; Mascle, 2013; Mascle and Zhao, 2008; Zhang et al., 2013). There are multiple benefits to this view.

If a system is taken to be a dynamic entity with interaction between its various nodes, as suggested by Mercier (2009), then the need to employ multiple strategies by an organization can fit better into the creation of methods and tools for sustainability (Chen et al., 2012; Petrick and Echols, 2004; Trotta, 2010; Zhang, 2011). Design for Rebirth (DFRb) is conceptualised to incorporate not only the traditional life-cycle analysis approaches such as end-of-life as well as elements from DfE, D4S, DFR, DFRM/U, DFD (See Appendix 1.0) and eco-design but it also uniquely integrates the concept of "rebirth" (Mascle, 2013). All these concepts when combined into one, ensure the reuse, reconditioning, redesign at every stage of a product's life-cycle, as may be required. The cradle to grave life-cycle is redesigned as the cradle-to-cradle life-cycle to incorporate the element of reuse as follows (Belz and Peattie, 2009; Manda et al., 2016; Metta and Badurdeen, 2013): 


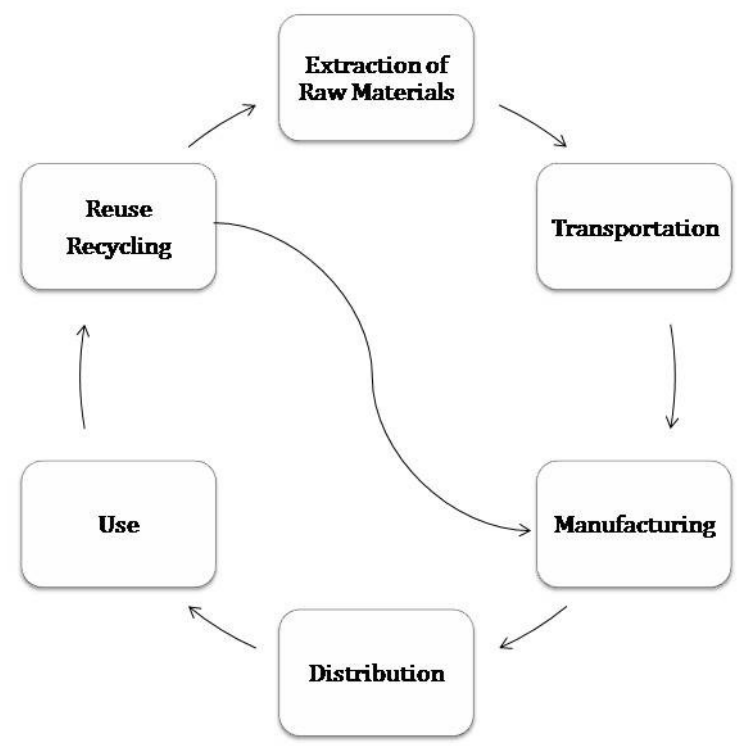

Figure 2.1

Cradle to Cradle life-cycle (Source: Belz and Peattie, 2009)

The research of Christian Mascle (2013; Mascle and Zhao, 2008) is devoted to improving the viability of product rebirth. His latest work focuses on creating opportunities throughout the product life-cycle for improving product rebirth by breaking down each product into 'purer' components and gathering detailed information for the best use and best time for use of each of the same. The very concept of rebirth hinges around the best possible environmental loop available for a product or its component. The aim is to provide a closed loop based on structure modularization and redesigning to iteratively improve the life-cycle loop for each component. For this very reason, DFRb "includes design for end-of-life, for recycling, for environment, for sustainability, eco-design, etc." (Mascle,2013, p. 235), all aspects that can be reworked and developed based on procedural or technical specifications. 
Another important conceptual part of rebirth is the idea of 'ease-of-disassembly' taken from Design for Disassembly (DFD). As seen before, since components and their breakdown is an integral part of determining their environmental loop, disassembly is critical to the process. Each of these components are also analysed for their environmental, social and economic impacts and measures are used to control for and alleviate the anticipated negative portion of these impacts. Therefore, not only does rebirth support the previously understood notion of sustainability (in a purely environmental sense such as recycling and refurbishment) but it also supports economic and social aspects, through various advantages such as cost savings, reconversion of products and resources, retraining human capacities and skills.

In this, Mascle's (2013) research is very important since it leads to the wider perspective of sustainable development and sustainability as related to organizations. Further, his research also addresses the impacts on all three aspects; social, environmental and economic, while using an approach which is close to the systems approach and complements the purpose of this research. This is important, since most research till now only focussed on specific stages, such as end-of-life, or early product design. When combined with a systems approach, these two streams of thought form the basis of the 'black box' of this research, that of the processes that comprise Sustainable Product Development or S-PD.

The Second research gap that was identified also relates to the nature of the research objectives till date. It should be noted that almost all of the literature available on sustainability in the systems approach focuses on the creation of sustainable products from their design-stage forward, inclusive of the most recent research (Hallstedt et al., 2013; Mascle, 2013; Zhang et al., 2013; Hallstedt et al., 2010; Mascle and Zhao, 2008;De Toni et al., 2001). There is a lack of 
literature on the re-evaluation of products that are already in the market or those already in various stages of design or manufacture, which can be developed into sustainable products.

With respect to technical analysis, whether it is for the creation of models to support sustainability functions (e.g. Mascle, 2013), or for the prescription of a validated or theorised approach (e.g. Keskinet al., 2013), there is an implicit understanding of the fact that each product has various stages of development, not just related its perceived life-cycle but also its developmental changes after conceptualization. However, this understanding does not materialise into a grasp of the fact that the products currently in existence should be restructured or redesigned or reemployed to increase their ability to cater to a more sustainable future. Current literature only considers 'the drawing board', either designing sustainable products and processes afresh; or assisting in the potential restructuring of the organization at a strategic level. This research considers the potential that all products and processes, regardless of their 'stage' in development or their life cycle are candidates for rework to render them closer to, if not within, the objective of the organizational sustainability. This point itself brings us to the next gap in this academic area, the question of how the current literature propagates ideas.

The Third research gap encountered within the literature of interest is the apparent lack of translation of educational information for management and academics into concrete strategic points of focus. Latest research has provided immensely useful and in-depth compilations of theory, method, perceptions, previous work as well as points of interest for future research and requirements (Boons et al., 2013; Franceschini et al., 2016; Gaziulusoy et al., 2013; Hallstedt et al., 2013; Mascle, 2013; Zhang et al., 2013;Hallstedtet al., 2010;Carrillo- Hermosilla et al., 2010;Boons, 2009). But there is a serious requirement for literature that aids in understanding how to focus the 'educational' pedagogical literature to create plans which would positively steer 
the functioning of organizations into the realm of true sustainability. In this research, homage is paid to salient relevant educational aspects, but the focus remains on an attempt to begin to discover what is, till date, the hypothetical 'black box' in this area - sustainable NPD processes and their workings within an organization.

The Fourth and last research gap relates to the various levels of analysis encountered in the literature. A similar gap has also been noted in the very recent research of Zhang et al., (2013). The authors note that local tools as well as local solutions are not as effective in an organization as global solutions and tools. They posit that most sustainability issues call for solutions applicable throughout the organization, regardless of the management level (what the authors classify as operational, tactical and strategic, See Figure 2.2 below) and across the developmental processes of NPD, since even the design process is "a multitask, multi-domain and multi-activity process" (p. 203). The authors use the concept of 'interoperability' to indicate operations between different management levels within the organization.

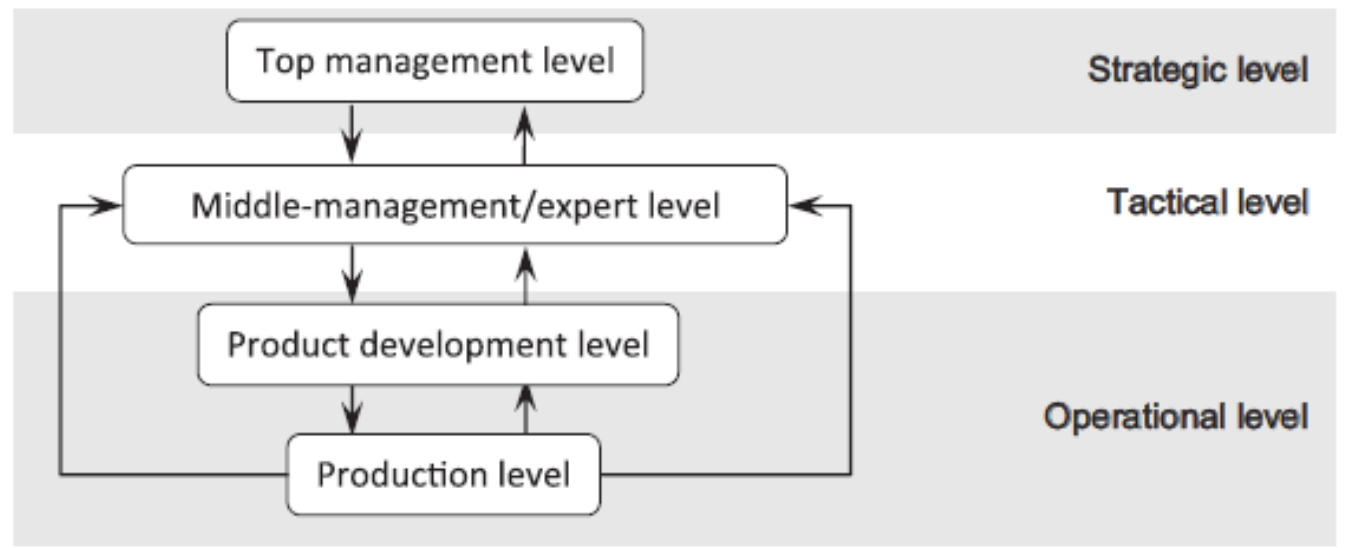

Figure 2.2

Interactivity and coherence between hierarchical corporate levels for environmental management (Source: Zhang et al., 2013) 
If this concept is viewed along with the pedagogy of Gaziulusoy and Boyle (2013), it becomes clear that there is a pressing need for research to span across the previously constraining boundaries demarcating product development from production process from organizational processes and so on.

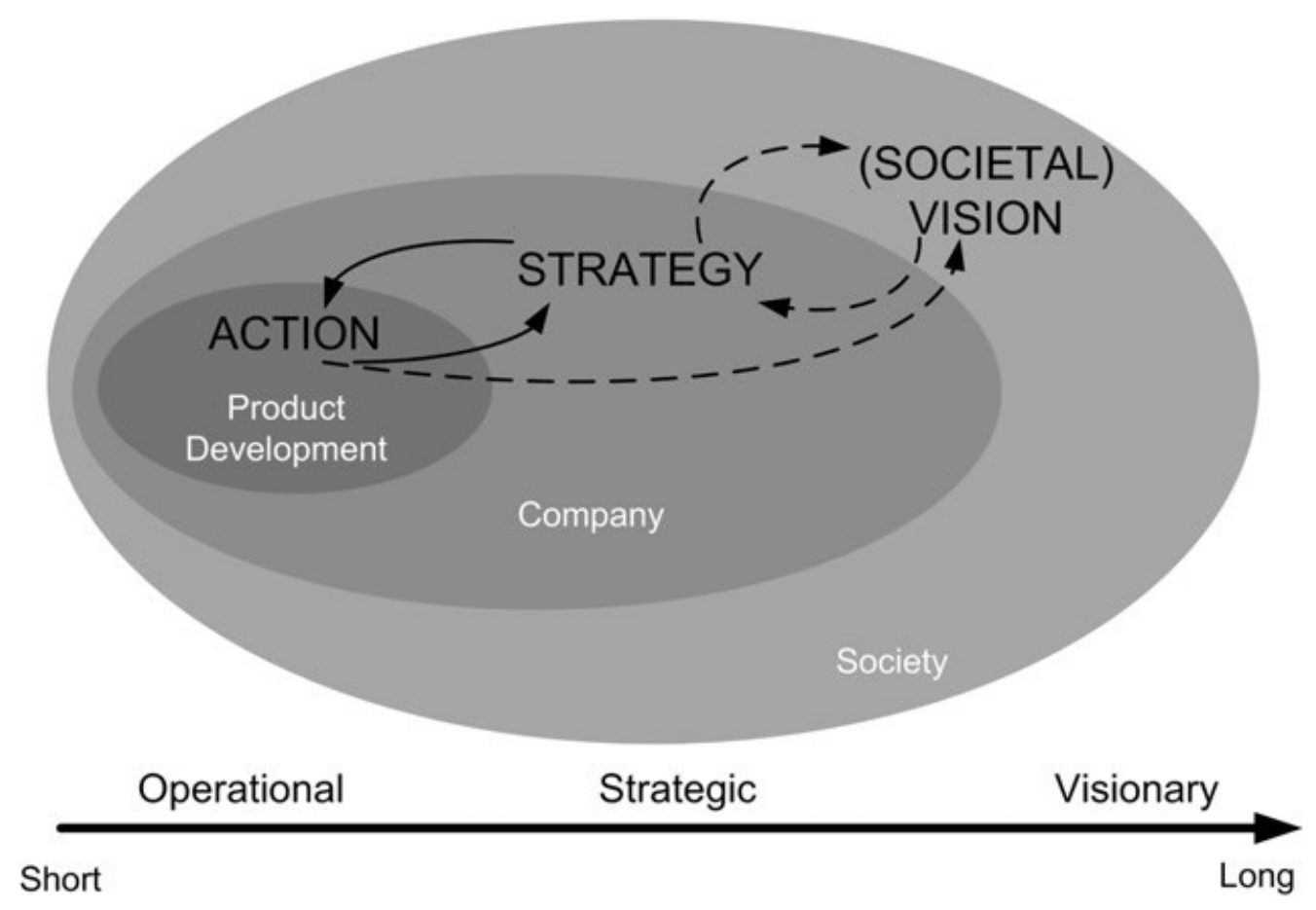

Figure 2.3

A systemic model for product development function in the organization. (Source: Gaziulusoyet al., 2013)

From the model presented in Figure 2.3, as researched by Gaziulusoy et al. (2013), it becomes clear that various levels of analysis correspond with various time-frames. However, the synergistic relationships across these levels of analysis are seen to hold together and stipulate the 
continuity of operations from the short to the long term. This model does not need to provide an indication of the focus of the tasks and rising complexity in interactions as one moves from product development to society. Also, because the model analyses only 3 levels, that of product development, company and society are indicated.

The following adaptation, Figure 2.4, acts as a supplement to this model, for the purposes of this research.

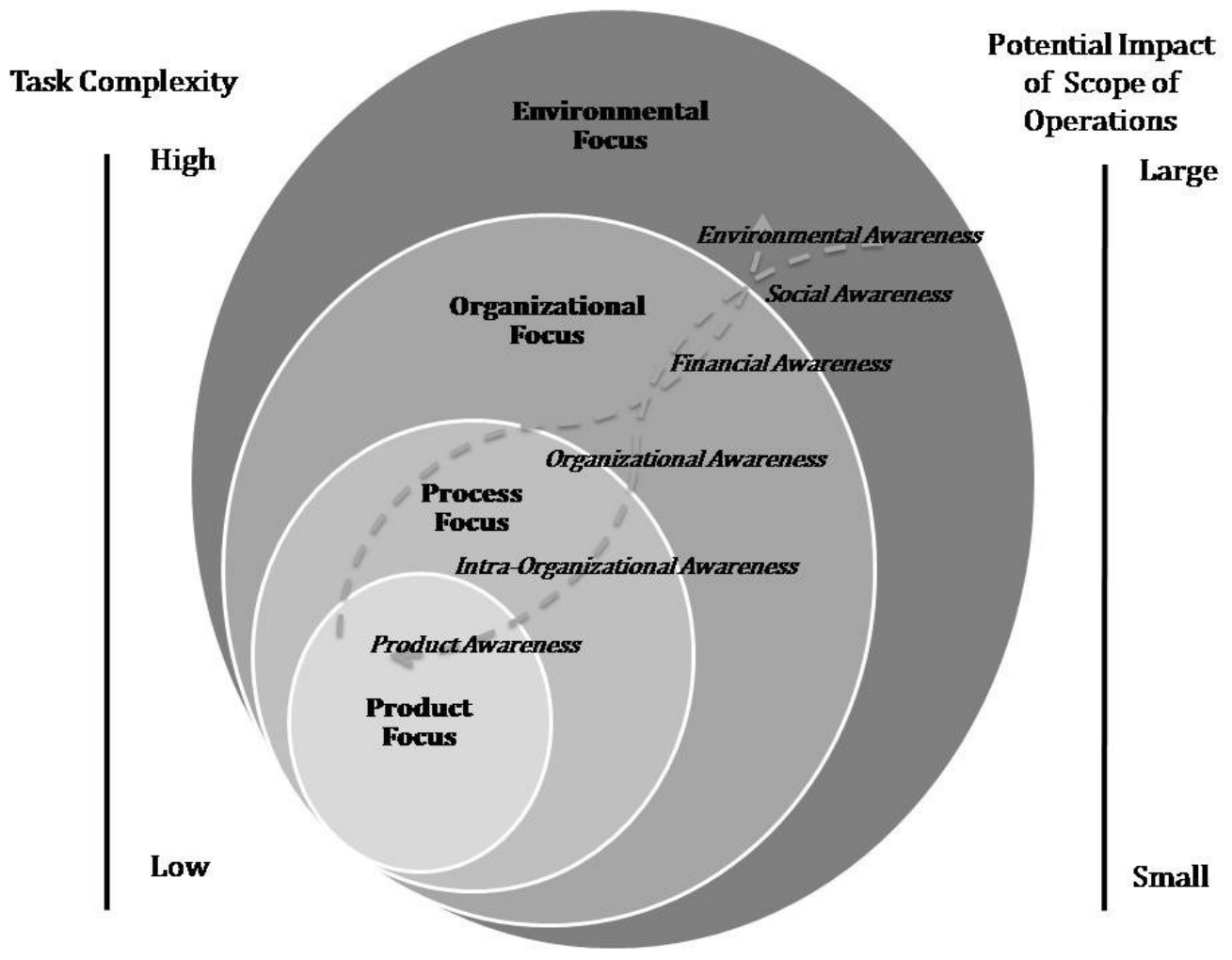

Figure 2.4

A modified systemic model showing the gradations of focus and consequent impact of an organization. (Source:

Gaziulusoy et al., 2013) 
In the context of this research, this gap is addressed when the investigation cuts across, what are termed, the various "socio-technical domains" (Boons et al, 2013; Gaziulusoy and Boyle, 2013) in an organization to assess a holistic cross-section of the systemic view. It is posited that as the focus of an organization shifts towards it being a part of a larger system, its scope of operations has a greater impact on its environment. Also, we see that as the systemic boundaries also expand, tasks increase in their complexity because of the increasing number of variables under consideration (Gaziulusoy et al., 2013; Zhang et al., 2013). Though the time frame under consideration is long range (strategic level), the various levels of analysis: from the product to the organizational and beyond are equally important for our study.

In the previous sections, the antecedents that define the context of this study have been discussed. Also, four important and pertinent research gaps have been identified that will be addressed by the proposed study. A perspective has been outlined, that of a combination of systems approach as well as DFRb as part of the life-cycle approach. In the following Sections, (2.1.1 to 2.4.2), a detailed analysis of the literature on the topics of the strategic orientations of an organization, the product development processes, the attributes of sustainable products as well as organizational performance is conducted. The analysis begins with the strategic orientation(s) of an organization, which, for this research is the starting point, and precedes the product development processes. 


\subsubsection{Strategic Orientation(s)}

The dictionary meaning of orientation is given below.

(Orientation: noun :

1. the action of orienting someone or something relative to the points of a compass or other specified positions:

2. a person's basic attitude, beliefs, or feelings in relation to a particular subject or issue (Oxford Dictionary, 2014))

Strategic orientations, as explained by Gatignon and Xuereb (1997, p. 78) are organizationally implemented strategic choices and directions that "create the proper behaviors for the continuous superior performance." These orientations are important in their entirety as well as individual orientations since various components at times are seen to have differing effects on different dimensions of organizational performance (Mariadoss et al., 2016; Spanjol et al., 2012).

Traditionally, a substantial part of the literature around new product development and strategy focuses on contrasting internal and externally-driven strategic approaches taken by organizations (Paladino, 2007). Internal drivers such as the deployment of the Resource based view's resource bundles (Collis and Montgomery, 1995; Barney, 1991) are considered to be a different competitive strategy as compared to external drivers such as market or customer orientation (Narver and Slater, 1990; Moorman and Rust, 1999) in, what is newly perceived as a 
'dynamic' competitive environment. The link between various strategic orientations and performance however, as seen above, has always been clearly perceived in literature. Performance as a multidimensional construct, consisting of factors beyond simple economic performance has been explored by multiple studies (e.g. Baker and Sinkula, 2005; Gassman and von Zedwitz, 2003; Jaworski and Kohli, 1993; Jin and Sun, 2010; Kuhl et al., 2016; Paladino, 2007; Rauniar and Rawski, 2011). The literature also shows that there is a distinct relationship between various strategic orientations and performance (Baker and Sinkula, 2005; Jaworski and Kohli, 1993; Kohli and Jaworski, 1990; Mariadoss et al., 2016; Narver and Slater, 1990; Paladino, 2007; Slater and Narver, 1994).

In addition to this, a growing literature can be found on strategic orientations along withstrategic decision-making and strategic flexibility, both on the organizational and the product development levels (Eisenhardt, 1990; Elbanna, 2006; Evans, 1991; Hitt, Keats, and de Marie, 1998; Rajagopalan, Rasheed, and Datta, 1993; Sanchez, 1995; Sharfman and Dean, 1997). It has been suggested that strategic decision-making acts as an enabler for firms to re-orient and renew themselves for survival, better performance and NPD success (Ansoff, 1975; Debruyneet al., 2002; Evans, 1991; Acur, Kandemir and Boer, 2012). The following Sections, from 2.1.1.1. to 2.1.1.6., further discuss the relevant literature on each of the strategic orientations previously mentioned. 


\subsubsection{Market Orientation}

A number of articles suggest that the relationship between market orientation andthe ability for innovatively develop products is strongly positive in nature (e.g., Atuahene-Gima, 1995; Kahn, 2001; Langerak, Hultink, and Robben, 2004; Narver, Slater, and MacLachlan, 2004). More specifically, it has been found that market orientation is linked to the intensity of competition in the market, the type of products and type of technology offered (Atuahene-Gima, 1995; Paladino, 2008; Yang et al., 2012) and also to the product life-cycle stages and the turbulence of the environment (Kohli and Jaworski, 1990; Paladino, 2008). Studies conducted by Cooper (1979) as well as Bharadwaj, Varadarajan and Fahyhave (1993) long established that idea behind successful new product development is that a product is most substantially differentiated via its unique and novel nature in the market (Yang et al., 2012). This unique nature is what provides a sustained competitive advantage for its organization. The competitive advantage gained by product innovations which are relatively radical in nature cannot be undermined substantially by substitution or even imitation without unique value addition, which leads to improved growth in sales, revenue and market share (Hunt and Morgan, 1995; Narver et al., 2004) and thus product performance. Research by Yang, Wang, Zhu and Wu shows that advantages such as quality, reliability, cost and newness are all found to be critical for successful new product development, its processes as well as product adoption and therefore form a part of an organization's market orientation on a strategic level (2012).

Lukas and Ferrell (2000) refine on previous work (Narver and Slater, 1990; Gatignon and Xuereb, 1997) to find that the main dimensions for market orientation remain (1) competitor orientation; (2) customer orientation; and (3) interfunctional coordination. All three of these 
orientations have specifically different areas within which they work. Competitor orientation is concerned with the analysis of current and potential competitors within the marketplace. Whereas, customer orientation is used to assess the current and future needs of existing and potential customers. Both these orientations are considered to have an external focus for the creation of value. On the other hand, interfunctional coordination is internally focussed and refers to the harmonized utilization of available resources within a firm for the creation of greater value for the target consumer (Lukas \& Ferrell, 2000; Yang et al., 2012). So, even though all three constituent orientations, or 'components', comprise a holistic idea of 'market orientation', it is deemed very much possible that, based on the financial or socio-ecological environment, specific individual orientations may be more relevant, even though the nature of 'market orientation' and its magnitude may not differ per se. It has been previously established that the three component orientations differ in terms of focus. It follows that the orientations also have differing sets of required resources as well as incumbent organizational processes (Narver and Slater, 1990). To attain a superior understanding of the effect of these specific strategic orientations, this research adopts the approach previously followed by Yang et al., 2012, Kahn (2001) and Jeonget al., (2006) and also analyses each one of the component orientations of market orientation as individual strategic orientations, as explored in subsections 2.1.1.2 to 2.1.1.5.

\subsubsection{Competitor Orientation}

Competitor orientation is the ability of an organization to identify sources of competition, current or potential, and analyse, anticipate and proactively respond to the actions of those 
competitors (Lukas and Ferrell, 2000; Yang et al., 2012). Narver and Slater (1990) originally defined it as understanding the "short-term strengths and weaknesses and long-term capabilities and strategies of both the key current and the key potential competitors". There is some literature that suggests that competitor orientation, by itself, may be, in some cases, antithetical to customer orientation, since a focus on the consumer is likely to yield better product performance in the marketplace (Deshpandéet al., 1993; Campbell and Furrer, 1995). Armstrong and Collopy (1996) suggest that there is a chance that competitor-oriented behaviour as a stand-alone objective might actually lead to a decrease in profitability through loss of focus and decreased task performance at any stage of the product design or manufacturing process. Furthermore, strong competition can lead to increased consumer choices in the marketplace, rendering the orientation itself potentially weakly linked to performance (Kohli and Jaworski, 1990). However, these relationships are more suggestive of the fact that competitor orientation may function better in conjunction with other orientations than alone. As a strategic orientation, competitor orientation remains important since it is seen to not only have a positive impact on strategic performance, but to also function as a safeguard against the activities of the competing firms and other external forces in the marketplace (Campbell and Furrer, 1995; Narver and Slater, 1990; Yang et al., 2012).

To ensure that advantage of a firm's offerings over its competitors, the firm should have the ability to proactively identify and develop attributes which lead to product differentiation. Moreover, competitor actions must be assessed to develop action plans for competitive advantages ahead of the competing firms instead of blindly following leading rivals (Cooper, 1979; Hunt and Morgan, 1995; Narver and Slater, 1990). This can also be effective in the case 
where competitor information is periodically and systematically collected for analysis by the firm (Yang et al., 2012). In the case where a market is expanding or demand is high or increasing due to other reasons, competitor orientation is not likely to have a particularly high impact on performance. In this case, the focus of the organization should be on the development of new products, new processes and services to meet the needs of the growing market (Yang et al., 2012).

\subsubsection{Customer Orientation}

The concept of customer orientation is based on assessing customer needs and proactively responding to them. This orientation is also of an external focus (Paladino, 2007). It depends on "understanding of one's target buyers to...identify, analyze, understand, and answer the current and future customer needs" (Yang et al., 2012). The competitive advantage, in this case, is gained from focussing on comprehending customer needs, potential needs and how to satisfy these needs (Gatignon and Xuereb, 1997; Han, Kim, and Srivastava, 1998). For continuing advantage, not only does information have to be collected on current and future needs of customers, but follow-up action should also be taken, in the form of satisfaction surveys (Paladino, 2007; Yang et al., 2012). The relationship between customer orientation in the development of new products and performance has been a topic of extensive study. The relative performance of a new product and the way in which it is produced can be examined and evaluated with respect to meeting or exceeding the various defined expectations of the customer such as the quality of the product; its technological value and perceived superiority; the speed with which the consumer accepts it; the perceived utility and potential length of the product's 
life-cycle (Baker and Sinkkula, 2005; Day, 1990; Deshpandé, et al., 1993; Jaworski and Kohli, 1993; Kahn, 2001; Paladino, 2007; Slater and Narver, 1994). The example may be given that the process of development of these products as well as the products themselves also can be seen to fulfil customer expectations related to sustainable life-cycles of the products (Dangelicoet al., 2013; Hallstedtet al., 2013; Gatignon and Xuereb, 1997; Paladino, 2007).

It can be thus expected that a firm with a customer orientation focus would achieve superior standards of sustainable new product development and subsequently strategic performance. Further, it has been previously shown that the nature of an organization's strategic orientation is affected by not only the technological environment but also the state of the marketplace (Jeonget al., 2006; Kohli and Jaworski, 1990). As discussed before, the degree of competition within a particular industry would affect the behaviour of the consumers (Kohli and Jaworski, 1990). As the competition increases, the customer has a wider variety of choices. For a firm to retain its competitive advantage, it must provide for the changing needs of its customers to ensure that competing alternatives do not take over the firm's own market share. More significantly, it should be noted that in a mature market, as opposed to a growing market, customers are likely to be highly sensitive to the value provided by a product, underscoring the importance of market research for customer satisfaction (Kohli and Jaworski, 1990; Yang et al., 2012). In such scenario, the characteristics of the product as well as the manner in which it is produced become even more important and the organization must be responsive to the needs of the customer to provide consistent and increasing value. 


\subsubsection{Interfunctional Coordination}

Lukas and Ferrell (2000) refer to Narver and Slater's (1990) meaning of interfunctional coordination, which is, the utilization of organizational resources in a coordinated manner to create superior value for the target customer. This particular orientation has a distinctly internal focus which it derives from its underlying principle. Interfunctional coordination is seen as the value derived from the efficiency and effectiveness displayed internally by an organization via its culture and policies for the sharing resources and existing or developed levels of cooperation and coordination (Kahn, 2001; Yang et al., 2012). Such effective and efficient interfunctional coordination prompts better sharing of vital information such as market information and experience which assists in the creation of new and specialised organizational knowledge (Dougherty, 1992; Frishammaret al., 2012; Yang et al., 2012). Critical values of sharing information and coordination also foster an attitude of team spirit among the product development personnel (Kahn, 2001; Yang et al., 2012). Organizations with a more insular departmentalised approach are seen to have a lesser understanding of the common tasks which in turn inhibits effective integration of critical thinking, process development and consequently innovation and product development (Cooper and Kleinschmidt, 1987; Deshpandéet al., 1993; Frishammaret al, 2012; Genç \& Benedetto, 2015; Lawrence and Lorsch, 1967).

A number of previous studies have also looked at the relationship between specific organizational functions which may be particular to a single department and the cross-functional integration and its subsequent effect on these department-specific functions. This body of research has examined not only effect of cross-functional integration and information sharing on the functioning of the organization, but also at the effect on product development and its 
performance. The results of these studies show that multiple factors such as organizational culture; team spirit; firm structure; team tenure; innovation type; product development functions and turnover time; market turbulence and technological uncertainty and more, determine how important cross-functional integration is for performance (Colazo, 2010; Kahn, 2001; Gassman and von Zedwitz, 2003; Genç \& Benedetto, 2015; Souder, Sherman, and Davis-Cooper, 1993; Wang, 1997). There is still some uncertainty in the literature whether a high growth or a mature market might be more conducive to greater performance results related to interfunctional coordination. Though, it can be seen that, not only the product development processes and knowledge management processes, but the performance of the innovation are dependent on the state of internal functions and coordination of a firm (de Medeiros, 2014; Narver and Slater, 1990; Wang, 1997). Correspondingly, improved interfunctional coordination can improve product development and knowledge processing and eventually performance.

\subsubsection{Technology Orientation}

Any organization with high utilization of and heavy investment in research and development as well as the consistent acquisition and development of sophisticated or cuttingedge technologies for use in its products may be considered to have a strong technology orientation (Lukas and Ferrell, 2000; Teece, 1988; Yang et al., 2012). More precisely, it has been previously pointed out that a firm's technology orientation comprises of using sophisticated or state-of-the-art technologies in development of new products for the rapid "integration of new technologies, and proactively developing new technologies and creating new product ideas" (Gatignon and Xuereb, 1997). Technology orientation can be very closely linked to market orientation because of its emphasis on novelty and innovation (Yang et al., 2012). In fact, earlier 
research on technology orientation stemmed from the market response to technology-based firms in the early stages of their life-cycle (Song and Parry, 1997). From the earliest stages, the technology orientation of a firm (such as aggressive R\&D input and first-in-market technology development) is critical to its survival and its prosperity (Atuahene- Gima, 1995; Gatignon and Xuereb, 1997; Kim and Kim, 2009; Kumar and Boyle., 1999).

The relationship between a firm's technology orientation, its product development practices and the effect on performance has been studied by a number of articles (Dangelicoet al., 2013; Cooper, 1985; Gatignon and Xuereb, 1997; Jeonget al., 2006; Song and Parry, 1997; Yang et al., 2012). A well conceived technology orientation is a combination of internal technological resources such as design and development processes; technological knowledge; and scientific expertise as well as external technological opportunities such as knowledge networks; technology scanning; andintelligence gathering (Colazo, 2010; Frishammaret al.,2012; Gassman and von Zedwitz, 2003; Gatignon and Xuereb, 1997). A well-thought combination of both the internal and external components cannot easily be imitated by competition and gives an organization a significant competitive advantage (Cohen and Levinthal, 1989; Cooper, 1985; Lukas and Ferrell, 2000).

The implications of the advantage gained by the right technology orientation go beyond the simple protection of the unique mix of the internal resources and external opportunities. Through its makeup, technology orientation can extensively affect knowledge management in the organization; affect its cross-functional integration through the organization and also affect its inter-functional coordination, all of which chiefly affect the evolution of product development 
processes and practices, which in turn have an effect on strategic performance (Colazo, 2010; Gaziulusoyet al., 2013; Gatignon and Xuereb, 1997; Hallstedtetal., 2013; Hallstedt et al., 2015; Kuhl et al., 2016; Song and Parry, 1997). Furthermore, several studies show that most of the generic product innovations are not a result of consumer research, but are developed by the $R \& D$ department, the employees of which may not even be a part of the target consumer base (Bennett and Cooper, 1981; Houston, 1986).

However, meeting and incorporating customer needs remains a significant part of technology orientation (Yang et al., 2012). As the market matures and competition increases, firms have to use both internal and external resources to collect relevant information to maintain a dynamic knowledge base. This in turn fosters a technology orientation with focus on $R \& D$, innovativeness, dynamic knowledge use and superior product and process quality (Acur et al., 2012; Frishammaret al., 2012; Hallstedt et al., 2015; Paladino, 2008; Yang et al., 2012). In addition, increased competition from a technology perspective leads to a potentially turbulent market characterised by rapid change in technology and demand where passive response is not a strategic option. To weather and thrive in a volatile environment, a firm needs to by-pass the death knell of technology obsolescence and ever-shortening product life-cycles to proactively create opportunities for a superior competitive advantage using the application of new knowledge and concepts rooted in sustainable engineering (Dangelicoet al., 2013; Genç \& Benedetto, 2015; Hallstedtet al., 2013; Paladino, 2007; Yannopouloset al., 2012). Thus it may be reasonable to conclude that a strong and focussed technological orientation is essential for sustainable product development, survival and holistic evolution of the firmand consequently, strategic performance. 


\subsubsection{Sustainability Orientation}

The concept of sustainability orientation, while being of great importance to this research, is perhaps the most nebulous at this stage of research. Despite the immense interest in sustainable development on environmental, social and economical fronts within and outside organizations, there has been little work on the concept of sustainability orientation other than the research of Kuckertz and Wagner, (2010). As evidenced by their research, no exact definition exists in the literature and the authors are the first to operationalize and test the measure, borrowing from the fields of social and environmental entrepreneurship; environmental psychology and sustainability management. From the literature compiled, it is seen that sustainability orientation assists in taking advantage of new opportunities which are caused by market imperfections in the current system (Bansal and Roth, 2000; Cohen and Winn, 2007; Dean and McMullen, 2007; Santamaria et al., 2016). The political pressure exerted by non-governmental organizations on the level of policy making also is a motivating factor for seeking sustainability-related opportunities in the marketplace, creating a niche for sustainability orientation, for not only individuals but also organizations (Kuckertz and Wagner, 2010; Oppenheimer, 2006; Santamaria et al., 2016; van Weenen, 1995). This is bolstered by the natural tendency of people with deep-seated environmental and social concerns to act on their values through professional mediums and engage and display sustainability orientation on an organizational level (Bruyere and Rappe, 2007; Wang \& Wu, 2016).

Therefore, sustainability orientation is seen to support the identification of sustainability

related opportunities like sustainable new product development as well as encourage the 
formation of actionable items via the support of sensitised individuals who drive the initiative (Bennett, 1991; Berle, 1991; Zahra et al, 2009). In some cases, the reduction waste or the prevention of pollution may be the main goal, while in others, using raw materials that are environmentally friendly (Dangelicoetal., 2013; Kuckertz and Wagner, 2010; van Weenen, 1995). Sustainability orientation is also shown to synergistically flow from an individual to an organizational level (and vice versa) where hidden opportunities in the market are better spotted and the intent to act on such opportunities is also stronger (Zahra et al, 2009; Kuckertz and Wagner, 2010).

In some cases, the pursuit of sustainability related opportunities decreases with an increase of pragmatic decision-making. This occurs when the pursuit of moral legitimacy takes a lower rank to pragmatic legitimacy due to the nature of the opportunity available as well as the perceptions of the key stakeholders in a venture (Aldrich and Fiol, 1994; Delmar and Shane, 2004; Starr and Macmillan, 1990; Suchman, 1995; Zimmerman and Zeitz, 2002). However, realistic decision-making does not, as a rule, have to decrease sustainability orientation while pursuing opportunities, but rather, is context dependent (Kuckertz and Wagner, 2010; Löbleret al., 2012). Context specific internal and external drivers are more compelling in adopting sustainability orientation (Mann et al., 2010; Mariadoss et al., 2016). Research shows that the environmental impact of the product throughout its life-cycle is perhaps the largest consideration for sustainability orientation (Dangelicoetal., 2013; Gaziulusoy et al. 2013; Kuckertz and Wagner, 2010; Mascle, 2013; Mascle and Zhao, 2008; Mann et al., 2010). With respect to this research; the context is already specified as being sustainable product development. 


\subsection{Sustainable Product Development}

From the literature available, it is seen that three overarching knowledge-related processes form the backbone of product development processes, linking organizational level strategy to product strategy, product development, and ultimately leading to firm performance. These three key processes (which will be referred to as supra-processes) are adopted by this study to form a part of the conceptual 'black-box' that is sustainable product development processes or S-PDP. These supra-processes are considered most apt for this research because they create three separate but vital connections. First, these supra-processes form a mid-level network interconnecting the organizational and the product levels of strategic analysis (Frishammaret al., 2012; Hargadon and Fanelli, 2002). This is in keeping with the recommended multi-level analysis(that of strategic, process and product) aim of this study, as propounded by Gaziulusoy et al's. (2013) study. Second, these supra-processes connect and ensure the continuity of the organizational knowledge once the project is concluded, thus providing a vital link from the knowledge acquired at the project level to the organisational knowledge base (Cooper and Kleinschmidt, 1986; Yang et al., 2012; Zhang et al., 2013). Third, the supraprocesses form a balanced connection between the internal (organizational) as well as external (marketplace/environmental) knowledge streams (Brockman and Morgan, 2003; Frishammaretal,. 2012). In doing so, the supra-processes utilise a very similar base of indicators in their operationalization to organizational capabilities (Acur et al., 2012; Dangelicoet al., 2013; Frishammaret al., 2012; Gaziulusoyet al., 2013; Hallstedtet al., 2013; Hallstedt et al., 2015; Inigo \& Albareda, 2016; Sriboonlue et al., 2016). For the purposes of this research, these processessuccessfully circumvent the need to independently consider specific capabilities of the organization. These strategic product development processes namely: domain specific knowledge 
integration; procedural knowledge integration and flexible decision-making are described in subsections 2.2.1 to 2.2.3.:

\subsubsection{Domain-specific knowledge integration.}

The idea of domain-specific knowledge has been successfully explored since the 1980s, from its relation to requisite organizational results to noting specific events related to product development (Anderson, 1983; Cohen, 1991; Henderson and Clark, 1990). To consider the definition of Ullman (2010, p. 50) domain specific knowledge is related to the "form or function of an individual object or class of objects", which implies a certain degree of continuity in function or previous experience of work. Therefore, according to previous studies, domain specific knowledge is related to handling and processing the knowledge elements of work from either previous or current product development endeavours (Frishammaret al. 2012; Hargadon and Fanelli, 2002; Ramesh and Tiwana, 1999). This knowledge can vary with respect to its inherent nature. Domain specific knowledge is generally held to be fact-based or event-based and can be historically cumulative; project-specific; product-specific or even be based on an organization's expertise domain such as its technological know-how and intellectual property (IP). Further, this knowledge may be stored within the organization either explicitly or implicitly depending on its nature (Cohen, 1991; Nonaka and Takeuchi, 1995; Reid and DeFilippi, 1990). Frishammar, Lichtenthaler, and Rundquist (2012, p. 576) define domain specific knowledge as "the extent to which the firm has routines, systems, and methods to acquire, share, and use such knowledge in the context of NPD." 
The process of integrating domain specific knowledge is, therefore, derived from the specific events or facts from product development which may or may not have intentional origins, but clearly attain importance by virtue of the results obtained. Preceding studies have shown that this supra-process is essential for the improvement of the NPD effectiveness as well as efficiency as long as innovativeness itself is not stifled (Brenner and Tushman, 2003; Christensen and Bower, 1996; Clark and Fujimoto, 1991; Henderson and Clark, 1990; Hoopes and Postrel, 1999).

A number of studies validate how exactly domain specific knowledge forms a part of the network of three levels of analysis described above in section 2.2 (organization, process and product). With respect to the intrinsic ties, the integration of domain specific knowledge helps cultivate knowledge development and further learning or product development and commercialization opportunities for the organization deriving from the product level or project level (Frishammaret al. 2012; Hargadon and Fanelli, 2002; Küçüksayraç, 2015). With respect to external-internal ties, it is seen that domain specific knowledge integration assists in understanding and creating the required synergies among projects of the firm in terms of internal technology exploitation as well as in terms of internal-external transactions (Cooper and Kleinschmidt, 1986; Frishammaret al. 2012; Montoya-Weiss and Calantone, 1994; Santamaria et al., 2016). In addition, sharing and utilizing domain specific knowledge can motivate a closer link to the marketplace and the environment in general to provide a better perspective for current and future product development opportunities and ideas which are so critical for product development processes (Brockman and Morgan, 2003). Further, it can be seen that the methods 
and tools employed to acquire domain-specific knowledge are an integral part of the success of acquisition and integration (Boons et al., 2013; Gaziulusoy and Boyle, 2013).

The next part of this supra-process, the acquisition of technical know-how is considered vital for the continued success of product development processes. Previous research shows that it is not actually enough to simply create or maintain external networks or collaborations for new product development ideas and processes, but rather such networks should be considered sources and be used to integrate sustainability issues into current and future NPD programs (Dangelicoet al., 2013; Hallstedt et al., 2015; Kuhl et al., 2016).

Another important use of external knowledge sources verified in the literature is in assisting the merging of the newly acquired knowledge with the accumulated knowledge within an organization (Verona, 1999; Yang et al., 2012). Along with the knowledge acquired, the acquisition of the supporting technical know-how, assets and requisite tools also form a part of the supra-process of acquiring and integrating technical know-how. This acquisition spans acquiring new supporting technology, machinery, staff or re-training/modifying previous resources for new development activities and is shown to be closely linked to the absorptive capacity as well as innovation capability of the firm in question (Cohen and Levinthal, 1990; Dangelicoetal., 2013; Ngo and O'Cass, 2012; Sriboonlue et al., 2016; Yang et al., 2012). As seen previously, research shows that strategic decision-making and product development activities related to sustainability and green product design have a greater and more immediate need for the effective acquisition of technical know-how and its accompanying tools and knowledge 
mechanisms, confirming the status of this process as a supra-process (Dangelicoet al., 2013; Kandemir and Acur.; 2012).

\subsubsection{Procedural knowledge integration}

The second supra-process that comprises the strategic product development processes is the integration of procedural knowledge. In other words, it is the knowledge of how to perform the actual functions associated with the NPD process. For clarity and consistency, let us consider the definition given by Ullman (2010, p. 50) of procedural knowledge being the "knowledge of what to do next" for the duration of the NPD process. A more exact definition comes from Frishammaret al., (2012, p. 576) where procedural knowledge integration is "the extent to which the firm has routines, systems, and methods to acquire, share, and use such knowledge in the context of NPD".

In traditional circumstances, procedural knowledge is seen to be embedded in codified methods, best practices or internally understood routine procedures (Olivera, 2000). The 'open innovation' wave, led to innovation activities being driven by interactions which are connected to external sources and structured in a format which opens up internal R\&D and NPD activities to cooperative development (Chesbrough, 2007). The benefits of opening the product development and R\&D processes span from enriching a firm's knowledge base to avoiding erosion of the

already-established base of knowledge hence shrinking the firm's future potential to collaborating and creating wider structures with the firm's suppliers and other external 
knowledge sources to increasing a firm's innovativeness (Chesbrough, 2003; Christensen et al., 2005; Enkelet al., 2009; Koschatzky, 2001; Laursen and Salter, 2006; Mariadoss et al., 2016). While the open model of innovation may be useful in many ways, it may not be practically applicable for many organizations in its totality. Putting aside the increased costs of collaboration and coordination along with contractual negotiations, completely open structures lead to loss of product development and commercialization opportunities, not to mention control, as well as 'leakage' of a number of knowledge-intensive processes such as know-how and potential IP belonging to the organization (Chesbrough, 2007; Christensen et al., 2005; Enkel, Kausch, and Gassmann, 2005)

For this reason, a more practical approach is the middle ground, where an organization performs its core activities internally to protect its knowledge base and related know-how and the total NPD process also comprises of complementing peripheral open activities with the requisite collaboration for the growth of innovative ideas. Setting into place systems and methods to share procedural knowledge as well as acquire it from external sources thus becomes important (Chesbrough and Schwartz, 2007; Enkel et al., 2009; Kahn, 2001). This in turn facilitates the supra-process of integrating procedural knowledge into the product development process with the various activities being categorised according to their nature and importance on product, project and organizational strategic levels and insures that the integrated knowledge is also available for future use (Frishammaret al., 2012). 


\subsubsection{Flexible Strategic Decision-making}

The first two supra-processes dealt with the integration of various kinds of knowledge within an organization and its NPD processes. In essence, these two dealt with the 'what' of process and knowledge integration. The third supra-process complements the first two by prescribing 'how' to deal with NPD processes and the afore-mentioned knowledge. The third supra process is that of flexibility in strategic decision-making. Literature shows that flexibility in decision-making at a strategic level is important for organizations to dynamically deal with changes in its environment. In fact, proactive decision-making enables pre-emptive responses and adjustmentsbased on informed forecasts and can help avoid the pitfalls of entrenched standard procedure (Evans, 1991; Grewal and Tansuhaj, 2001; Petrick and Echols, 2004).

Furthermore, such flexibility also allows appropriate responses to unforeseen changes in demand or emerging trends and threats, and enforces action which might lead to potential opportunity or sometimes even change the competitive 'playing field' to an organization's advantage (Dess and Lumpkin, 2005; Eppink, 1978; Evans, 1991; Kandemir and Acur., 2012; Sanchez, 1995). The organization then also has the ability to recognise, faster, appropriate initiatives and opportunities to develop new products for their benefit. In addition, the organization is able to better predict their future requirements based on the speed of their decision-making processes and accordingly make commitments (Gerwin, 1993; Johnson et al., 2003).

The resultant speed in implementation and degree of freedom of reaction is an appropriate accompaniment to the two knowledge integration supra-processes. When placed in conjunction 
with the relevant principles of DFRb this is hypothesized to create a sustainable NPD processes system. This is because when the life cycles of products are designed, altered or extended and the knowledge base of an organization is commensurately dynamic, the reactive processes connecting the organization to its environment also require a corresponding increase in sensitivity (Gaziulusoyet al., 2013; Kandemir and Acur., 2012; Zhang et al., 2013). In their study,Kandemir and Acur. (2012) find that this strategic decision-making flexibility is inherently linked to a firm's technological capability andthe creation of new opportunities and lead to better strategic performance as well as NPD performance outcomes.

The link to technological capabilities is noted at this junction as well, again emphasizing that the indicators for the supra-processes perform an overlapping function to capabilities related to NPD processes in organizations, validating their use for the purpose of this research.

\subsection{Attributes of Sustainable Products}

In accordance with the approach taken in this study, some basic desirable attributes of products that have potential for being sustainable should be outlined. It should be noted that these attributes change over time and as products are modified for sustainability, just as the development of sustainable (new) products is not just a simple one-time re-design issue (Hallstedtet al., 2013; Mascle and Zhao, 2008). As previously discussed, it is reductionist to assume that there a fixed algorithm for any given product to be simply labelled as 'sustainable'. An organization's ideology, its functioning, its processes and practices, its modes of gathering knowledge and intelligence, the manner of managing its knowledge base and other resources as 
well as its use of specialized personnel and information networks for sustainability, all contribute to the conceptualization and realization of sustainable product development (Dangelicoet al., 2013; Dyllick and Hockerts, 2002; Frishammaret al., 2012; Hallstedtet al., 2013; Yannopouloset al., 2012).

In this research the attributes of sustainable products are hypothesized to play an augmenting role to the concept of re-engineering products for rebirth, a better life-cycleand eventually better organizational performance. This may be studied by virtue of how attractive the adoption of such products may appear to the consumer, in the following manner (Guo, 2008, Langley et al., 2012; Moon et al., 2016). In understating the mechanisms of adoption, studied well in the extant literature, and examining the potential for a link between these and how sustainable products might be received (adopted) by customers, a relationship may be established between such products and the relevant dimensions of performance of a firm. Thus, this study bases its approach on the method suggested by Gaziulusoy and Boyle (2013) for assembling different lines of research. The assessment of how attractive a sustainable product may be, and for what reasons, is found to be based on the three-part model of social contagion (Dawkins, 1976) adapted from evolutionary biology(Dennett, 1995; Hurley and Chater, 2005; Williams, 2002) and tested by Langley, Bijmolt, Ortt and Pals (2012) in the context of what stimulates new product adoption and usage; as a part of extant NPD literature. The process consists of three main components, which deal with the following behaviours. First, the behaviour related to being attracted to use or adopt the new product; second, the behaviour related to the correct use of the new product and third, the behaviour related to the continued use of the new product over a long period of time. These three attributes(Product Fecundity, Product Fidelity and Product 
Longevity) relating to the adoption and the correct as well as long-lived use of a product are seen to affect the performance of a firm (Langley et al., 2012).

\subsubsection{Product Fecundity}

The concept of product fecundity is based on the general idea of multiplicative behaviour. A fecund product could be said to be capable of producing abundance of new growth. That is, it is specifically concerned with the actual extent to which a product prompts, from a consumer, as many instances of a specific behaviour that is related to that particular product. It is the capacity of a particular product-consumer combination that stimulates other consumers to adopt similar behaviour. In other words, a product is said to have a high level of fecundity if it stimulates a number of consumers to adopt and use it, or it stimulates its users to use it a large number of times (Langley et al., 2012; Melnyk et al., 2013) like use of texting by teenagers today.

Of the determinants of product fecundity, some are found from the innovation management literature itself, suggesting strong correlation on a conceptual level. An important determinant of product fecundity is its "observability", which is the level to which the product or its induced behaviour can be copied or followed just by observing it (Rogers, 2003). Another important determinant is the characteristic "reach" of the product, which refers to the amount of people that can see or experience the product while it is in use. Yet another important determinant variable is "intrinsic persuasion", which refers to the degree to which the use of the

product itself persuades other people to express a similar behaviour. In a competitive marketplace, a product with relatively low fecundity runs the risk of not launching successfully, or not being able to out-compete its rivals if it cannot diffuse into the target consumer market 
easily. This would occur if a majority of the consumers do not follow early adopters and innovators (Moore, 2002) and adopt its repeated usage. The performance of the product and subsequently that of the firm is singularly dependent on the successful adoption and use of the new product.

\subsubsection{Product Fidelity}

The concept of product fidelity is related to the influence the product characteristics have over the accuracy of the behavioural copies that are made. In the context of new product adoption, it is the exactness and correctness with which one consumer is able to copy the behaviour of using the product, either from another consumer or his/her own previous behaviour or use. In the case of low product fidelity, the resulting behaviour after a few instances of imitation would not be recognizable as the original consumer behaviour (Langley et al., 2012). The first determinant of product fidelity is the concept of "simplicity", which is the extent to which a behaviour associated with using a product can be learnt and expressed without errors or frustration. The concept can be divided into two parts, simplicity of 'idea' and simplicity of 'behaviour'. The concept of 'simplicity of idea' refers to the processing of understanding and communicating the idea of the product. Whereas 'simplicity of behaviour' refers to the actual learning and carrying out of the behaviour related to the product use without frustration or error (Langley et al., 2012). Another important and researched determinant of product fidelity is "trialability", which refers to the degree to which a product-related behaviour might be experimented with or tried out (Rogers, 2003). When product use and its related behaviour prompts "trialability", learning processes may follow, which in turn increase the chances that a consumer may operate the product correctly and more efficiently. A third important determinant 
of product fidelity is "negative consequences when done incorrectly" (Langley et al., 2012). The more drastic of dramatic consequences of misuse of a product may be efficient teaching behaviour but may be inherently discouraging to product longevity, the third attribute (Fishbein and Ajzen, 1975; Havlena and DeSarbo, 1991; Moore, 2002; Ostlund, 1974). A product which is difficult to use or functionally inflexible would have low fidelity, which would lose out to simpler rival products in the marketplace. Even at the expense of greater functionality, such products fail in the market due to their complexity (Mukherjee and Hoyer, 2001). Products that secure a market share due to high fidelity may positively affect overall performance not only at the product level but also the strategic level, since the vision of the organization is in touch with the needs of the market.

\subsubsection{Product Longevity}

The third attribute of sustainable product use is product longevity, which refers to the ability of the behaviour associated with the product to be long lived. This perhaps, is the most relevant of the three attributes, since it mandates that ability of a product life-cycle to be more than short-lived based on the user-related behaviour a product inspires. An important determinant of product longevity is "compatibility", which refers to user-behavioural compatibility with existing behaviours in the consumer (Rogers, 2003). Another important determinant is "invariance", which is the potential for stability of the expressed behaviour over time. Such behaviours help determine how product longevity can outweigh the resistance to change and may be supportive of new learning processes (Heylighen, 1998). Short term popularity or 'hype' is often the result of failed product longevity, where the product fails to hold the interest of this consumers due to lack of utility (Henard and Szymanski, 2001). On the other hand, products 
which are used for longer periods of time positively affect the firm's performance, by not only being a selling product, but also by maintaining a strategic advantage and a positive reputation for the organization in question.

\subsection{Product Attributes and Characteristics of Sustainable Products}

It should be noted here, that these three attributes also can be compared to (and may overlap across) the six characteristics of sustainable products as put forth by Belz and Peattie (2009). The following table (Table 2.1) summarises what product attributes and characteristics are posited to match each other. The product attributes consist of items that make them richer and more complex, hence meaningfully encompass multiple sustainable product characteristics each, as discussed in detail below:

\begin{tabular}{|l|c|}
\hline \multicolumn{1}{|c|}{ Characteristic } & Attribute \\
(source: Belz and Peattie, 2009) & (source:Langley et al., 2012) \\
\hline Customer Satisfaction & Fecundity, Fidelity \\
\hline Dual Focus & Fidelity, Longevity \\
\hline Life-cycle Orientation & Longevity, Fecundity \\
\hline Significant Improvements & Fidelity, Longevity \\
\hline
\end{tabular}




\begin{tabular}{|l|c|}
\hline Continuous Improvement & Longevity, Fecundity \\
\hline Competing Offers & Fecundity, Fidelity, Longevity \\
\hline
\end{tabular}

Table 2.1

Matching Sustainable Product Characteristics and Attributes

(source: Analyses in Chapters 01 and 02)

\subsubsection{Customer Satisfaction and Fecundity/Fidelity}

Belz and Peattie (2009) posit that the survival of a sustainable product in the marketplace is due to its ability to satisfy customer needs. In a similar vein, the attribute of product fecundity encompasses items such as 'novelty', 'intrinsic persuasion', 'publicity' as well as 'source credibility'. The literature finds that these behaviours are intrinsically linked with customer satisfaction, since potential customers are persuaded to act propelled by the need for acceptance and the need to express something that is seen to be held in high regard as well as in order to possess a product that is desirable (Heylighen, 1998; Langley et al., 2012; Pornpitakpan, 2004; Rogers, 2003; Wells et al., 2005).

With respect to the attribute of product fidelity, the items comparable to customer satisfaction are that of 'trialability', 'social risk' as well as 'formality'. All these behaviours are prompted by the need to attempt a potentially attractive behaviour - in this case the use of a sustainable product - and the social consequences of this behaviour (such as the possession of the product) being socially approved of, as well as the need for the actual expression (possession of the product) to be seen in an unambiguous way(Bauer, 1960; Heylighen, 1998; Goldenberg, 
Lehmann, and Mazursky, 2001; Veryzer, 1998). The behaviour of approving of a product and using it may thus be seen as inherently related to customer satisfaction.

\subsubsection{Dual Focus and Fidelity/Longevity}

Belz and Peattie (2009) posit that the dual focus of a sustainable product should be social as well as ecological. The two product attributes of fidelity and longevity match this inclination toward a dual focus. First, product longevity and fidelity includes items that allow for the social aspect of the dual focus, which are: 'social risk', 'social norm' and 'simplicity of behaviour'. These behaviours ensure that the product is used with ease, is socially approved of, hence usage is encouraged and that there are ideally no (or limited) negative social consequences of usage (Bauer, 1960; Fishbein and Ajzen, 1975; Heylighen, 1998; Veryzer, 1998).

With respect to the ecological aspect of the dual focus characteristic of sustainable products, both longevity and fecundity include the items of: 'negative consequences when done incorrectly', 'social risk' and 'social norm' once again (Bauer, 1960; Fishbein and Ajzen, 1975; Havlena and DeSarbo, 1991;Veryzer, 1998). These behaviours combine to ensure applicability in the sustainability context, since negative consequences and socially disapproved behaviour includes anything that might have negative ecological consequences. Also, the expression of a disapproved action or behaviour leads to an individual being potentially outcast, thus ensuring an ecological focus. 


\subsubsection{Life-cycle Orientation and Longevity/Fecundity}

Belz and Peattie (2009) find that the life-cycle of a product is important to its overall sustainable nature. The attributes of longevity and fecundity put forth by Langley et al., (2012) also cover similar ground via the items of 'source credibility', 'compatibility' and 'invariance'. It may be seen that the consistency and support of a product over a length of time and its ability to function in a continued and consistent manner is important to maintain a cradle-to-cradle lifecycle wherein the product and/or its component(s) may be 're-birthed' for continued use (Heylighen, 1998; Rogers, 2003). Also, it may be helpful if such a cycle and/or transformations

are seen to stem from domain expertise so as to inspire consumer support and acceptance (Pornpitakpan, 2004).

\subsubsection{Significant Improvements, Continuous Improvement and Fidelity/Longevity/}

\section{Fecundity}

According to Belz and Peattie (2009), a sustainable product should be conducive to assessment on a socio-ecological scale, preferably as related to performance. As previously seen, the product attributes of fidelity and longevity assist in this sphere. The items of 'social risk', 'social norm' as well as the 'negative consequences when done incorrectly'would encourage behaviours that reduce potential negative socio-ecological impact (Bauer, 1960; Fishbein and Ajzen, 1975; Havlena and DeSarbo, 1991;Veryzer, 1998).

With respect to continuous improvement, Belz and Peattie (2009) state that products should change with the changing nature of the market. This relates to the longevity and fecundity attributes put forth by Langley et al., (2012). The items of 'compatibility' as well as 'reach' 
would assist in creating behaviours that support the changing market, whereas not compromising the performance and consistency of the products at various stages of their life-cycle (Heylighen, 1998; Rogers, 2003).

\subsubsection{Competing Offers and Fecundity/ Fidelity/Longevity}

Perhaps the most challenging of all the characteristics of a sustainable product put forth by Belz and Peattie (2009) is that of competing offers. The authors find that sustainable products may actually lag behind in offering a competitive advantage in the market since they have to compensate for the increased costs related to socio-ecological issues. This last characteristic is matched by a combination of different items of all three of the product attributes used by Langley et al., (2012). The items include: 'source credibility', 'publicity', 'reach', 'social risk', 'formality', 'social norm' and 'self justification'. In other words, the potential for a competitive lag, while imminent, can be overcome if the behaviours associated with the use of sustainable products are known to create an overall socio-ecological advantage. This can be reinforced by the expertise of the sustainable products domain, the desirability and social support of using sustainable products, the extent of the message of sustainability being popularised, the social risks associated with spurning socio-ecologically desirable actions as well as the mutual support of these combined behaviours (Bauer, 1960; Fishbein and Ajzen, 1975; Havlena and DeSarbo, 1991; Heylighen, 1998; Pornpitakpan, 2004; Rogers, 2003; Veryzer, 1998; Wells et al., 2005).

The next Section, 2.5., details the types of organizational performance that should be considered with respect to the proposed research. 


\subsection{Performance Types}

\subsubsection{Strategic Performance}

The first dimension of performance is strategic. From the perspective of the organization, performance from a long-term perspective or strategic performance plays an important part of its continued functioning. As stated by Kandemir and Acur (2012), strategic performance is seen to encompass the following aspects: (1) the creation of opportunities in the marketplace for products, (2) the fit of these products with the market conditions and moreover demands as well as, (3) the ability of the organization to achieve specific product attributes based on their information.According to the authors, strategic performance also consists of the ability to open new technological as well as market-based opportunities as required by the organization for its successful and continuing operations.On the other hand, Zhang et al., (2013) refer to Porter's idea of strategy and find that strategic performance is related to finding the best possible positioning as compared to competitors, while retaining key strategic indicators that change according to the need of the organization. It may be noted that various studies find differing aspects of strategic performance are more applicable to their research; the two descriptions above appear to be most applicable for this study. The following paragraphs discuss diverse aspects as they relate to strategic performance.

Aspects of product competition, meeting market demands, entering new markets and organizational placement in the market at the strategic level are found to determine strategic performance (Barney, 1991; Chen et al., 2006; Evans, 1991 Kandemir and Acur., 2012). Strategic performance is also affected by decision-making flexibility which allows an organization to maintain numerous alternative and dynamic characteristics in their development 
processes as well as new product lines and flexibility in their product offering (Eisenhardt, 1990; Sanchez, 1995). This creates a more flexible system for the organization, product development processes, accessing and working with new technologies as well as for the product (Elbanna, 2006; Evans, 1991; Hitt et al., 1998; Kandemir and Acur., 2012; Ngo and O'Cass, 2012; Rajagopalan et al., 1993; Sharfman and Dean, 1997; Yang et al., 2012). For example, the research of Liem Viet Ngo and Aron O'Cass (2012) uses the resource based theory and shows that strategic performance is a context-specific outcome of the synergistic resource combinationdeployed and is dependent on a firm's knowledge base as well as the market conditions. The authors stress that the relative value of the combination of resources is almost entirely based on the external context (market conditions) and the firm's strategic objectives.

As mentioned above, an important constituent with respect to strategic performance is the identification of valuable opportunities for the development of new product lines, especially in the sustainability context (Atuahene-Gima, 2003; Acuret al., 2012; Kuckertz and Wagner, 2010; Sriboonlue et al., 2016). Studies show that potentially hidden opportunities may be largely rewarding, in terms of increased strategic performance, for an organization aiming to successfully integrate sustainability issues into its products (Frishammar et al., 2012; Kandemir and Acur., 2012; Kuckertz and Wagner, 2010). Products that are perceived as new, with greater quality and of a highly sustainable nature are shown to lead to better long-term performance for their organization in the marketplace (Carbonell and Rodriguez, 2006; Kessler and Bierly, 2002; Ngo and O'Cass, 2012). Consequently, those organizations that not only identify such opportunities but also acquire the related knowledge to develop products more responsive to market conditions are likely to perform better strategically as well as better meet unarticulated 
customer needs (Cooper and Kleinschmidt, 2000; Frishammar et al., 2012; Kleinschmidt et al., 2007).

\subsubsection{The Triple Bottom Line: Economic, Social and Environmental Performance}

The triple bottom line (3BL) concept of performance, coined by John Elkington (1997) has been widely discussed in sustainability literature, to the extent that most definitions of sustainability aspects include this performance type (see Table 1.1) (Bereketli and Genevois 2013; Boons et al., 2013; Boons, 2009; Dangelicoetal., 2013; Govindan et al., 2013; Seuring and Müller, 2008; Zhang et al., 2013). The triple bottom line may ideally be seen as a tool to determine the progress toward sustainability based on how the three performances are measured (Pagell and Gobelli, 2009; Sriboonlue et al., 2016).As discussed in the previous Sections, identifying and developing sustainable products is a market opportunity for organizations, but is offset by potential risks such as greater costs, stakeholder concerns and gathering additional data for the environmental and social impacts (Dangelicoet al., 2013; Keskin et al., 2013).

With the 3BL performance measures in place, social, environmental as well as the requisite financial/economic dimensions are taken into consideration, assisting in the achievement of sustainable product development. Systems such as quality function deployment for environment (QFDE), the environmentally-conscious extended format of the quality function deployment (QFD) method; or (Fuzzy) Analytical Hierarchy Process((F)AHP)for sensitive prioritization, also assist in attaining sustainability goals (Bereketli and Genevois, 2013; Trotta, 2010; Younesi \& Roghanian, 2015). There is of course, the debate that differing contexts and differing adherence to sustainability issues would lead to varying performance results across 
countries or organizations (Boons et al., 2013; Boons and Leudeke-Freund, 2013; Linton et al., 2007; Yang et al., 2012). Slater and Narver's (1994) research deals with this potential issue by introducing relative performance as a controlling variable.

The following three paragraphs deal with the three different components of the triple bottom line: economic performance, social performance and environmental performance. It is worth noting however, that with respect to the $3 \mathrm{BL}$ the different performances may not necessarily be independent of each other.

\subsubsection{Economic Performance}

Economic performance as related to the triple bottom line may be broadly considered along two lines of research. The first is related to economic performance as it applies to the prevention of costs, which isthe conservative approach (Bullard and Manchanda, 2013; Hallstedt et al., 2013). This includes the reduction of costs as associated with 'doing business', such as the reduction of energy consumption costs, materials purchasing costs, the reduction of waste disposal or treatment costs, the reduction of fines as relating to environmental accidents or not following regulations (de Medeiros, 2014; Keskin et al., 2013; Lockrey and Johnson, 2013). However, this line of research may not be comprehensive in its aims, since the incorporation of sustainability issues sometimes leads to increased costs for the organization (Belz and Peattie, 2009).

The second line of research on economic performance relating to the triple bottom line is more proactive and relatesto the creation of value and strategic advantage for the organization by utilising appropriate methods, approaches, designs and tools (e.g. D4S, DfE, DFRb and so on) 
(Keskin et al., 2013; Mascle, 2013; Yannopoulos et al., 2012).Multiple studies, increasing in recent years, have shown that product designs and development with sustainability issues integrated lead to better organizational performance (e.g.Chung and Tsai, 2007; Keskin et al., 2013; Mascle and Zhao, 2008; Yang et al., 2012; Yannopoulos et al., 2012). In the study of Keskin et al., (2013) value creation becomes the most important performance outcome, based on the prioritised sustainability goals. In the case of Lockrey and Johnson's (2013) paper, the idea propagated is that of student designers using DfE (design for environment) techniques in concurrence with strategic goals to solve organizational performance issues. Bereketli and Genevois (2013) find that cost and quality considerations matter along with stakeholder expectations and environmental requirements. The authors identify improvements strategies using Quality Function Deployment (QFD) for the environment (QFDE). As a result, organizations get further opportunities to enter new markets, acquire new technical know-how and have an advantage in developing newer technologies previously unexplored, which as loop enhances their future performance further(Dangelico et al., 2013) and complements strategic performance as seen in Section 2.4.1. above.

\subsubsection{Social Performance}

Social performance as a part of the triple bottom line may be viewed as a conceptual extension of the more established concept of corporate social responsibility (Govindan et al., 2013; Hallstedt et al., 2013). Hallstedt et al. (2013)clearly differentiate between sustainability as it applies to society and sustainability with respect to a business. The social performance might have been seen as a measure more related to the reduction or management of negative social 
impact, in the interests of "societal well-being", inclusive of seeing to vocational training, providing a share of profit for philanthropy, cementing relations with the community and such; which is more in sync with the conservative approach (Bullard and Manchanda, 2013; Hallstedt et al., 2013; Metta and Badurdeen, 2013).

However, there has been some research related to a more proactive approach as it relates to closing the life-cycle loop to create a cradle-to-cradle life-cycle (Belz and Peattie, 2009; Metta and Badurdeen, 2013; Pagell and $\mathrm{Wu}, 2009)$.Including the positive societal impacts has revealed even greater benefits (such as improved corporate image, greater competitive advantage, better product differentiation, new market penetration) for organizational performance as shown by performance metrics (Bansal and Roth, 2000; Boons et al., 2013; Chen et al., 2006; Dangelico etal., 2013; de Medeiros, 2014; Kleindorfer et al., 2005; Lockrey and Johnson, 2013; Pujari, 2006).

\subsubsection{Environmental Performance}

Previous studies have shown that there are significant benefits to introducing the environmental dimension alone to organizational strategy (such as increased efficiency of resource use and reduced waste) (Lockrey and Johnson, 2013; Pagell and Gobeli, 2009; Porter and van der Linde, 1995; Shrivastava, 1995). One of the most important forms of environmental performance is in reducing waste and pollution creating activities, while switching to cleaner modes of production (Lockrey and Johnson, 2013; Keskin et al., 2013; Pagell and Gobeli, 2009).

Reduction of waste can take the form of decreasing air, water or solid waste; decreasing consumption of hazardous materials; decreasing costs of waste treatment/discharge; decreasing 
energy consumption costs; or decreasing material purchasing costs. Also, an organization has to possess the ability to improve its environmental situation by decrease in environmental accidents and associated fines and include requisite standards and training for personnel (Keskin et al., 2013; Lockrey and Johnson, 2013; Mann et al., 2010; Mascle and Zhao, 2008). All the above actions are shown to have a significant impact on the environmental, economical and social aspects of sustainability performance.

In summation, the literature available on the subject being examined may be considered to be scattered across various fields and not available as a cohesive unit under any specific topic or area. In this chapter, the strategic organizational orientation mix, taken from new product development literature, is found to comprise of a market orientation consisting in turn of customer orientation, technological orientation, competitor orientation and interfunctional coordination. In the case where sustainable products are concerned, another strategic orientation, sustainability orientation also should be considered. When literature on product development processes is considered, a number of potential processes can be considered at various organizational levels, however the most important appear to be those related to assimilating knowledge at various levels and how that knowledge is used. Hence, the literature suggests domain-specific and procedural knowledge integration as important product development processes as well as decision-making flexibility. As far as the products themselves are concerned, the literature investigating product attributes specifies three attributes essential to product proliferation, which are identified as product fidelity, fecundity and longevity. Moving on to performance, the important aspects of organizational performance that have been explored in the literature are those of the triple bottom line i.e. economic, environmental and social performance as well as strategic performance, which is more organization-specific in nature. The next chapter 
provides insights into how these various constructs are theorized as interacting with each other in the form of a posited theoretical framework and its related hypotheses.

This chapter examines the academic available in the areas related to this research. The chapter begins with a description of the antecedents of sustainable product development and discusses the challenges and research gaps encountered by the researcher. It then moves to outline the various areas of interest as outlined by the research objectives, beginning from an organization's strategic orientation mix, to sustainable product development processes, product attributes and then various aspects of performance. The chapter also discusses how product attributes from the NPD literature can be applied to the case of sustainable products and compares them to the Belz and Peattie (2009) characteristics of sustainable products. 


\section{Chapter 3 Theoretical Framework}

\subsection{Investigative Questions}

In an endeavour to encompass these core concepts and in the light of extant literature, a theoretical framework (figure 3.1 and 3.2) is developed, which is presented in the next Section. The investigative questions that require an answer are enumerated as follows:

1. Do strategic market orientations (technological, competitor, customer and interfunctional coordination) (positively) impact sustainable product development processes in the organization?

2. Does strategic sustainability orientation (positively) impact of sustainable product development processes?

3. Do the sustainable product development processes of integrating domain specific knowledge, integrating procedural knowledge and flexible decision-making (positively) affect development of sustainable products?

4. Do sustainable products; with the attributes of longevity, fecundity and fidelity have a (positive) impact on the strategic performance, social performance, economic performance and environmental performance of the organization? 
5. Do the sustainable product development processes of integrating domain specific knowledge, procedural knowledge and flexible decision-making (positively) affect strategic performance, economic performance, social performance and environmental performance?

The questions will vary based on the stage of the proposed study, since the first exploratory stage is dedicated to qualitatively understanding how these constructs, which have been tested in the NPD area, are related in the context of sustainable products. The second, confirmatory stage is committed to understanding and validating the strength of relationships of the constructs. Therefore, in the questions presented above, the positive impact is anticipated (from the findings in the literature) but not assumed, before the first stage of the study is conducted. Furthermore, the implications from the literature only extend to product development of regular products at this stage. As this study focuses on extending that discourse and understanding the implications in the context of sustainable products, the measures themselves are not inherently for sustainable products but have been oriented in that direction on the strategic level by this research. In other words, the strategic orientation of the organization and its performance goals both lend the context toward sustainability. The product attributes and the processes themselves are to be tested in the context of sustainability for the first time and to further contextualise them as related to sustainable products would require further research, which would be based on the findings of this study (and potentially other studies as well). 


\subsection{Theoretical Framework}

In this Section, the theoretical framework is presented which would be used for this study. From the literature review in Chapter 2, and in an attempt to answer the investigative questions from Section 3.1, the following general framework (in figure 3.1 below) and theoretical framework (in figure 3.2 below) have been proposed. The literature review from chapter 2 forms the basis of the investigative questions described above in section 3.1 and the theoretical framework in figure 3.2. The expected relationships between the constructs enumerated in the previous chapter and represented in the posited framework below (figures 3.1 and 3.2) are discussed in the next Section, 3.3.

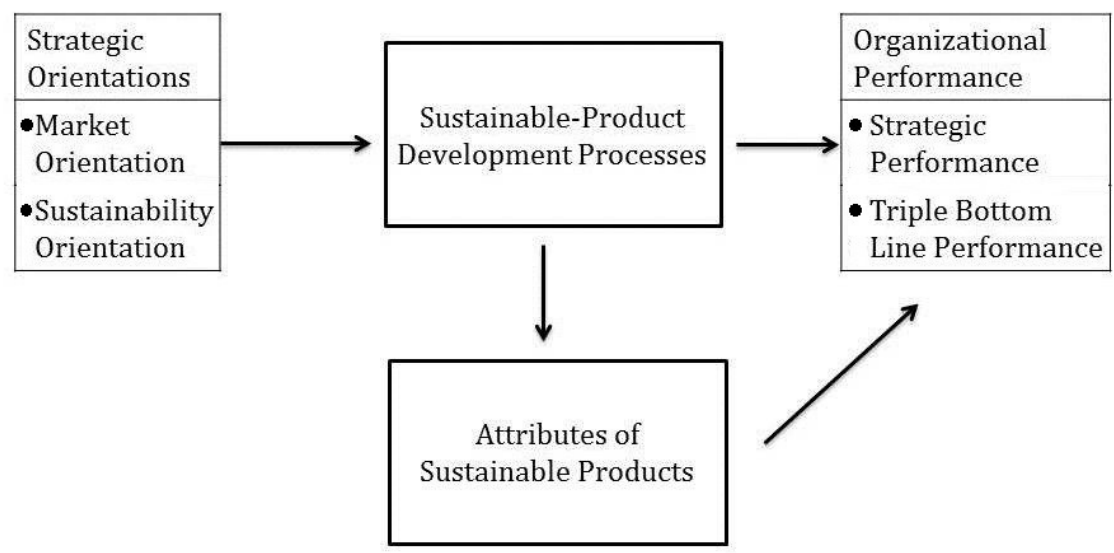

Figure 3.1

General Framework 


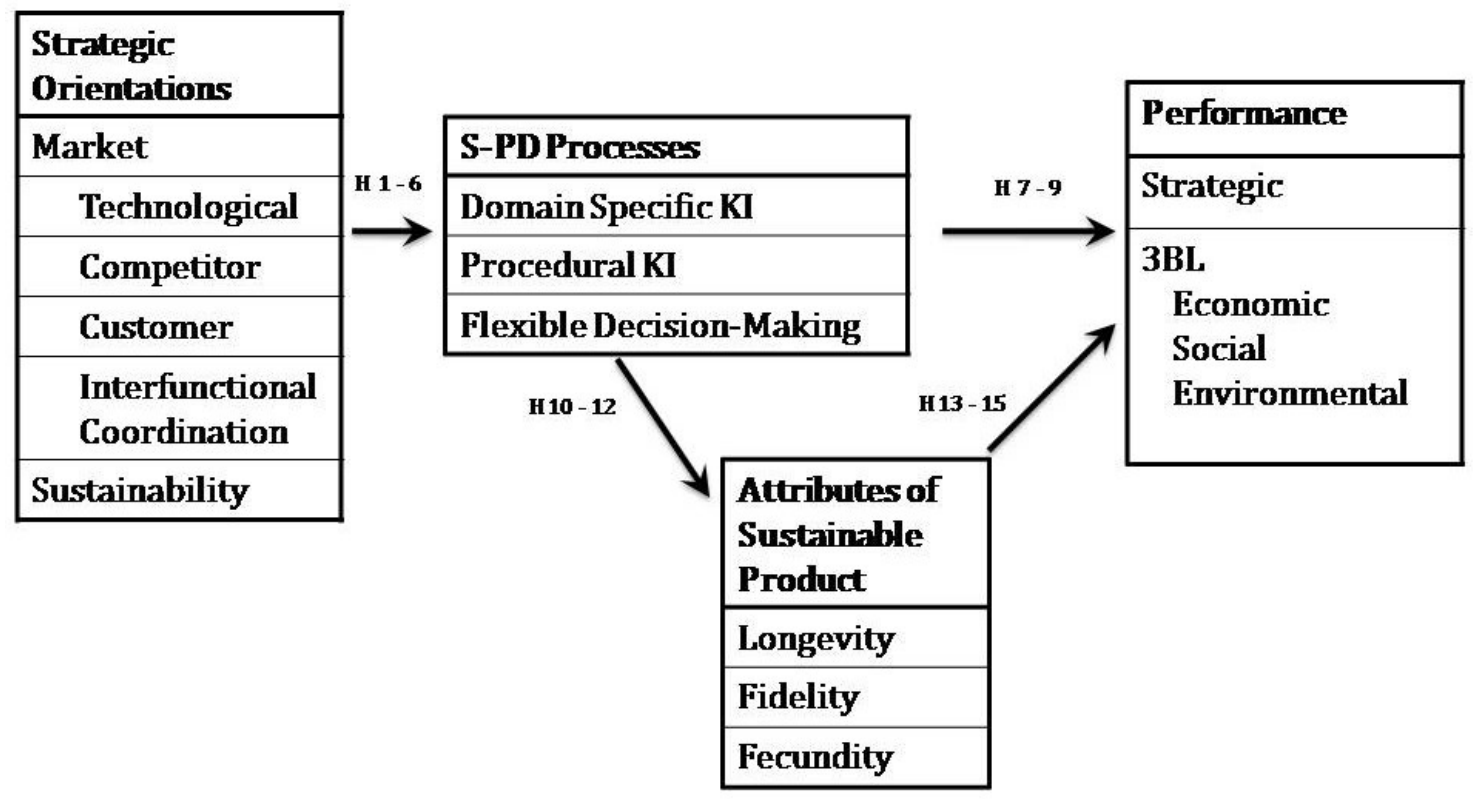

Figure 3.2

Theoretical Framework

The basic premise of the posited framework is that specific strategic orientations of an organization affect the manner in which product development processes function within an organization, which further affects the performance of an organization. In the situation where an organization wishes to produce sustainable products, the organization's strategic orientation would include sustainability orientation, which in turn, is expected to affect the product development processes. The attributes of sustainable products are also envisaged to be different from non-sustainable products by virtue of the fact that the life-cycle and impacts (social, environmental and economic) of sustainable products differ from other products. Thus, not only are the product development processes expected to affect the attributes of sustainable products, 
but the attributes of the sustainable product(s) being developed are also expected to affect the performance of the organization.

Since the development processes important for sustainable products have not as yet been sufficiently explored by previous research, this study demarcates its scope as being limited to three strategic-level development processes (Domain-Specific Knowledge Integration (KI); Procedural Knowledge Integration (KI) and Flexible Decision-making), so as to avoid unwieldiness. This will also assist in limiting unnecessary respondent attrition. Other product development processes at various levels are deemed active but do not comprise this particular research's objectives. Thus, the other processes are considered to constitute a conceptual blackbox, outside the scope of this study. The framework and its operationalization are discussed in this chapter's following Sections, 3.3. and 3.4.

\subsection{Expected Relationships}

From the literature reviewed in Chapter 2 and to assist in answering the investigative questions from Section 3.1, fifteen hypotheses are developed based on the research framework

presented above. As per the results of the previous studies, the expected relationships among the constructs within the proposed framework are grouped as follows: 


\subsubsection{Strategic Orientation and S-PD processes (SPDP)}

Many studies have focussed on the impact of strategic orientations on strategic decisionmaking, strategic flexibility and product development success (e.g.Debruyne et al., 2002; Evans, 1991; Kandemir and Acur, 2012; Rajagopalan, et al., 1993; Sanchez, 1995; Sharfman and Dean, 1997 among others). Research has covered various aspects: authors Yannopoulos et al., (2012) conduct a survey on Canadian firms to find how proactive market orientations can be better than a responsive market orientation, where one of the most important differences between the twois how knowledge is generated, disseminated integrated and/or used as well as how decisions are made; Ngo and O'Cass, (2012) find that a firm's market orientation affects its deployment of market-based knowledge resources andinternal knowledge processes; while Kleinschmidt et al., (2007) show that competition can be overcome by knowledge integration in a firm. More interestingly, strategic orientation has been seen to also positively impact the product development processes and strategic interactions of an organization (Eisenhardt, 1990; Elbanna, 2006; Acuret al., 2012). For example, Acur et al., (2012) find that proficiency in understanding technological and market conditions supplemented by inter-functional collaboration/coordination between various department assists in more focussed development of products which match the strategic goals of the firm. The well researched and many-times-over tested composite that is market orientation consists of competitor orientation, customer orientation, interfunctional coordination and technology orientation (Lukas and Ferrell, 2000; Gatignon and Xuereb, 1997; Narver and Slater, 1990; Yang et al., 2012). Of all these constructs, two are more externally focussed (customer orientation, competitor orientation) where as the other two are internally focussed (interfunctional coordination, technology orientation). 
The externally focussed orientations are seen to have a stronger influence on an organization's functioning, but all four strategic orientations are seen to influence product development processes to various (significant) degrees(Atuahene-Gima, 1995; Bharadwaj et al., 1993; Kahn, 2001; Paladino, 2008). For example, the seminal work of Atuahene -Gima, (1995) finds that market orientation affects all stages of product development, hence should not be discounted after the early stages of the development processes and the total life-cycle of the product are complete.

As stated by Spanjol et al., (2012) strategic orientation is an aggregated concept, so it is important that each of the orientations be a subject of study in its own individual right to distinguish its particular effect in a specific context. The effect of each of the component orientations on product development processes is also seen to be significant and varying depending on the context and nature of study (Jeonget al., 2006; Kahn, 2001; Kim et al., 2013; Paladino, 2008; Yang et al., 2012). The study of Kim et al., (2013) finds that these specific strategic orientations in NPD organizations contribute to a firm's knowledge processes, which then lead to new product development success. The authors use resource based theory to posit that strategic market orientation influences the characteristics of products, which when augmented by knowledge that has been transferred or shared through or even among organizations leads to an enhanced new product advantage.Paladino (2008) and Yang et al. (2012) find that the right combination of strategic orientations augmented by flexibility in decision-making and proper modes of knowledge integration can offset potential performance pitfalls such as the results of turbulence in the marketplace and fast-changing demands. From the previous research detailed in Chapter 2, it may be concluded that strategic market orientation would indeed have a positive influence on sustainable product development practices and 
processes within a new and growing market. In the context of this research, it is expected that the strategic orientations mentioned above would affect strategic product development processes in the case of sustainable products as well. Thus, the following are posited as the relationships between the strategic orientation of a firm and its development processes:

H1: the composite market orientation is positively related to sustainable product development processes.

H2: competitor orientation is positively related to sustainable product development processes.

H3: customer orientation is positively and significantly related to sustainable product development processes.

H4: interfunctional coordination is positively and significantly related to sustainable product development processes.

H5: technological orientation is positively and significantly related to sustainable product development processes.

The various components of strategic orientation in the context of this study are posited to be the composite construct of market orientation as well as sustainability orientation, since the development of sustainable products would naturally be a result of an organization possessing an orientation toward sustainability. Little research has been conducted on the concept of sustainability orientation, but the work of Kuckertz and Wagner (2010) covers all the aspects relevant to this study, including prevention as well as assessing impacts of the product life-cycle 
in its entirely. As in the case of the other strategic orientations discussed above, it may be probable that sustainability orientation, as put forth by Kuckertz and Wagner (2010), would significantly influence knowledge integration and decision-making processes for sustainable product development. The authors study how the sustainability orientation of individuals is a very important factor in the recognition, creation and pursuit of sustainability benefits for an organization or entrepreneurial venture, which then affects what kind of processes are set into place by such individuals for the functioning of their firm (Kuckertz and Wagner, 2010). The authors operationalize sustainability orientation using six items that relate to environmental protection and social responsibility. This study attempts to test whether the influence of sustainability orientation would hold true in the case of the organization as well, since all the items used to measure individual sustainability orientation by Kukertz and Wagner (2010) may logically apply to organizations as well.Thus, it is anticipated that the effect of sustainability orientation will positively impact sustainable product development processes.

H6: sustainability orientation is positively and significantly related to sustainable product development processes.

\subsubsection{S-PD processes (SPDP) and performance}

It has been previously mentioned that development processes that result in sustainable products are as yet somewhat unexplored in academic research. In this investigative research, the aim is to identify a part of the strategic processes that enable the development of products that are increasingly sustainable. This study does not claim that the processes, their relationships and 
impacts studies are the only, or even the most important ones. This research, however, does attempt to commence the identification of such processes that lead to sustainable products being developed. For this reason, the processes that are begun with in this research are on a strategic level, though they act as links across the various levels of analysis: the product level, project level, organizational level and beyond as well.

Holistic study across the various levels of analysis is considered to be most beneficial to research such as this (Gaziulusoy et al., 2013). Previous studies have noted that product development outcomes directly impact strategic performance on an organizational level (Acuret al., 2012; Ngo and O'Cass, 2012; Yannopoulos et al., 2012). The processes within the scope of this study include the integration of domain-specific knowledge (including the acquisition of technical know-how); the integration of procedural knowledge and flexibility of decision-making (Boons et al., 2013; Cohen 1991; Gaziulusoy and Boyle, 2013; Frishammar et al. 2012; Kandemir and Acur, 2012; Ullman, 2010). The main expected effects of the knowledge-related processes is posited to be seen in related activities of whether relevant knowledge is gathered, stored and used for future projects (Frishammar et al. 2012; Ullman, 2010).As seen in the work of Frishammar et al.(2012), domain-specific as well as procedural knowledge must be well documented, processed and used for future projects in order to reap strategic as well as financial benefits for the organization in the form of strategic organizational performance, financial performance as well as product performance in the capacity that it is successfully commercialized and innovative in nature. Sharing and utilizing domain-specific knowledge is seen to motivate a closer link to the marketplace and the environment in general to provide a better perspective for current and future product development opportunities and ideas which are so critical for the sustainable functioning of product development processes (Brockman and 
Morgan, 2003).Adaptability for survival is also seen as an important strategic consideration for an organization, especially one aiming for long term sustainability in its offerings. Previous studies have shown that strategic performance is affected by how flexible its decision-making is, in addition to its strategic orientations and handling of procedures and technical know-how (Akgün et al., 2012; Ansoff, 1975; Atuahene-Gima and Li, 2004; Debruyne et al., 2002; Evans, 1991; Frishammar et al., 2012; Acuret al., 2012; Sanchez, 1995; Verganti, 1999). In addition, the incorporation of sustainability issues fits smoothly in the process of integrating procedural knowledge of open as well as protected activities (Gaziulusoy et al., 2013).These points are only magnified when, in this study, the need to integrate domain-specific and procedural knowledge is viewed in conjunction with the concept of design for rebirth (DFRb) as it applies to this research. Sustainable product development is envisaged to be more closely linked with such knowledge processes and consequently more reactive, or adaptive, to the external as well as internal forces.

Frishammar et al. (2012)also mention the integration of general knowledge, but in the context of this study, general knowledge as well as technical know-how is analysed in an aggregated form along with domain-specific as well as procedural knowledge. This is because this specific study deals with the context-specific effects related to product development processes and not the organization in general. According to Dangelico et al., (2013) the acquisition of domain-specific knowledge as well as technical know-how is considered vital if sustainability issues are to be successfully integrated with product development processes to result in superior strategic performance. With respect to flexible strategic decision-making, the actual flexibility and how that affects product development goals and results is of importance (Gaziulusoy and Boyle, 2013; Kandemir and Acur., 2012).The research of Kandemir and Acur (2012)examines how strategic decision-making flexibility assists in the transformation of a firm's 
resources and other inputs to strategic performance goals as well as assists them in successfully delivering new products. The authors also find that flexible strategic decision-making greatly assists in foreseeing new and changing demands, which in turn enables a firm to successfully adapt to customer demands and cater to the requisite needs. Research also shows that product development processes that enable organizations to find new markets, products and domains enabling them to better meet consumer demands, offer better quality, successfully reduce costs and most importantly, timely deliver new products (Acuret al., 2012; Kim et al., 2013; Yannopoulos et al., 2012).

For the purposes of this study, it is expected that the strategic product development processes would have a significant impact on one or more of the organizational performances as shown in figure 3.1: i.e. strategic performance as well as the triple bottom line of sustainability performance (in the context of developing sustainable products). The processes are posited to significantly impact the overall performance of the organization as follows:

H7: integration of domain-specific knowledge and technical know-how is positively and significantly related to performance.

H8: procedural knowledge integration is positively and significantly related to performance. H9: flexible (strategic) decision-making is positively and significantly related to performance. 


\subsubsection{S-PD processes (SPDP) and Product Attributes}

The same processes seen in Section 3.3.2, are also envisaged to affect the posited attributes of sustainable products in this research. The sustainable product attributes themselves are adopted from research on product adoption, they relate to the desired characteristics products may possess in order to be successful in the marketplace (Langley et al., 2012). The authors find that three attributes, product longevity, product fidelity and product fecundity lead to the successful adoption of products in the marketplace. This study aims to test if these attributes are affected by the product development processes that are culled from NPD literature in a context involving the development of sustainable products.Since the mechanism of adoption, as explained by Langley et al,'s research (2012), inspires certain behaviours that lead to successful product use, the same theory may be applied to sustainable products and how attractive they appear to customers; following the rules set out by Gaziulusoy and Boyle's (2013) work relating to assembling different lines of research. As seen in Chapter 2, the processes related to the development of sustainable products may be compatible with what attributes are emphasized, for example, domain-specific knowledge integration of how to increase the life-cycle of a component may affect the product longevity attribute by increasingthe general compatibility of the product. As another example, it may be seen that flexibility in decision-making may affect the attribute of fecundity of a sustainable by making it possible to create products that support the changing needs of the market with the increased 'reach' and the 'self justification' of the product. Potentially, another example would be how both procedural and domain-specific knowledge could reinforce product fidelity and the ease with which a product might be designed for disassembly by increasing the 'simplicity of behaviour' as inspired by the product (Frishammar et al., 2012; Langley et al., 2012; Mascle, 2013). 
It is envisaged in this study that these product attributes, in their meaning and application appear in all probability valid for sustainable products as characterised by Belz and Peattie (2009)and their penetration of the market (as discussed in Section 2.3). How product development processes affect the sustainable product attributes requires exploration (exemplified in the previous paragraph), and is a part of the research objective of this study. It may be posited that the sustainable product development processes affect, to some degree, each of the three attributes of sustainable products. The following group of hypotheses relates to this concern:

H10: Product fecundity is positively and significantly related to the three attributes of sustainable products

H11: Product fidelity is positively and significantly related to the three attributes of sustainable products

H12: Product longevity is positively and significantly related to the three attributes of sustainable products

\subsubsection{Product Attributes and Performance}

As discussed in the previous Section (3.3.3), the attributes of sustainable products used in this study originate from the research on the manner in which products are adopted by customers and what renders these products attractive and worthy of continued use (Guo, 2008, Langley et al., 2012). In adopting these attributes for sustainable products, the potential relationships that may naturally emerge in the forefront on the basis of conceptual affinity are as follows.

First, the attribute of product fecundity, that encourages the spreading and continued use

of the product may positively impact economic performance as a direct result of increasing and 
stable usage among customers. In addition to this, product fecundity would affect social performance and environmental performance as the sustainability aspects of the product would be perceived socially desirable and environmentally preferable. This in turn would mean that strategic performance would also be affect by fecundity as reinforced by the desirability of the product for the triple bottom line. Second, product fidelity may positively impact social performance as a sustainable product is posited to be safe to use and user-friendly on an individual as well as social level. Product fidelity would also affect environmental performance since safety issues render a product preferable for consumption, which would in turn be expected to affect economic and strategic performance if the product is deemed preferable along social and environmental lines. Third, product longevity may positively affect environmental performance since the product is posited to continue its functions true to form through its life-cycle as well as maintaining a high level of adaptability and compatibility with other emerging applications/technologies. This would have a further effect on environmental and social performance since products built with lifecycles more sensitive to use in the environment would be desirable environmentally as well as socially preferable. This in turn, would affect strategic performance of the organization since product desirability at the level of the triple bottom line would render it desirable strategically for the organization as well.

Hence these three sustainable product attributes reinforce the sustainability context of our proposed theoretical framework. The following hypotheses relate to the relationships expected between the sustainable product attributes and organizational performance:

H13: Product fecundity positively and significantly impacts performance. 
H14: Product fidelity positively and significantly impacts performance.

H15: Product longevity positively and significantly impacts performance.

It should be noted here that the triple bottom line concept of performance would be related to more than just cost saving or profit-making aspects as performance is traditionally understood in economic terms. However, the constructs that the next section presents reflect a more conservative or "base" estimation of what these types of performances actually mean since they are adopted from previously empirically-tested research. As research progresses in this area, it is expected that more dimensions are added to the understanding of what aspects of performance can be measured to gain a deeper understanding of the effects theorised by this pioneering study.

\subsection{Constructs and Indicators}

The constructs and hypotheses mentioned in Sections 3.2 and 3.3 have all been previously operationalized in the literature. A number of indicators constitute each of the constructs that interact in the framework proposed by this study. The following table (3.1) provides a detailed listing of the constructs, their indicators and the primary academic sources of the same:

\begin{tabular}{|l|l|l|l|}
\hline $\begin{array}{l}\text { Composite } \\
\text { Construct }\end{array}$ & Construct & Source $^{2}$ & Indicators \\
\hline Strategic & Customer & Lukas and & $\bullet$ Meeting customers to determine needs; \\
\hline
\end{tabular}

\footnotetext{
${ }^{2}$ Please note that only the primary sources of the items of the posited constructs have been indicated here. The other sources, in specific, the originating sources of particular items have been discussed previously in Chapters 02 and 03 (section 3.3).
} 


\begin{tabular}{|c|c|c|c|}
\hline Orientation & Orientation & Ferrell, 2000 & $\begin{array}{l}\text { - Conducting surveys to determine end- } \\
\text { user satisfaction; } \\
\text { - Conducting market research to } \\
\text { understand customer needs. }\end{array}$ \\
\hline & $\begin{array}{l}\text { Competitor } \\
\text { Orientation }\end{array}$ & $\begin{array}{l}\text { Lukas and } \\
\text { Ferrell, } 2000\end{array}$ & $\begin{array}{l}\text { - } \text { Collecting information on competitors; } \\
\text { - Considering competitor actions before } \\
\text { determining action plans; } \\
\text { - Responding to competitor actions timely; } \\
\text { - Learning of competitor product launches } \\
\text { before time. }\end{array}$ \\
\hline & $\begin{array}{l}\text { Interfunctional } \\
\text { Coordination }\end{array}$ & $\begin{array}{l}\text { Lukas and } \\
\text { Ferrell, } 2000\end{array}$ & $\begin{array}{l}\text { - Inter-departmental working to meet } \\
\text { market demand; } \\
\text { - Displaying good team spirit for product } \\
\text { development; } \\
\text { - Inter-departmental collaborations among } \\
\text { different functional divisions for product } \\
\text { development; } \\
\text { - Inter-departmental sharing of experience } \\
\text { and other information for product } \\
\text { development. }\end{array}$ \\
\hline & $\begin{array}{l}\text { Technological } \\
\text { Orientation }\end{array}$ & $\begin{array}{l}\text { Hallstedt et } \\
\text { al., 2013; } \\
\text { Yang et al., } \\
\text { 2012; Lukas } \\
\text { and Ferrell, } \\
2000\end{array}$ & $\begin{array}{l}\text { - Employing state-of-the-art technology for } \\
\text { product development; } \\
\text { - Aggressively pursuing R\&D as compared } \\
\text { to competitors; } \\
\text { - Leading in sophisticated technology use } \\
\text { as compared to competitors; } \\
\text { - Building forward-looking technologies to } \\
\text { meet customer needs. }\end{array}$ \\
\hline
\end{tabular}




\begin{tabular}{|c|c|c|c|}
\hline & $\begin{array}{l}\text { Sustainability } \\
\text { Orientation }\end{array}$ & $\begin{array}{l}\text { Dangelicoet } \\
\text { al., 2013; } \\
\text { Kuckertz and } \\
\text { Wagner, } 2010\end{array}$ & $\begin{array}{l}\text { - Using environmentally friendly raw } \\
\text { materials when possible; } \\
\text { - Preventing waste during production; } \\
\text { - Preventing pollution during production; } \\
\text { - Evaluating the environmental impact of } \\
\text { the entire product life-cycle. }\end{array}$ \\
\hline & $\begin{array}{l}\text { Market } \\
\text { Orientation }\end{array}$ & $\begin{array}{l}\text { Lukas and } \\
\text { Ferrell, } 2000\end{array}$ & $\begin{array}{l}\text { Composite of the first four constructs. No } \\
\text { individual indicators }\end{array}$ \\
\hline \multirow[t]{3}{*}{ S-PDP } & $\begin{array}{l}\text { Domain- } \\
\text { specific } \\
\text { knowledge } \\
\text { integration }\end{array}$ & $\begin{array}{l}\text { Frishammar et } \\
\text { al., } 2012\end{array}$ & $\begin{array}{l}\text { Employing systems and methods to } \\
\text { acquire thematic knowledge from } \\
\text { product development projects; } \\
\text { - Employing systems and methods to share } \\
\text { thematic knowledge from product } \\
\text { development projects within the firm; } \\
\text { - Using the thematic knowledge acquired } \\
\text { from previous projects for future product } \\
\text { development. }\end{array}$ \\
\hline & $\begin{array}{l}\text { Domain } \\
\text { specific } \\
\text { knowledge } \\
\text { integration } \\
\text { (Acquisition } \\
\text { of technical } \\
\text { know-how) }\end{array}$ & $\begin{array}{l}\text { Dangelicoet } \\
\text { al., } 2013\end{array}$ & $\begin{array}{l}\text { - Hiring competent new staff; } \\
\text { - Installing new machinery; } \\
\text { - Training existing staff for new } \\
\text { endeavours, technologies, tools and } \\
\text { methods. }\end{array}$ \\
\hline & $\begin{array}{l}\text { Procedural } \\
\text { knowledge } \\
\text { integration }\end{array}$ & $\begin{array}{l}\text { Frishammar et } \\
\text { al., } 2012\end{array}$ & $\begin{array}{l}\text { Employing systems and methods to } \\
\text { acquire procedural knowledge from } \\
\text { product development projects; } \\
\text { - Employing systems and methods to share }\end{array}$ \\
\hline
\end{tabular}




\begin{tabular}{|c|c|c|c|}
\hline & & & $\begin{array}{l}\text { procedural knowledge from product } \\
\text { development projects within the firm; } \\
\text { Using the procedural knowledge acquired } \\
\text { from previous projects for future product } \\
\text { development. }\end{array}$ \\
\hline & $\begin{array}{l}\text { Flexible } \\
\text { decision- } \\
\text { making }\end{array}$ & $\begin{array}{l}\text { Kandemir and } \\
\text { Acur., } 2012\end{array}$ & $\begin{array}{l}\text { Ability to forecast future requirements } \\
\text { and providing commitments for product } \\
\text { development decisions and actions; } \\
\text { - Ability to adjust decision-making } \\
\text { processes on the estimate of future } \\
\text { requirements; } \\
\text { - Ability to estimate the requisite speed of } \\
\text { product development on the basis of } \\
\text { future requirements; } \\
\text { - Ability to adjust the commitment to } \\
\text { translating decisions to actions on the } \\
\text { basis of requirements; } \\
\text { - Ability to estimate future requirements } \\
\text { on the basis of total development time. }\end{array}$ \\
\hline \multirow[t]{2}{*}{$\begin{array}{l}\text { Attributes of } \\
\text { Product } \\
\text { Sustainability }\end{array}$} & $\begin{array}{l}\text { Product } \\
\text { Longevity }\end{array}$ & $\begin{array}{l}\text { Langley et al., } \\
2012\end{array}$ & $\begin{array}{l}\text { - Sustainable product is compatible and } \\
\text { supported by a fair range of applications; } \\
\text { - Sustainable product performs } \\
\text { consistently over time; } \\
\text { - Sustainable product offers a unique } \\
\text { financial advantage to users; } \\
\text { - Use of Sustainable product is socially } \\
\text { supported/encouraged. }\end{array}$ \\
\hline & Product & Langley et al., & $\begin{array}{l}\text { Potential users can try sustainable } \\
\text { product with ease; }\end{array}$ \\
\hline
\end{tabular}




\begin{tabular}{|c|c|c|c|}
\hline & Fidelity & 2012 & $\begin{array}{l}\text { - Users can learn the sustainable product's } \\
\text { functions without difficulty; } \\
\text { - Misuse of the sustainable product does } \\
\text { not cause significant damage or harm to } \\
\text { user. }\end{array}$ \\
\hline & $\begin{array}{l}\text { Product } \\
\text { Fecundity }\end{array}$ & $\begin{array}{l}\text { Langley et al., } \\
2012\end{array}$ & $\begin{array}{l}\text { - Sustainable product can reach/appeal to a } \\
\text { large number of potential customers; } \\
\text { - Sustainable product can be clearly } \\
\text { understood with the aid of one or more of } \\
\text { the five senses; } \\
\text { - Sustainable product has the ability to } \\
\text { encourage self-use with built-in features; } \\
\text { - Sustainable product is original as } \\
\text { compared to other products in the market. }\end{array}$ \\
\hline Performance & $\begin{array}{l}\text { Strategic } \\
\text { Performance }\end{array}$ & $\begin{array}{l}\text { Kandemir and } \\
\text { Acur, } 2012\end{array}$ & $\begin{array}{l}\text { - Current product development projects } \\
\text { include new product market options; } \\
\text { - Product development allows for new } \\
\text { markets being open to organization; } \\
\text { - Product development has led the } \\
\text { organization to new product areas; } \\
\text { - Product development allows for use and } \\
\text { adoption of new technologies; } \\
\text { - Organization incorporates unarticulated } \\
\text { customer needs in product development. }\end{array}$ \\
\hline & $\begin{array}{l}\text { Economic } \\
\text { Performance }\end{array}$ & $\begin{array}{l}\text { Mann et al., } \\
2010\end{array}$ & $\begin{array}{l}\text { - Decrease in cost for materials } \\
\text { purchasing; } \\
\text { - Decrease in cost for energy consumption; } \\
\text { - Decrease in fee for waste disposal; } \\
\text { - Decrease in fee for waste treatment; }\end{array}$ \\
\hline
\end{tabular}




\begin{tabular}{|c|c|c|}
\hline & & $\begin{array}{l}\text { Decrease in fines applied for } \\
\text { environmental accidents. }\end{array}$ \\
\hline $\begin{array}{l}\text { Social } \\
\text { Performance }\end{array}$ & $\begin{array}{l}\text { Mann et al., } \\
2010\end{array}$ & $\begin{array}{l}\text { - Organization has increased vocational } \\
\text { training time for employees; } \\
\text { - Organization is philanthropic in sharing } \\
\text { profit; } \\
\text { - Organization has increased the number of } \\
\text { internships and similar opportunities } \\
\text { offered; } \\
\text { - Organization has decreased its scrap rate } \\
\text { significantly. }\end{array}$ \\
\hline $\begin{array}{l}\text { Environmental } \\
\text { Performance }\end{array}$ & $\begin{array}{l}\text { Mann et al., } \\
2010\end{array}$ & $\begin{array}{l}\text { - Reduction of air emission (pollution); } \\
\text { - Reduction of waste water; } \\
\text { - Reduction of solid wastes; } \\
\text { - Decrease in consumption of } \\
\text { hazardous/toxic/harmful materials; } \\
\text { - Decrease in frequency of environmental } \\
\text { accidents; } \\
\text { - Improvement in organization's } \\
\text { environmental situation/standing. }\end{array}$ \\
\hline
\end{tabular}

Table 3.1

Constructs and their Indicators

(Source: Literature review, Chapter 2)

In summation, this chapter describes the posited theoretical framework and discusses the investigative questions that will inform the latter parts of the study such as the stages of data collection. The chapter also explores the expected relationships as derived from the literature that 
form a part of the posited theoretical framework. Lastly, the chapter offers a list of the adapted constructs and their constituent items that will be used in the next stages of this study. The next chapter discusses the research and data collection methodology that was used in this study. 


\section{Chapter 4 Methodology}

\section{Overall Approach}

This research investigates a cross-section of high-technology firms in North America (USA, Canada) and India. The aforementioned countries have been chosen as the countries of interest for this study since these countries provide an accessible and adequate sample of hightechnology firms from both developed and developing (second world) countries housing a large number of such firms and therefore are a natural point of interest for this study. More specifically, the posited research is designed to understand what strategic orientation is responsible for product development processes that support sustainability for an organization, which would lead to sustainable products, which would in turn affect organizational performance. Qualitative and empirical data was collected in two stages of this study, an interview stage and a survey stage, in an attempt to determine what Strategic Orientations (Market: including Competitor, Customer, Interfunctional Coordination, Technology-and Sustainability) would lead to product development processes (S-PDP) that support the production of sustainable products. The effect of how these S -PD processes are carried out on the attributes of sustainable products (Longevity, Fidelity and Fecundity), are examined. The relationship between the S-PD processes, sustainable product attributes and various dimensions of Performance (Strategic and 3BL, as discussed in Chapter 2) is also examined and assessed.

The data for analysis was collected from designations similar to Directors, Presidents, Senior Scientists, R\&D Team Leads, Project Managers and Chief Operating Managers in charge of Product Development (as discussed in Section 4.2). The study is designed in a manner as to assess the performance of organizations as perceived by the senior management, which means 
that no separate control variable is required to compensate for differing perceptions of performance - which may have been required if this study involved industry/organizational benchmarking (Slater and Narver, 1994). The study provides insight into what constitutes S-PDP for this industrial cross-section and what factors may lead to creating sustainable products which affect various aspects of organizational performance. The study is expected to be generalizable to any firm that develops and manufactures/produces/processes (incrementally or radically new) sustainable products. As a precautionary measure, to decrease potential disparity in results across countries, the interview stage of this study takes into account those organizations that have operations across various continents, especially Asia and North America. However, due to the scale of the survey for the second stage of the study, this precaution may not be equally applicable. Therefore, the results may not be equally applicable across different countries and should be interpreted with care.

\subsection{Research Design}

The research design was formatted as two types of surveys. Because this study has two clear objectives as stated in Section 1.3 (page 2), requiring two different approaches; the research design is structured accordingly to accommodate these. In the cases where an exploratory study is required to answer questions that are explanatory in nature, qualitative methodologies are more appropriate in capturing material for the depth and complexity of analysis required to extract meaningful results (Lee et al., 1999). Since the first part of the study is exploratory in nature, the instrument used to capture the rich data is in the form of semi-structured face-to-face interviews with industry experts as well as academics with industry experience in sustainable products. Such an approach is required to delve into the explanations that provide satisfactory information 
pertaining to "how" and "why", which is required when any new academic formulation explains phenomena observed in the world (Sutton \&Staw, 1995).Questions and the discussion resulting from probes specifically cover the following topics:

A. Their experience with the development of sustainable products as well as the performance of the sustainable products with respect to the organization. Issues experienced during the development of the sustainable products that are seen to be different from what was planned.

B. Their opinion on how sustainable products are defined as well as what characteristics or attributes should be considered important in their experience.

C. Their opinion on what organizational orientations and strategic sustainable product development processes might be important for the development of sustainable products and whether orientations these might affect the development processes that are used.

D. Their opinion on whether the strategic sustainable product development processes might affect sustainable product attributes and whether these processes and product attributes might affect organizational performance. Further, they will be asked what types of performances may be seen to be affected by the same.

The template for the questions used in the semi-structured interviews is available for perusal in Appendix 2.0. The face-to-face interviews were conducted as and when access was best available to senior management and academics with industry experience in the area of developing sustainable products, in accordance with the snowball sampling technique.

The explanations gained from the open-ended interviews provided in-depth answers which enriched the researcher's understanding of the phenomenon being studied. Further, the 
answers from this stage led to the extraction of meaningful data on whether the real-life interactions support the framework posited on the basis of academic research. This data from the stage 1 interviews was used to augment and improve the second survey instrument, an online questionnaire. The second part of the study acted as a confirmation of the relationships elicited from the literature as well as the interview data. The interviewees were also requested to fill the survey questionnaire so that a check and validation of their previous responses could be conducted. Since the results gained from the questionnaires of the interviewees were already expected to contain data which to assist in further refining of the survey questionnaire, conducting a second pilot study would have been redundant. This survey was circulated among industry experts in Canada as culled from Scott's Directories, in USA from Hoovers database and in India from the Confederation of Indian Industry (CII) (further detailed in Section 4.2). The data collected was analysed as described in the latter Sections.

\subsection{Sampling Design}

A high-technology firm, according to a provincial Employment Standards Act, "is a company in which more than 50 percent of the employees are either "high technology professionals" or managers of those professionals, or are employed in an executive capacity." $\begin{array}{llll}\text { (Employment } & \text { Standards } & \text { Branch } & \text { Factsheet, }\end{array}$ http://www.labour.gov.bc.ca/esb/facshts/high_tech.htm).

The size categories of the businesses are based on the Statistics Canada (2011) standards and are detailed as follows: 


\begin{tabular}{|c|c|}
\hline Micro & $1-4$ employees \\
\hline Small & 5-99 employees \\
\hline Medium & $100-499$ employees \\
\hline Large & $500+$ employees \\
\hline
\end{tabular}

Table 4.1

Organizational Size Categories as accounted by the number of employees

(Source: Statistics Canada, 2011)

The exploratory part of the survey, entailing face-to-face in-depth interviews, was conducted using a combination of consecutive sampling and snowball sampling from the population of senior and executive-level personnel in high-technology firms. The target firms for the interviews employ anywhere from 50 to 499 employees. The reason why firms smaller than this size would not have qualified for use in this study is that they may not have any specific development 'processes' in place, which are requisite for the objective of the proposed study. Initially, a total of eight to ten interviews were the targeted sample size for this stage of the study, the final number of interviews conducted was twelve. The first two interviewees were from the researcher's extended professional network and then snowball interviews were gained from their contacts within the population of interest and so on. The interviewees were contacted by phone or via email to request an interview (Appendix 7.0 provides a script for the same).This type of sampling is most suited to the purposes of the first stage of the study, which is the exploratory study, since the target population and thus sample is of a specialized nature (Statistics Canada, 2003).This stage was crucial in determining the applicability of the posited theoretical framework 
extracted from the analysis of the literature. This stage was also important since it confirmed whether the theoretical framework was a holistic representation of the relationships being studied or any new factors should be considered, which may potentially lead to the modification of the model, if any.

The survey population for the second stage of the study was inclusive of North American and Indian large and medium-large high-technology firms in the field of manufacturing or processing electronic parts/components/whole products which are substantially or completely new in their intended marketplace. Specifically, firms employing 300 employees onward were targeted. The contact information for the sample was collected from Scott's Business Directories for Canadian firms, Hoovers database for US firms and CII for Indian firms, which are all extensive online databases of business contacts and information. The directories offer researchers and professionals access to business and individual profiles segmented as required, based on key business metrics such as firm type, business and size (Scott's, 2014). For this stage of the study, an approximate minimum of 200 survey responses was required for proper statistical analysis. Since executives and top managers have an extremely low response rate, a response rate of $11 \%$ was initially assumed, which would render the targeted respondents an approximate 2000 individuals (Cycyota and Harrison, 2006; Kaplowitz et al., 2004). Since the emails were sent in a staggered form due to their volume, the actual emails sent were a little less than the projected 2000, at 1653. Emails were not sent anymore when the number of received responses crossed 200. Firms under the categories of general manufacturing or electronics manufacturing were selected randomly (the designation of interest for every $\mathrm{n}^{\text {th }}$ firm was picked, where $\mathrm{n}$ was a randomly guessed number from 1 to 10 , as listed alphabetically in the database) from the respective databases. Emails were sent to the email address on file. In the case of Canada, the 
2014 Canadian Anti-Spam Legislation (CASL) prevented direct blind contact with individuals. So the company websites were visited and the email on the website (or in some cases phone on record) was used to connect to the person of interest, if directed by the person monitoring the general email. Chapter 7 provides the details of the responses received and the descriptive statistical breakdown of the data sample for the empirical stage of the research.

\subsection{Data Collection}

Data for this study was collected in two main stages. The first stage of qualitative data collection corresponds with the exploratory part of the study. Face-to-face in-depth interviews were conducted with senior management of companies. Since the objective of the study is clear, as discussed in the previous section (4.0), only individuals concerned with and/or overseeing product development initiatives for sustainable products were interviewed. The aim of the interviews was to access the knowledge and experience of a sufficient number of interviewees to enhance the researcher's understanding of the phenomenon put forth by the current research, by presenting a well-rounded case-study format (Lee et al., 1999). Before the beginning of the interview, the respondents were presented with explanations related to all concepts that may be open to interpretation, such as what constitutes a sustainable product, what strategic level

processes entail, what characteristics or attributes etc. may relate to the concept of sustainable products and what types of performances are posited to be affected, as culled from the literature in the area (available for reference in Appendix 8.0). A probing discussion of these concepts and the reaction and understanding of the respondent was recorded as a part of the exploratory study. The purpose of this part of the interview was to minimise and ideally eradicate any potential 
discrepancy of concepts between the respondent and the researcher, or any unstated preconceived notions that may hinder the exploratory purpose of the first phase of the study (Hill et al., 2005).

The interview then moved on to semi-structured questions which aimed to capture how the respondents assess each of the relationships hypothesized in the theoretical framework (See Appendix 2.0). The respondents were also asked to rank each of the components of the constructs according to their own understanding of the importance. It is recommended that a base of four interviews be a starting point and add-on interviews be conducted till the data repeats, indicating the saturation point (Eisenhardt, 1989). A total of twelve interviews were conducted. This data was used to refine the second stage of the study and add to the results of the research, as elucidated in Chapter 5.

For the second phase of the study, data was collected using a self-administered online questionnaire (Dillman, 2000).An online host of Canadian origin, Fluid Surveys, was used to host the survey. A cover letter explaining the purpose and importance of the study and requesting participation was emailed, with the survey link as well as a link to further details on the nature of the research and contact information (See Appendix 3.0). A statement of confidentiality was also attached, ensuring the respondent's right to privacy and an assurance of the confidential treatment of the data he/she may provide (see Appendix 4.0). As per the directions of Dillman, Smyth and Christian (2009), the follow-up was conducted be via email, as necessary. This resulted in a data set that was used for analysis in chapters 7,8 and 9. 


\subsection{Data Analysis Techniques}

For the first part of the analysis, the interviews were digitally recorded, transcribed and manually coded so as to extract the main themes from the transcripts. A large amount of data was generated from the interviews as expected. The data was filtered for the identification of themes and patterns which was used to validate material from previous studies to identify how the opinions of the practitioners affected the research culled from the literature (Lee et al., 1999). First, a qualitative analysis was conducted, where the transcripts were read through for agreement/disagreement with the premises of the hypotheses of the study. Then the data was open coded as well as axially coded, for the textual indicators as well as the conceptual information using NVivo software. Open coding involves the creation of tentative labels/themes or categories based on the reading and review of the interview transcript. Axial coding consists of determining relationships between the categories/concepts and themes that emerge from open coding. The NVivo software interface is similar to MS Excel and facilitates such coding by allowing the creation of labels and categories when transcript text is highlighted and annotated. Then these annotations, which are themes or categories, are put in a spreadsheet-like format to compare and make connections across various interview transcripts. Using NVivo and Excel software, data was also colour-coded in spreadsheets and compared to the premises of the study for discrepancies and possible augmentation/refinement of the items in the prepared questionnaire and the implications for the study.

The data collected from the questionnaire was first entered into the software most appropriate for analysis SPSS, and later in LISREL. The data was scanned for possible discrepancy and unusable results. Primary analysis was conducted to confirm data viability, 
checking for missing data, assumptions of data normality, for outliers and to check for common method bias. After the data was cleaned, SPSS was used to run descriptive statistics to verify the basic nature of the sample to identify whether the data overrepresented or was biased in favour of any specific industry, certification, product offerings etc. This is discussed in further detail in Chapter 7. According to Stevens' (2002) guidelines, of approximately 15 survey informants per predictive construct, the study required a minimum of 165 responses; however, structural equation modelling itself requires a minimum of 200 responses (total) for a useful analysis. CFA of each of the constructs was conducted to determine construct validity in LISREL. The a-priori model was then tested for goodness of fit, using the various parameters run in LISREL. The model was then assessed to confirm if changes are required. Next, the models were compared and interpreted to identify and understand the relationships between the constructs. Chapter 8 and 9 provide the details of the aforementioned analyses.

\subsection{Survey Instrument}

From the objectives discussed previously in Chapter 1, the format of the survey instrument used to collect data was an online questionnaire. The questionnaire consisted of five basic sections and be prefaced with an introduction which would include the survey instructions and deemed purpose (Appendix 9.0). Each of the sections of the questionnaire required answers which holistically met the research's stated objectives. The respondents to the questionnaire were requested to reflect on the organization's functions with respect to products developed during their tenure. The development may be independent in-house or take an associative form, excluding any form of purely managerial or regulatory consulting. The product(s) under consideration must also be a new concept or a significant modification or improvement over the 
last version of the developed product. In the case of the semi-structured interviews conducted for the first part of the study, the instructions above were the same. Also, the specified questionnaire sections constituted the main line of questioning in the interview. The following are representative of the sections comprising the questionnaire (which is attached in Appendix 9.0):

I. An exploration of the strategic orientations that are displayed by the firm: market (inclusive of: customer, competition, interfunctional coordination, technology) as well as sustainability.

II. An exploration of the construct of sustainable product development processes (SPDP) within the organization. Also, an exploration of each of the processes that constitute S-PDP within an organization: domain specific $\mathrm{KI}$; procedural $\mathrm{KI}$; and flexible strategic decision-making.

III. An exploration of the construct of the three attributes of sustainable products, namely: fecundity, fidelity and longevity.

IV. An exploration of related organizational performance, namely: strategic performance and triple bottom line performance (economical, social and environmental).

V. A verification of the profile of the respondent and the organization as compared to the sample selected.

\subsection{Reliability and Validity Issues}

The research is structured in a manner so as to overcome, as far as possible, inherent and external validity issues. A detailed discussion of the potential issues is presented in this Section, according to the directions of Dillman et al., (2009), Groves et al., (2009) and Stevens (2002). 
With respect to the internal validity, or the degree of confidence associated with this study, the following have been considered to be potentially applicable:

Selection Bias and History: Based on the sample profile, there could possibly be a difference in the responses based on the origins and conditions of work of the participants. It can be assumed that the research environment, opportunities and available resources for participants in a high technology environment in a first or second world economy would be mostly uniform.

Mortality and Differential Attrition: The research sample is that of (new) product development in the high-tech industry. Differential attrition is not considered to be an issue for this research because though product development is an organization-specific phenomenon; all respondents have an equal status for the purposes of the study in terms of having experience with sustainable products.

Diffusion and Compensatory Rivalry: As a side-effect of globalization, product development cases might have participants which have been present in other environments and exposed to product development practices from other organizations, countries or industries. While this would reduce selection bias, it might lead to 'response bias' i.e. responses which are more globally 'acceptable' and reduce differences in the actual product development practices.

The external validity of the study can be noted to not provide any particular concerns, since the sample itself would cover a wide range of organizations. As mentioned before, conclusions drawn from the sample under study are expected to be generalizable to the 
population under survey, that is, industries undertaking product development. However, results might not be conducive to one-to-one adaptation across different countries with varying economies and should be interpreted with caution.

The only point of concern was, as already mentioned above, that participants may provide answers more from the impetus of appearing socially acceptable, rather than what reflects actual practice. This issue was substantially mitigated by the validity of the scale used for measurement. The scales being adapted by the study have been tested and validated by previous peer-reviewed published studies from academic journals. Therefore, it might be reasonably assumed that the tested and published scales accurately measure the constructs being used.

There are four adapted measures used this study: The constructs for Strategic Orientation, Sustainable Product Development Processes (S-PDP), Product Attributes and Performance. There are two ways in which these measures overcome content and construct validity problems. First, for content validity, the measures are adapted from tested and published measures. Second, for construct validity, the measures have different questions which both measure the sustainable nature of a product, during and after development. The expectation here is that these questions in the different measures have high levels of correlation.

The survey instrument was also tested to determine content validity and the theorised correlation. With respect to the stability and consistency of the measurement, all measures using the Likert scale were tested using the Composite Reliability and the Average Variance Extracted (AVE) scores. 
In summation, this chapter provides an overview of how the study proceeded with respect to methodology of the data collection. The overall approach, research design and sampling design are discussed along with data collection and analysis techniques. Lastly, potential issues with respect to reliability and validity, as well as their resolution are discussed. The next chapter presents the details and the results of the first (interview) stage of data collection for this research. 


\section{Chapter 5 Stage 1 Results}

This chapter begins with an outline of the data analysis techniques used for this stage of the study, followed by a description of the sample. The findings from each of the interviews are analysed along the lines of the theoretical framework presented in Chapter 3. The chapter concludes with a discussion of the implications of the key findings and the potential impact on the next stage of the study.

\subsection{Data Analysis}

As previously mentioned in Chapter 4, the first stage of this study was conducted in the format of semi-structured face-to-face interviews with senior executives of various high-technology firms. It was felt that only top management would have the most holistic perspective on product development at an organizational level, from both the strategic and operations points of view. As stated in the previous chapter, each interview was initiated with a discussion of the concepts related to the interview. The interviewees were provided a print copy of the definitions and characteristics under discussion (Available in Appendix 8.0) so that they had adequate opportunity to form and frame their opinions while agreeing or disagreeing with the academically accepted concepts. The interviews were initiated with a discussion about the respondents' organizational experiences on product development and sustainability. Following this, openended questions with probes were asked with respect to each posited relationship from the theoretical framework from Chapter 3. The respondents were also asked to rate each component of the constructs of the theoretical model based on their perception of their relative importance. 
The scale of ratings ranged from 1 being the most important to the higher numbers being least important. The respondents had the freedom to provide the same score for perceived tied importance as well.

A total of twelve interviews were conducted, which included two pre-test interviews. The pre-test interviews confirmed that the prepared structure of the interviews was effective in eliciting rich and detailed information from the respondents. As recommended (Eisenhardt, 1989), interviews were conducted till the conceptual saturation point of collected data was reached. In other words, the interviews were conducted till the first examination of the interview transcripts showed that the interviews no longer yielded new information for the study. The interviews approximately averaged one hour, thirty minutes to two hours in length. The longest interview measured approximately four hours, since the respondent was from the medical devices field and was very interested in discussing how their products fitted into the sustainability concept as well as its perception in the industry. In the interest of gathering the richest data possible for the exploratory study, interviews were only curtailed by the interviewee based on the time available to them. Every interview was audio-taped, with the express written permission of the respondent. All respondents agreed to fill the online survey for the second stage of the study as a pre-test of potential changes introduced from the findings of the first stage.

The audio-taped interviews were transcribed and the physical print copies were checked against the audio files for accuracy of script. Each interview, or case, was first assessed on an individual basis along the theoretical lines posited by this study's findings from the literature. The interviews were categorically stored according to their identifying numbers in separate files and entered into a database indexed by their identifying number and each question number. The individual case analyses of single interviews were conducted, as planned, with points of 
agreement/disagreement being noted in comparison to the proposed theoretical premises of this study. The cases (interviews)were then further open coded for textual indicators of concepts in each response provided. Finally, axial coding was conducted, where the textual indicators from the response transcripts were scanned in comparison the conceptual themes available from the literature. These themes are enumerated in Chapter 4, under 'Research Design' and tabulated more specifically below in section 5.4, table 10 .

The next step involved cross-case comparisons. The cases were compared along the lines of the previously established themes and research questions to develop conceptual insights. Tables were used from the individual case databases to specifically compare thematic development and to avoid assumptions, bias or logic-based deviations on the part of the researcher, as recommended by Eisenhardt (1989).

\subsection{Sample Description}

\subsubsection{Respondent Profile}

The interviews were conducted with respondents in positions of senior to top management in the organizations they represented. Table 5.1 below provides an exact breakdown of the positions as well as the profiles of their organizations:

\begin{tabular}{|c|c|c|c|c|c|}
\hline $\begin{array}{l}\text { Identifying } \\
\text { Number }\end{array}$ & $\begin{array}{l}\text { Position of } \\
\text { Interviewee }\end{array}$ & $\begin{array}{c}\text { Head } \\
\text { Quarters }\end{array}$ & $\begin{array}{l}\text { Type of } \\
\text { Organization }\end{array}$ & $\begin{array}{l}\text { Area of } \\
\text { Operations }\end{array}$ & $\begin{array}{l}\text { Approximate } \\
\text { Number of } \\
\text { Employees } \\
\text { (branch/unit) }\end{array}$ \\
\hline ORG1 & CEO & India & Education & USA, Japan, & 70 \\
\hline
\end{tabular}




\begin{tabular}{|c|c|c|c|c|c|}
\hline & & & Support & $\begin{array}{l}\text { Middle East, } \\
\text { Asia }\end{array}$ & \\
\hline ORG2 & CEO & USA & $\begin{array}{l}\text { Sustainable } \\
\text { Portable Devices }\end{array}$ & India & 50 \\
\hline ORG3 & CTO & USA & $\begin{array}{l}\text { Sustainable solar } \\
\text { devices and } \\
\text { Integrated } \\
\text { Circuits }\end{array}$ & USA, Asia & 60 \\
\hline ORG4 & $\mathrm{COO}$ & India & $\begin{array}{l}\text { Integrated } \\
\text { Circuits for } \\
\text { Research }\end{array}$ & $\begin{array}{l}\text { Canada, } \\
\text { Scotland, India }\end{array}$ & 60 \\
\hline ORG5 & CEO & India & $\begin{array}{l}\text { Sensor Systems } \\
\text { for Construction }\end{array}$ & $\begin{array}{l}\text { Middle East, } \\
\text { Asia, Africa }\end{array}$ & 70 \\
\hline ORG6 & $\begin{array}{l}\text { Vice } \\
\text { President }\end{array}$ & India & Heavy Machinery & $\begin{array}{l}\text { Middle East, } \\
\text { Asia, Africa }\end{array}$ & 250 \\
\hline ORG7 & $\begin{array}{l}\text { Senior } \\
\text { Scientist }\end{array}$ & USA & $\begin{array}{l}\text { Software } \\
\text { Solutions }\end{array}$ & $\begin{array}{l}\text { Global } \\
\text { (Fortune } 500 \\
\text { ranked) }\end{array}$ & 400 \\
\hline ORG8 & $\begin{array}{l}\text { Head of } \\
\text { Product } \\
\text { Development } \\
\text { Solutions }\end{array}$ & USA & $\begin{array}{l}\text { Soft Solutions for } \\
\text { Products }\end{array}$ & $\begin{array}{l}\text { USA, Europe, } \\
\text { India }\end{array}$ & 60 \\
\hline ORG9 & Co-Founder & India & $\begin{array}{l}\text { Green Building } \\
\text { Consulting and } \\
\text { Support }\end{array}$ & $\begin{array}{l}\text { Asia, Middle } \\
\text { East }\end{array}$ & 60 \\
\hline ORG10 & $\begin{array}{l}\text { Vice } \\
\text { President, } \\
\text { Business } \\
\text { Development }\end{array}$ & Canada & $\begin{array}{l}\text { Medical Devices } \\
\text { for Therapy } \\
\text { Clinics }\end{array}$ & Canada, USA & 80 \\
\hline ORG11 & $\begin{array}{l}\text { Associate } \\
\text { Director, }\end{array}$ & USA & Medical Devices & $\begin{array}{l}\text { Global } \\
\text { (Fortune } 500\end{array}$ & $150 / 400$ \\
\hline
\end{tabular}




\begin{tabular}{|l|l|l|l|l|l|}
\hline & R\&D & & & ranked) & \\
\hline & Regional & Canada & Medical and & Global & \\
Director of & & Healthcare & (Fortune 500 & \\
ORG12 & R\&D & & Devices & ranked) & $300 / 800$ \\
\hline
\end{tabular}

Table 5.1: Respondent Profiles

As specified before, it was perceived that only individuals in a position to holistically comment on the strategic as well as operational elements of their business would be able to satisfactorily respond to the questions posed in the interviews. For the smaller organizational units, the best possible contact consisted of a mix of Founders, CEOs, CTO/COOs and Vice Presidents. For the larger companies, the heads of business units such as Senior Scientists, Head of Product Development or Associate/Regional Directors were approached and interviewed since they were deemed to be the best source of holistic information about their organizational units. For larger organizations, regional heads were the preferred source for the interviews since they would have the necessary knowledge and product or process related detail which might be diluted at the level of the corporate center. The respondents had been in these or similar positions of responsibility from a minimum of three to five years in most cases to a maximum duration of eight to ten years in two cases. Hence it may be safely surmised that the respondents had sufficient understanding of their areas of responsibility and the products as well as the organizational processes involved.

Taking into account all the above points, it may be concluded that the data collected from the interviews matches the requirements set in Chapter 4, sections 4.1 and 4.2 and is of more than acceptable richness and complexity to satisfy the objectives of this stage of the study. The following subsection is a brief description of the organizations listed in Table 4. 


\subsubsection{Case Profiles}

Subject 1 is the Chief Executive Officer of a small organization in the domain of Education Support. The organization is 8 years old and sells products and services that assist technical training and education in Computer Hardware, Software and Elementary Sciences. They operate in USA, Japan, Middle East and Asia reaching over 1 million customers.

Subject 2 is the Chief Executive Officer of a small enterprise manufacturing and selling electronic products. The organization addresses various verticals including electronic consumer products, defence technologies, security and surveillance. The organization sells to government agencies as well as directly to the consumer market. Operating out of Mumbai, India it focuses on the development of sustainable engineering products, sustainable energy solutions and strategic surveillance devices.

Subject 3 is the Chief Technical Officer of a small sized organization developing sustainable alternative energy technologies, products and services such as ones related to solar energy and solar powered devices. The organization has based its operations in USA and Asia and work in the areas of solar cell manufacturing services, consulting services for migration to alternative energy and development of new semiconductor based technologies in the solar energy space.

Subject 4 is the Chief Operating Officer of a small Electronic Chip Research and Manufacturing firm with its focus on Nano-technology and operations in Canada, USA, Europe and sub continental Asia. The organization performs mainstream research in Nanotech Chip and Micro-Sensor designs. At the same time it manufactures it's designed ICs (Integrated Circuits) in collaboration with fabrication facilities in South East Asia, Europe and Scotland. The firm sells 
its products to research groups all over the world working on similar sensor technologies in healthcare, homeland security, chemical characterization and upcoming areas like mobile computing and cloud enabled sensor deployment.

Subject 5 is the Chief Executive Officer of a small sized automotive electronics manufacturing company that manufactures and sells control systems and safety indicators for heavy vehicles, machinery and civil infrastructure establishments such as container ports, railways etc. The organization operates in emerging economies in Asia, Middle East and Africa. Catering to a wide customer base, the subject categorizes customers in developing economies into those educated about the technical specifications and safety requirements and those who are unable to perform a technical comparison of the various products and hence depend mainly on retail price for comparison.

Subject 6 is the Corporate Vice President of a medium sized industrial manufacturing organization producing heavy automotive machinery for the global material handling and construction industry. Catering to both civil as well as defence markets, the organization has been manufacturing cranes, load handling equipment, recovery vehicles for the last 50 years. The products developed for the construction industry are expected to perform under heavy duty cycles and can see operational tenures as high as even 30 years.

Subject 7 is a Senior Scientist in a Fortune 500 Software Product Development organization with global operations and a customer base ranging from individual customers to large corporate clients. The organization is a global leader in imaging, image processing and document handling software and caters to various business verticals such as Computer Software, Web interfaces, Mobile devices and Cloud based software. Headquartered in USA, the 
organization has major offices in Canada, Europe and Asia with distributed product development centers.

Subject 8 is the Head of Product Development for a small sized software product development and services company. The organization develops technology solutions in areas such as Advanced Automotives, Telematics, Machine Vision, Image Processing, Medical Imaging, Defence and Space technologies. The organization sells software solutions as well as takes up custom product design projects to service clients all over the world with a strong presence in North America, Europe and Asia.

Subject 9 is the Co-founder of a small sized organization working on sustainable green solutions for the construction industry. Established as a group of architects specializing in green materials and alternative energy technologies, they provide consultation services and product development expertise for green building construction. The organization concentrates on technology consulting in emerging markets and has its base of operations in Asia and Middle East.

Subject 10 is the Vice President of business development in a Canadian organization producing medical devices for sleep and other therapy clinics. The organization focuses on operations in North America; however, their products are available for worldwide purchase and support. The company has a patent-intensive approach and provides modular designs for the majority of their products.

Subject 11 is an Associate Director of R\&D with a United States-based, globally operating, Fortune 500 organization specializing in medical devices and instrumentation (in a USA branch office). A global leader in orthopaedic medical devices, the organization sells and supports its products in over a 100 countries of operations. 
Subject 12 is a Regional Director of R\&D with another globally operating, Fortune 500, US-based healthcare solutions provider (in a Canadian branch office). The organization offers a wide range of products from medical devices and healthcare solutions to nutritional supplements and other health related lifestyle solutions in over 150 countries.

\subsection{Findings}

In this section, findings from each of the above cases are discussed along the lines of the themes developed based on the research questions and hypotheses posited by this study. The four broad themes that inform this stage's line of enquiry have been enumerated previously in the section on 'Research Design' in Chapter 4. The following subsections are formulated in a manner that links the findings to the hypothesized theoretical framework, illustrated where required by quotations from the respondents. As mentioned in section 5.1, each of the respondents also rated the components of the theoretical framework's constructs based on their perception of their relative importance. In some cases, ranking may be tied based on the perceived importance or the precedent for operations in the organization. Tables 5 to 8 provide a collated view of the rankings.

\subsubsection{Strategic Orientations}

The first construct under consideration is that of an organization's strategic orientations. A number of interesting points were noted from the analysis of the interviews conducted. Table 6

provides an overview of the rankings of the perceived importance of each strategic orientation by 
each of the interviewees with respect to the particular organization and industry they answered for.

\begin{tabular}{|c|c|c|c|c|c|}
\hline \multirow[b]{3}{*}{$\begin{array}{l}\text { Identifying } \\
\text { Number }\end{array}$} & \multicolumn{5}{|c|}{ Strategic Orientations } \\
\hline & \multicolumn{4}{|c|}{ Market Orientation } & \multirow[b]{2}{*}{$\begin{array}{l}\text { Sustainability } \\
\text { Orientation }\end{array}$} \\
\hline & Technological & Competitor & Customer & $\begin{array}{l}\text { Interfunctional } \\
\text { Coordination }\end{array}$ & \\
\hline ORG1 & 3 & 2 & 1 & 4 & 5 \\
\hline ORG2 & 3 & 4 & 1 & 5 & 2 \\
\hline ORG3 & 1 & 3 & 2 & 3 & 1 \\
\hline ORG4 & 1 & 4 & 2 & 3 & 2 \\
\hline ORG5 & 2 & 3 & 1 & 4 & 2 \\
\hline ORG6 & 1 & 1 & 2 & 3 & 2 \\
\hline ORG7 & 1 & 2 & 2 & 3 & 4 \\
\hline ORG8 & 2 & 4 & 1 & 4 & 3 \\
\hline ORG9 & 1 & 3 & 2 & 4 & 1 \\
\hline
\end{tabular}




\begin{tabular}{|l|l|l|l|l|l|}
\hline ORG10 & 3 & 2 & 1 & 5 & 4 \\
\hline ORG11 & 1 & 3 & 2 & 4 & 1 \\
\hline ORG12 & 1 & 2 & 1 & 3 & 1 \\
\hline
\end{tabular}

Table 5.2: Ranking of Strategic Orientations

A number of interesting observations emerge from the results of the analyses. As seen from Table 5.2, a customer-based orientation was considered a vital orientation in every organization. It was always ranked first or second in importance. This orientation remained prominent regardless of the industry, the countries of operations, the product lines, the size of the firm or even how established they were. As the respondent from ORG1 succinctly summarised:"High customer engagement is very good for a product - since it builds a trust in the customer."

In fact, ORG8 built its entire product line from multiple "wishlists" compiled from potential customers while working with their first contracted customers in creating their first product. The entire organization sprang from articulating a customer need and providing the product via expert know-how and resources while being directed by the customers and their sometimes changing - needs. The respondent believes that this is the primary reason why they are able to consistently maintain customer interest and consequently keep a steady demand for their products in the marketplace.

The second orientation ranked constantly high by all the interviewees was that of technology. Most respondents stated, in one way or another, that the technology their organization brought to the table was a very important part of how they conducted business. This 
was regardless of whether the technology was conceived during the formation of the organization or developed later as part of ongoing operations for new customers or potential markets. Despite this consensus that a firm's technological orientation is vastly important, a pervasive sense of realism ran through all conversations regarding the place of technology in the actual continuation of a business's operations. The idea of technology as an orientation for the sake of itself was not an item on any respondent's agenda. For example, the CEO of ORG1 believes that:"research and development primarily is not the differentiating factor [any more]. Every product will have some sort of research and development."

The need for a harmonious interplay with other strategic orientations was expressed by all respondents. The CEO of ORG2 qualified his support best as: "So the decision has to be that, till what depth is it practical to go in terms of technology, to deliver a concept because you have so many other constraints around it."

The third most interesting result was in relation to sustainability orientation. This orientation was raked relatively low only by three organizations, on the principle that the orientation toward sustainability is contingent upon the orientation aligning with a strategic advantage for the firm, which was not very applicable in their individual cases. The concern that comes into play here for some firms was expressed by the CEO of ORG2:

"one has to look at it from the perspective, 'is there something coming up that can also be sustainable - in the sense that can it also be adopted or not.' If there is something which cannot be adopted then the impact that it is going to have is going to be zero. Only something that sells can have an impact. Things that don't sell despite having a huge [environmental] impact don't [ultimately] impact the ecology." 
He goes on to explain his own case where an orientation toward sustainability was a primary consideration from the beginning:

"the initial thoughts were from the perspective of giving people an alternative... The other factor was doing it using technologies that don't consume conventional fuel. ...We were focused on alternative energy ...People were facing a lot of difficulty in surviving and sustaining their portable devices off grid. So we wanted to help them and do this in a manner that doesn't impact the environment while they use the device."

Nine out of the twelve organizations under examinations proactively oriented themselves toward sustainability. The reasons were multi-fold for each organization. In the case of ORG3, ORG4 and ORG9, the orientation was driven by the type of (green/alternate) technology which formed the firms' niche and advantage and the envisioned need to create positive social impact. For the others such as ORG5 and ORG6, compliance standards, quality materials and certifications provide them the benefit of being preferred by their customers and providing a long-term advantage in terms of product life and functionality. ORG6 also used the high degree of sustainability offered by their products and processes as a strategic point for re-entry into the market as an organization marketing its products independently, as versus just a back-end manufacturer for partners. ORG11 and ORG12, as long standing leaders in their fields leverage their positions in the industry to proactively create programs that add a financial advantage to introducing sustainable elements in their products and processes. 
As far as a competitive orientation is concerned, it has been ranked relatively lower by the interviewees since the field is not as populated in terms of the competition they incur with the sustainability advantages they offer. This is not to state that the interviewees are unaware of the eventual importance of competition and the need to keep an eye on competing offerings. The founder of ORG9 notes:

"once the need for sustainable products is realized competition becomes a big differentiating factor...if you are a conventional service provider, the competition is fierce, while if you have a non-conventional expertise, then you can always leverage this factor to get the business."

The conclusion may be drawn that with progressing maturity, the competition in sustainable products may add more layers of complexity in creating competitive advantages and the use of resources and differentiation to gain these advantages.

The lowest ranked strategic orientation is that of interfunctional coordination. This is not because its importance is considered any less by the interviewees, but because a logical consensus was observed in why the orientation was ranked low. The respondents individually felt that interfunctional coordination is a 'given' for the smooth organizational functioning and perhaps not an orientation that stems from their company's vision or mission. It was assumed more to be of a format of a tool than a strategic inspiration. However, in the case of ORG5, interfunctional coordination was ranked higher because the company was forced to make a strategic decision to regroup its departmental resources to channel into a changed research plan even before their product was launched. This fostered a noticeable orientation toward 
interfunctional coordination which continued as a legacy of the re-focussed organizational mission.

\subsubsection{Sustainable Product Development Processes}

Table 5.3 shows that sustainable product development processes were ranked by the interviewees in an almost uniform manner, with a few marked variations. The reasons for these variations and the overall uniformity are discussed below.

\begin{tabular}{|c|c|c|c|}
\hline & Sustainable Product Devel & pment Processes & \\
\hline $\begin{array}{l}\text { Identifying } \\
\text { Number }\end{array}$ & $\begin{array}{l}\text { Domain Specific } \\
\text { Knowledge Integration }\end{array}$ & $\begin{array}{l}\text { Procedural Knowledge } \\
\text { Integration }\end{array}$ & $\begin{array}{l}\text { Flexible } \\
\text { Decision-Making }\end{array}$ \\
\hline ORG1 & 2 & 3 & 1 \\
\hline ORG2 & 1 & 3 & 2 \\
\hline ORG3 & 1 & 3 & 2 \\
\hline ORG4 & 1 & 3 & 2 \\
\hline ORG5 & 1 & 3 & 2 \\
\hline ORG6 & 2 & 1 & 2 \\
\hline ORG7 & 1 & 3 & 2 \\
\hline ORG8 & 1 & 3 & 2 \\
\hline ORG9 & 2 & 3 & 1 \\
\hline
\end{tabular}




\begin{tabular}{|l|l|l|l|}
\hline ORG10 & 2 & 3 & 1 \\
\hline ORG11 & 1 & 1 & 2 \\
\hline ORG12 & 2 & 1 & 3 \\
\hline
\end{tabular}

Table 5.3: Ranking of Sustainable Product Development Processes

The first result noticeable is the highest ranking of domain-specific knowledge by the interviewees. This perhaps is expected, considering the importance given to technological orientation, as apparent in the previous section. The ongoing and dynamic integration of domain specific knowledge was unanimously seen as the most important sustainable product development process for the organization, regardless of its size or recency of establishment. The ORG3 interviewee explains:

"[integrating] domain knowledge is most critical. If you don't have that, then you don't even have a starting point."

Integrating domain specific knowledge is also seen as a way to introduce new products and refine on what is already present. The senior scientist at ORG7 elaborates:

"I would say [integrating] domain knowledge is indispensible...if you have the domain knowledge, you [can] concentrate on [the] features of the product, make it and start selling it."

The second most important process was perceived to be flexible decision-making. Except for ORG12, all interviewees ranked this dimension high. Interestingly, younger organizations or 
newer product lines were seen to be most in need of such flexibility by the respondents. The CEO from ORG1 elucidates: "Most of the companies succeed or fail ... because either they are too attached to the vision or too detached from it. Neither works - you have to have a middle ground."

Moreover, decision-making flexibility is seen as an extension of doing business, stemming from the strategic orientation, affecting the product and through it the potential performance of the organization. This attitude is similar to the one observed for the orientation toward interfunctional coordination. The CTO from ORG3 weighs in:

"Flexibility is important because there are a lot of factors that you do not consider upfront, even if you have the domain knowledge. You have to flexible to ensure that you can change your product to become marketable. If you are not flexible, you will stick to a certain product definition. As you learn more you need to change or morph the product definition to meet the customer's expectations. If you're not flexible this is difficult."

Perhaps even more noteworthy, is the reason why procedural knowledge integration is ranked last by all but three organizations. In younger organization with a product focus, the idea that processes might create a significant advantage is not, perhaps, as applicable. The VP at ORG10 states:

"Now [integrating] the procedural knowledge - the process of knowing how to make it - you either have that or you're out of business. In most industries there 
are procedures that are legislated, well documented and laid out ... I don't know

of an industry where this is not important. I have seen industries which lose focus of this an[d] eventually fall flat on their face."

The case with the other three organizations is different since they have been established for much longer at a much larger scale. For example, ORG6's corporate vice president sees procedural knowledge integration as being strongly linked to their organization's primary strategic orientations and as a part of their product's unique selling point, which in turn influences their performance. He says: "we take our process compliance very seriously, allowing no deviations." In this scenario, the compliance with their achieved certifications and their commitment toward environmental issues take clear precedence. He elaborates that their product lines have been clearly established for some time and the heavy construction machinery industry does not see a great deal of flux in innovation, which decreases the chances that flexible decision-making would be required as versus the need for day-to-day strict adherence to their quality, environmental and safety goals.

In the cases of ORG11 and ORG12, procedural knowledge integration becomes greatly important because their sustainability programs are built around processes making the products and/or programs sustainability oriented. This, again, is the case because the firms and (medical) industry itself has been long established, while the sustainability aspect acts as an operational and strategic augmentation for the business. As articulated by ORG12's regional R\&D director:

"Procedural knowledge integration has the maximum impact on sustainability in [the] case of sustainable product development. [The] decision towards sustainable alternatives on every step of the product development lifecycle counts." 
ORG11 also relies on procedural knowledge integration to focus on changing the lifecycle of devices they term as "reprocess-able" and employs a stringent system of processes to facilitate reuse.

\subsubsection{Attributes of Sustainable Products}

The specific attributes of sustainable products were ranked by the interviewees as listed below in Table 5.4.

\begin{tabular}{|c|c|c|c|}
\hline \multirow{3}{*}{$\begin{array}{l}\text { Identifying Number } \\
\text { I. }\end{array}$} & \multicolumn{3}{|c|}{ Product Attributes } \\
\hline & \multirow[t]{2}{*}{ Fecundity } & \multirow[t]{2}{*}{ Fidelity } & \multirow[t]{2}{*}{ Longevity } \\
\hline & & & \\
\hline ORG1 & 1 & 2 & 3 \\
\hline ORG2 & 1 & 3 & 2 \\
\hline ORG3 & 1 & 3 & 2 \\
\hline ORG4 & 1 & 2 & 1 \\
\hline ORG5 & 1 & 1 & 2 \\
\hline ORG6 & 3 & 2 & 1 \\
\hline ORG7 & 1 & 3 & 2 \\
\hline ORG8 & 1 & 2 & 3 \\
\hline
\end{tabular}




\begin{tabular}{|l|l|l|l|}
\hline ORG9 & 1 & 2 & 1 \\
\hline ORG10 & 1 & 1 & 2 \\
\hline ORG11 & 2 & 3 & 1 \\
\hline ORG12 & 1 & 1 & 2 \\
\hline
\end{tabular}

Table 5.4: Ranking of Product Attributes

A number of results are seen in the area of product attributes as well. The first result, as expected, was the uniformity of the perceived importance of fecundity as a product attribute. The view of ten of the twelve interviewees was articulated by the CEO of ORG2, that fecundity was "more important... a no brainer - the sense that the use becomes obvious." This was because there was a general consensus that it was "the most relevant attribute that led to the sale of [the product]" (Head of product development, ORG8). This link to the financial performance was also reinforced by the idea that the speed with which the product became popular was a consideration. This is observed to even offset some of the costs associated with the sustainable product and increase its environmental performance. The regional director of ORG12 states:

"I feel that the impact of an idea or a product is highest when launched. Globally, marketing campaigns target fast adoption as being the most effective means of making a product successful. Therefore to establish sustainable products, fecundity is a very important attribute followed by longevity which greatly contributes to the ecological impact of the product. We have seen re-usable medical devices being adopted by our customers very easily even with use and throw alternatives being far less expensive." 
Another perspective with a similar end in view is put forth by the CEO of ORG1, who feels that the attribute of fecundity can be useful in directing the kind of performance of the product is required and expected in the market. He says: "we implement in a way that you also control the experience of using it."The senior scientist at ORG8 also pointed out another important function of fecundity where financial performance of a product is impacted positively because "people are more inclined towards emulation."The more interesting finding here perhaps is the almost equal overall ranking of fidelity and longevity. The reason for this is that fidelity is often seen either at par with fecundity, as being equally important for the functional integrity of a product; or at par with longevity, as being a function of maintaining its integrity over time.

There are only two organizations where fecundity is ranked less that 1 , and in both cases longevity is ranked at 1 . In the case of ORG6, the product is service-intensive and the unique selling point is product quality via regulation, which creates a long-term sustainability an inherent function of the product. This leads to an intrinsic prioritisation of product longevity. The corporate vice president elaborates: "during the technical evaluation of the [tender] offers, longevity in the sense the life of the product in the field is a strong motivator for tipping the scales in one's favour."

This attitude is mirrored in the view of the ORG11 associate director of R\&D: "Reuse directly impacts longevity which impacts the overall cost of using the solution....emphasis on lower costs due to longevity is the key attribute that influences product success." The vice president of ORG10 talks at length about the importance of creating sustainability by building in longevity through modularising product 'families' instead of simple product lines. The CEO of ORG1 finds longevity a multidimensional concept: "I would rather call it continuous 
reinvention", which is a known characteristic of sustainable products (as noted in Chapter 3). At the same time, many interviewees also emphasized on the interaction present between all three sustainable product attributes to truly affect performance. This suggests a potentially positive interaction and an enhancement of the overall effect of the attributes on performance. For example, one practical manifestation of the interaction between fecundity and longevity with a performance aim was expressed by the ORG9 co-founder:

"I find a correlation between fecundity and longevity. You have to start selling from somewhere - the hold on at least one client is very important. In this client you will have to invest more in terms of time and effort and this is not one sidedthe client also understand this concept better being a first mover in this area. So he invests more time and money. So he understands longevity better, he understands lifetime orientation of the product better and also his benefits in terms of the payback cycle etc. At the end of the day it is all about business and money for everybody - for me as a service or product provider and for him as an owner of the product."

\subsubsection{Performance}

The rankings of the various types of performance are listed below in Table 5.5.

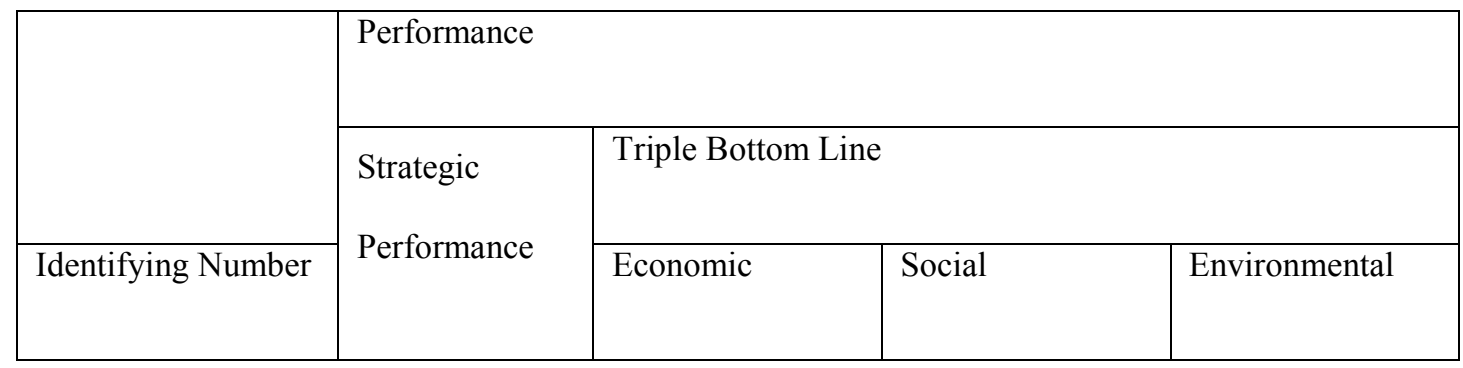




\begin{tabular}{|l|l|l|l|l|}
\hline ORG1 & 1 & 1 & 2 & 3 \\
\hline ORG2 & 1 & 2 & 3 & 4 \\
\hline ORG3 & 1 & 2 & 3 & 2 \\
\hline ORG4 & 1 & 2 & 2 & 3 \\
\hline ORG5 & 1 & 2 & 3 & 2 \\
\hline ORG6 & 1 & 1 & 2 & 1 \\
\hline ORG7 & 2 & 1 & 4 & 3 \\
\hline ORG8 & 1 & 1 & 2 & 2 \\
\hline ORG9 & 1 & 1 & 3 & 3 \\
\hline ORG10 & 2 & 2 & & \\
\hline ORG11 & 2 & 1 & & \\
\hline & & 1 & 3 & \\
\hline
\end{tabular}

Table 5.5: Ranking of Performance

From the table above, a clear division can be seen in the manner of ranking by the interviewees. The strategic and economic performances of the organizations have an overall lead in the prioritization of performance. As the vice president of ORG10 states:

"Organizations exist to make up profits....The whole reason for this is to keep the cash flowing. No matter what, it would always come down to the financials because capitalism is all about dollars." 
In addition to this, a lot of the interviewees viewed strategic and financial performances as complementary to each other for an organization's working. For a well established fortune 500 global company such as ORG7, this tie is even stronger: "strategic and financial goals go hand in hand."

Overall, aiming for strategic performance is seen almost as a prerequisite for economic performance. While this result may be unsurprising, the reasons behind the difficulty with which such rankings were prioritised are perhaps more interesting. When requested to rank the individual performances, executives chose to rank the economic and strategic higher because they were seen as "goal" performances. However, they often explained how performance in other spheres was equally important as a "driving" performance. Thus the hierarchy of rankings is more a reflection of accountability to stakeholders rather than a comment on the importance of any particular performance. For example, the associate director of R\&D at ORG11 clarifies that in terms of performance "our organizational focus is both sustainability as well as financial success emerging out of sustainable activities." The organization has had continuous success in achieving their planned sustainability and financial targets and runs a program to help other healthcare organizations to reduce supply costs as well as environmental impact.

The other large medical devices organization, ORG12 also used sustainability performance (the triple bottom line) to enhance their financial performance. They leverage their organizational size to create a larger impact with respect to local initiatives and support multiple sustainable alternatives globally, resulting in the extremely high industry scores for economic, social and environmental performance when benchmarked according to the Dow Jones Sustainability Index (DJSI). 
A similar approach is taken by ORG6, where strict adherence to quality management, environment management and health and safety management systems provide the backbone for process-based sustainability performance. The corporate vice president states:

"we show full commitment towards the environment and the health of our workmen. The products developed and manufactured ... strictly adhere to all these processes and hence fall in the category of sustainable products. We conduct annual audits and semi-annual internal audits to ensure compliance towards our sustainability promise.”

However, not all organizations are as yet equally successful in quantifying and operationalizing performance from a sustainability perspective. The newer areas and younger firms are still in the process of discovering the scope and best methods to do so. The ORG2 CEO elucidates:

"ecological impact is really a questionable metric... [because] consumption will always have a negative impact....an ideal sustainable product is like the product never existed. It does your task but goes back to the environment like it never existed... [to] reduce the extent to which nature will be impacted is the only thing that we can do."

ORG4 also find that they have "not yet fully evaluated" how to quantify environmental performance and the potential for creating greater gains for the organization through it. The other influencing performance is seen to be social performance. A number of organizations make a 
conscious decision to function in a manner that creates a positive social impact. For ORG1, ORG2, ORG4 and ORG9, key strategic decisions were taken to ensure that a part of the organizational performance be measured through social performance and the positive impact of the product on the community. In fact, the co-founder of ORG9 differentiates the scope of product use to amalgamate the environmental and social performance of sustainable products:

"if the product is related to the masses then it [also] has a social factor but otherwise sustainable products [will naturally] tilt more towards the ecological side."

\subsection{Discussion}

The results from the first stage of the study provide useful insights into the perceptions of executives dealing with sustainable products. A number of implications arise from the results presented in the subsections above. These mostly relate to the relationships between the different constructs about which the executives were questioned.

As a summative reference of what the areas of deliberation in stage 1 of this research were, table 5.6 below provides a break-up of the points of concentration for each interviewee (as compared to the theoretical framework posited):

\begin{tabular}{|l|l|l|l|}
\hline INTERVIEWEE & PRIMARY FOCUS & SECONDARY FOCUS & TERTIARY FOCUS \\
\hline ORG1 & $\begin{array}{l}\text { Strategic orientation, } \\
\text { customer } \\
\text { technology }\end{array}$ & $\begin{array}{l}\text { Performance, economic } \\
\text { and strategic }\end{array}$ & $\begin{array}{l}\text { SPD processes, domain } \\
\text { specific integration }\end{array}$ \\
\hline
\end{tabular}




\begin{tabular}{|c|c|c|c|}
\hline ORG2 & $\begin{array}{l}\text { Performance social and } \\
\text { ecological }\end{array}$ & $\begin{array}{l}\text { Strategic orientation, } \\
\text { technology }\end{array}$ & $\begin{array}{l}\text { SPD processes, decision } \\
\text { making flexibility and } \\
\text { domain specific integration }\end{array}$ \\
\hline ORG3 & $\begin{array}{l}\text { Strategic orientation, } \\
\text { sustainability }\end{array}$ & $\begin{array}{lr}\text { Product } & \text { attributes, } \\
\text { product fidelity and } \\
\text { longevity }\end{array}$ & $\begin{array}{l}\text { SPD processes, domain } \\
\text { specific integration, }\end{array}$ \\
\hline ORG4 & $\begin{array}{l}\text { Strategic orientation, } \\
\text { customer, competition } \\
\text { and technology }\end{array}$ & $\begin{array}{l}\text { Performance, economic } \\
\text { and strategic }\end{array}$ & $\begin{array}{l}\text { Product attributes, product } \\
\text { fecundity and longevity }\end{array}$ \\
\hline ORG5 & $\begin{array}{lr}\text { Strategic } & \text { orientation, } \\
\text { customer } & \text { and } \\
\text { sustainability } & \end{array}$ & $\begin{array}{l}\text { Performance, } \\
\text { environmental and social }\end{array}$ & $\begin{array}{l}\text { Product attributes, product } \\
\text { longevity }\end{array}$ \\
\hline ORG6 & $\begin{array}{lr}\text { Strategic } & \text { orientation, } \\
\text { technology } & \text { and } \\
\text { sustainability } & \end{array}$ & $\begin{array}{l}\text { Product attributes, } \\
\text { product longevity }\end{array}$ & $\begin{array}{l}\text { Performance, environmental } \\
\text { and financial }\end{array}$ \\
\hline ORG7 & $\begin{array}{l}\text { Performance, economic } \\
\text { and strategic }\end{array}$ & $\begin{array}{lr}\text { Strategic orientation, } \\
\text { sustainability } \\
\text { technology }\end{array}$ & $\begin{array}{l}\text { SPD processes, decision } \\
\text { making flexibility and } \\
\text { domain specific integration }\end{array}$ \\
\hline ORG8 & $\begin{array}{lr}\text { Strategic } & \text { orientation, } \\
\text { customer } & \text { and } \\
\text { sustainability } & \end{array}$ & $\begin{array}{l}\text { Performance, strategic } \\
\text { social economic and } \\
\text { environmental }\end{array}$ & Product attributes, fecundity \\
\hline ORG9 & $\begin{array}{lr}\text { Strategic orientation, } \\
\text { technology } & \text { and } \\
\text { sustainability }\end{array}$ & $\begin{array}{l}\text { Product attributes, } \\
\text { product fecundity and } \\
\text { longevity }\end{array}$ & $\begin{array}{l}\text { SPD processes, decision } \\
\text { making flexibility and } \\
\text { domain specific integration }\end{array}$ \\
\hline ORG10 & $\begin{array}{l}\text { Strategic orientation, } \\
\text { customer }\end{array}$ & $\begin{array}{r}\text { attributes, } \\
\text { fidelity, }\end{array}$ & $\begin{array}{l}\text { Performance, economic, } \\
\text { environmental and social }\end{array}$ \\
\hline
\end{tabular}




\begin{tabular}{|l|l|l|l|}
\hline & & fecundity and longevity & \\
\hline ORG11 & $\begin{array}{l}\text { Strategic orientation, } \\
\text { sustainability }\end{array}$ & $\begin{array}{l}\text { Product attributes, } \\
\text { longevity }\end{array}$ & $\begin{array}{l}\text { SPD processes, domain } \\
\text { specific integration, } \\
\text { procedural integration }\end{array}$ \\
\hline ORG12 & $\begin{array}{l}\text { Strategic orientation, } \\
\text { customer, technology } \\
\text { and sustainability }\end{array}$ & $\begin{array}{l}\text { Product attributes, } \\
\text { longevity and fecundity }\end{array}$ & $\begin{array}{l}\text { SPD processes, procedural } \\
\text { integration }\end{array}$ \\
\hline
\end{tabular}

Table 5.6: Respondent Focus on Hypothesized Themes

The first two results relate to the potential effect of the profile of the organization itself. It was observed that larger organizational size assisted in creating an offset of overall costs related to sustainable products. The larger organizations had the advantage of creating a more planned entry into sustainability ventures as compared to the smaller or new organizations where the core idea was rooted in sustainability but overall operations were not very process-dependant. Also, the resources and stability available to larger organizations is seen to help offset initial costs after which sustainability advantages begin to evidence themselves. It was further noted that better development and codification of processes might be needed to support products and performance goals, which is inferred to be a function of how long an organization has been functioning as well as at what scale. In addition to this, an established organizational orientation mix was determined to have a potentially positive effect on the development processes of the organization and product attributes as well.

Another result was based on the product version. The stage of adoption that the product is in the market also affected the kind of supporting processes and attribute-mix that would lead to 
performance. This can also be extended to encompass the dynamic nature of the product. As the product changes according to the needs of the market, the interactions between the attributes as well as the supporting development processes change in strength. For example, the dynamic interaction between integrating domain knowledge and product features (an indicator of product fecundity) is noted by multiple interviewees. This is articulated best by the CEO of ORG1 as "the product psychology keeps on changing". However, this result is currently not within the scope of our study.

In addition to the above results there are other observations which are very useful to note. First, there is a consensus seen with respect to the way $R \& D$ is conducted in the organization. $\mathrm{R} \& \mathrm{D}$ no longer is seen as a sole differentiator for product success or failure. As the CEO of ORG1 articulates, "Every product will have some sort of research and development." In the case of sustainable products, the product design and its ability to lend itself to a modularised approach is now the important differentiator which leads to product success and hence long-term (i.e. strategic and financial) performance. The vice president of ORG10 states:

"you're marketing a family of products...[using modularization] you have a new product that caters to a different market need at a different billing capability. ... to be an organization that lasts you have to have this kind of an outlook."

This observation falls in the category of indirect interaction between the organizational orientation and performance through product development processes. The proactive creation of an orientation toward sustainability which help in accessing a different market/consumer base which in turn lead to triple bottom line performance goals supports the idea that organizational goals from start to finish can indeed tend toward entrenched sustainability. 
The second very important observation relates to the total cost of ownership of the sustainable product. A strong agreement of opinion between executives is noted when they talk of how their sustainable product is superior to other regular products on the market. The education of the consumer is an important part of the process. However, due to the inherent features of the product or its supporting development processes, the total cost of ownership becomes significantly lower for the end consumer. This coupled with the reduced ecological impact and the social responsibility element, increases the product's overall desirability. As the regional director of a large medi-care organization finds: "We have seen re-usable medical devices being adopted by our customers very easily even with use and throw alternatives being far less expensive." Thus, overall the strategic and triple-bottom-line performance may be affected positively by the product attributes of the sustainable product.

The third, and perhaps most important, observation relates to the nature of the sustainable products themselves. The greatest consensus amongst the executives was the way sustainable products are viewed in the market as well as their viability. The success of a sustainable product was felt to be based entirely on how commercially viable it was and what it provided in addition' to the value offered by the regular products. More importantly, the future success of the sustainable products was felt to be related to the awareness levels of the consumer. Sustainability is currently felt to be a new and untested concept, hence strategically, sustainable products may not even be marketed as 'sustainable' in the beginning. The CEO of ORG5 admits: 
"We do not publicize the sustainability aspect [in the beginning] as the customer is not yet educated to appreciate his investment in a more ecologically responsible product.... sustainability benefits should be visibly proven [for customer buy-in].”

This is an important observation since it can potentially cause complexity within the hypothesized relationships in the theoretical framework. On the one hand, pushback from traditional organizational functioning may decrease the acceptance of sustainability because it may be felt that the consumer is not ready, willing or able to pay for sustainable/sustainably made products. On the other hand, when costs are offset and long run advantages become apparent, or consumer awareness and willingness is present, sustainable products may be considered a superior alternative. However, what is a more probable option is not yet clear. The next stage of the study is expected to shed more light on this dilemma.

Finally, for all the executives interviewed, the sustainable products were successful because they created value in addition to performing financially for the organization. This was attributed to the clear orientation of the organization in the first place. The performance goals in turn motivated clearer definition of the organizational orientation, hinting at the possibility of a cyclical relationship. Though the implications of this particular finding are outside the immediate scope of this research, such a relationship may ensure a strong relationship between organizational orientation to performance as well.

In summation, the hypothesized relationships are vetted within the sustainability context as perceived by practitioners in stage 1 of this research and are found to have potential for further analysis in an empirical assessment to determine the strength of the same. This chapter delineates 
the results of the first stage of this study and provides a description of the sample profiles. The chapter also offers an analysis of the findings of the interviews conducted along with a discussion of the implications of these findings for the study at large. The next three chapters provide the results of the second stage of this study. 


\section{Chapter 6: Stage 2 Survey Results}

In this chapter, the pre-test of the survey instrument is discussed, followed by a description of how the data collected from the survey was prepared for analysis. Initial tests and preliminary analysis is presented. The aim of this is to pave the way for the required advanced statistical analysis presented in the next chapter.

\subsection{Pre-Test}

In the light of the interviews conducted and analysed (including the pilot survey carried out) in the previous section, modifications were made in the survey instrument. The resultant instrument was pre-tested for the presentation and feel of the survey for the respondent. This exercise differed in its utility from the previous testing of the survey at the stage 1 of the research, one of the goals of which was to confirm and refine of the theoretical content of the instrument to accurately reflect the aim of the study so that useful data is collected. In this pretest, five participants were requested to critically analyse (A) the survey, (B) its introductory email and (C) disclosure/information page for any issues with the presentation, the clarity and the technical functionality of how the complete survey would be perceived and experienced by a respondent. The aim of this exercise was to reduce attrition rates in respondents for the final survey. After each participant gave their feedback, the survey was modified to incorporate the suggestions.

The tables below provide the details of reach participants' suggestions and how they were incorporated in the formatting of the survey. 
Table 6.1 to 6.5. Survey Pre Test Feedback and Remedial Action

\begin{tabular}{|l|l|}
\hline Respondent Feedback & Remedial Action \\
\hline Provide a link to the survey in the introductory & Hyperlink to survey provided in the \\
email itself. & introductory email for quick and easy access. \\
Suggestion to add (current) Question 6 as & Created Question 6 in addition to Question 7. \\
separate from (current) Question 7. & \\
\hline
\end{tabular}

Table 6.1: Test Respondent: JK

\begin{tabular}{|l|l|}
\hline Respondent Feedback & Remedial Action \\
\hline Reduce size of introductory email. & Complete details related to survey provided in \\
a separate introduction hyperlink. \\
Make the questions stand out for a faster read. & $\begin{array}{l}\text { Elements of each question bolded for a quicker } \\
\text { read. }\end{array}$ \\
Suggestion to clarify Question 9. & Suggestion taken to add clarifying working to \\
& Question 9. \\
\hline
\end{tabular}


Table 6.2: Test Respondent: MIJ

\begin{tabular}{|c|c|}
\hline Respondent Feedback & Remedial Action \\
\hline $\begin{array}{l}\text { Make the survey link more visible in the } \\
\text { introductory email and the introduction page } \\
\text { link less prominent. }\end{array}$ & $\begin{array}{l}\text { Brought the survey link higher up in the } \\
\text { introductory email. } \\
\text { Detailed introduction page brought down in the } \\
\text { email. }\end{array}$ \\
\hline $\begin{array}{l}\text { Suggestion to add the option "Other" to } \\
\text { Question } 5(1), 6 \text { and } 7 \text {. }\end{array}$ & $\begin{array}{l}\text { Option of "Other, Please Specify } \\
\text { added to the questions. }\end{array}$ \\
\hline Make survey more accessible. & $\begin{array}{l}\text { Survey structured and tested for three web } \\
\text { browsers (Chrome, Firefox and Internet } \\
\text { Explorer) as well as tested on mobile devices } \\
\text { (Tablets and Smartphones) }\end{array}$ \\
\hline
\end{tabular}

Table 6.3: Test Respondent: GN

\begin{tabular}{|l|l|}
\hline Respondent Feedback & Remedial Action \\
\hline Make the instructions clearer and different. & Font bolded and italicised for instructions. \\
\hline
\end{tabular}




\begin{tabular}{|l|l|}
\hline Make the survey look as small as the actual & Survey restructured to fit into one webpage \\
time taken to fill it. & page. \\
Suggestion to add time from to every item of & $\begin{array}{l}\text { Time frame of reference added to every item of } \\
\text { questions }\end{array}$ \\
\hline
\end{tabular}

Table 6.4: Test Respondent: MS

\begin{tabular}{|l|l|}
\hline Respondent Feedback & Remedial Action \\
\hline Make survey more universal. & Increased designations for survey respondents. \\
Give instructions for each question in the & Instructions provided for each question in the \\
survey. & survey. \\
\hline
\end{tabular}

\section{Table 6.5: Test Respondent: SV}

After the participants provided feedback which was incorporated, the survey was again circulated to the five, for a second opinion. All participants provided a positive feedback for the newer version of the survey and offered no further suggestions for improvement. 


\subsection{Administration of Survey and Response Rate}

The online survey went live on the $10^{\text {th }}$ of March, 2015 and emails were sent from that day forward. Large to medium-large organizations were the target population for this stage of the study because the findings from stage 1 (chapter 5) showed that smaller organizations may have external factors affecting the proposed ecosystem such as operational instability or excessive caution in business strategy due to limited resources etc. Such factors would form a framework of effects different to the one being hypothesized and tested by this particular study.

Because of a recent amendment to the Canadian privacy laws (Canada's anti-spam legislation i.e. CASL), blind emails to individuals are no longer permitted. Thus emails were requested from organizations and separate databases were compiled for USA, Canada and the Indian subcontinent with the promised intent to delete contact details after responses were compiled. The Canadian organizations, especially, were contacted first via the contact information (email or phone) available from their websites (which were randomly selected from the population of interest) and then emails were sent to the recommended person or forwarded contact. Due to the volume of emails to be sent, a staggered approach was considered. A reminder was sent 20 days after the first email and then again a month afterward. For the Indian subcontinent, an updated list of member organizations of CII (Confederation of Indian Industry) was received at the end of April, when some more emails were sent to the updated addresses and members. Staggered reminders (based on when the initial email was sent to the potential respondent) were sent on the $20^{\text {th }}$ of March, $1^{\text {st }}$ of April, $30^{\text {th }}$ of April, $20^{\text {th }}$ of May and $10^{\text {th }}$ of June. The final reminder that the survey was closing on the $30^{\text {th }}$ of June was sent on the $10^{\text {th }}$ of June. Each recipient received a maximum of one introductory email with two short reminder emails. For each reminder email sent to the recipients, there was a noticeable increase in 
responses received in the next 4 to 5 days. Appendix (11.0) provides the exact breakup of total responses received over the duration of the survey being live online. The chart shows an expected trend in the received responses, with spikes in volume of survey responses received corresponding with the time periods immediately after the reminder emails being sent. Also, the closing date of the survey was a good incorporation into the second reminder email because responses received on the closing date also spike considerably.

The total response rate from the emails sent, numbering 1653 , was $12.28 \%$ or approximately $12 \%$ which is an acceptable response rate for the type of target population and mode of delivery of the survey (de Medeiros et al., 2014; Dillman et al., 2009). Breaking down the responses, the response rates from each country were as follows. The best response rate was from Canadian companies, $14.14 \%$ or approximately $14 \%$ at 82 responses out of 580 emails sent. Indian organizations produced a response rate of 12\% (69 responses from 575 emails sent) and organizations from the USA produced a response rate of $10.97 \%$ or approximately $11 \%$ (34 responses from 310 emails sent). There was also a small section of responses included in the dataset that were received from areas outside the zones earmarked for data collection (such as Europe, Asia or Africa, 16 responses from 188 emails sent to "North America" designations). This category also includes IP addresses earmarked as "Private" or of a null value. It can be reasoned that these responses are from individuals that either are traveling at the time they responded or have an IP proxy screen for privacy. The response rate from such individuals was understandably lower than the rest of the participants, at $8.51 \%$ or approximately $8.5 \%$. 


\subsection{Data Preparation}

Before any analysis of the data can be done, the obtained survey results need to be screened, cleaned and prepared to facilitate meaningful interpretation. Such preparation confirms the suitability of the data being used and inferences being made. It also ensures the validity of the theoretical implications and ultimately the applicability of the results obtained from the statistical analysis (Stevens, 2002). This section outlines the processes followed to ensure that data was prepared properly and carefully before the testing of the hypotheses took place. The data was checked for inaccuracies related to data entry as well as the nature of the sample distribution. This included checking for missing values, unengaged responses, outliers and normality. As a part of preparing the data, dealing with common method bias and non-response bias is also discussed.

\subsubsection{Data Screening}

\subsubsection{Data Cleanup and Missing Values}

One of the best methods of increasing useful data is crafting the survey instrument in a manner that promotes a smooth respondent experience, which in turn facilitates the best possible transition to analysable results (Millar \& Dillman, 2011). To this end, strategic design at various points was used to encourage usable responses. First, the survey was designed to increase its appeal on the first glance, in a manner where it had no 'parts' or 'pages' which makes respondents wary. Second, the content of the survey was conducive to the fact that every scale question was created to be Likert type, which decreased the answering time and the length of the survey. All but two cases (discussed below in missing data) were admissible and were clearly 
usable from an analytical perspective. This may also partially be the case because of the reasonable length of the survey itself. Since the questions were framed as neutrally as possible, no variable required reverse coding in the data set. Five variables, PRODNEW, PRODOFFER, PRODVER, PRODYRS and ISOYRS all related to descriptive analysis related to the product were initially string values, which were then coded to numeric values, as shown in Table 6.6

\begin{tabular}{|c|c|c|c|}
\hline Item & Variable & Item Response/ String Value & $\begin{array}{c}\text { Numeric } \\
\text { Value Coded }\end{array}$ \\
\hline $\begin{array}{l}\text { The level of } \\
\text { newness of the } \\
\text { product }\end{array}$ & PRODNEW & $\begin{array}{l}\text { - Incrementally new (new version) } \\
\text { - New to the company } \\
\text { - New to the country of operations }\end{array}$ & $\begin{array}{l}1 \\
2 \\
3 \\
3 \\
4\end{array}$ \\
\hline $\begin{array}{l}\text { The type or range of } \\
\text { product-offering }\end{array}$ & PRODOFFER & $\begin{array}{l}\text { - The only product the company offers } \\
\text { in total } \\
\text { - One of multiple sustainable products } \\
\text { the company offers } \\
\text { - The only sustainable product the } \\
\text { company offers (along with other, } \\
\text { regular products) }\end{array}$ & $\begin{array}{l}1 \\
2 \\
2 \\
3\end{array}$ \\
\hline $\begin{array}{l}\text { The version of the } \\
\text { product }\end{array}$ & PRODVER & $\begin{array}{l}\text { - } \quad \text { Version } 1 \\
\text { - } \quad \text { Version } 2 \\
\text { - } \quad \text { Version } 3 \\
\text { - } \quad \text { Version } 4 \\
\text { - } \quad \text { Version } 5 \text { or more }\end{array}$ & $\begin{array}{l}1 \\
2 \\
3\end{array}$ \\
\hline
\end{tabular}




\begin{tabular}{|c|c|c|c|}
\hline & & & $\begin{array}{l}4 \\
5\end{array}$ \\
\hline $\begin{array}{l}\text { The number of years } \\
\text { the product has been } \\
\text { on the market }\end{array}$ & PRODYRS & $\begin{array}{l}\text { - Less than } 1 \text { year ago } \\
\text { - } 1-2 \text { years ago } \\
\text { - } 2-3 \text { years ago } \\
\text { - } 4-5 \text { years ago } \\
\text { - } \quad \text { More than ago years ago }\end{array}$ & $\begin{array}{l}1 \\
2 \\
3 \\
4 \\
5 \\
6\end{array}$ \\
\hline $\begin{array}{l}\text { The number of years } \\
\text { the company has } \\
\text { held ISO } 14000 \\
\text { certification }\end{array}$ & ISOYRS & $\begin{array}{ll}\text { - } & \text { No certification } \\
\text { - } & \text { Maintained for less than } 3 \text { years } \\
\text { - } & \text { Maintained for more than } 3 \text { years }\end{array}$ & 1 \\
\hline
\end{tabular}

Table 6.6. Coding of the Categorical Data

These values may be interpreted as the higher value being greater, but in this study the various states of the variables are not necessarily required to be ranked, ie. are treated as categorical variables. So while the values may differ in their potential desirability for the company in question, the scope of this research is not affected by the difference. These values are only used to analyse whether organizations having one particular value differ in any significant manner from others in the sample. If a significant difference is found (discussed in a latter 
section of this chapter) then the analysis conducted for that particular subgroup of data may be different from the rest in the sample. First, the data was examined for any observable pattern in potentially missing data. In this case, there was no pattern observed, so the assumption was that the data was randomly missing.

Missing data poses a problem for research in general by resulting in loss of data, missing values or even a reduced sample size. This may be due to flaws in the design of the survey instrument. Even more importantly, missing data that is not random in nature creates a substantial problem for the usability of the entire dataset obtained, especially when compared to random missing data (Rubin, 1976). So as a third measure, the online survey subsections were programmed as mandatory, which helped in reducing missing data substantially. In using such a measure, it may be argued that attrition rates may increase if a survey does not let the respondent skip answering questions. But on examining the data set, it was seen that only 9 of the 203 responses were labelled "incomplete" by the web host, and most of those were based on descriptive questions not being answered or lack of applicability (such as product version, scale of operations of operations or ISO certification). Missing data was first screened for case-by-case and then by variable. Two rows, case IDs 118 and 180 were inadmissible for high amounts of missing data (far in excess of the 5\% admissible mark). Thus these cases were dropped from the analysis, leaving 201 cases as usable data. 36 cases had less than 5\% missing data. Screening by variables, it was further found that these cases had only categorical descriptive variables missing. Seeing that $5 \%$ missing data is generally acceptable and none of the key variables were missing, these cases were retained for analysis (Rubin, 1976). Since the data was categorical, the mode of the variable was used for imputation. Mode is generally the method used to impute categorical variables because there is an interpretable meaning, instead of mean which may potentially return 
decimal values (Little \& Rubin, 1989). In our case, as seen in table 6.3, variables translate to meanings such as the time period ISO certification is maintained, or how new a product is when introduced by a company, and thus have meanings that can only be imputed as mode. For example, a mean imputation of a hypothetical mean 2.5 would have no meaning for a question asking if a certification is held for more than or less than 3 years. The response would either be 2 (less than 3 years) or 3 (more than 3 years) but cannot be 2.5 .

\subsubsection{Checking Response Abnormality: Outliers and Unengaged Responses}

Before preliminary analysis on the nature of the dataset can begin, the nature of the responses received also required verification. For this usually, the number and severity of outliers is checked and the cases are checked to estimate the engagement of the respondent. First, outliers are discussed below, followed by respondent engagement. Outliers essentially represent extreme values, in other words, data points that differ vastly from other data points of the same sort (eg. in the same variable across cases) and can either be detected using multivariate, bivariate or univariate outlier analysis. Multivariate analysis in the form of Mahalanobis Distance (or MD, which measures the distance of responses from the center of the rest of the response clusters) was used in tandem with boxplots, which are good for univariate outlier analysis. This study does not call for bivariate analysis. For this study, the MD was calculated for all the responses and then the p-value of the chi-square distribution was checked against the 0.001 value as suggested by Tabachnick \& Fidell (2007). None of the cases were seen to be extreme values, though 4 cases which were very near the cut off value, so all the responses were kept in the analysis but cross-

checked for outliers using univariate analysis as well. The reason for this was that this study had a very large and diverse number of total variables, so univariate outlier analysis was also used to 
assess the cases that were close to the multivariate cut off point. For univariate outlier analysis, the boxplots of the Likert scale variables are examined and the starred outliers are followed back to their complete cases to check intra-response integrity of the outlier case. Nine variables had responses ranging from 1 to 4 cases that seemed extreme values. In particular, case numbers 100, 183 and 69 featured in more than one variable outlier star. The responses of these cases were checked against the questionnaire and it was found that each of the cases were of a logically uniform opinion. In other words, the respondents answered all their questions in a cohesive and logical manner which showed that the respondent answered genuinely across various questions pertaining to the same construct. The integrity of the cases remained intact and they remained a part of the analysis.

Respondent engagement refers to the genuine intent with which the responses are given in each case. For this, the cases are checked to ensure that no one answers at random, such as all "5" on the scale or answers that do not logically make sense. Checking the boxplot and outliers in a Likert questionnaire already ensured that logic is maintained in all cases. Unengaged random responses were checked by examining the standard deviations of each case across the variables. Extremely low or zero variation would show that the respondent has just clicked on any one response throughout the survey (Stevens, 2002). None of the cases showed a questionable standard deviation across all key variables. The conclusion from the MD, the boxplots and standard deviation analyses was that the data set was free from unusable cases or responses.

\subsubsection{Data Normality}

Most of the envisaged statistical analysis in this study requires the data to be normal in nature. That is, the distribution of the sample should be 'normal' or of the form of a bell curve. 
Non-normal data can result in results that are not generalizable (Stevens, 1996). In this study, three methods are used to check on the normal nature of the key variables. The first is the use of histograms, where the distribution is 'eyeballed' for a normal curve. This step is useful to detect distributions that differ substantially from a normal to near-normal distribution pattern. After this first stage, the symmetry and the peak of the distribution was calculated for the variables by using skewness and kurtosis. According to Curran et al. (1996), skewness within the range of \pm 2 and kurtosis within the range of \pm 7 should be considered a normal distribution. Table 6.7 proves the values of the composite dependent and independent variables used in the study. Appendix (11.0) provides the same descriptive statistics of each individual item in the study.

Skewness is an indication of the symmetry of the distribution, a positive skew indicates more values clustered to the left hand side and a negative skew indicates more values clustered toward the right hand side. From table 6.7, it may be seen that all skewness values are well within the acceptable \pm 2 range. However, a trend toward negative skew can also be noted. This indicates that some variables show a general response leaning toward the higher end of the Likert scale related to those items.

Kurtosis is an indication of the shape or the peak of the distribution. A highly peaked distribution shows positive kurtosis and a flat curve shows negative kurtosis. The table below shows that the variables have a near normal shape, with most variables having a positive kurtosis very close to zero. Only one variable has a slightly negative kurtosis and no values are near the extreme \pm 7 mark (Appendix 11.0 gives the skewness and kurtosis values for all variables in the dataset). 


\begin{tabular}{|l|l|r|r|r|r|}
\hline Variable & Mean & Std. Deviation & Variance & \multicolumn{1}{c|}{ Skewness } & Kurtosis \\
\hline CUST & 4.9287 & 1.08674 & 1.181 & -.501 & -.063 \\
TECH & 5.1891 & 1.07283 & 1.151 & -.798 & .868 \\
COMP & 4.4042 & 1.16666 & 1.361 & -.448 & .019 \\
SUSO & 4.9167 & 1.22023 & 1.489 & -.414 & .442 \\
IFC & 5.4279 & 1.00736 & 1.015 & -1.105 & 2.387 \\
DSKI & 4.6982 & 1.01042 & 1.021 & -.453 & .496 \\
PKI & 4.8939 & 1.20730 & 1.458 & -.661 & .602 \\
FDM & 4.7632 & 1.07575 & 1.157 & -.713 & .769 \\
FEC & 5.3744 & 1.04317 & 1.088 & -1.144 & 2.149 \\
FID & 5.2521 & 1.25146 & 1.566 & -.843 & .710 \\
LONG & 5.2517 & 1.00624 & 1.013 & -1.084 & 2.908 \\
ENVPERF & 4.5017 & 1.38564 & 1.920 & -.472 & .186 \\
ECONPERF & 3.9244 & 1.31280 & 1.723 & .012 & .087 \\
STRPERF & 4.9881 & 1.13607 & 1.291 & -.822 & 1.247 \\
SOCPERF & 4.1204 & 1.12251 & 1.260 & -.118 & .364 \\
\hline
\end{tabular}

Table 6.7. Descriptive Statistics of Dependent and Independent Variables

\subsection{Common Method Variance}

Common method variance is a result of using a particular (usually only one) kind of method to collect data. This extends to the measurement context, similarity of items, single respondent or a common source. This may result in a bias which may affect the analysis and resultant inferences derived (Podsakoff et al., 2003). Common methods such as mixed mode surveys, longitudinal research design or multiple respondents may be used to reduce this kind of bias. However, these are often time consuming and may also be costly (Millar \&Dillman, 2011). Ensuring respondent anonymity is also another way to ensure that a bias is not incurred by a respondent answering in a socially desirable manner (Podsakoff et al., 2003). Respondent anonymity was a high priority in the data collection for this study. Another method utilised to reduce such bias (discussed in the previous section) was the construction of the survey questions 
and the order of survey questions. Pretesting the questionnaire was done to reduce biases related to item context and misunderstanding.

Further, to test for common method bias, confirmatory factor analysis (CFA) was used in LISREL; specifically Harman's single factor test (Sabherwal and Fernandez,2003; Podsakoff et al., 2003). In this test, all the items are loaded onto one factor to test how much of the variability one single factor would explain. An unsatisfactory explanation of variance indicates the lack of a common method bias. The model was run and it was observed that a single factor loading only explained $29.2 \%$ of the variance, which is a small amount. It was concluded that common method variation was not a significant source of bias in the data.

In summation, this chapter provides the first part of the results of the second stage of this study, those related to the survey pre-test, the administration of the survey and response rate as well as the process of data preparation. Common method variance is also discussed. The next chapter provides an outline of the preliminary data analysis of the sample obtained from the processes documented in this chapter. 


\section{Chapter 7: Preliminary Data Analysis}

This chapter covers two areas of preliminary data analysis. The first part comprises of the sample characteristics, or descriptive statistics of the data set. The second set of analyses is the essential preliminary analysis of the nature of the data as it fulfills the requirements of this study. In other words, the scales (and items) are checked for their construct and content validity.

\subsection{Sample Characteristics}

To verify the reach of the survey instrument, a number of questions in the survey were administered to gain an understanding of the respondent and organization profiles. This section details the sample characteristics of the data obtained. Questions 2(8) to 2(11) and 5(1) to 5(5) on the questionnaire relate to this analysis (See Appendix 9.0 for the Survey Questionnaire). The following subsections first outline the respondent profiles and then the characteristics of the organizations and the products referred to in the sample.

\subsubsection{Respondent Profiles}

The results from the survey define a sample of senior executives from multiple industries across North America and the Indian subcontinent. Since this study wishes for a fairly balanced representation of organizations from the two continents, a good mix of the two geographical areas was hoped for. Figure 7.1 provides a breakup of the percentages of received responses from various geographical areas. Of all the responses received, responses from individuals answering from Canada totalled 82 , which constituted $41 \%$ of the sample. Respondents from the United 
States constituted a total of 34 , at $17 \%$, which meant that the respondents from North America were $58 \%$ of the total sample. Responses from India totalled 69 , or $34 \%$. Another $8 \%$ of the respondents showed a privacy barrier or IP addresses which were outside the areas of interest. As explained in the previous chapter, these may be due to reasons of travel or IP anonymity.

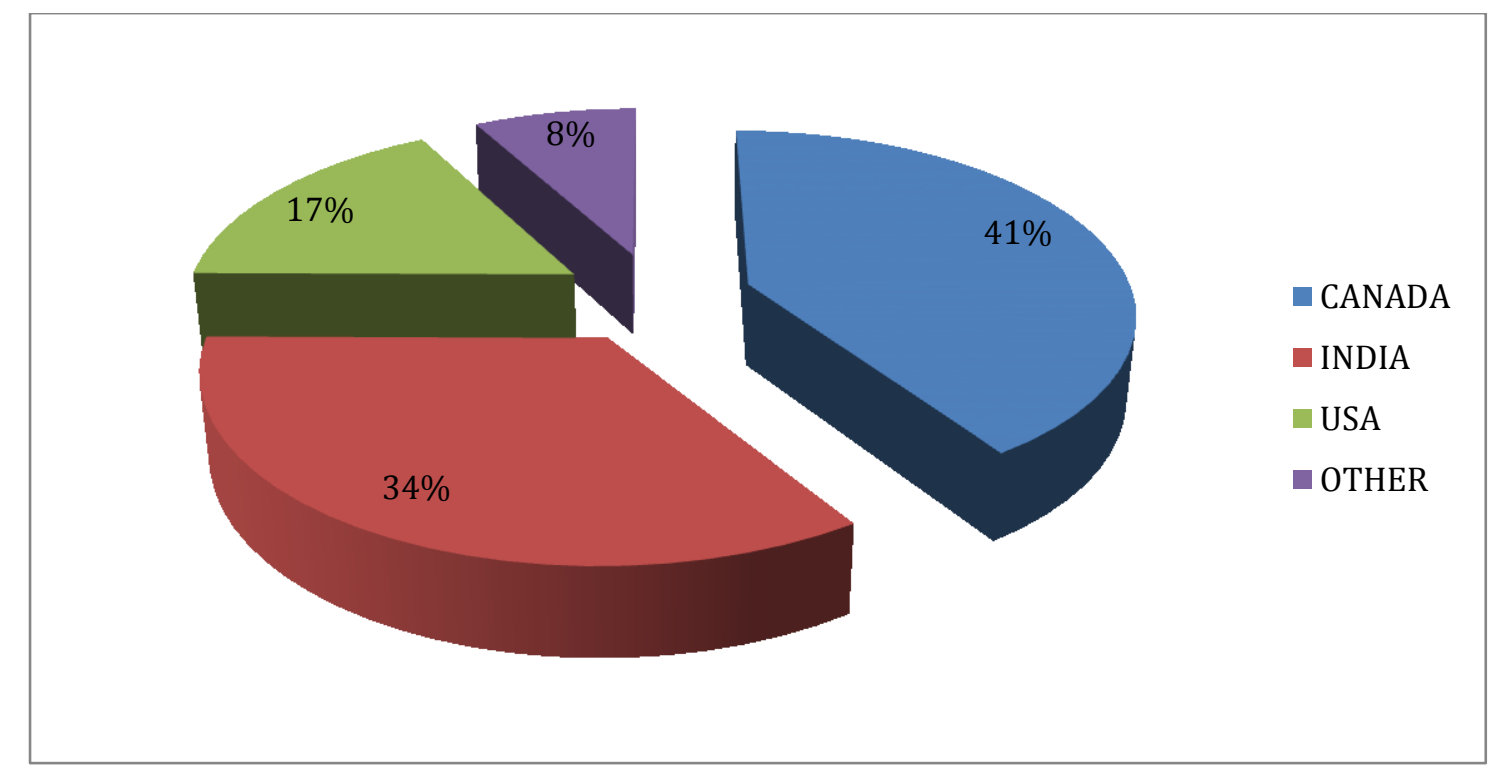

Figure 7.1 Locations of Respondents

The respondents themselves were of senior executive positions, a number of them being designated multiple roles of responsibility in the organization for which they responded. For this reason, some categories were kept as multi-role in figure 7.2 (below) as these particular combinations were check-marked by a substantial number of respondents. 


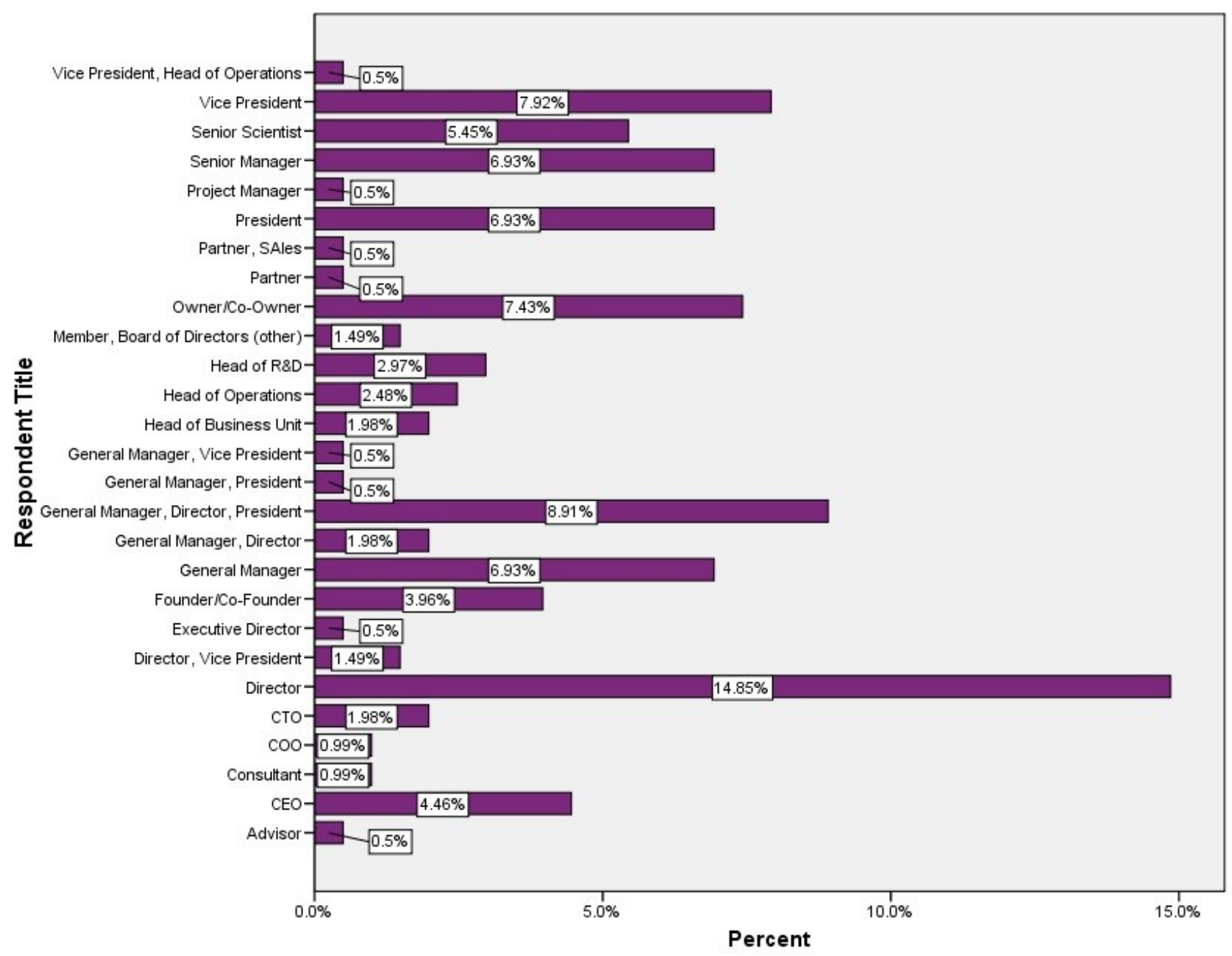

Figure 7.2 Designations/Titles of Respondents

It was seen that the largest range of respondents at $14.85 \%$ were company directors. The next most represented segment consisted of General Manager/Director/President and Vice President categories at $8.91 \%$ and $7.92 \%$ respectively. Close behind these, were categories of Owner/Co-Owner, President, General Manager and Senior Manager (a category of a similar responsibility grade to the previous designations for global organizations) at $7.43 \%$ and $6.93 \%$ for the latter three. The Senior Scientist category was represented at a percentage of 5.45(\%) of the sample, $\mathrm{CEO}$ at $4.46 \%$ and Founder/Co Founder at $3.96 \%$. Other designations were 
represented between less than $3 \%$ and more than or equal to $0.5 \%$ of the collected sample. The designations of the respondents are included in this descriptive analysis in order to check whether the respondent profiles matched the population of interest. It is important to check this since the holistic opinions of these individuals would be fit for use in this study, whereas departmentspecific employees would not have sufficient exposure or experience to address the survey's requirements. The next section deals with the organizations represented in the data sample collected.

\subsubsection{Organizational Characteristics}

Organizational characteristics of the companies in the dataset were related to the industry, the area of operations of the organization, the ownership of the organization and the current (at the time of survey administration) ISO status of the organization in question. The respondents hailed from organizations that defined themselves as part of twelve industries of interest. The reason why this characteristic is presented in the descriptive analysis is to check whether there is any overrepresentation or bias in favour of any particular industry, which would have an impact on the generalizability of the results of this research. The three most represented in the sample, as shown in figure 7.3 , are that of Computer and electronic product manufacturing at $16.83 \%$; Electrical equipment, appliance and component manufacturing also at $16.83 \%$ as well as General manufacturing, predictably the largest percentage, at $17.33 \%$. These three industries are expected to be the largest represented since they have the most affinity to 'high-technology' operations. 


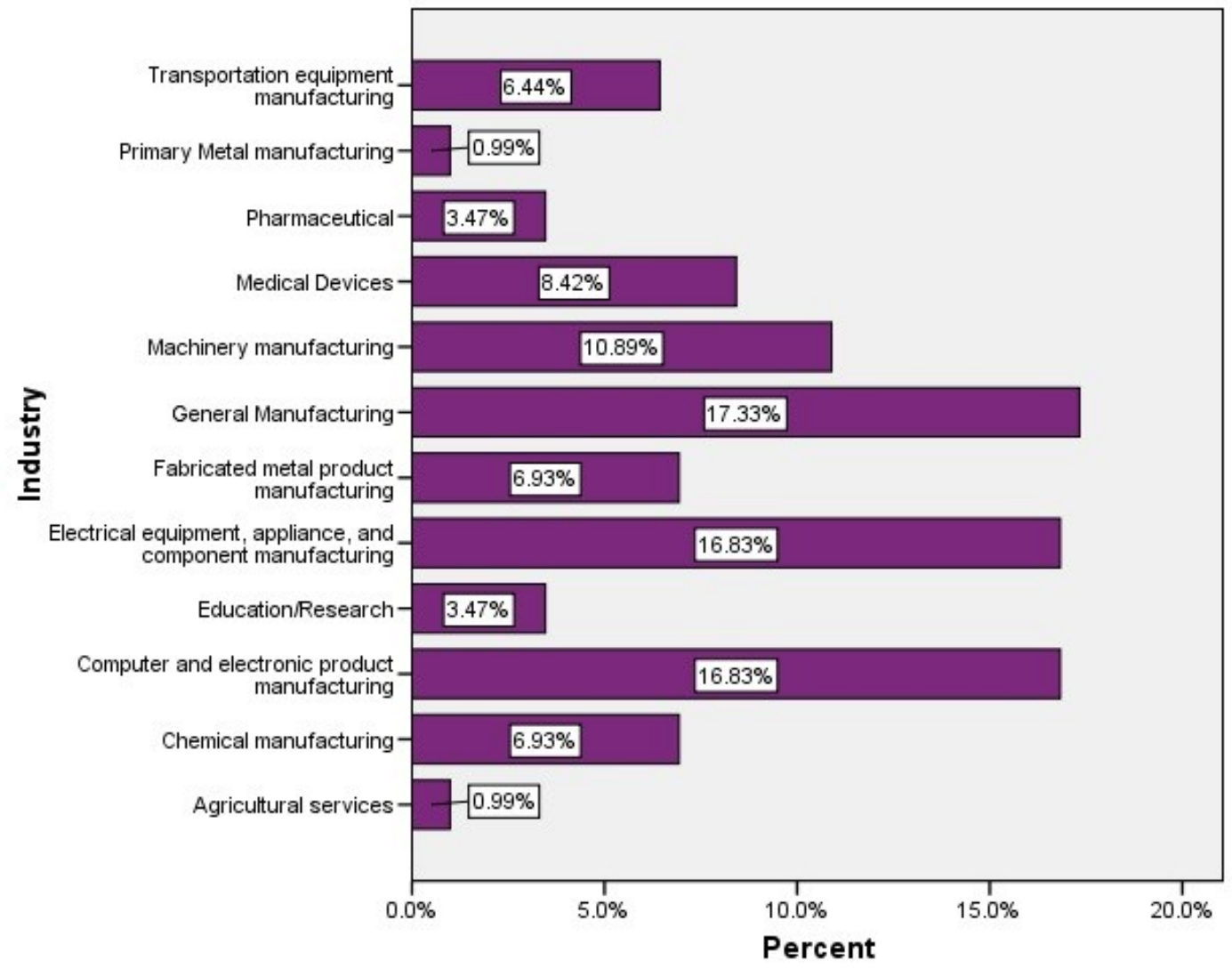

Figure 7.3 Industries Represented

The next most represented industries at $10.89 \%$ and $8.42 \%$ are Machinery manufacturing and Medical devices. The other seven industries are within the $7 \%$ and $.99 \%$ ranges. This includes Transportation equipment manufacturing (6.44\%), Primary metal manufacturing (0.99\%), Pharmaceuticals (3.47\%), Fabricated metal product manufacturing (6.93\%), Education/Research (3.47\%), Chemical manufacturing (6.93\%) and Agricultural services $(0.99 \%)$. It is interesting to note that the lowest represented industries are Agricultural services and Primary metal manufacturing. This may be because only a limited number of organizations use a substantial component of high-technology in their processes or products. The low representation of Pharmaceuticals as well as Education/Research facilities on the other hand 
would probably be because these are less in number as compared to businesses in other industry segments.

The area of organizational operations as reported by the respondents is also an interesting and complex mix. This characteristic is included as a check for whether the sample represents our population of interest as well as to gain insight into where most high-technology firms are supplying products. Since the survey was administered to medium and large organizations, (as defined by Statistics Canada and put forth in Chapter 4, section 4.2)most organizations conduct operations in more than their home country. A break-up of the home country is provided in the previous section where the locations of the respondents match the address to which the emails for the survey were sent (see Figure 7.1). From figure 7.4 below, it is observable that the largest section of organizations represented is those reported to be operating on a Global scale at $23.38 \%$ of the total data sample. 


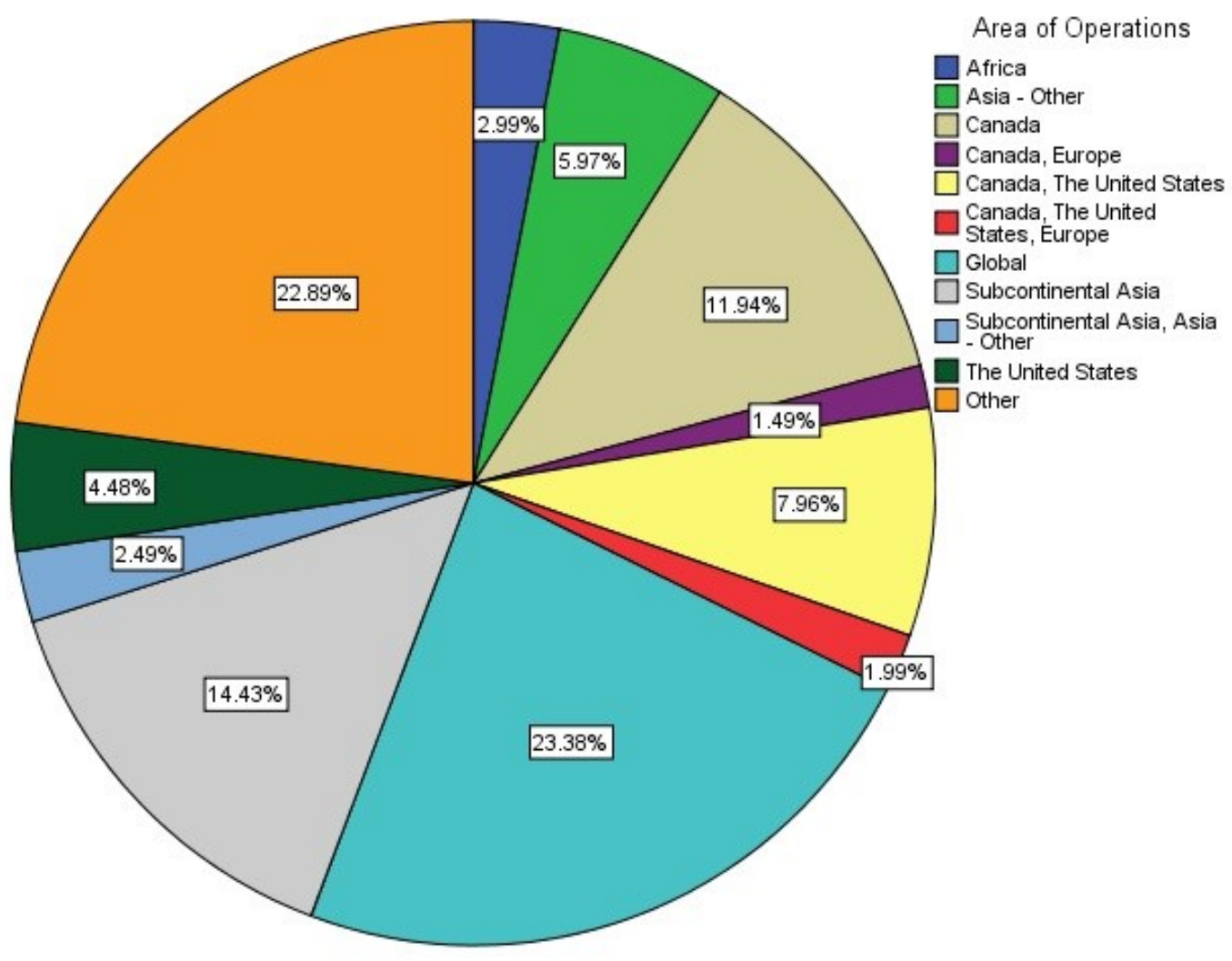

Figure 7.4 Area(s) of Operations

The second largest representation is that of companies doing business in Subcontinental Asia at $14.43 \%$ of the total organizations in the collected sample. Close to this are organizations doing business in Canada at $11.94 \%$ and those doing business in Canada and the United States at $7.96 \%$. A representation of companies doing business in various combinations of two or more continents are clubbed together to form $22.89 \%$ of the total sample but these are individually less than $0.5 \%$ of the data sample. Businesses catering only to other parts of Asia (such as China) totalled $5.97 \%$ and those serving only the United States were $4.48 \%$ of the total sample. Businesses supplying Africa were a total of $2.99 \%$ of the data collected and those supplying the entire continent of Asia were 2.49\%. The last prominent category was that of organizations servicing Canada and Europe, at $1.49 \%$ of the total sample. 
The respondents were also asked to identify the ISO 14000 status of their organization in length of time. The period of time was divided according to the other questions in the questionnaire to maintain uniformity of the information being reported. So the respondents were asked whether they had no certification, were in the process of getting certification or had maintained their certification for either less than or more than 3 years (which was the same as the time period over which they reported performance, process, product and orientation answers). This characteristic is included in the descriptive analysis because it offers an insight into the importance given to certification by organizations leaning toward sustainability. The status of the organizations from the data sample is shown below in figure 7.5

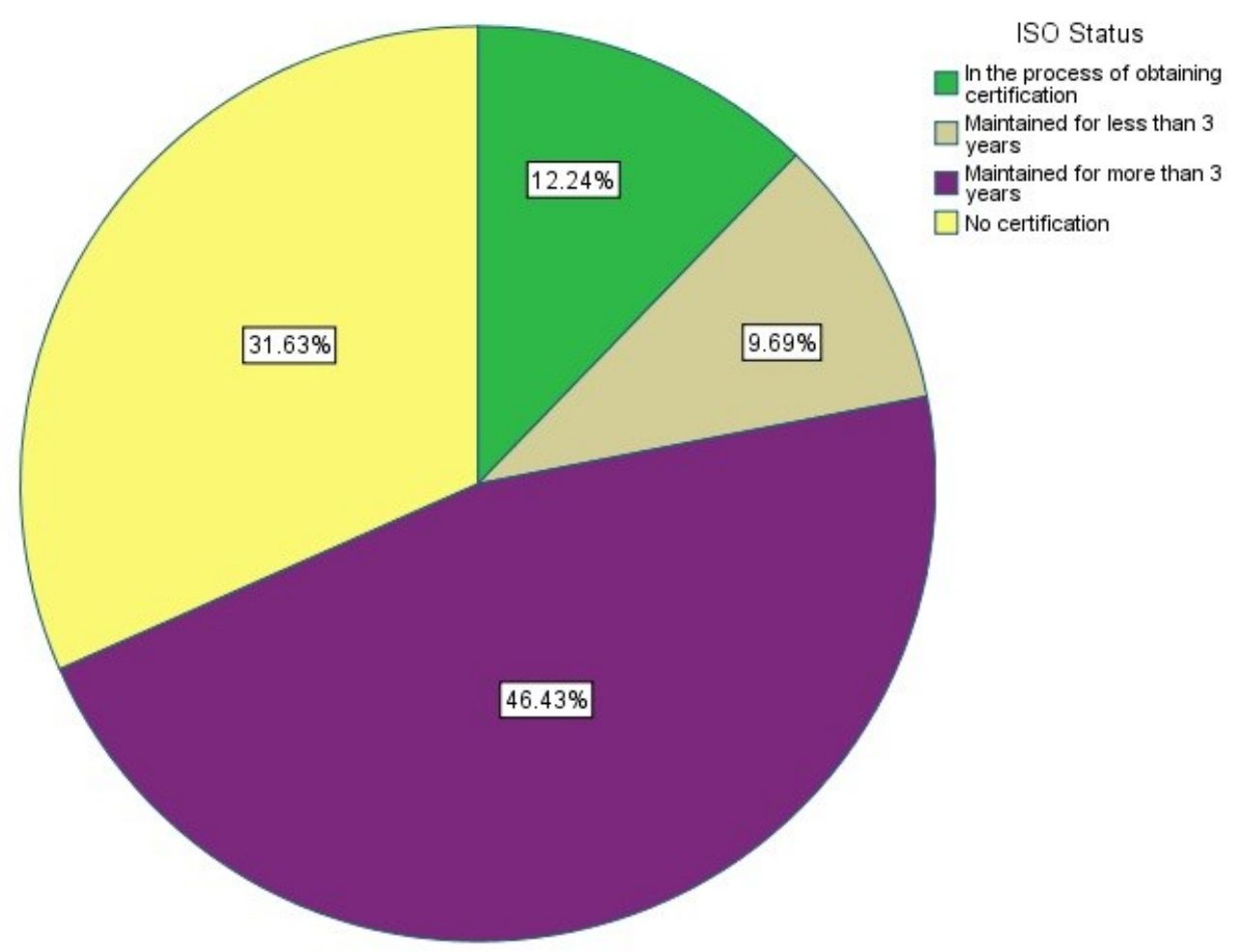

Figure 7.5 ISO 14000 Certification Status 
The highest percentage of organizations was those who have maintained the ISO 14000 certification for over 3 years, at $46.43 \%$. The second highest representation was that of organizations who had no certification at the time of the survey, at $31.63 \%$. At $12.24 \%$, the organizations that were in the process of obtaining certification were represented in the data collected. The least represented organizations, at $9.69 \%$ of the data sample, were those that had the ISO 14000 certification maintained for less than 3 years.

The last organizational characteristic was the ownership type of the companies represented in the data sample. Figure 7.6 provides a break-up of the ownership types of the organizations in the data set.

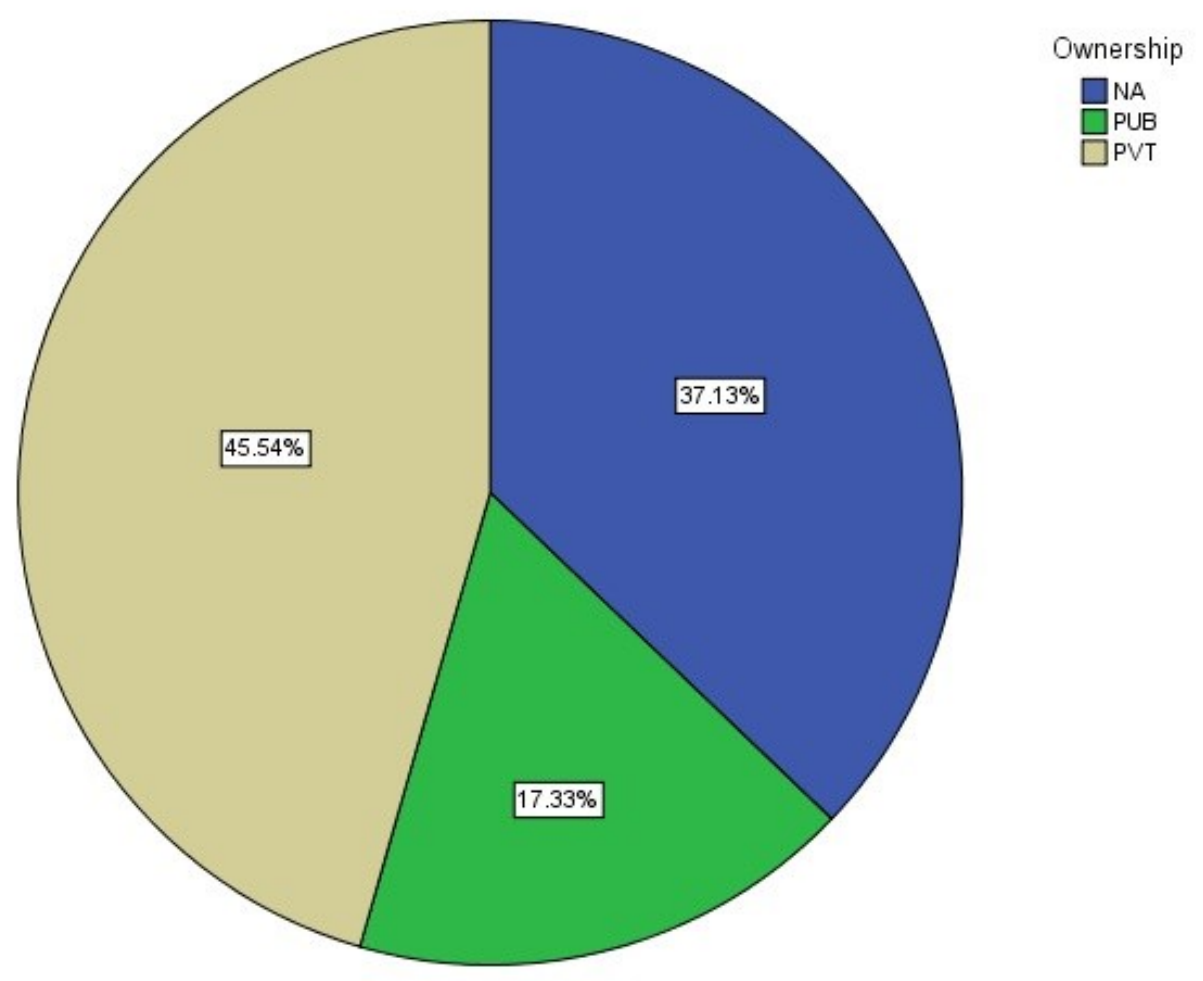

Figure 7.6 Ownership Type 
As can be seen, the largest percentage of the respondents who answered were from privately owned organization at $45.54 \%$. On the other hand, $17.33 \%$ were reported to be hailing from publicly owned organization. This characteristic is included in the descriptive analysis to determine whether private or public organizations show more of a propensity to be sustainable, which in turn may be a reflection on what drives the move toward sustainability. Since this was an optional question, a substantial number of respondents $(37.13 \%)$ did not mention what kind of ownership their organization was under. The next section deal with characteristics of the products the respondents answered in reference to in the data sample.

\subsubsection{Product Characteristics}

Respondents were asked to identify the kind of product they used in reference to the survey with questions related to product offering, product novelty, product version and the number of years the product has been in the market. The reason why these three characteristics are included in the descriptive analysis is to determine the importance of the sustainable product and its place in the organization. For example, the only product offering would mean high stakes for the organization, a larger version number might mean an organizational trial-and-error approach, a completely new product in a country may mean increased attention to the sustainable product, a greater number of years on the market would mean a longer history of understanding what attributes sustainable products should have in order to be successfully sold.

With respect to the product offerings by organizations in the collected data, the most represented are those organizations that offer more than one sustainable product, at a majority total of $60.70 \%$. Figure 7.7 below provides a chart of the three states of product offerings in question. 


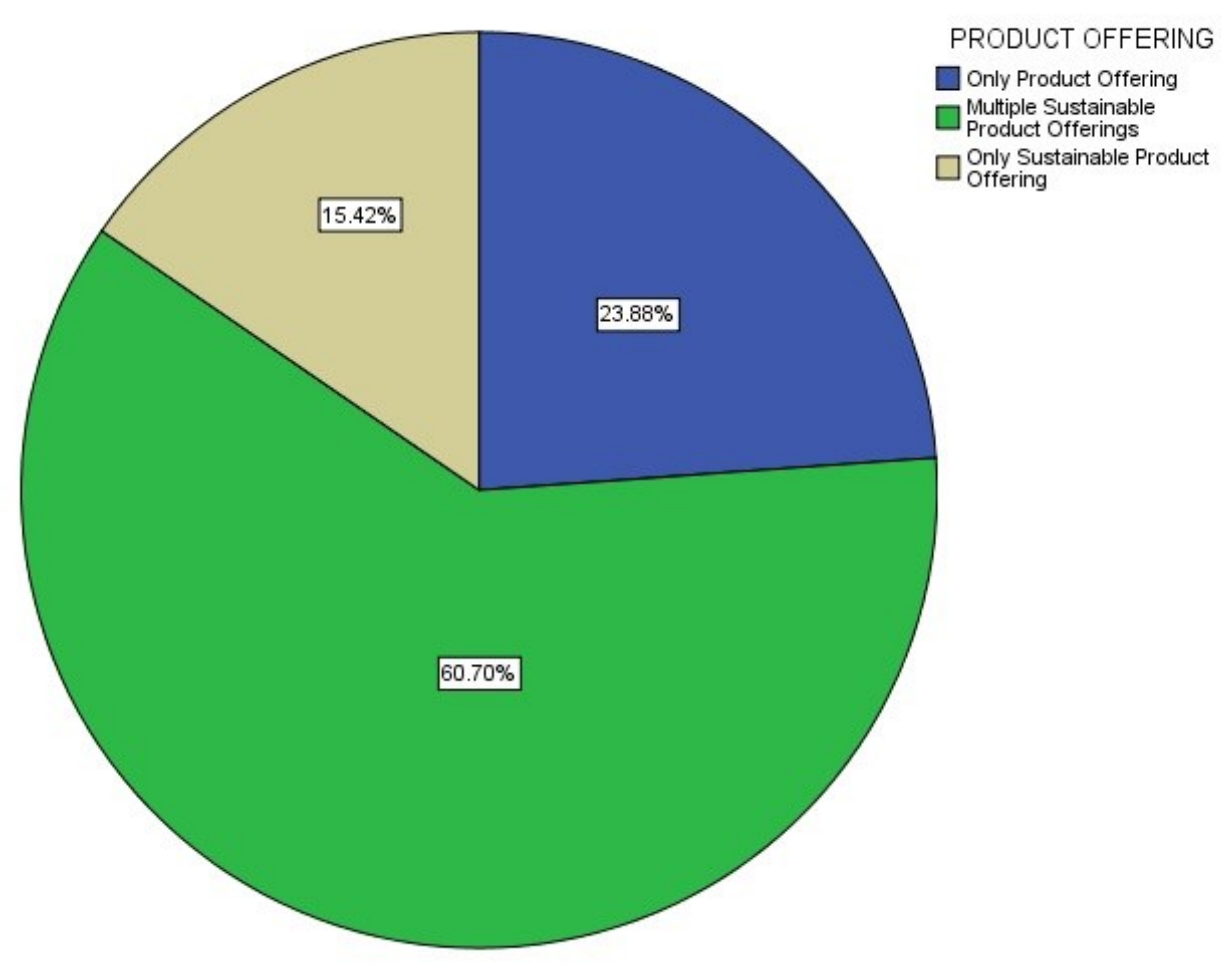

Figure 7.7 Product Offering

The second highest representation is that of organizations that have the referenced product as their organization's only product offering, at $23.88 \%$. Organizations that offer only one sustainable product with a host of other non-sustainable products are relatively less at $15.42 \%$. This could be because of policy or strategic choices the organizations make that would promote sustainable products but ensure that one type of products don't cannibalize another type.

Another product characteristic was related to the novelty of the product referred to in the survey by the respondent. The product newness was measured by the nature of inventiveness of the product. Figure 7.8 below shows the break-up of the responses received with respect to this characteristic. 


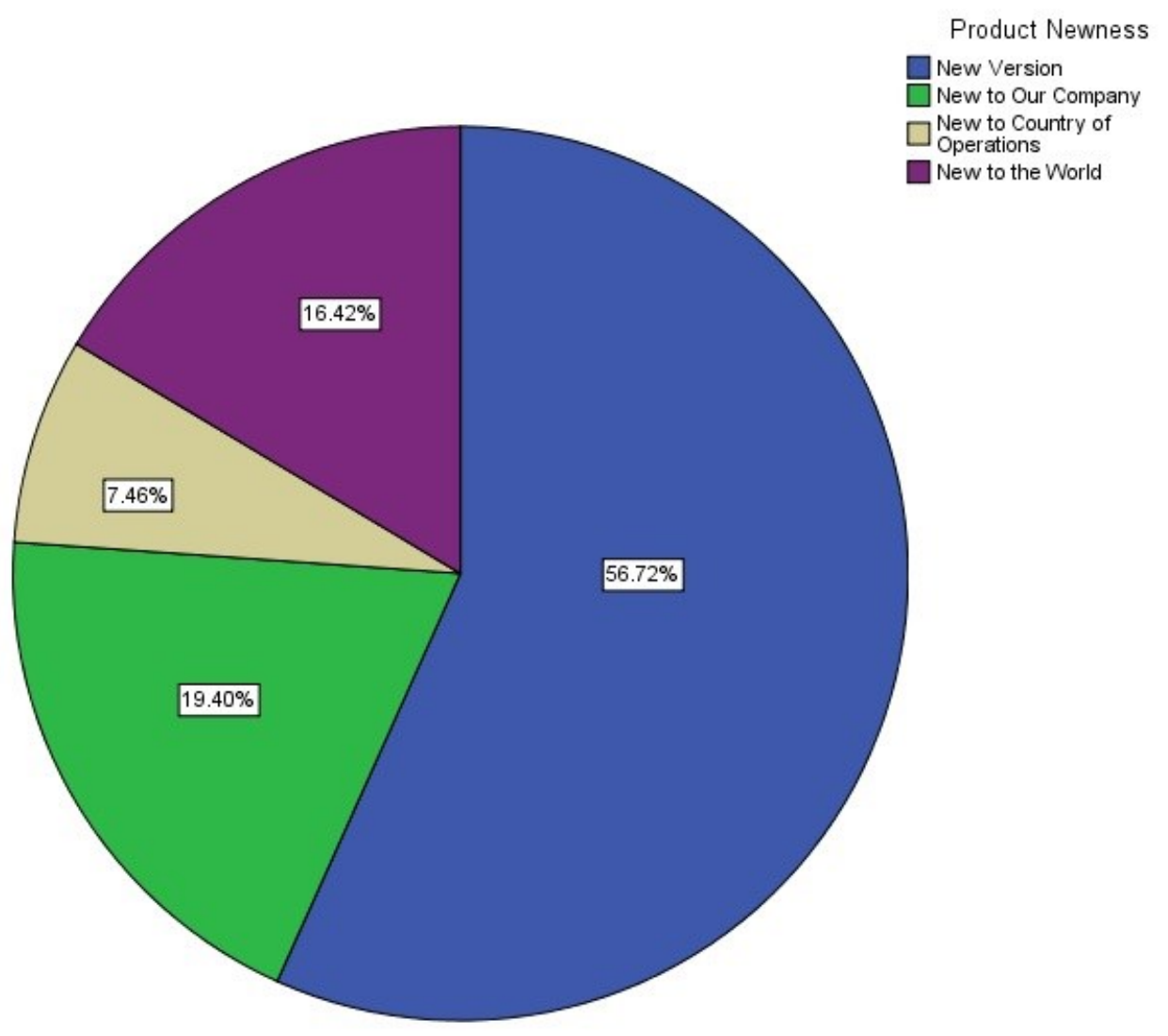

Figure 7.8 Product Novelty (Newness)

The highest representation, at a majority percentage, was that of products which were only incrementally new at $56.72 \%$. The next most represented category, at $19.40 \%$, was that of products that were new to the company that the respondent belonged to.At $16.42 \%$, was the next most represented type of products, which were new to the world. Last, at $7.46 \%$ were those products that were new to the country of operations of the organization in question.

An interesting product characteristic was that of the version of the product referred to in the survey questionnaires, as shown in figure 7.9 below. 


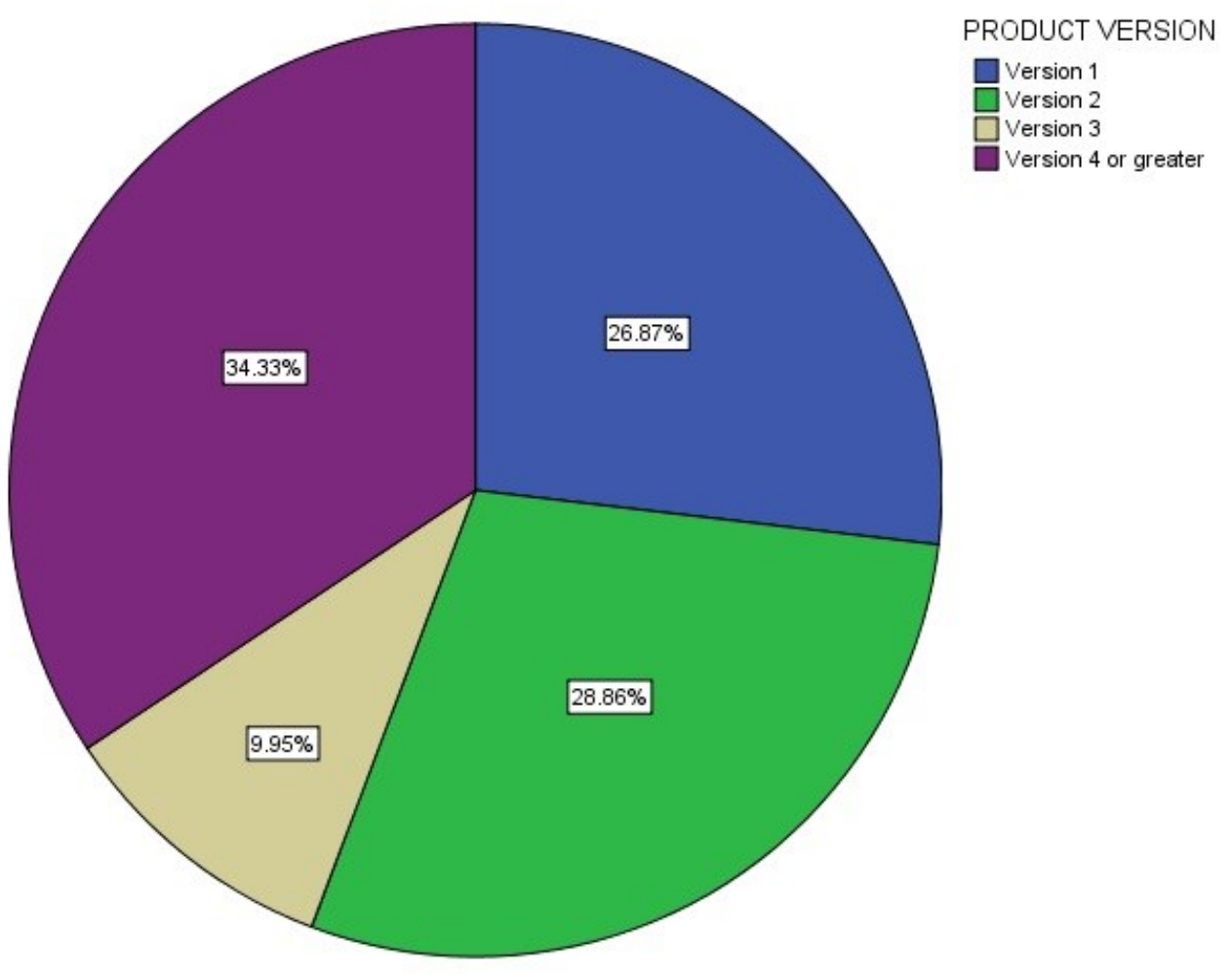

Figure 7.9 Product Version

This was mostly interesting because most of the products represented in the data were of Version 4 or higher at $34.33 \%$. The second most referred version was Version 2 at $28.86 \%$. Close to this was Version 1 at $26.87 \%$ and the product version with the least representation in the sample was that of Version 3, which was at $9.95 \%$ of the total data. The reason for this divide may be because certain organizations release a number of versions of products in the market place that are incremental improvements while other organizations, release only one or two versions and focus on perfecting those before release.

The last product characteristic that was polled in the survey was that of the number of years the referred product version had been in the market. In this case, the survey asked for the introduction period with reference to the current version of the product at the time of the 
respondent being surveyed. The figure below (7.10) shows a break-up of the number of years for the products. What is worth noting is that a large part of the products were introduced since less than 2 years in the market.

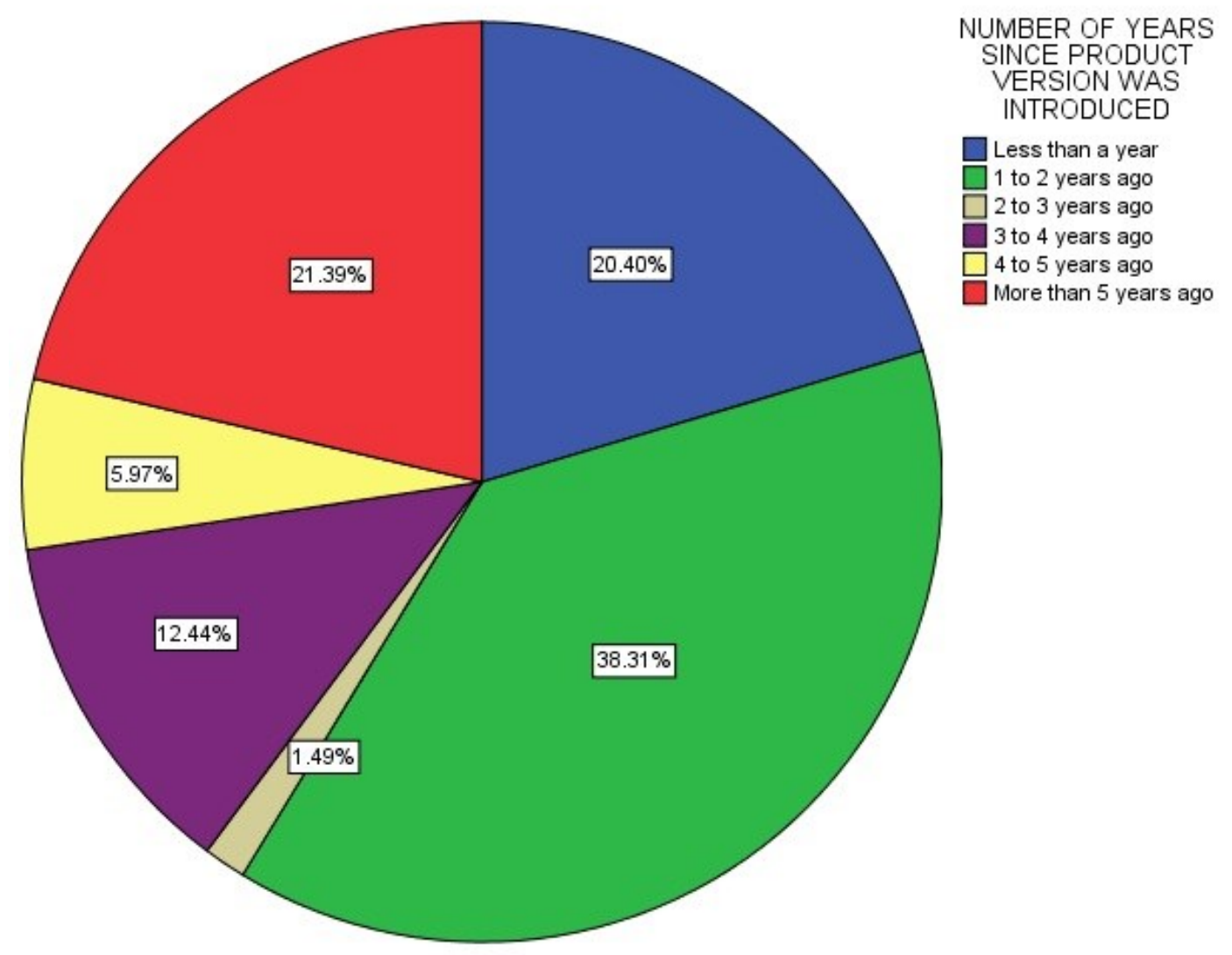

Figure 7.10 Number of Years since Product Version was Introduced in the Market.

Products that were introduced less than a year ago were $20.40 \%$ of the data sample and the product that were introduced 1 to 2 years ago were the highest in representation in the data sample at $38.31 \%$. In total that is $58.71 \%$, which implies that most respondents referred to very new products in the marketplace in their surveys. Products that were introduced more than 5 years ago were interestingly $21.39 \%$ of the sample, while those that were introduced 3 to 4 year ago were next most represented at $12.44 \%$ of the data collected. At $5.97 \%$ of the total data were 
those products that were introduced 4 to 5 years ago. The least represented were products that were introduced to the market 2 to 3 years prior to the survey.

\subsection{Reliability and Validity}

Before conducting any in-depth analysis or model comparisons, the reliability and validity of the scales in question have to be checked. This is because, even though the scales are from previously validated literature, the applicability to a related yet different context, that of sustainability, may alter their suitability. The a-priori model has already been established from what has been theorised from the available literature in this area. Since some areas of the literature in this area are sparse, the a-priori model is expected to take on a more exploratory nature as research. For this very reason, another layer of research in the form of qualitative data from interviews (as seen in Chapter 5) was added to confirm the theorising of the researcher and to add the weight of the judgement of field professionals to the theoretical underpinnings. The qualitative data confirmed the importance of the hypothesized relationships in the a-priori model within this research's context.

The next step entails addressing construct reliability and validity of the adapted constructs before moving ahead with structural equation modeling and model comparisons.

\subsubsection{Reliability, a-priori model}

The reliability of a construct or measure refers to the internal consistency of that construct or measure. In other words, reliability is an estimation of how much a particular measure or 
construct is free from what is known as random error. The usually used Cronbach alpha has been recently called into question for giving an under-estimated value because it assumes perfect correlations between the items forming the construct or measure, which is more likely true for constructs or models that are (correctly) specified as formative and not reflective (Ping, 2004). For this research, composite reliability is used considering that structural equation modeling (SEM) techniques are used here. Composite reliability, according to equation 1(below) given by Raykov (1997) uses both the standardised loadings and the error variance to compute the score, hence eliminating the possibility that the reliability will be underestimated. Normally, the tendency has been to move from Nunally's (1967) 0.6 score of acceptable reliability to that of 0.7 (Fornell and Larcker, 1981). However, in the case that a study is exploratory in nature, where preliminary theorising is involved, an acceptable reliability can be 0.6 to even 0.5 (Shay \& Baack, 2004). Composite reliability (CR) is calculated as follows:

$$
C R=\frac{\left(\sum_{\mathrm{i}=1}^{\mathrm{n}} \lambda_{\mathrm{yi}}\right)^{2}}{\left(\sum_{\mathrm{i}=1}^{\mathrm{n}} \lambda_{\mathrm{yi}}\right)^{2}+\left(\sum_{\mathrm{i}=0}^{\mathrm{n}} \operatorname{Var}\left(\varepsilon_{\mathrm{yi}}\right)\right)}
$$

Where,

$\lambda_{\mathrm{yi}} \quad$ is the standardised factor loading, and

$\operatorname{Var}\left(\varepsilon_{\mathrm{yi}}\right) \quad$ is the error variance

Composite reliability for all the measures was over 0.6 (See Table 7.1 below), which was an acceptable level for the purpose of this research. 


\begin{tabular}{|c|c|c|}
\hline Indicator & $\begin{array}{l}\text { Standardized } \\
\text { Loading }\end{array}$ & Error Variance \\
\hline \multicolumn{3}{|c|}{ Strategic Orientation } \\
\hline CUST1 & 0.48 & 0.770 \\
\hline CUST2 & 0.48 & 0.770 \\
\hline CUST3 & 0.83 & 0.311 \\
\hline \multicolumn{3}{|c|}{ COMPOSITE RELIABILITY FOR CUST $=0.634$} \\
\hline TECH1 & 0.74 & 0.452 \\
\hline TECH2 & 0.81 & 0.344 \\
\hline TECH3 & 0.90 & 0.190 \\
\hline TECH4 & 0.72 & 0.482 \\
\hline \multicolumn{3}{|c|}{ COMPOSITE RELIABILITY FOR TECH $=0.873$} \\
\hline COMP1 & 0.80 & 0.360 \\
\hline COMP2 & 0.79 & 0.376 \\
\hline COMP3 & 0.75 & 0.438 \\
\hline COMP4 & 0.69 & 0.524 \\
\hline \multicolumn{3}{|c|}{ COMPOSITE RELIABILITY FOR COMP $=\mathbf{0 . 8 4 4}$} \\
\hline
\end{tabular}




\begin{tabular}{|l|l|l|}
\hline SUSO1 & 0.78 & 0.392 \\
\hline SUSO2 & 0.86 & 0.260 \\
\hline SUSO3 & 0.88 & 0.226 \\
\hline SUSO4 & 0.75 & 0.438 \\
\hline COMPOSITE RELIABILITY FOR SUSO $=\mathbf{0 . 8 9 0}$ \\
\hline IFC1 & 0.74 & 0.452 \\
\hline IFC2 & 0.80 & 0.360 \\
\hline IFC3 & 0.91 & 0.172 \\
\hline IFC4 & 0.88 & 0.226 \\
\hline COMPOSITE RELIABILITY FOR IFC $=\mathbf{0 . 9 0 2}$ \\
\hline Sustainable Product Development Processes \\
\hline DSKI1 & 0.88 & 0.078 \\
\hline DSKI2 & 0.96 & 0.860 \\
\hline ACQTE & \multicolumn{2}{|l|}{} \\
\hline
\end{tabular}




\begin{tabular}{|c|c|c|}
\hline ACQTEC3 & 0.44 & 0.806 \\
\hline \multicolumn{3}{|c|}{ COMPOSITE RELIABILITY FOR DSKI $=0.836$} \\
\hline FDM1 & 0.83 & 0.311 \\
\hline FDM2 & 0.85 & 0.278 \\
\hline FDM3 & 0.83 & 0.311 \\
\hline FDM4 & 0.74 & 0.452 \\
\hline FDM5 & 0.69 & 0.524 \\
\hline \multicolumn{3}{|c|}{ COMPOSITE RELIABILITY FOR FDM $=\mathbf{0 . 8 9 2}$} \\
\hline PKI1 & 0.86 & 0.260 \\
\hline PKI2 & 0.94 & 0.116 \\
\hline PKI3 & 0.86 & 0.260 \\
\hline \multicolumn{3}{|c|}{ COMPOSITE RELIABILITY FOR PKI $=0.918$} \\
\hline \multicolumn{3}{|c|}{ Sustainable Product Attributes } \\
\hline FEC1 & 0.52 & 0.730 \\
\hline FEC2 & 0.77 & 0.407 \\
\hline FEC3 & 0.74 & 0.452 \\
\hline
\end{tabular}




\begin{tabular}{|c|c|c|}
\hline FEC4 & 0.22 & 0.952 \\
\hline \multicolumn{3}{|c|}{ COMPOSITE RELIABILITY FOR FEC $=0.666$} \\
\hline FID1 & 0.80 & 0.360 \\
\hline FID2 & 0.86 & 0.260 \\
\hline FID3 & 0.47 & 0.779 \\
\hline \multicolumn{3}{|c|}{ COMPOSITE RELIABILITY FOR FID $=0.764$} \\
\hline LONG1 & 0.45 & 0.797 \\
\hline LONG2 & 0.71 & 0.496 \\
\hline LONG3 & 0.57 & 0.675 \\
\hline LONG4 & 0.74 & 0.452 \\
\hline LONG5 & 0.79 & 0.376 \\
\hline \multicolumn{3}{|c|}{ COMPOSITE RELIABILITY FOR LONG $=0.792$} \\
\hline \multicolumn{3}{|c|}{ Performance } \\
\hline ECPERF1 & 0.69 & 0.524 \\
\hline ECPERF2 & 0.79 & 0.376 \\
\hline ECPERF3 & 0.95 & 0.098 \\
\hline
\end{tabular}




\begin{tabular}{|c|c|c|}
\hline ECPERF4 & 0.96 & 0.078 \\
\hline ECPERF5 & 0.64 & 0.590 \\
\hline \multicolumn{3}{|c|}{ COMPOSITE RELIABILITY FOR ECPERF $=\mathbf{0 . 9 0 7}$} \\
\hline SOCPERF1 & 0.62 & 0.616 \\
\hline SOCPERF2 & 0.79 & 0.376 \\
\hline SOCPERF3 & 0.88 & 0.226 \\
\hline SOCPERF4 & 0.58 & 0.664 \\
\hline SOCPERF5 & 0.52 & 0.730 \\
\hline \multicolumn{3}{|c|}{ COMPOSITE RELIABILITY FOR SOCPERF $=\mathbf{0 . 8 1 5}$} \\
\hline ENVPERF1 & 0.86 & 0.260 \\
\hline ENVPERF2 & 0.89 & 0.208 \\
\hline ENVPERF3 & 0.91 & 0.172 \\
\hline ENVPERF4 & 0.90 & 0.190 \\
\hline ENVPERF5 & 0.81 & 0.334 \\
\hline ENVPERF6 & 0.86 & 0.260 \\
\hline COMPOSI & ILI & $2 F=0.950$ \\
\hline
\end{tabular}




\begin{tabular}{|l|l|l|}
\hline STRPERF1 & 0.70 & 0.510 \\
\hline STRPERF2 & 0.82 & 0.328 \\
\hline STRPERF3 & 0.88 & 0.226 \\
\hline STRPERF4 & 0.80 & 0.360 \\
\hline STRPERF5 & 0.59 & 0.652 \\
\hline COMPOSITE RELIABILITY FOR STRPERF $=\mathbf{0 . 8 7 4}$ \\
\hline
\end{tabular}

Table 7.1 Composite Reliability

\subsubsection{Validity, a-priori model}

Validity consists of two types: Content and construct validity. This is because the measurement instrument not only is representative of a certain domain but it should also correctly measure and reference that domain to be a successful instrument of data collection (Nunally, 1978).

\subsubsection{Content Validity}

Content or face validity is achieved through ensuring that literature is exhaustively consulted and that the questionnaire formed and administered reflects theory and the previous work achieved in the area. This assists in the match between the conceptual idea of the construct 
to what is being measured by the instrument. The survey instrument can also be vetted by area experts or tests can be run to ensure that potential respondents in the target population understand the relevance and meaning of the questions. In this study, these procedures were rigorously followed. Not only were the measures taken from previously empirically tested research, in many cases tested in multiple contexts; but the survey was reviewed by three area experts and then pilot tested (as detailed in Chapter 5 and 6 ) to ensure that the discrepancy between the questions and the respondents' understanding was minimal to nil.

\subsubsection{Construct Validity}

Construct validity refers to the interpretation of the theoretical concepts to statistical results. Measures should be in agreement with each other systematically and be supported by the theory. For example, those measures that are not related in theory should not show statistical relationships (Ping, 2004). Construct validity, therefore, consists of a further two types of validity, convergent and discriminant validity. Convergent validity shows whether the measures within a theoretical construct are related to each other and are significantly higher than zero. Discriminant validity shows whether concepts that theoretically dissimilar are also statistically proven to have near zero or relatively very low relationships. Both these validities have to be tested, since neither one can establish construct validity by itself.

Convergent validity is measured by a combination of reporting reliability of the measures as well as the percentage of error variance in the measures (Fornell \& Larcker, 1981; Ping, 2004). So, for this study a combination of the reliability scores (from section 7.2.1) and average variance extracted (AVE) is used. The commonly understood guideline is that composite reliability (CR) should be around 0.8 as well as the AVE should be around 0.5 for convergent 
validity to be achieved (Ping, 2004). Below, equation 2 provides the formula used to estimate AVE from the data collected.

$$
A V E=\frac{\sum_{\mathrm{i}=1}^{\mathrm{n}}\left(\square_{\mathrm{yi}}{ }^{2}\right)}{\sum_{\mathrm{i}=1}^{\mathrm{n}}\left(\mathrm{Q}_{\mathrm{yi}}{ }^{2}\right)+\left(\sum_{\mathrm{i}=0}^{\mathrm{n}} \operatorname{Var}\left(\square_{\mathrm{yi}}\right)\right)}
$$

From table 7.2 (and table 7.1 above for $\mathrm{CR}$ ), it can be seen that AVE and CR are reasonably close to the desired limits for convergent validity to exist for the constructs in this study.

\begin{tabular}{|c|c|}
\hline Construct & AVE \\
\hline CUST & 0.441 \\
\hline TECH & 0.667 \\
\hline COMP & 0.576 \\
\hline SUSO & 0.671 \\
\hline IFC & 0.698 \\
\hline DSKI & 0.492 \\
\hline FDM & 0.625 \\
\hline PKI & 0.788 \\
\hline
\end{tabular}




\begin{tabular}{|c|c|}
\hline FEC & 0.365 \\
\hline FID & 0.534 \\
\hline LONG & 0.441 \\
\hline ECPERF & 0.667 \\
\hline SOCPERF & 0.478 \\
\hline ENVPERF & 0.761 \\
\hline STRPERF & 0.585 \\
\hline
\end{tabular}

\section{Table 7.2 Average Variance Extracted}

When dealing with discriminant validity, Fornell and Larcker (1981) suggest that these variances between any two constructs should be less than the variance extracted by each of the individual constructs themselves. In this direction. Yang, Kang and Mason (2008) suggest that the correlations between constructs should be monitored and the AVE of each construct should be greater than the construct correlation between any of the two other constructs. From the matrix below, in table 7.3, it may be observed that DSKI and FEC do not exhibit discriminant validity as clearly as the other constructs. This may be because these are made of or are a part of higher order constructs which will be tested and examined in the following chapter. It may also be noted here that sometimes discriminant validity is not clearly seen for latent variables that may be somewhat correlated (Koufteros et al., 2009). Also, the correlations among the constructs themselves are much below the threshold as suggested by Kline (2005) of 0.85, so discriminant validity may be indeed considered to be achieved in a moderate manner. 


\begin{tabular}{|c|c|c|c|c|c|c|c|c|c|c|c|c|c|c|c|}
\hline & CUST & TECH & COMP & SUSO & IFC & DSKI & PKI & FDM & FEC & FID & LONG & $\begin{array}{l}\text { ENV } \\
\text { PERF }\end{array}$ & $\begin{array}{l}\text { EC } \\
\text { PERF }\end{array}$ & $\begin{array}{l}\text { STR } \\
\text { PERF } \\
\end{array}$ & $\begin{array}{l}\text { SOC } \\
\text { PERF }\end{array}$ \\
\hline CUST & 0.441 & & & & & & & & & & & & & & \\
\hline $\mathrm{TECH}$ & 0.362 & 0.667 & & & & & & & & & & & & & \\
\hline COMP & 0.470 & 0.251 & 0.576 & & & & & & & & & & & & \\
\hline SUSO & 0.274 & 0.199 & 0.120 & 0.671 & & & & & & & & & & & \\
\hline IFC & 0.205 & 0.487 & 0.125 & 0.432 & 0.698 & & & & & & & & & & \\
\hline DSKI & 0.470 & 0.476 & 0.423 & 0.499 & 0.414 & 0.492 & & & & & & & & & \\
\hline PKI & 0.352 & 0.420 & 0.329 & 0.427 & 0.382 & 0.749 & 0.788 & & & & & & & & \\
\hline FDM & 0.343 & 0.478 & 0.367 & 0.397 & 0.458 & 0.615 & 0.604 & 0.625 & & & & & & & \\
\hline FEC & 0.286 & 0.343 & 0.312 & 0.383 & 0.423 & 0.407 & 0.367 & 0.479 & 0.365 & & & & & & \\
\hline FID & 0.199 & 0.087 & 0.349 & 0.261 & 0.234 & 0.250 & 0.237 & 0.341 & 0.649 & 0.534 & & & & & \\
\hline LONG & 0.256 & 0.406 & 0.259 & 0.558 & 0.491 & 0.426 & 0.454 & 0.464 & 0.517 & 0.434 & 0.441 & & & & \\
\hline ENVPERF & 0.245 & 0.067 & 0.219 & 0.603 & 0.174 & 0.472 & 0.368 & 0.326 & 0.239 & 0.298 & 0.342 & 0.761 & & & \\
\hline ECPERF & 0.217 & 0.065 & 0.127 & 0.323 & 0.212 & 0.305 & 0.253 & 0.209 & 0.248 & 0.174 & 0.254 & 0.633 & 0.667 & & \\
\hline STRPERF & 0.306 & 0.462 & 0.285 & 0.388 & 0.501 & 0.537 & 0.560 & 0.597 & 0.384 & 0.276 & 0.527 & 0.436 & 0.353 & 0.585 & \\
\hline SOCPERF & 0.248 & 0.205 & 0.247 & 0.436 & 0.373 & 0.525 & 0.467 & 0.416 & 0.274 & 0.287 & 0.307 & 0.669 & 0.619 & 0.575 & 0.478 \\
\hline
\end{tabular}

Table 7.3 Construct Correlations with AVE on the diagonal

As a result of the above, it may be summarised that the reliability and the validity of the $a$ priori model are achieved with moderate to good success and that the theoretical underpinnings of the conceptual constructs may be interpreted as established.

This chapter provided an insight into the sample characteristics of the data sample obtained. Descriptive analysis with respect to the respondents, the organizations and the products in question was conducted and the reliability and validity of the constructs that form the a-priori model were calculated. The next chapter presents the in-depth data analysis conducted via SEM and the results of the posited a-priori model. 


\section{Chapter 8: Data Analysis}

This chapter is divided into three main sections. These sections deal with data analysis using structural equation modeling (SEM) and the testing of the hypotheses proposed in the third chapter of this document. The first section deals with the measurement models of the constructs or measures used in the study. The second section presents the second order measurement models of these constructs and the third section introduces the a-priori model from the theoretical framework proposed in Chapter 3, section 3.2. The third section also provides results of the hypotheses proposed in Chapter 3, section 3.3.

\subsection{Structural Equation Modeling}

SEM is a multivariate statistical analysis technique that combines factor analysis and multiple regression to determine multiple relationships at once, both in terms of the structure and the strength of the relationships (Kline, 2005; Ullman, 2001). Three distinct advantages SEM offers, over any other analysis technique, relate to the complexity of the phenomenon under observation in this study. It allows multiple relationships to be tested at once, taking into account the effects of one another. The technique also allows the measurement of latent constructs though observed variables. More importantly, SEM takes into account measurement error. This means that the model being analysed provides estimates that take this error into account, or rather,

provide resultant coefficients while controlling for measurement error (Kline, 2005). The resultant analyses provide a holistic picture and allow more scope for theoretically sound 
modification and reassessment (Ping, 2004). This study uses the LISREL software (version 8.72) to conduct SEM, for measurement as well as structural models.

\subsubsection{Confirmatory Factor Analysis (CFA) and Measurement Models}

The first step in conducting SEM is the analysis of measurement models for latent constructs which can done by using CFA (Podsakoff et al., 2003). CFA is used to assess the unidimensionality of the latent constructs as well as confirming construct validity. Once the measurement models of the constructs are validated, a structural model is specified, based on theoretical considerations to define the relationships between the said constructs.

The previous chapter provides an estimate of the construct validity of each of the latent constructs used in this study. In this section, first-order CFA is conducted for each of the fifteen constructs. Four second-order construct CFA are then conducted for the constructs of strategic orientation, product attributes S-PD processes and performance, in order to assess whether these constructs are appropriate since they are theoretically mandated in this research. According to Kline (2005) uni-dimensionality in standard CFA models depends on observed variables being simple indicators which depend on single factors with errors that are not correlated. Unidimensionality is a prerequisite for validity and reliability, thus in many cases a researcher might be tempted to assume that just because reliability and validity of constructs are high, there is unidimensionality. However, only examination of the indicators of the constructs themselves can ensure lack of multi-dimensionality as constructs with muti-dimensional indicators have also yielded high validity and reliability (Kline, 2005; Raykov, 1997). In this study, before the calculations for the base constructs were conducted in Chapter 7, items were scanned to ensure 
simple indicators and checked for correlations in error terms. Many of the following CFA below confirm that the indicators are simple (that is, depending on a single factor) and that error terms within a construct are not highly correlated. The minimum number of indicators that are recommended by Kline (2005) are three. In some cases, the resultant CFA contains three indicators and shows model saturation. For this study, where contextual scale development or scale modification is an inherent aim, increase in composite reliability is considered a benchmark of what CFA is retained as a desirable measurement model. According to Raykov et al., (2013) model saturation in some cases is not as meaningless as some researchers denounce it to be, though a saturated model may not always a perfect fit for the data as others assume it to be. Theoretical considerations are paramount in these cases, so indicators are only discarded if the statistical practice can be theoretically backed from the available literature. According to Tabachnick and Fidell (2007) the cut off indices are 0.45 for a fair fit and 0.55 for a good fit. Hence, this study uses 0.5 as the cut off for discarding items, only if theoretically appropriate. The measurement model fit statistics are reported where meaningfully available. $\mathrm{Hu}$ and Bentler's (1999) comparative analysis is taken as a guide for fit indices in general. As a general rule, Chi-square/df $<3$ is considered a reasonably good fit and $<5$ may be sometimes permissible fit depending on the scale. RMSEA of $<0.05$ is considered very good, and around $<0.1$ moderate with greater values mostly bad fit. NNFI and CFI are reported and a excellent to good fit is $>0.90$. Where non-centrality may raise discrepancies between relative and absolute goodness-of-fit measures, Bollen's IFI is also reported to offset potential RMSEA bias issues (which can arise in the cases where non-centraility parameter sample estimates are the source of disagreement of the statistical parameters (Hu \& Bentler, 1999; Raykov, 2005). Maximum 
likelihood estimation is used in the CFA analysis method employed for the measurement models below.

\section{Technology Orientation}

Technology Orientation (TECH), a uni-dimensional construct, uses four indicators for measurement, TECH1 to TECH4. The measurement model run showed a good fit with acceptable standardised factor loadings (see figure 8.1 below). Modification was not mandated because all items loaded satisfactorily well. Model fit indices confirmed the measurement model fit as satisfactory to the data (Chi-square/df $=2.41 / 2, \mathrm{RMSEA}=0.034, \mathrm{NNFI}=1.00, \mathrm{CFI}=$ $1.00)$.

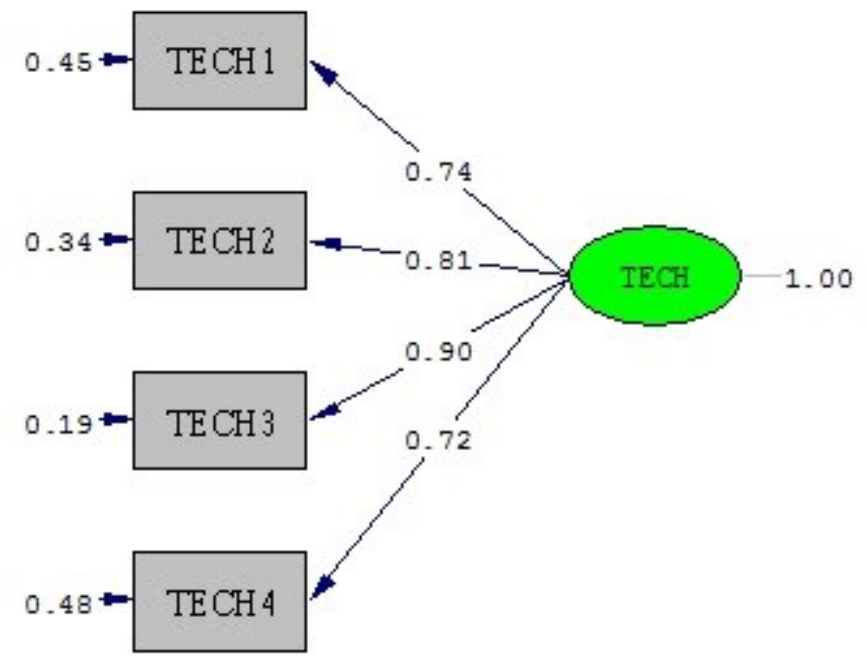

Figure 8.1 Measurement model of Technology Orientation (TECH)

\section{Competitor Orientation}

The construct of competitor orientation (COMP) was conceptualized as uni-dimensional and measured using four indicators: COMP1 to COMP4. The measurement model showed 
satisfactory standardised loadings (see figure 8.2 below). Goodness of fit to data showed RMSEA at a moderate fit at 0.11 and Chi-square $/ \mathrm{df}=7.14 / 2$, but relative fit indices showed a good fit, with NNFI $=0.96$ and CFI $=0.99$. IFI was noted to be 0.99 . The measurement model was retained as-is.

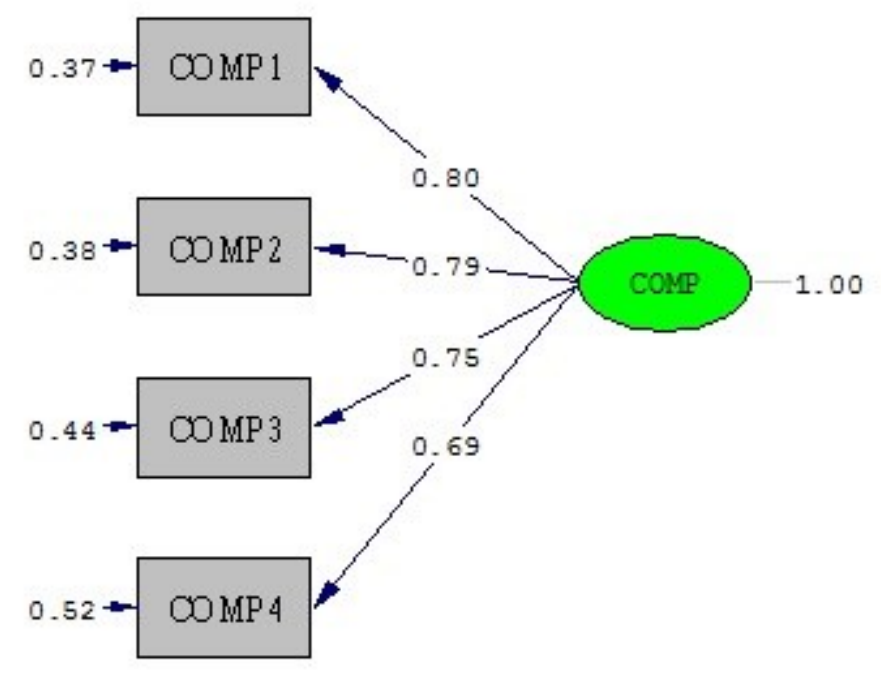

Figure 8.2 Measurement model of Competitor Orientation (COMP)

\section{Sustainability Orientation}

Sustainability orientation (SUSO), conceptualised as uni-dimensional, is a construct measured by four indicators, SUSO1 to SUSO4. The measurement model showed acceptable standardised loadings (see figure 8.3 below). Relative fit indices showed good results (NNFI $=$ $0.90, \mathrm{CFI}=0.97$ and $\mathrm{IFI}=0.97)$. The measurement model was retained as-is. 


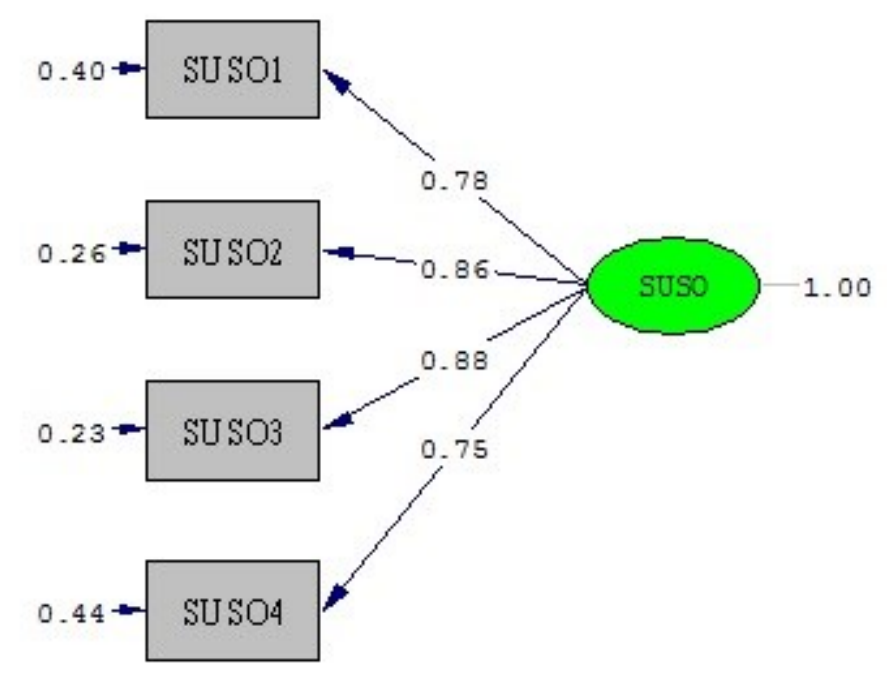

Figure 8.3 Measurement model of Sustainability Orientation (SUSO)

\section{Interfunctional Coordination (Orientation)}

The construct of Interfunctional coordination (IFC), envisaged as uni-dimensional, is measured using four indicators, IFC1 to IFC4. The standardised loadings were good (in figure 8.4 below). Model fit was also provided and acceptable fit to data (Chi-square/df $=4.77 / 2$, $\mathrm{RMSEA}=0.085, \mathrm{NNFI}=0.99, \mathrm{CFI}=1.00)$. Thus the measurement model was retained as-is.

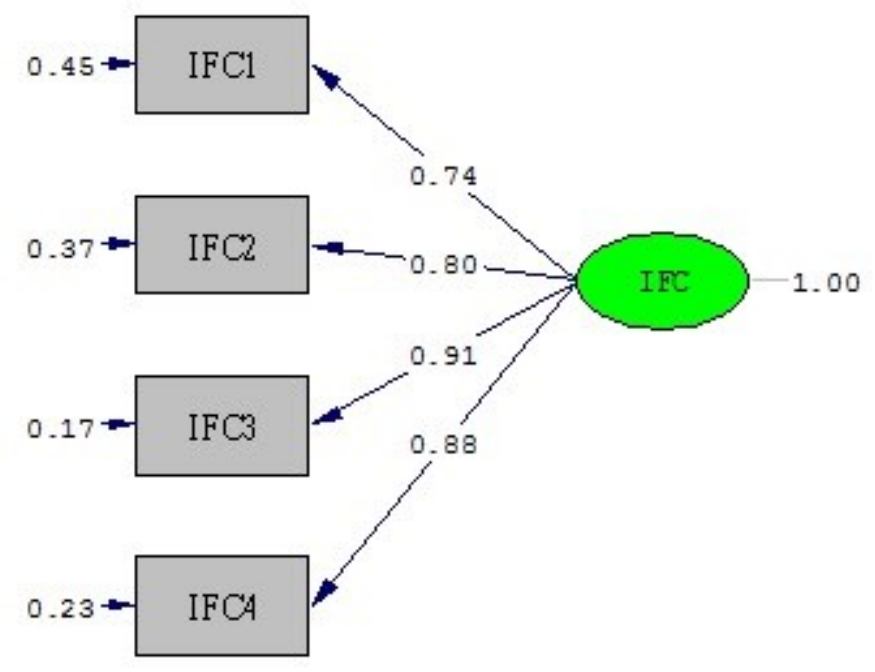




\section{Figure 8.4 Measurement model of Interfunctional Coordination (IFC)}

\section{Customer Orientation}

Customer Orientation (CUST) as a construct is measured by three indicators (CUST1, CUST2, CUST3) with moderate standardised loadings. Since the number of indicators here are three, the measurement model is saturated and the goodness of fit statistics are not available. Figure 8.5 provides the measurement model retained for CUST.

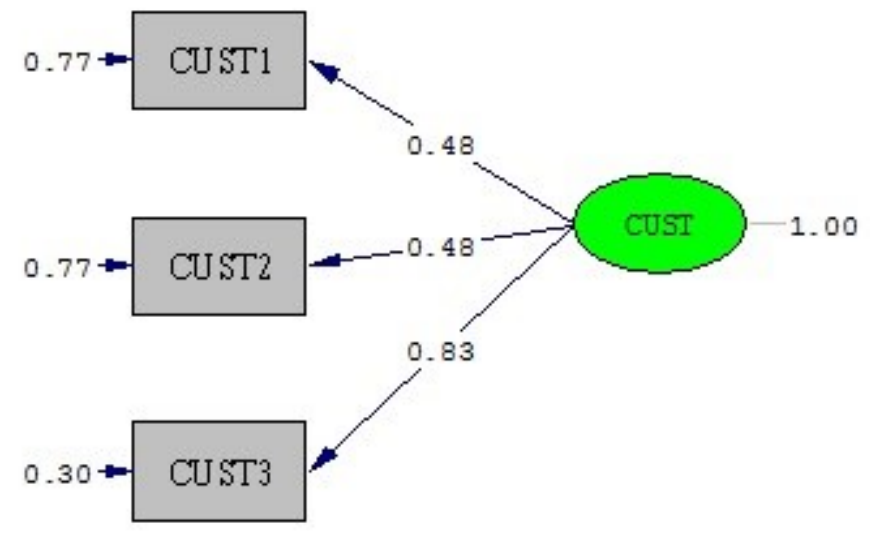

Figure 8.5 Measurement model of Customer Orientation (CUST)

\section{Domain Specific Knowledge Integration}

The construct of Domain-specific knowledge integration (DSKI) was originally conceptualised as containing six simple indicators, three for knowledge integration and three for knowledge acquisition. In this study, the acquisition indicators did not theoretically have significance, because our measurement was not concerned with how the knowledge is acquired from external factors. However, since the scale was transferred to the framework for this study, the decision was made to cautiously retain the scale and consider its performance when the 
measurement model was run. The six indicators used were DSKI1 to DSKI3 and ACQTEC1 to 3. The factor loadings on all ACQTEC1, ACQTEC2 and ACQTEC3 indicators were extremely low $(0.43,0.37$ and 0.44 respectively). Since these three indicators did not fit into the theoretical considerations of the study, the decision was made to exclude them and rerun the measurement model. The model reached saturation in terms of fit. The modified measurement model is provided below infigure 8.6:

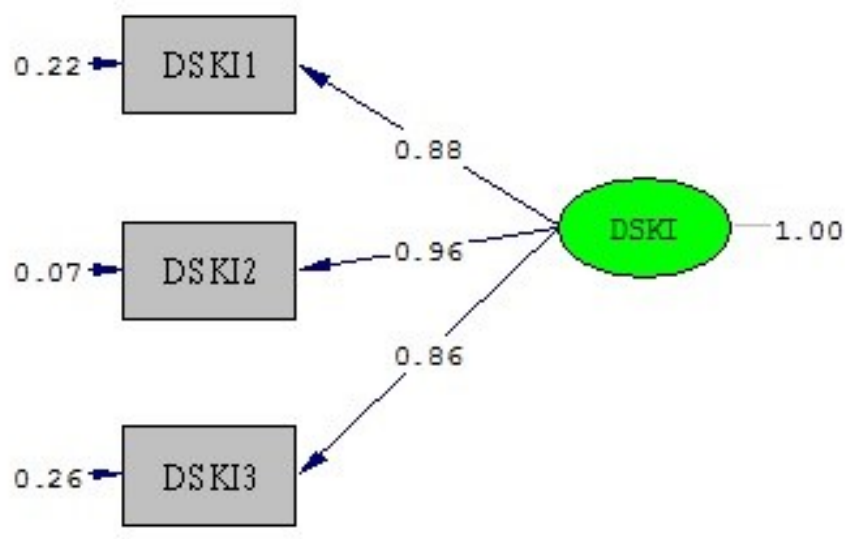

Figure 8.6 Measurement model of Domain Specific Knowledge Integration (DSKI)

\section{Procedural Knowledge Integration}

The construct of Procedural knowledge integration (PKI) was measured by three indicators with very good standardised loadings $(\mathrm{PKI} 1=0.86, \mathrm{PKI} 2=0.94$ and $\mathrm{PKI} 3=0.86)$ as can be seen from figure 8.7 below. Since the measurement model consists of three indicators, it is saturated so fit statistics are not available. The measurement model is acceptably retained as-is. 


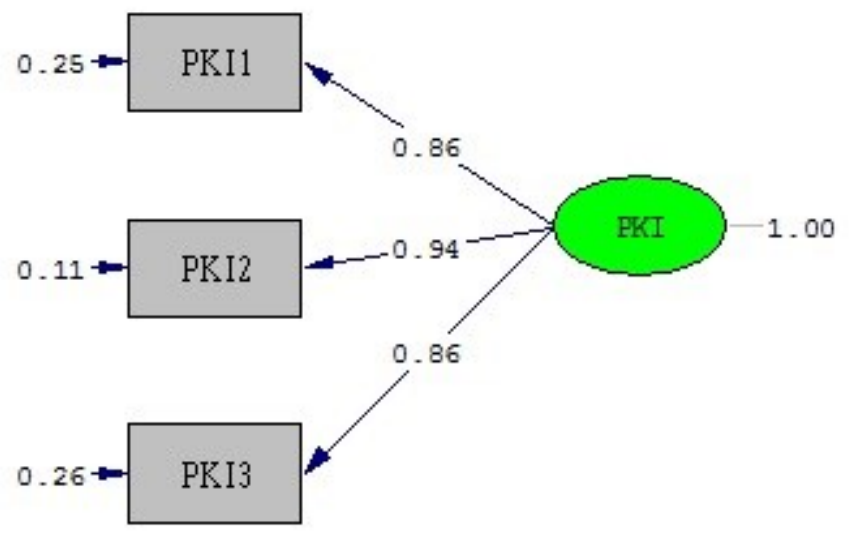

Figure 8.7 Measurement model of Procedural Knowledge Integration (PKI)

\section{Flexible Decision Making}

The construct of Flexible decision making (FDM) was conceptualised as measured by five indicators, FDM1 to FDM5. The standardised loadings of these indicators were mostly very good, except for FDM5, loading at a moderately good 0.69. The fit indices show an acceptable fit $($ Chi-square/df $=19.33 / 5$ and RMSEA $=0.12)$. Relative fit indices are $:$ NFI $=0.97, \mathrm{NNFI}=0.95$ and $\mathrm{CFI}=0.98$. The measurement model was retained as-is and is displayed below in figure 8.8. 


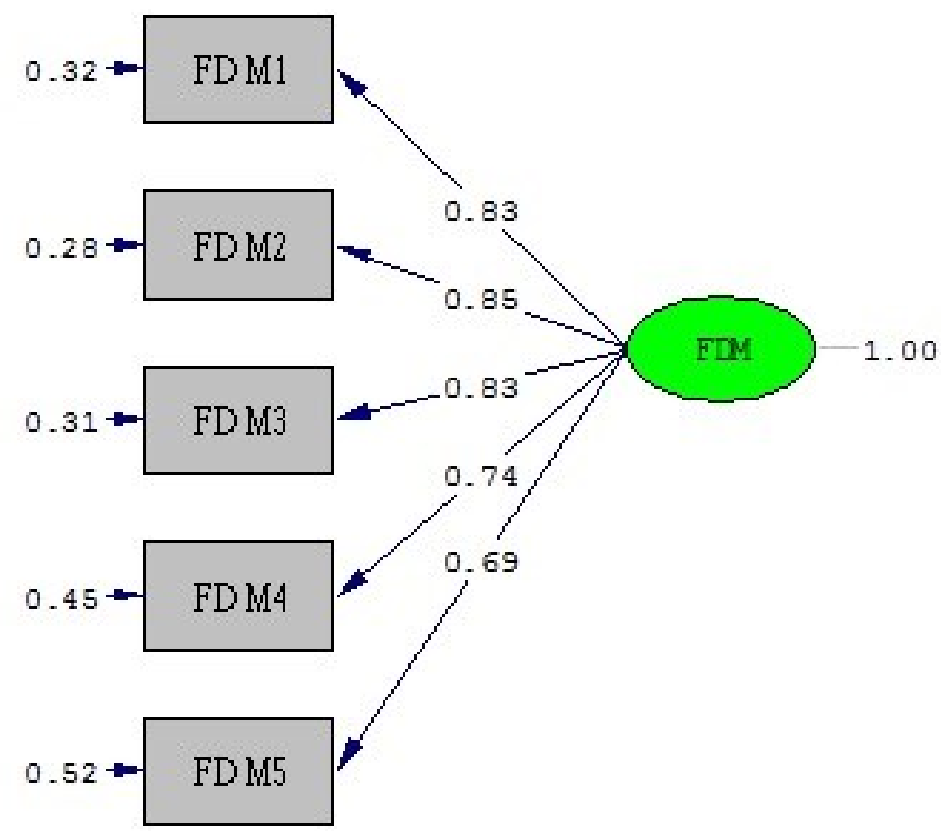

Figure 8.8 Measurement model of Flexible Decision Making (FDM)

\section{Product Fecundity}

The construct of product fecundity (FEC) was conceptualised as having four indicators, FEC1 to FEC4. The standardised loadings showed FEC4 with a poor loading of 0.22 and poor fit to data (Chi-square/df $=34.40 / 2, \mathrm{RMSEA}=0.27)$. Theoretically, FEC4 refers to the product being new and original as compared to other products on the market. Again, this item is a part of the original scale and not a consideration for this research. The aim of the study is to discover product fecundity as related to the sustainable aspect of the product which may not necessarily be novel. This shift is expected because the scale is derived from new product development literature, where the novel nature of the product is a consideration, which is not the case for the product being sustainable. FEC4 is excluded and the modified measurement model yields a saturated model, as can be seen in figure 8.9 below: 


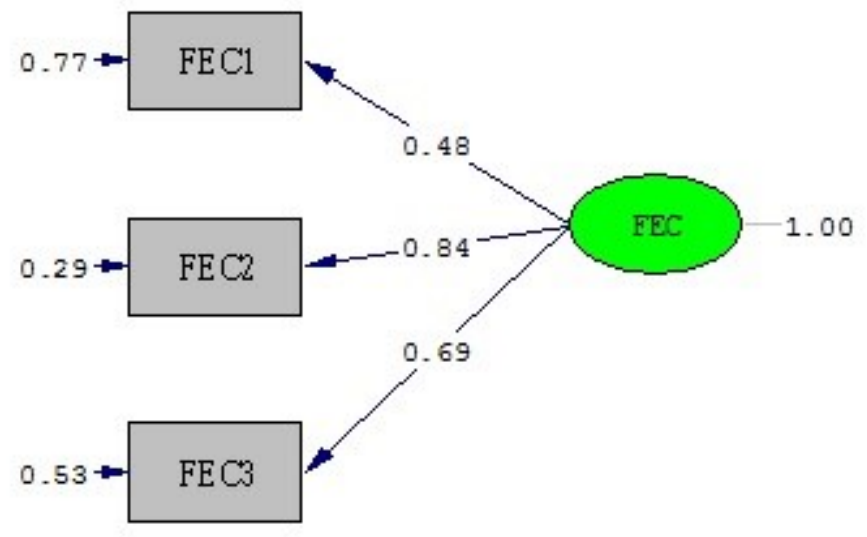

Figure 8.9 Measurement model of Product Fecundity (FEC)

\section{Product Fidelity}

The construct of product fidelity (FID) is measured with three indicators, FID1, FID2 and FID3 with acceptable standardised loadings (in figure 8.10). The measurement model shows saturation and the model retained is displayed in the figure (8.10) below:

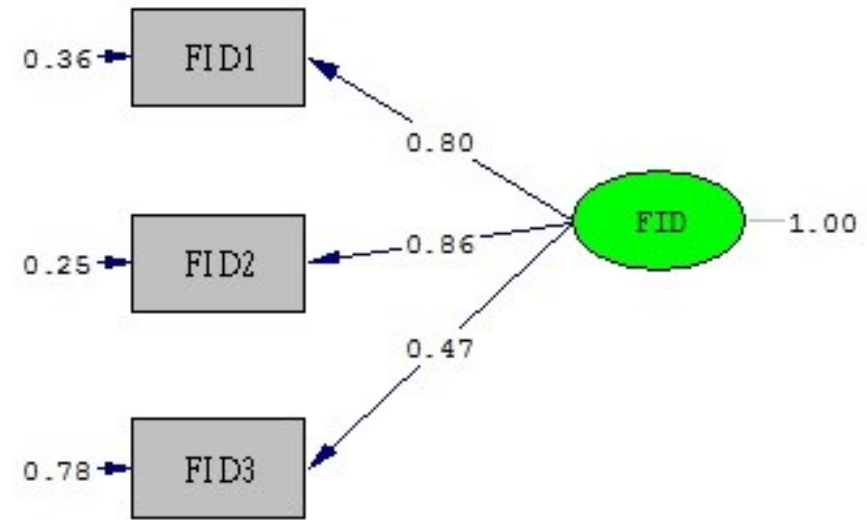

Figure 8.10 Measurement model of Product Fidelity (FID) 


\section{Product Longevity}

The construct product longevity (LONG) was conceptualised as having five indicators, LONG1 to LONG5 with acceptable standardised loadings other than LONG1 which loaded at 0.45. The model fit statistics were fair (chi-square/df $=9.67 / 5, \mathrm{RMSEA}=0.068$ ). The item related to the indicator was that of product compatibility. The item determined whether the product was compatible with or supported a range of other products. At this stage, the literature indicates that sustainable products have potentially less or unspecified market penetration; let alone be at a stage mature enough to have wide ranging compatibility. (For example, Boons et al. (2013, pg. 2) find that the business community is mostly still at the stage where the "idea of transforming challenges into business opportunities" is being increasingly considered.) The data appears to support this, so LONG1 is excluded and the modified measurement model is provided in figure 8.11 below. The model goodness of fit statistics also are favourable (Chi-square/df $=$ $3.00 / 2, \mathrm{RMSEA}=0.046, \mathrm{NNFI}=0.99, \mathrm{CFI}=1.00)$. The modified measurement model is retained due to better model fit, and most importantly, because the theoretical implications are more relevant to this study (see figure 8.11 below). 


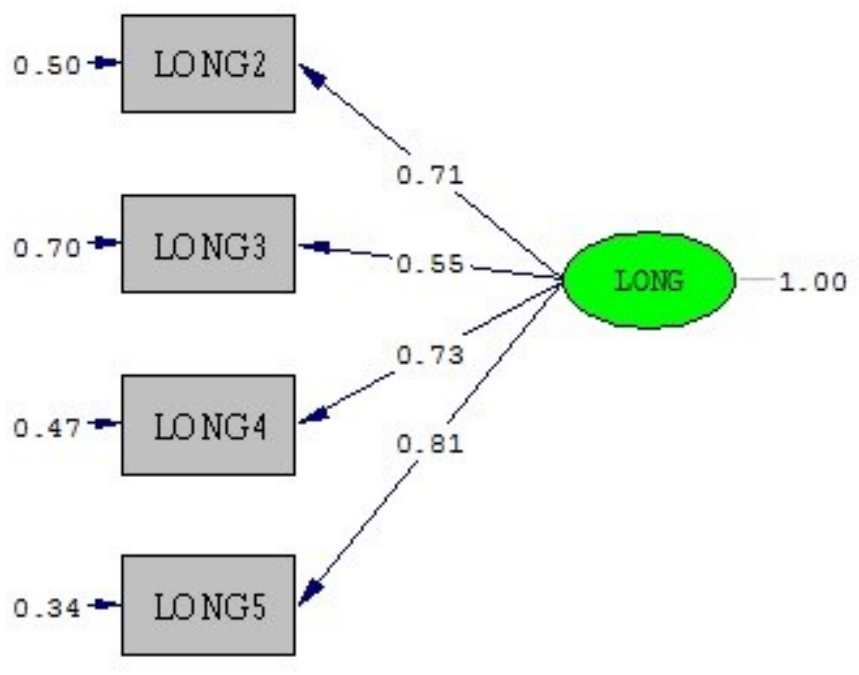

Figure 8.11 Measurement model of Product Longevity (LONG)

\section{Economic Performance}

Economic performance (ECPERF) as a construct was conceptualised as having five indicators, ECPERF1 to ECPERF5. The items loaded well, as can be seen from figure 8.12. The measurement model fit indices were good (Chi-square/df $=14.59 / 5, \mathrm{RMSEA}=0.094, \mathrm{NFI}=$ 0.98, NNFI $=0.98$ and CFI $=0.99$ ). The measurement model (see figure 8.12 below) was therefore retained as-is. 


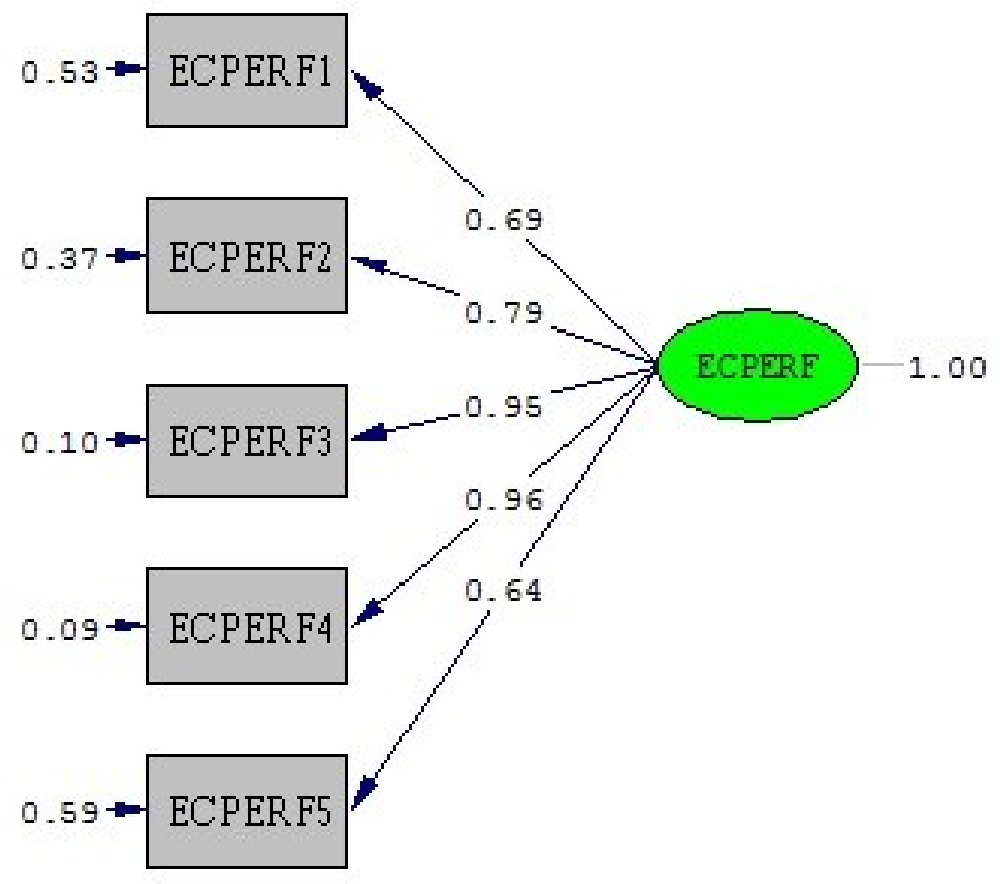

Figure 8.12 Measurement model of Economic Performance (ECPERF)

\section{Social Performance}

Social performance (SOCPERF) is envisaged as a uni-dimensional construct with five indicators SOCPERF1 to SOCPERF5. The measurement model showed acceptable model fit to data $($ Chi-square $/ \mathrm{df}=21.38 / 5, \mathrm{RMSEA}=0.13)$. The relative fit indices were $\mathrm{NFI}=0.95, \mathrm{NNFI}=$ 0.93 and $\mathrm{CFI}=0.96$ so the model was retained as-is. 


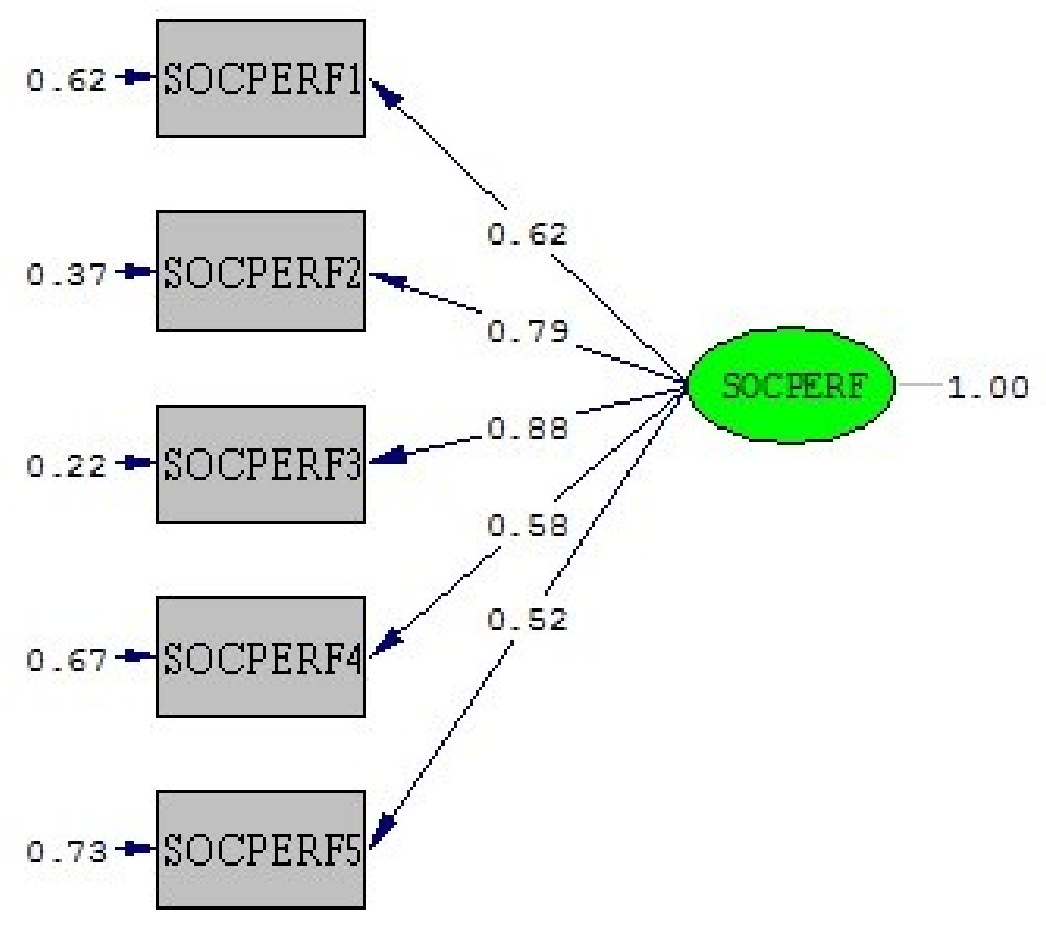

Figure 8.13 Measurement model of Social Performance (SOCPERF)

\section{Environmental Performance}

The construct of environmental performance (ENVPERF) comprises of six indicators, ENVPERF1 to ENVPERF6 withexcellent standardised loadings. The measurement model,in figure 8.14 below, shows an acceptable fit to the data (Chi-square/df $=104.54 / 9, \mathrm{RMSEA}=0.23$, $\mathrm{NFI}=0.94, \mathrm{NNFI}=0.91, \mathrm{CFI}=0.95)$ and thus was retained for the next stage of the analysis asis: 


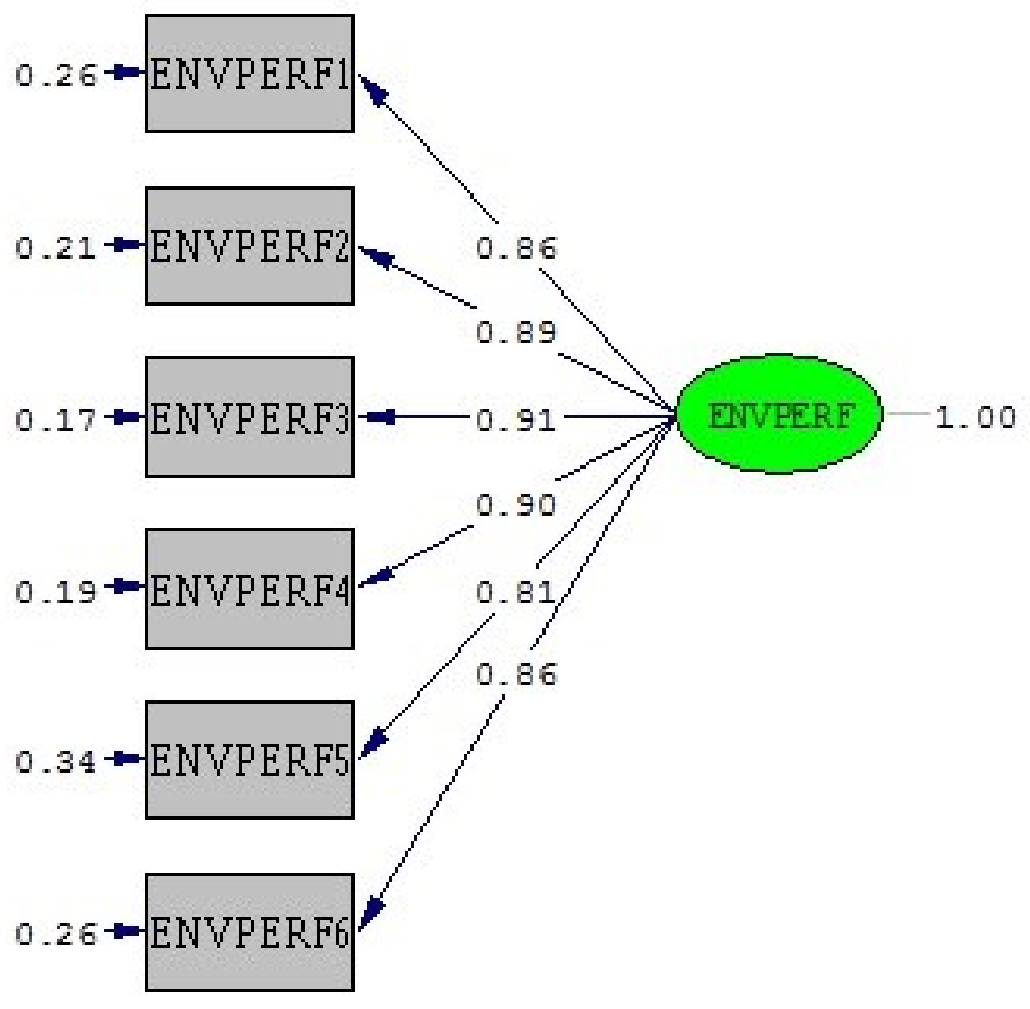

Figure 8.14 Measurement model of Environmental Performance (ENVPERF)

\section{Strategic Performance}

Strategic performance (STRPERF) as a construct comprises of five indicators, from STRPERF1 to STRPERF5 with an acceptable fit to data(Chi-square/df $=53.06 / 5$, RMSEA $=$ $0.22, \mathrm{NFI}=0.93, \mathrm{NNFI}=0.86$ and $\mathrm{CFI}=0.93$ ). The measurement model, as seen in the figure 8.15 below, was retained for the analysis as-is: 


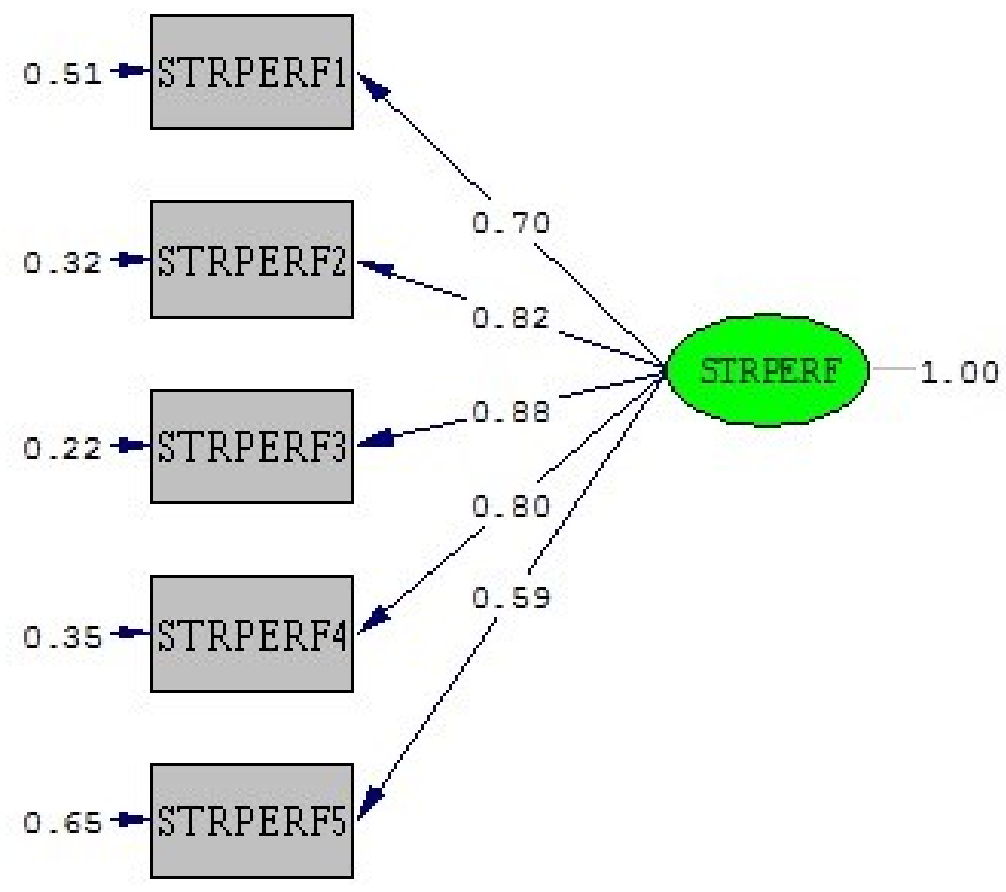

Figure 8.15 Measurement model of Strategic Performance (STRPERF)

Appendix 16 provides a table of the items that were excluded after CFA and the loadings of these items as well as the theoretical basis of these exclusions.

\subsubsection{Fitting constructs with theory: Second Order Modeling}

Higher order constructs or hierarchical CFA models are more abstract and so are relatively less popular in research. A second order construct, for example, is where the indicators of the second order latent construct are themselves latent constructs, that in turn have observed variables as their indicators. According to Kline (2005) there are a number of reasons why second order constructs may be considered preferable for a particular study. The primary reason, 
of course, is theory-driven; that is, rarely does a complex phenomenon consist of unrelated underlying causes. Using multiple related first order latent constructs together for a complex phenomenon may cause concerns with discriminant validity and may even inappropriately and incompletelycapture information leading to inaccurate inferences. Second order constructs help with: A) a more accurate reflection of theory B) discriminant validity issues for constructs that are conceptually related C) accurate capture of information and significance of the effects of the theoretical phenomenon in all its complexity, D) preserve the characteristics of the first order latent constructs and E) increase parsimony in complex models (Kline, 2005; Koufteros et al., 2009). It may be noted that though a second order construct provides a better explanation for abstraction while keeping its component constructs intact, it might not necessarily provide a 'better' fit for data. The model is simply an alternate solution for holistic understanding and better conceptual fit (Raykov et al., 2013; Tanaka, 1993). The minimum number of first order latent constructs for one second order latent construct recommended by Kline (2005) are three, with preferably three indicators per first order construct.

Based on the directions provided by Byrne (1998), Kline (2005) and Koufteros et al. (2009) the goodness of fit statistics are used in tandem with the Target (T) coefficient to determine the best alternative of five model variations. The $\mathrm{T}$ coefficient is computed as the ratio of the chi-square of the base (first order) model to the chi-square of the higher order (in this case, second order) model.

\section{I.e. $\mathrm{T}=\chi^{2}\left(1^{\text {st }}\right.$ Order Model $) / \chi^{2}\left(2^{\text {nd }}\right.$ Order Model $)$}

The $\mathrm{T}$ coefficient provides the percentage of the variation in the first order constructs that can be explained by the underlying higher order construct. In this research, theory dictates (see Table 3, Chapter 3) four second order constructs, namely strategic orientation, sustainable 
product development processes, product attributes and performance. For these four constructs, the analysis that follows below will include a tabulated evaluation of the fit of five model variations, which will be the point of comparison of which model to retain. The model variations that were not retained for all four constructs can be referred to in Appendix (12.0)

\section{Strategic Orientation}

The second order reflective construct of Strategic orientation (MKTO) in the context of sustainable products (i.e. for this research) was conceptualised to consist of five first order reflective constructs, customer orientation (CUST), technology orientation (TECH), competitor orientation (COMP), sustainability orientation (SUSO) and interfunctional coordination (IFC). Of these constructs, it may be noted that theoretically, there are expected correlations between the orientations since market research in an organization is a complex result of collecting information on general industry standards (such as those related to sustainability), customers, new technology as well as the competition. As a result of how proactive an organization is with respect to the above, the attitude toward coordination between different functional areas (or departments) would also be established. This would mean that a higher order latent construct should make sense both in theory as well as statistically. Five variations of the model were assessed in comparison to each other. Table 8.1 provides an aggregated statistical overview of these models:

\begin{tabular}{|l|r|r|r|r|r|}
\hline $\begin{array}{l}\text { Goodness of fit Statistics for } \\
\text { alternative models } \\
\text { (acceptable values) }\end{array}$ & Model A & Model B & Model C & Model D & Model E \\
\hline Chi square & 1530.23 & 423.37 & 201.82 & 277.74 & 165.38 \\
\hline Chi-square/df $(<3)$ & 11.34 & 3.14 & 1.61 & 2.14 & 1.37 \\
\hline
\end{tabular}

\footnotetext{
${ }^{3}$ Modification Indices applied: COMP1 to CUST; CUST3 to TECH; CUST2 \& CUST3 to COMP; CUST1 to SUSO; CUST1, CUST2, CUST3 \& SUSO2 to IFC. For details please see Appendix 17.
} 


\begin{tabular}{|l|r|r|r|r|r|}
\hline NFI $(>0.9)$ & 0.67 & 0.88 & 0.94 & 0.92 & 0.95 \\
\hline NNFI $(>0.9)$ & 0.65 & 0.91 & 0.97 & 0.95 & 0.98 \\
\hline CFI $(>0.9)$ & 0.69 & 0.92 & 0.97 & 0.96 & 0.98 \\
\hline RMSEA (<0.08) & 0.23 & 0.103 & 0.055 & 0.075 & 0.043 \\
\hline $\begin{array}{l}\text { Standardized RMR (close } \\
\text { to 0.08) }\end{array}$ & 0.17 & 0.21 & 0.07 & 0.097 & 0.058 \\
\hline
\end{tabular}

\section{Table 8.1 Statistics for Alternate Models for Strategic Orientation}

The first model, Model A was run with the constituent 19 observed variables as indicators of the latent variable Strategic orientation. The model showed very poor fit to the data since the indicators were all conceptually different (multidimensional), rendering the model methodologically inappropriate.

The second model, Model B was run with the constituent five first order constructs (customer orientation, technology orientation, competitor orientation, sustainability orientation and interfunctional coordination), which were constrained to be uncorrelated. Since the first order constructs are from a theoretically linked perspective, the model fit the data poorly.

Model $\mathrm{C}$, the third model was run with the five first order constructs free to correlate. While the fit indices were quite acceptable and the chi-square/df was 1.61 , the model had validity issues. The correlation between what are supposed to be separate constructs shows definite discriminant validity (in other words, the different first order constructs show partial crossloadings) and potential multicollinearityissues.

To address the issues of validity and multicollinearity, Model D was conceptualised as a second order construct, Strategic orientation, of the five first order constructs, customer orientation, technology orientation, competitor orientation, sustainability orientation and interfunctional coordination. The model showed an acceptable fit to the data, though chi- 
square/df was slightly higher than Model C. The modifications suggested by the software output were taken into account and Model E was the final variation. This model proved a very good fit to data with the following goodness of fit statistics: Chi-square $=165.38$, chi-square $/ \mathrm{df}=1.37$, $\mathrm{RMSEA}=0.043, \mathrm{NFI}=0.95, \mathrm{NNFI}=0.98, \mathrm{CFI}=0.98, \mathrm{SRMR}=0.058$.

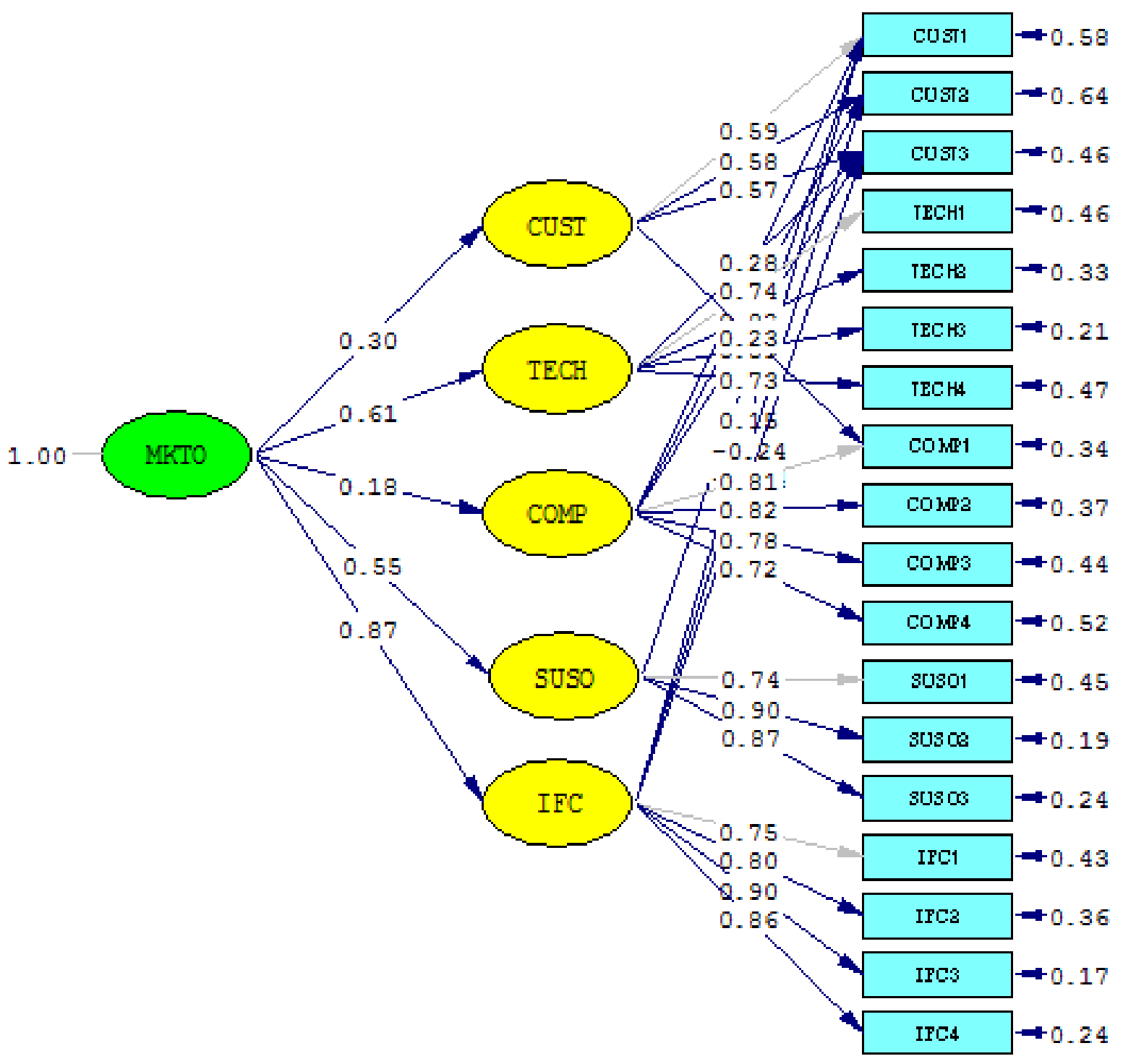

Figure 8.16 Measurement model of Strategic Orientation (MKTO) 
The $\mathrm{T}$ coefficient was calculated as $\chi_{\text {Model } \mathrm{C}}^{2} \chi^{2}$ Model $\mathrm{D}=0.73$, which means that $73 \%$ of the variance in the first order constructs was explained by the second order construct. The model was retained as the preferred option for use in the a-priori model (tested in the next section).

\section{Sustainable Product Development Processes}

The higher order reflective construct of sustainable product development processes (SPDP) consists of three component latent reflective constructs, of domain-specific knowledge integration (DSKI), procedural knowledge integration (PKI) and flexible decision making (FDM). Conceptually, these product development processes are inter-related because the speed and dynamic nature of decision-making affects to what extent both kinds of knowledge is integrated. Also, some degree of correlation can be expected between the first order constructs because practically speaking, what knowledge is domain-specific and what is simply procedure can vary in various individual and organizational perspectives. The fit statistics of the variations of the construct are provided in table 8.2 below and the model variation figures are provided in Appendix (12.0).

\begin{tabular}{|c|l|l|l|l|l|}
\hline $\begin{array}{l}\text { Goodness of fit Statistics } \\
\text { for alternative models } \\
\text { (acceptable values) }\end{array}$ & Model A & Model B & Model C & Model D & Model E \\
\hline Chi square & 706.65 & 328.37 & 106.88 & 167.34 & 44.08 \\
\hline Chi-square/df $(<3)$ & 16.06 & 7.46 & 2.61 & 4.08 & 1.30 \\
\hline NFI $(>0.9)$ & 0.84 & 0.90 & 0.97 & 0.87 & 0.97 \\
& & & & & \\
\hline
\end{tabular}

\footnotetext{
${ }^{4}$ Modification indices applied: FDM1 to PKI; FDM1 to DSKI; error covariance between: DSKI2 \& FDM1, DSKI3 \& FDM1; PKI1 \& FDM1; PKI2 \& FDM2; PKI1 \& FDM3. For details please see Appendix 17.
} 


\begin{tabular}{|l|l|l|l|l|l|} 
NNFI (>0.9) & 0.82 & 0.89 & 0.97 & 0.86 & 0.99 \\
\hline CFI (>0.9) & 0.85 & 0.91 & 0.98 & 0.90 & 0.99 \\
\hline RMSEA (<0.08) & 0.27 & 0.18 & 0.09 & 0.12 & 0.04 \\
\hline $\begin{array}{c}\text { Standardized RMR } \\
\text { (close to 0.08) }\end{array}$ & 0.11 & 0.39 & 0.04 & 0.13 & 0.04 \\
\hline
\end{tabular}

Table 8.2 Statistics for Alternate Models for Sustainable Product Development Processes

Here, Model A was again specified as a single latent variable SPDP with 11 indicator variables. The model was, as expected, a poor fit to data with chi-square/df $=16.06>>3$. This is becausethe variables specified as indicators to the single construct emerge from different domains and hence the condition of uni-dimensionality is violated.

Model B is constructed and run with the three constituent latent constructs as uncorrelated. Here, the model was also a poor fit to data (chi-square/df $=7.46>3$ ), which is expected considering (as previously discussed) that the three constructs are theoretically well related with each other.

The third model, Model $\mathrm{C}$ allows the three latent constructs to correlate. The model is a better yet only moderate fit to data. However, here issues with discriminant validity and multicollinearity (as discussed above) are encountered since the separate constructs are not supposed to be related.

Model D was constructed to be a reflective second order construct with all three latent (reflective) first order constructs. Here the fit to data is the same as model $\mathrm{C}$ but the 
abovementioned issues are statistically resolved and theoretically the model is a better reflection of the concept of SPDP.

Model $\mathrm{E}$ was run with the addition of the suggested modifications, which further show that the three constructs are highly related, as is expected theoretically. The model shows very good fit to data and provides a theoretically sound underpinning for the research to data fit. The indices are as follows: chi-square $/ \mathrm{df}=1.3, \mathrm{RMSEA}=0.038, \mathrm{NFI}=0.97, \mathrm{NNFI}=0.99, \mathrm{CFI}=$ 0.99 and standardized $\mathrm{RMR}=0.042$, in figure 8.17 below.

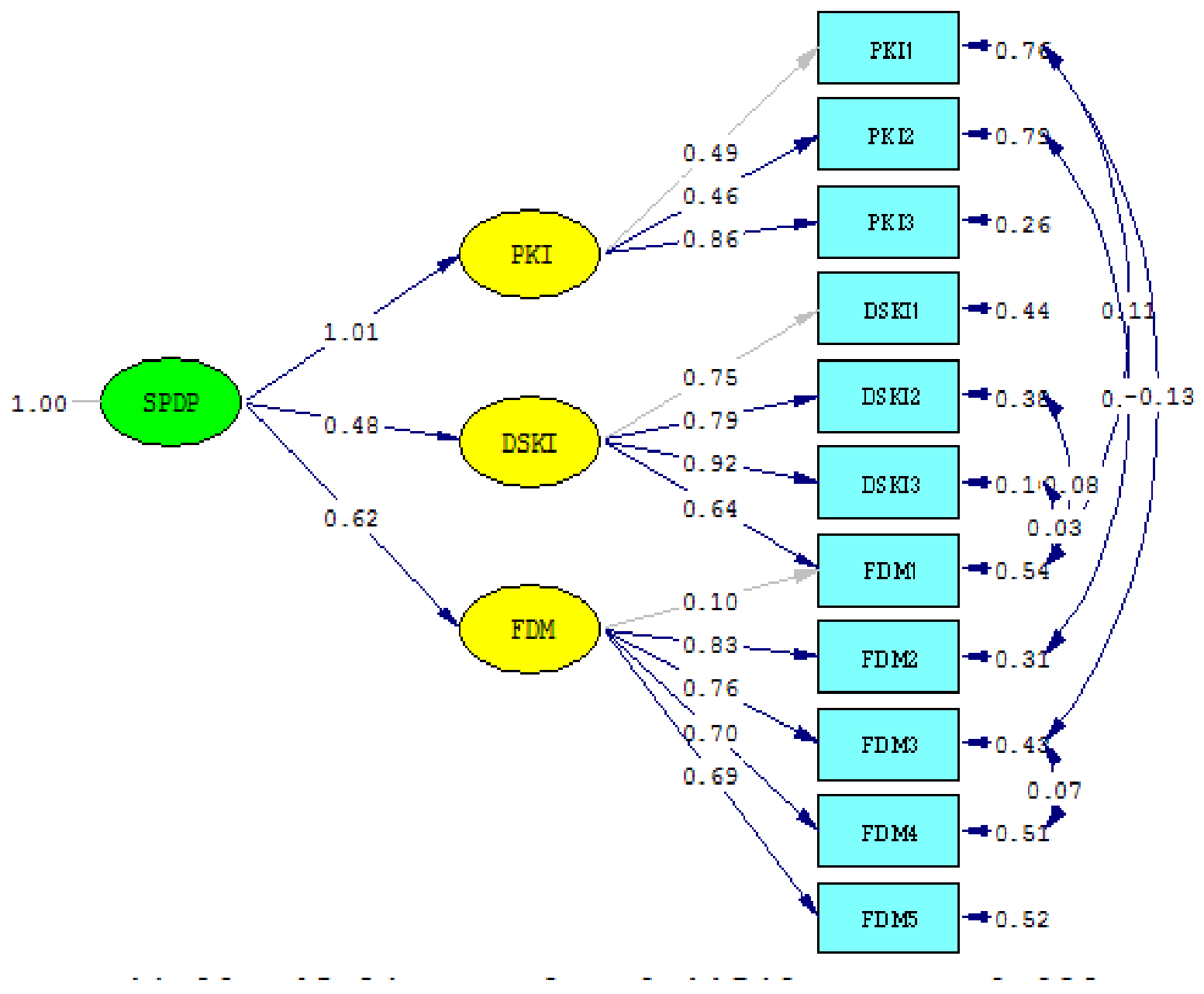

Figure 8.17 Measurement model of Sustainable Product Development Processes (SPDP) 
The $\mathrm{T}$ coefficient for SPDP was calculated as $\chi_{\text {Model } \mathrm{C}}^{2} \chi^{2}$ Model $\mathrm{D}=0.6387$ which means that $63.87 \%$ the variation among the first order latent constructs was explained by the second order latent construct, which is an acceptable value. Model E was retained for further analysis in the full structural model.

\section{Product Attributes}

Product attributes (ATTR) was conceptualized as a reflective second order construct comprising of three first order latent constructs, product fecundity (FEC), product fidelity (FID) and product longevity (LONG). From the literature, it is known that these constructs are interrelated since they form various dimensions of the desirable, or envisaged, product attributes. For example, the manner in which a product functions or how widely compatible it is very much related to the overall lifecycle of the product. So a multidimensional second order construct was considered to be required to fully capture and relate data to theory. The goodness-of-fit statistics for model variations to assess the best possible model type are tabulated in 8.3 below.

\begin{tabular}{|l|r|r|r|r|r|}
\hline & & & & & \\
$\begin{array}{l}\text { Goodness of fit Statistics } \\
\text { for alternative models } \\
\text { (acceptable values) }\end{array}$ & Model A & Model B & Model C & Model D & Model E \\
\hline Chi square & 435.3 & 235.31 & 98.29 & 98.29 & 28.66 \\
\hline Chi-square/df $(<3)$ & 12.4371429 & 6.723143 & 3.071563 & 3.071563 & 1.19416667 \\
\hline NFI $(>0.9)$ & 0.71 & 0.8 & 0.91 & 0.91 & 0.98 \\
\hline NNFI $(>0.9)$ & 0.66 & 0.77 & 0.91 & 0.91 & 0.99 \\
\hline CFI $(>0.9)$ & 0.73 & 0.82 & 0.94 & 0.94 & 0.99 \\
\hline RMSEA $(<0.08)$ & 0.24 & 0.17 & 0.1 & 0.1 & 0.031 \\
\hline
\end{tabular}

\footnotetext{
${ }^{5}$ Modification indices applied: LONG2 \& LONG5 to FEC; LONG5 to FID; FID1 \& FEC1 to LONG; error covariance between: FID1 \& LONG2; LONG2 \& LONG4; FEC2 \& LONG3. For details please see Appendix 17.
} 


\begin{tabular}{|l|l|l|l|l|l|}
$\begin{array}{c}\text { Standardized RMR } \\
\text { (close to 0.08) }\end{array}$ & 0.17 & 0.25 & 0.073 & 0.073 & 0.038 \\
\hline
\end{tabular}

\section{Table 8.3 Statistics for Alternate Models for Product Attributes}

Model A, the first model was run as a single latent construct (ATTR) of the 10 indicator variables. As expected, the model was a poor fit to data since the variables were indicators of three different theoretical facets of product attributes. The chi-square/df was much greater than 3 at 12.43 .

The second model, B was run with the three first order constructs of product fecundity, product fidelity and product longevity, all as uncorrelated constructs. This model also showed an ill fit tothe data (chi-square/df $=6.7$ ), which can easily be explained because the three product attributes are dimensions of what the overall attributes of the product are envisaged to be.

Model $\mathrm{C}$ was run with these three attributes free to correlate and a better model fit was achieved, with chi-square/df $=3.07$ and RMSEA $=0.1$. However, the model specified this way raised issues of validity and multicollinearity, the assumptions of which were violated.

The fourth model, model D, a second order reflective construct (ATTR) with the three first order reflective constructs was formed and run. The fit to data was same as that of the previous model, however the issues arising from model $\mathrm{C}$ were addressed by the structure of model D.

The $\mathrm{T}$ coefficient for ATTR was calculated as $\chi_{\text {Model } \mathrm{C}}^{2} \chi^{2}$ Model D $=1.00$ which implies that all the variation among the three first order latent constructs was explained by the second order latent construct. Suggested fit modifications were applied and a fifth model, model E was run to successful better fit to data (chi-square/df $=1.19, \mathrm{RMSEA}=0.031, \mathrm{NFI}=0.99, \mathrm{NNFI}=$ 
$0.98, \mathrm{CFI}=0.98$ and standardized $\mathrm{RMR}=0.038$ ) as shown below in figure 8.18. Model E was retained for further analysis in the full structural model.

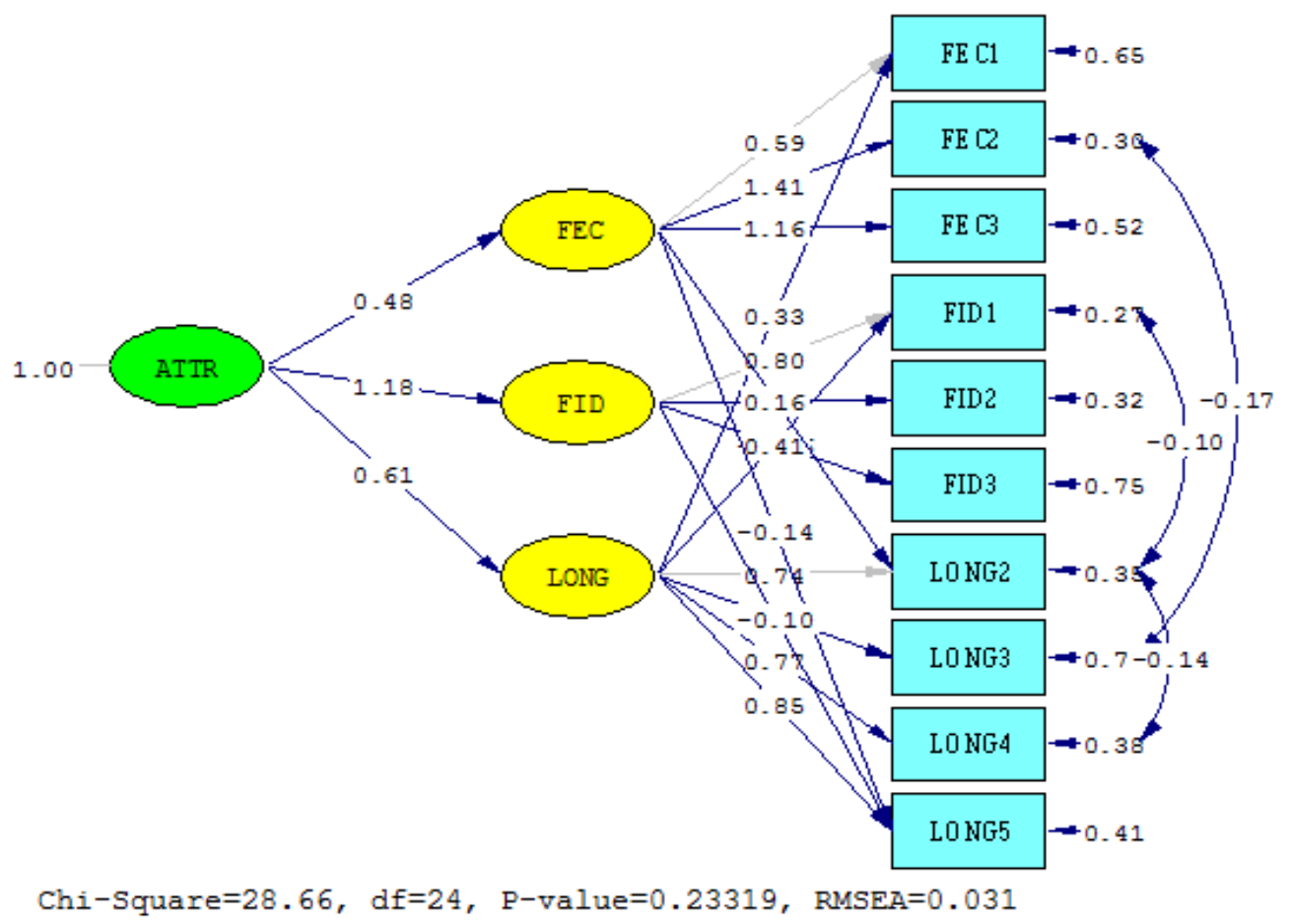

Figure 8.18 Measurement model of Product Attributes (ATTR)

\section{Performance}

The final second order construct was performance (PERF), which was conceptualized as a reflective construct of four first order reflective latent constructs environmental performance (ENVPERF), economic performance (ECPERF), social performance (SOCPERF) and strategic performance (STRPERF). Performance is theoretically a complex phenomenon, and various kinds of performance of an organization have an impact on each other. For example, strategic performance for an organization may mandate certain economic, environmental or social goals. Similarly, social performance for most organizations may involve being environmentally responsible, which in turn is related to environmental performance. With respect to the 
organizational bottom line, social and environmental performance goals would also create animpact on the economic performance of an organization. The fit statistics for the five model variations for performance are reported below in table 8.4. No Model E was required because no modifications were suggested by the output.

\begin{tabular}{|c|c|c|c|c|}
\hline $\begin{array}{l}\text { Goodness of fit Statistics } \\
\text { for alternative models } \\
\text { (acceptable values) }\end{array}$ & Model A & Model B & Model C & Model D \\
\hline Chi square & 1968.53 & 948.01 & 660.51 & 678.44 \\
Chi-square/df (<3) & 10.41 & 5.01 & 3.60 & 3.66 \\
\hline NFI $(>0.9)$ & 0.82 & 0.9 & 0.93 & 0.93 \\
\hline NNFI (>0.9) & 0.82 & 0.91 & 0.94 & 0.94 \\
\hline CFI $(>0.9)$ & 0.84 & 0.92 & 0.95 & 0.95 \\
\hline RMSEA ( $<0.08)$ & 0.22 & 0.14 & 0.11 & 0.115 \\
\hline $\begin{array}{c}\text { Standardized RMR } \\
\text { (close to 0.08) }\end{array}$ & 0.13 & 0.33 & 0.079 & 0.083 \\
\hline
\end{tabular}

Table 8.4 Statistics for Alternate Models for Performance

The first model, model A was run as performance being a first order reflective construct of the 21 indicator variables. This model, as expected, showed a very poor fit to data (chisquare $/ \mathrm{df}=10.41>>3, \mathrm{RMSEA}=0.22)$. This is because the indicators are parts of four different 
dimensions of performance, so the one latent construct would violate the assumption of unidimensionality.

The second model, model $\mathrm{B}$, was run with the four first order constructs of environmental, economic, social and strategic performance as uncorrelated. This model was also a somewhat poor fit to the data (chi-square/df $=5.01, \mathrm{RMSEA}=0.14)$ because (as discussed above) the various dimensions of performance are logically and theoretically related to one another.

The next model (C) was run with the four first order constructs free to correlate with one another. While this was theoretically correct and the data fit the model acceptably (chi-square/df $=3.60$ and RMSEA $=0.11$ ), the statistical assumptions of construct validity (as discussed previously) as well as multicollinearity became issues in the model because the four first order constructs were found (as expected) to be correlated.

Model D, the fourth model was conceptualized as performance being a second order reflective latent constructs with the four different first order reflective constructs of environmental, economic, social and strategic performance as components. The model fit the data somewhat acceptably (chi-square/df $=3.66$ and RMSEA $=0.115)$ and the $\mathrm{T}$ coefficient for PERF was then calculated as $\chi_{\text {Model }}^{2} / \chi^{2}$ Model $D=0.973$, which means that $97 \%$ of the variance among the four first order constructs (ENVPERF, ECPERF, SOCPERF and STRPERF) can be explained by the higher order construct of performance (PERF) which is a impressively large percentage. This model (figure 8.19 below) was retained for further analysis in the full-model SEM analysis. 


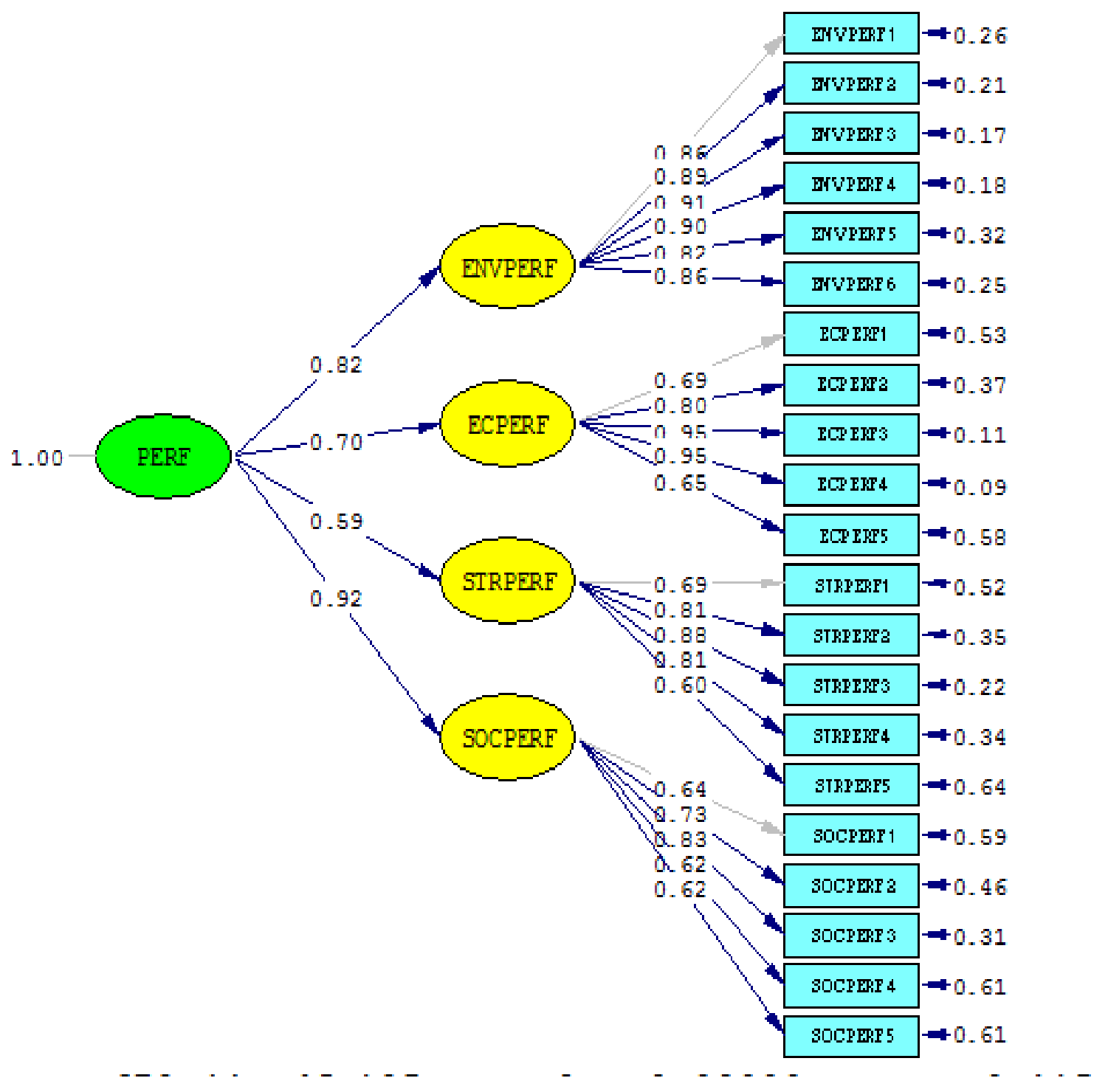

Figure 8.19 Measurement model of Performance (PERF)

The composite reliability scores for the second order constructs are provided in table 8.5 below for reference.

\begin{tabular}{|l|l|}
\hline Second Order Construct & Composite Reliability \\
\hline
\end{tabular}




\begin{tabular}{|l|l|}
\hline Strategic Orientation & 0.746 \\
\hline Sustainable Product Development & 0.765 \\
\hline Processes & \\
\hline Performance & 0.846 \\
\hline
\end{tabular}

Table 8.5 Composite Reliability for Second Order Constructs

\subsection{The Complete Structural Model: Testing Posited Hypotheses}

On completion of the validation of the measurement models, the structural model is specified and analyzed to test the hypotheses posited in Chapter 3, section 3. The basic structural model was specified using scaled second order constructs of Strategic orientation, leading to sustainable product development processes which in turn affected performance, also mediated by product attributes. Here, the exogenous variable is the second order Strategic orientation construct and the three other second order constructs are endogenous variables (as treated in LISREL). The model was estimated using maximum likelihood as the sample was near normal in distribution and had no significant issues with kutosis or skewness. The basic structural model is provided in figures 8.20 (basic conceptual model) and 8.21 (structural model with the standardized solution estimates) below. 


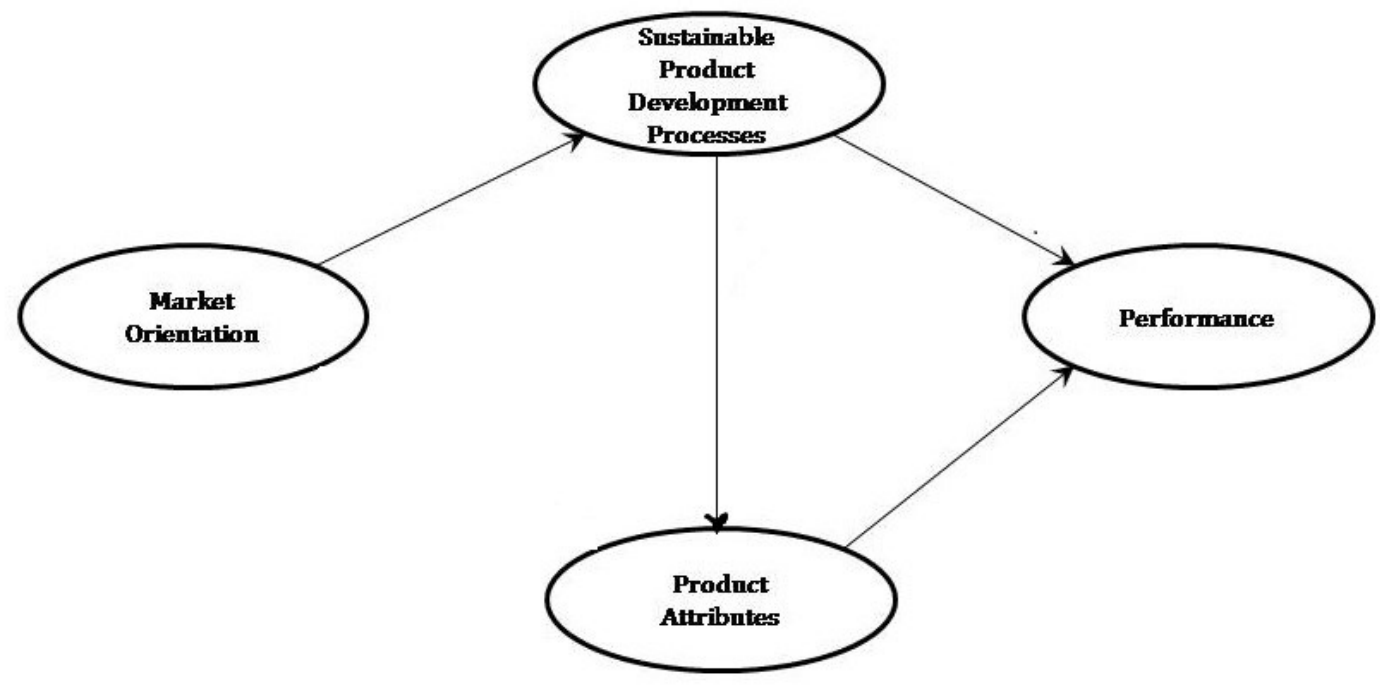

Figure 8.20 Conceptual Hypothesized Structural Model 


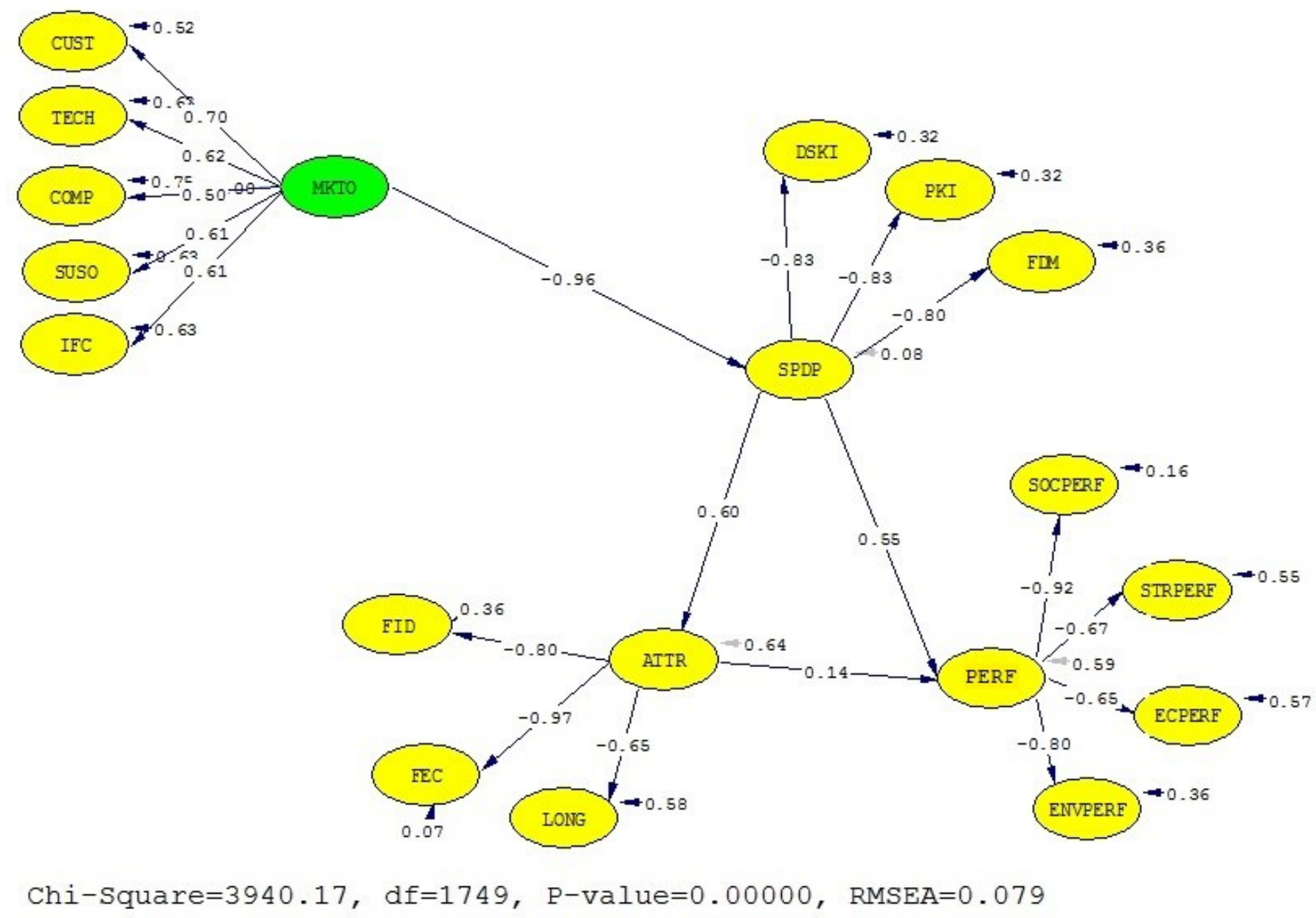

Figure 8.21 Structural Model $^{6}$ (with the standardized solution path coefficients)

It should be noted that the full model in this research is a hierarchical mediation model.

For the analysis of mediation, the core and most important assessment is considered to the total and indirect effects among constructs. In the case of hierarchical models such as the second order latent construct model this research assesses, individual path segments may sometimes incur statistically insignificant t-values (significance cut off for which is \pm 1.98 at $\alpha=0.05$ ) because of the complexity of the relationships among the various order latent constructs and should not be

\footnotetext{
${ }^{6}$ The path from ATTR to PERF is not significant at 1.45 (where 1.98 is the significance threshold).
} 
considered an indication of lack of strength of the overall relationship between constructs (Hayes, 2013; Kenny \& Judd, 2014). Considering the complexity of the full model, the resultant goodness of fit statistics showed an overall excellent fit to data with chi-square/df $=2.25(<3)$, $\mathrm{RMSEA}=0.079(<0.08), \mathrm{NFI}=0.89, \mathrm{NNFI}=0.93, \mathrm{CFI}=0.93$ and standardized $\mathrm{RMR}=0.11$ (close to 0.08).

For estimating the strength of the effects of the constructs in a mediation model, the product of the (standardized) path coefficients for each path between the constructs are summed. For example, the total effect of Strategic orientation on performance is as follows:

$$
\begin{aligned}
& \mathrm{EF}_{(\mathrm{MKTO}->\mathrm{PERF})}=[(\text { Path Coefficient } \text { MKTO->SPDP }) \mathrm{X}(\text { Path Coefficient } \text { SPDP->PERF })]+[(\text { Path } \\
& \text { Coefficient } \left.\text { MKTO->SPDP }_{\text {) X (Path Coefficient }} \text { SPDP->ATTR }\right) \text { X (Path Coefficient ATTR->PERF)] }
\end{aligned}
$$

The following paragraphs provide a breakdown of the hypothesized relationships proposed a-priori and the results from the standardized solution path coefficients of the structural equation model. In the analysis of the effects of the constructs on each other, the guiding hypotheses from the theoretical framework are revised and further broken down into more precise hypotheses that point to specific relationships for a more detailed assessment the structural model.

H2: competitor orientation is positively related to sustainable product development processes.

H2a: competitor orientation is positively related to domain-specific knowledge integration.

H2b: competitor orientation is positively related to procedural knowledge integration. 
H2c: competitor orientation is positively related to flexible decision making.

The path from competitor orientation to domain-specific knowledge integration was found to have a positive magnitude of 0.398. Since all three paths from COMP to DSKI were significant, the effect can be considered significant. Thus, H2a can be said to be supported.

The path from competitor orientation to procedural knowledge integration is found to have a positive magnitude of 0.398 and the component paths are statistically significant, so the effect cannot be considered insignificant. Thus, $\mathrm{H} 2 \mathrm{~b}$ can be said to be supported.

The path from competitor orientation to flexible decision-making is found to have a positive magnitude of 0.384 and the component paths are statistically significant, so the relationship cannot be considered insignificant. Thus, H2c can be said to be supported.

H3: customer orientation is positively and significantly related to sustainable product development processes.

H3a: customer orientation is positively related to domain-specific knowledge integration. H3b: customer orientation is positively related to procedural knowledge integration. H3c: customer orientation is positively related to flexible decision making.

The path from customer orientation to domain-specific knowledge integration was found to have a positive magnitude of 0.557 . Since all three paths from CUST to DSKI were significant, the effect can be considered significant. Thus, H3a can be said to be supported. 
The path from customer orientation to procedural knowledge integration is found to have a positive magnitude of 0.557 and the component paths are statistically significant, so the effect can be considered significant. Thus, H3b can be said to be supported.

The path from customer orientation to flexible decision-making is found to have a positive magnitude of 0.537 and the component paths are statistically significant, so the relationship cannot be considered insignificant. Thus, H3c can be said to be supported.

H4: interfunctional coordination is positively and significantly related to sustainable product development processes.

H4a: interfunctional coordination is positively related to domain-specific knowledge integration.

H4b: interfunctional coordination is positively related to procedural knowledge integration.

H4c: interfunctional coordination is positively related to flexible decision making.

The path from interfunctional coordination to domain-specific knowledge integration was found to have a positive magnitude of 0.486 . Since all three paths from IFC to DSKI were significant, the effect can be considered significant. Thus, H4a can be said to be supported.

The path from interfunctional coordination to procedural knowledge integration is found to have a positive magnitude of 0.486 and the component paths are statistically significant, so the effect can be considered significant. Thus, H4b can be said to be supported. 
The path from interfunctional coordination to flexible decision-making is found to have a positive magnitude of 0.468 and the component paths are statistically significant, so the relationship cannot be considered insignificant. Thus, $\mathrm{H} 4 \mathrm{c}$ can be said to be supported.

H5: technological orientation is positively and significantly related to sustainable product development processes.

H5a: technological orientation is positively related to domain-specific knowledge integration.

H5b: technological orientation is positively related to procedural knowledge integration. H5c: technological orientation is positively related to flexible decision making.

The path from technological orientation to domain-specific knowledge integration was found to have a positive magnitude of 0.494 . Since all three paths from TECH to DSKI were significant, the effect can be considered significant. Thus, H5a can be said to be supported.

The path from technological orientation to procedural knowledge integration is found to have a positive magnitude of 0.494 and the component paths are statistically significant, so the effect can be considered significant. Thus, H5b can be said to be supported.

The path from technological orientation to flexible decision-making is found to have a positive magnitude of 0.476 and the component paths are statistically significant, so the relationship can be considered significant. Thus, H5c can be said to be supported.

H6: sustainability orientation is positively and significantly related to sustainable product development processes. 
H6a: sustainability orientation is positively related to domain-specific knowledge integration.

H6b: sustainability orientation is positively related to procedural knowledge integration.

H6c: customer orientation is positively related to flexible decision making.

The path from sustainability orientation to domain-specific knowledge integration was found to have a positive magnitude of 0.486 . Since all three paths from SUSO to DSKI were significant, the effect can be considered significant. Thus, H6a can be said to be supported.

The path from sustainability orientation to procedural knowledge integration is found to have a positive magnitude of 0.486 and the component paths are statistically significant, so the effect can be considered significant. Thus, H6b can be said to be supported.

The path from sustainability orientation to flexible decision-making is found to have a positive magnitude of 0.468 and the component paths are statistically significant, so the relationship can be considered significant. Thus, H6c can be said to be supported.

H7: integration of domain-specific knowledge and technical know-how is positively and significantly related to performance.

H7a: integration of domain-specific knowledge is positively and significantly related to environmental performance.

H7b: integration of domain-specific knowledge is positively and significantly related to economic performance.

H7c: integration of domain-specific knowledge is positively and significantly related to social performance. 
H7d: integration of domain-specific knowledge is positively and significantly related to strategic performance.

The path from domain-specific knowledge integration to environmental performance was found to have a positive magnitude of 0.365 . Since all three of the component paths were significant, the total path can be considered significant. Thus, $\mathrm{H} 7 \mathrm{a}$ can be said to be supported.

The path from domain-specific knowledge integration to economic performance is found to have a positive magnitude of 0.296 and since all three of the component paths were significant, the total path can be considered significant. Thus, $\mathrm{H} 7 \mathrm{~b}$ can be said to be supported.

The path from domain-specific knowledge integration to social performance is found to have a positive magnitude of 0.419 and since all three of the component paths were significant, the total path can be considered significant. Thus, $\mathrm{H} 7 \mathrm{c}$ can be said to be supported.

The path from domain-specific knowledge integration to strategic performance is found to have a positive magnitude of 0.305 and since all three of the component paths were significant, the total path can be considered significant. Thus, H7d can be said to be supported.

H8: procedural knowledge integration is positively and significantly related to performance.

H8a: integration of procedural knowledge is positively and significantly related to environmental performance.

H8b: integration of procedural knowledge is positively and significantly related to economic performance.

H8c: integration of procedural knowledge is positively and significantly related to social performance. 
H8d: integration of procedural knowledge is positively and significantly related to strategic performance.

The path from procedural knowledge integration to environmental performance was found to have a positive magnitude of 0.365 . Since all three of the component paths were significant, the total path can be considered significant. Thus, H8a can be said to be supported.

The path from procedural knowledge integration to economic performance is found to have a positive magnitude of 0.296 and since all three of the component paths were significant, the total path can be considered significant. Thus, H8b can be said to be supported.

The path from procedural knowledge integration to social performance is found to have a positive magnitude of 0.419 and since all three of the component paths were significant, the total path can be considered significant. Thus, H8c can be said to be supported.

The path from procedural knowledge integration to strategic performance is found to have a positive magnitude of 0.305 and since all three of the component paths were significant, the total path can be considered significant. Thus, H8d can be said to be supported.

H9: flexible (strategic) decision-making is positively and significantly related to performance.

H9a: flexible decision-making is positively and significantly related to environmental performance.

H9b: flexible decision-making is positively and significantly related to economic performance.

H9c: flexible decision-making is positively and significantly related to social performance. 
H9d: flexible decision-making is positively and significantly related to strategic performance.

The path from flexible decision-making to environmental performance was found to have a positive magnitude of 0.352 . Since all three of the component paths were significant, the total path can be considered significant. Thus, H9a can be said to be supported.

The path from flexible decision-making to economic performance is found to have a positive magnitude of 0.286 and since all three of the component paths were significant, the total path can be considered significant. Thus, H9b can be said to be supported.

The path from flexible decision-making to social performance is found to have a positive magnitude of 0.404 and since all three of the component paths were significant, the total path can be considered significant. Thus, H9c can be said to be supported.

The path from flexible decision-making to strategic performance is found to have a positive magnitude of 0.295 and since all three of the component paths were significant, the total path can be considered significant. Thus, H9d can be said to be supported.

H10: Product fecundity is positively and significantly related to the three attributes of sustainable products

H11: Product fidelity is positively and significantly related to the three attributes of sustainable products

H12: Product longevity is positively and significantly related to the three attributes of sustainable products

H10a: Domain-specific knowledge integration is positively related to product fecundity 
H10b: Procedural knowledge integration is positively related to product fecundity

H10c: Flexible decision-making is positively related to product fecundity

H1 1a: Domain-specific knowledge integration is positively related to product fidelity

H1 1b: Procedural knowledge integration is positively related to product fidelity

H11c: Flexible decision-making is positively related to product fidelity

H12a: Domain-specific knowledge integration is positively related to product longevity

H12b: Procedural knowledge integration is positively related to product longevity

H12c: Flexible decision-making is positively related to product longevity

The path between DSKI and product fecundity is positive to a magnitude of 0.483 . The effect cannot be considered insignificant since all three of the component paths were significant, the total path can be considered significant. The path between PKI and fecundity is positive to the magnitude of 0.483 and all three of the component paths are statistically significant. The path between FDM and product fecundity is positive to the magnitude of 0.465 . All three of the component paths are statistically. Thus H10a, H10b and H10c can be said to be supported.

The path between DSKI and product fidelity is positive to a magnitude of 0.398 . The effect can be considered significant since its component paths are significant. The path between PKI and fidelity is positive to the magnitude of 0.398 and all three of the component paths are statistically significant. The path between FDM and product fidelity is positive to the magnitude of 0.384. All three of the component paths are statistically. Thus H11a, H11b and H11c can be said to be supported. 
The path between DSKI and product longevity is positive to a magnitude of 0.323 . The effect can be considered significant since its component paths are significant. The path between PKI and longevity is positive to the magnitude of 0.323 and the component paths are statistically significant. The path between FDM and product longevity is positive to the magnitude of 0.312 . All three of the component paths are statistically significant. Thus H12a, H12b and H12c can be said to be supported.

H13: Product fecundity positively and significantly impacts performance.

H13a: Product fecundity positively and significantly impacts environmental performance. H13b: Product fecundity positively and significantly impacts economic performance.

H13c: Product fecundity positively and significantly impacts social performance.

H13d: Product fecundity positively and significantly impacts strategic performance.

The path from product fecundity to environmental performance was found to have a positive magnitude of 0.108 and had two path components that were statistically significant. The path from ATTR to PERF was only insignificant to the magnitude of 1.42 so the relationship cannot be considered insignificant. Thus, H13a can be said to be supported.

The path from product fecundity to economic performance is found to have a positive magnitude of 0.088 and had two path components that were statistically significant. The path from ATTR to PERF was only insignificant to the magnitude of 1.42 so the relationship cannot be considered insignificant. Thus, $\mathrm{H} 13 \mathrm{~b}$ can be said to be supported.

The path from product fecundity to social performance is found to have a positive magnitude of 0.125 and had two path components that were statistically significant. The path 
from ATTR to PERF was only insignificant to the magnitude of 1.42 so the relationship cannot be considered insignificant. Thus, H13c can be said to be supported.

The path from product fecundity to strategic performance is found to have a positive magnitude of 0.091 and had two path components that were statistically significant. The path from ATTR to PERF was only insignificant to the magnitude of 1.42 so the relationship cannot be considered insignificant. Thus, H13d can be said to be supported.

H14: Product fidelity positively and significantly impacts performance.

H14a: Product fidelity positively and significantly impacts environmental performance. H14b: Product fidelity positively and significantly impacts economic performance.

H14c: Product fidelity positively and significantly impacts social performance.

H14d: Product fidelity positively and significantly impacts strategic performance.

The path from product fidelity to environmental performance was found to have a positive magnitude of 0.089 and had two path components that were statistically significant. The path from ATTR to PERF was only insignificant to the magnitude of 1.42 so the relationship cannot be considered insignificant. Thus, H14a can be said to be supported.

The path from product fidelity to economic performance is found to have a positive magnitude of 0.073and had two path components that were statistically significant. The path from ATTR to PERF was only insignificant to the magnitude of 1.42 so the relationship cannot be considered insignificant. Thus, $\mathrm{H} 14 \mathrm{~b}$ can be said to be supported.

The path from product fidelity to social performance is found to have a positive magnitude of 0.103and had two path components that were statistically significant. The path 
from ATTR to PERF was only insignificant to the magnitude of 1.42 so the relationship cannot be considered insignificant. Thus, H14c can be said to be supported.

The path from product fidelity to strategic performance is found to have a positive magnitude of 0.075 and had two path components that were statistically significant. The path from ATTR to PERF was only insignificant to the magnitude of 1.42 so the relationship cannot be considered insignificant. Thus, H14d can be said to be supported.

H15: Product longevity positively and significantly impacts performance.

H15a: Product longevity positively and significantly impacts environmental performance. H15b: Product longevity positively and significantly impacts economic performance.

H15c: Product longevity positively and significantly impacts social performance.

H15d: Product longevity positively and significantly impacts strategic performance.

The path from product longevity to environmental performance was found to have a positive magnitude of 0.073 and had two path components that were statistically significant. The path from ATTR to PERF was only insignificant to the magnitude of 1.42 so the relationship cannot be considered insignificant. Thus, H15a can be said to be supported.

The path from product longevity to economic performance is found to have a positive magnitude of 0.059 and had two path components that were statistically significant. The path from ATTR to PERF was only insignificant to the magnitude of 1.42 so the relationship cannot be considered insignificant. Thus, $\mathrm{H} 15 \mathrm{~b}$ can be said to be supported.

The path from product longevity to social performance is found to have a positive magnitude of 0.084 and had two path components that were statistically significant. The path 
from ATTR to PERF was only insignificant to the magnitude of 1.42 so the relationship cannot be considered insignificant. Thus, H15c can be said to be supported.

The path from product longevity to strategic performance is found to have a positive magnitude of 0.061 and had two path components that were statistically significant. The path from ATTR to PERF was only insignificant to the magnitude of 1.42 so the relationship cannot be considered insignificant. Thus, H15d can be said to be supported.

H1: the composite Strategic orientation is positively related to sustainable product development processes.

Since the standardized path coefficient from Strategic orientation to sustainable product development processes is negative (-0.96), it was found that the composite Strategic orientation does not positively impact SPDP as a composite, however, it does positively and significantly impact all three of the individual SPD processes. Thus, H1 can be said to be supported.

\subsection{Assessing Total Indirect Effects, Strategic Orientation and Performance}

This model is a mediation model, which means that direct relationships between Strategic orientation and the various components of performance were not posited and specified for analysis. However, the LISREL output for indirect and total effects provides an output for these effects for exogenous and endogenous variables on the $\eta$ (Eta) matrices, provided for reference in Appendix 13. The unstandardized values for the effects of Strategic orientation on environmental performance $(0.48, \mathrm{t}$-value $=7.00)$, economic performance $(0.40, \mathrm{t}$-value $=5.88)$, social performance $(0.56, \mathrm{t}$-value $=6.37)$ and strategic performance $(0.40, \mathrm{t}$-value $=5.88)$. These 
values provide support for the fact that Strategic orientation has a significant effect on the four types of organizational performance, mediated by sustainable product development processes and product attributes.

This chapter provided the results from an in-depth analysis of the data set from the second stage of this study. CFA was conducted to test the measurement models of each of the constructs as well as second order constructs. The a-priori model was tested using SEM and the posited hypotheses were checked. Indirect effects, in the form of the relationship between strategic orientation and performance, were also checked. The next chapter provides a discussion of the implications of the analysis conducted as well as tests components of the a-priori model to confirm the source of the effects seen in the full model. 


\section{Chapter 9: Discussion}

This chapter comprises of two main sections. In the first part, the theoretical interpretation of the a-priori model is discussed in the light of the analysis conducted. The second section revisits the research questions outlined in Chapter 1 and the relevance and significance of the findings across the two stages of this research are contextualised accordingly.

\subsection{Interpretation of the a-priori model and model variations}

As seen in the previous chapter (Chapter 8), the a-priori model provides an excellent fit for the data collected and also provides the basis for accepting all but one of the hypotheses posited in Chapter 3.

It may be noted that all the endogenous second order constructs show negative loadings from the first order latent constructs to the second order latent constructs. In such a case, there are two possible explanations. First, either the model is incorrect, for (sometimes inter-related) reasons such as model misspecification (such as not scaling the latent constructs or not correctly following SEM protocol such as tracing rules $^{7}$ etc.), violations of statistical assumptions by the data set (such as homoscedasticity), construct validity issues (so that the factor loadings are low) or even low sample size which cannot generate proper starting values for the iterative analysis

\footnotetext{
${ }^{7}$ Wright's $(1918,1934)$ method for estimating causal path coefficients by “decomposing” correlations between a group of variables. To this end, three basic rules for tracing a path diagram apply:

1) Tracing from one variable to another, one cannot pass through the same variable twice for any particular route

2) Going forward and then backward is not allowed through the same variable.

3) Only one bi-directional arrow is allowed in tracing from the first variable to the last variable in any path
} 
totake place and so on (Hayes, 2013; Kenny \& Judd, 2014; Kline, 2005; Koufteros et al., 2009).For this root cause, the best method for not encountering problems is prevention. In the case of this research, each of these issues was guarded against. The data was carefully scanned and prepared and the preliminary analysis showed a near normal distribution with no outlier issues. Also, the measurement models were carefully analysed, second order constructs were created to avoid discriminant validity issues as well as multicollinearity and factor loadings were consistently checked and always stayed well above cut-off marks. Also, the complete model was carefully specified, taking all precautions to correctly scale constructs, tracing paths according to the rules, ensuring correctly specified causality and keeping statistical and theoretical considerations in mind at every stage.

The second reason would be that the ecosystem generated by the full model is the cause of the negative signage encountered. It is then incumbent on the researcher to attempt to determine the source of this change of signage to assess whether it is a theoretically valid phenomenon being encountered, or whether the proposed theory, the data set and the preliminary analysis requires revisiting. Since (1) the negative signs were encountered uniformly through all the endogenous constructs and in the relationships between the first order and second order constructs; and (2) the measurement models of all second order constructs loaded well and positively; it was concluded that there must be an underlying theoretical cause which required isolation to understand its originating phenomenon. In this case, a number of models which were subsystems of the posited relationships were run to determine how the reversal of signs occurred.

From the subset models, it could be seen that the strategic orientation was forcing a nonsignificant relationship between the second order constructs of product attributes and performance. 
However, since the actual relationship (as well as the theoretically posited effect) between each attribute and dimension of performance was positive, the signs between the first and second order constructs were also reversed. In which scenario, the entire ecosystem of second order endogenous constructs had negative loadings of the constituent first order constructs. Table 9.1 shows a breakdown of the structural models run as subsets of the full-model ecosystem and the conclusions derived from those subset models. (See Appendix 14 for all four structural models with standardised loadings):

\begin{tabular}{|c|c|c|c|c|}
\hline $\begin{array}{l}\text { Model ID } \\
\text { (In } \\
\text { Appendix } \\
\text { 14) }\end{array}$ & $\begin{array}{l}\text { Relationship } \\
\text { Visited }\end{array}$ & Reason & $\begin{array}{l}\text { Structural Model } \\
\text { Results }\end{array}$ & Conclusion \\
\hline SUB A & $\begin{array}{l}\text { Effect of } \\
\text { Product } \\
\text { Attributes on } \\
\text { Performance }\end{array}$ & $\begin{array}{l}\text { To check whether } \\
\text { the direct } \\
\text { relationship } \\
\text { between ATTR and } \\
\text { PERF is negative } \\
\text { and consequently } \\
\text { affecting the entire } \\
\text { ecosystem. }\end{array}$ & $\begin{array}{l}\text { Significant, positive } \\
\text { relationship between } \\
\text { ATTR and PERF }\end{array}$ & $\begin{array}{l}\text { The direct relationship } \\
\text { between ATTR and } \\
\text { PERF is not responsible } \\
\text { for the change in signs }\end{array}$ \\
\hline SUB B & $\begin{array}{l}\text { Effect of } \\
\text { Strategic }\end{array}$ & $\begin{array}{l}\text { To check whether } \\
\text { the effect of }\end{array}$ & $\begin{array}{l}\text { Non-significant, } \\
\text { negative relationships }\end{array}$ & $\begin{array}{l}\text { The change in the } \\
\text { strength of the }\end{array}$ \\
\hline
\end{tabular}




\begin{tabular}{|c|c|c|c|c|}
\hline & $\begin{array}{l}\text { Orientation } \\
\text { on Product } \\
\text { Attributes } \\
\text { and the effect } \\
\text { on } \\
\text { Performance }\end{array}$ & $\begin{array}{l}\text { something else is } \\
\text { responsible for the } \\
\text { negative } \\
\text { relationship } \\
\text { between ATTR and } \\
\text { PERF }\end{array}$ & $\begin{array}{l}\text { between MKTO and } \\
\text { ATTR as well as } \\
\text { ATTR and PERF } \\
\text { when a path from } \\
\text { MKTO leads to } \\
\text { ATTR. All three of } \\
\text { the component first } \\
\text { order product attribute } \\
\text { constructs (FID, FEC } \\
\text { and LONG) now load } \\
\text { non-significantly on } \\
\text { ATTR. }\end{array}$ & $\begin{array}{l}\text { relationships appears to } \\
\text { be the result of the } \\
\text { effect of MKTO on the } \\
\text { relationship between } \\
\text { ATTR and PERF. } \\
\text { Shows weak effect of } \\
\text { product attributes. } \\
\text { Needs further } \\
\text { examination. }\end{array}$ \\
\hline SUB C & $\begin{array}{l}\text { Effect of } \\
\text { Strategic } \\
\text { Orientation } \\
\text { on } \\
\text { Sustainable } \\
\text { product } \\
\text { development } \\
\text { processes and } \\
\text { Performance }\end{array}$ & $\begin{array}{l}\text { To check whether } \\
\text { MKTO is the } \\
\text { reason for all } \\
\text { negative effects in } \\
\text { the full model } \\
\text { ecosystem. }\end{array}$ & $\begin{array}{l}\text { All relationships } \\
\text { (MKTO to SPDP and } \\
\text { SPDP to PERF) are } \\
\text { positive and } \\
\text { significant. }\end{array}$ & $\begin{array}{l}\text { Indication that SPDP } \\
\text { may not be the cause of } \\
\text { reversal of signage, nor } \\
\text { effect of MKTO } \\
\text { through SPDP would be } \\
\text { responsible for reversal } \\
\text { of signage. Needs } \\
\text { further examination. }\end{array}$ \\
\hline SUB D & Effect of & To check whether & All relationships are & The endogenous \\
\hline
\end{tabular}




\begin{tabular}{|l|l|l|l|l|}
\hline product & the relationships & positive and & construct variables are \\
development & ATTR and PERF & ATTR, SPDP to & responsible for the \\
processes on & are responsible for & PERF and ATTR to & reversal in signage. The \\
Product & negating signage & PERF) & effect appears to be an \\
attributes and & Performance & & & indirect effect of \\
& & & \\
\end{tabular}

Table 9.1 Subset Models to Determine the Cause of Sign Reversal

From the examination conducted above, it can be concluded, that strategic orientation is responsible for product attributes impacting performance weakly. While the independent effect (away from the ecosystem of the full model) of product attributes is significant and positive on performance, the presence and indirect of strategic orientation creates a weak effect.

From figure 8.20 and table 9.1 , it may be concluded that a strong strategic orientation (firm level) and a strong development processes (firm level) result in strong performance regardless of the individual product attributes (product level). In other words, organizations with a clear strategic orientation and well defined sustainable product development processes can afford to "carry" certain products in their mix of product offerings and still perform well. The relationship between performance and the product attributes is weak in magnitude and more importantly, is not significant statistically.

However, comparing the a-priori model and the subset models in table 9.1, it may be seen that there is a complex relationship between strategic orientation and product attributes. It may 
reasonably be deduced from assessing individual paths that an organization's strategic orientation that takes each of these specific product attributes into consideration actually helps create a relatively better relationship between product attributes and firm performance, but this relationship is not seen to be excessively strong. (The explanation of this is further discussed in section 9.2.2 below.) In the light of the above as well as the analysis conducted in Chapters 7 and 8 , the research question and objectives are revisited in the next section and the implications of the findings are further discussed as they relate to theory.

\subsection{Revisiting the Research Question and Objectives}

Reiterating from Chapter 1 of this document, the research question posited was: What strategic orientations and product development processes lead to the development of sustainable products in high-technology organizations and what is their effect on performance?

The two objectives of this study were then stated as:

1. To test whether the relationships mentioned in the research question above, as adopted from the NPD literature, similarly exist within the context of the development of sustainable products.

2. To study how strong these abovementioned relationships are within the context of development of sustainable products.

The previous chapter examined the fifteen hypotheses put forth in Chapter 3 on the basis of the a-

priori model conceived from the theoretical framework in Chapter 4. All but one of the hypotheses were admitted as not rejected. H1, the first hypothesis, stated: 
H1: the composite market orientation is positively related to sustainable product development processes.

At face-value, this hypothesis might have been rejected by the a-priori model. However, if individual SPD processes are considered, the posited hypothesis is actually accepted. The reason why the a-priori model appears to reject $\mathrm{H} 1$ is because the reversal of signs in the endogenous second order constructs forces a negative sign between the only relationship (arrow) between the exogenous construct strategic orientation and the endogenous construct sustainable product development processes. The following sections offer an elaboration on the implications of the construct relationships in the a-priori full model.

\subsubsection{Strategic Orientation and Sustainable Product Development Processes}

The relationship between strategic orientation and sustainable product development processes is significant and of strong magnitude in both the a-priori and subset models. Each of the five strategic orientations is positively and significantly related to each of the three development processes. This is an expected finding since the strategic orientation of an organization determines what kinds of product development processes are going to be a part of its operations. Since the development processes themselves are on a strategic level, they can form links between an organization's orientation to (1) the decisions on what kind of product attributes are important and also to (2) the performance of the organization in question. The models indicate that strategic orientation has a strong link to the SPD processes in an organization, both being inexorably and strongly linked. This means that a strategic orientation toward sustainability affects the nature of product development processes as well, creating an adjustment toward 
implementing sustainable practices at the process level;. This finding is very much in line with the research of Hallstedt et al. (2013) and Gaziulusoy and Boyle (2013), where strategic sustainability is found to be interlinked at the firm level, the process and decision-making level as well as the product development level. Boons et al. (2013) also state that considerations of sustainability should be built into the company systems right from the idea generation stage to commercialization as well as into the organizational model. The strong link from strategic orientation to development processes is a clear indication of the levels at which sustainability should be 'built-in' for true impact.

\section{Effect on Performance}

The effect on performance is also an expectedly straight-forward one. From both models, it may be seen that the four dimensions of performance are affected positively and significantly by the development processes. What this means is that the development processes and their strategic alignment are directly responsible for how well an organization performs. These results are mirrored by the opinions of the interviewees in the first stage of this study. For example, one of the senior executives said:

In our case [it] was the strategic decision that the founders took....It was domain knowledge [integration] that allowed us to impact the whole spectrum.

While another executive stated: "strategically, our performance was influenced most by domain knowledge and how we integrated [it]". For a lot of respondents procedural knowledge integration was "a given" which is reflected in the fact that it has the highest loading. However, 
the relative importance of all three of the processes was fairly (uniformly) high, which meant that all three are valued as important strategic development processes for sustainable products.

\subsubsection{Strategic Orientation and Product Attributes}

The relationship between strategic orientation and product attributes is a complex one. The a-priori model and subset models consulted appear to prima facie differ superficially with respect to how strategic orientation affects product attributes. However, the implications of the relationship essentially are the same, which can be deduced from the a-priori and the SUB B models. The strategic orientation of an organization with respect to sustainable products should specifically define the approach to the product attribute mix, or the attributes themselves increase performance to a certain degree (from the SUB B relationships). If an organization strategically allows product development processes to dictate the actual product attributes of individual product offerings, the attributes create an insignificant and weak impact for the organization's performance (as seen from the a-priori model).

It may therefore be concluded that the attributes themselves should be a consideration on the strategic level and not simply an after-thought at the product or process level. This is also an important finding and is in line with the work of Gaziulusoy and Boyle (2013) and Hallstedt el al. $(2015,2013)$ that emphasizes the importance of inter-level linkages between the strategic, process and product levels. 


\section{Effect on Performance}

As discussed above, the relationship between product attributes and performance is neither of great magnitude, nor is it statistically significant in both the a-priori model and the subset model. This is a very interesting finding because this causality does not show why the product attributes have a weak relationship with performance. There are two potential reasons that come to the forefront at this stage of the research. One questionable possibility is whether this weak relationship may be due to the particular attributes in question. Langley et al. (2012) do caution about the applicability of their results since their experts have a relatively subjective range of consumer and product attribute behaviour in mind while answering questions. However, the study does conclude that product attributes are a significantly better source for promoting use via social contagion than consumer behaviour. Also, the study by Bereketli and Genevois (2013) states that selecting the right product materials and characteristics would have the most potential to enhance environmental performance. In line with these important points, an alternate reason is more confidently posited for the weak relationship.

Another, perhaps much more plausible explanation, (given the current state of the market and business environment) is that the attributes of sustainable products are possibly still perceived as drawbacks with respect to enhancing performance. The fact that the relationship is not statistically significant may prove that this mindset may indeed be changing when sustainable products can create a win-win situation for the organization and the consumers/stakeholders by being competitive in their own right. 


\subsection{Summary}

A number of points can be made in summation of the discussion of results. First, a summary of the impact on performance is assessed in totality. Second, the results from the structural model and the subset models of interest are compared in terms of the results they produce for hypothesis testing. Finally, it bears on the researcher at this point to match the significant findings of both stages of the study and sync the learning from them, especially as it pertains to sustainability.

\section{Performance}

Organizational performance for the purposes of this study was conceived as an amalgam of the triple bottom line as well as strategic performance. The triple bottom line is important from the point of view of sustainability while strategic performance is also important for maintaining fit consistency across the conceptualisation of the model since the strategic level of organizational orientation would require an equal level of performance goals. As a theory-based assessment mechanism within the conceptualised model, performance was received very well in both stages of the study. For the interviewees, performance as a goal was paramount, beginning often with economic performance and adding on the other dimensions as the product offering(s) and/or organization grew more stable. According to the empirical results, however, social and environmental performance loaded the highest consistently across both models. This difference in results is easily explained because the sample for stage 2 of the research was drawn from a population of mostly large and some medium-large (i.e. medium organizations tending substantially toward being large) organizations. This clearly implies that those organizations with 
the luxury of being already established and financially stable can focus more on sustainability aspects. This is a point touched upon by one of the interview respondents as well, who states "the scale of operations and the profit margins do allow the manufacturer to make sustainability choices."

Another interesting finding is that triple bottom line performances: economic, environmental and social have all better loadings as compared to strategic performance. This is again possibly understandable considering that many aspects of strategic performance would be already covered by the triple bottom line, which is more holistic in its approach than just economic performance. This explanation is statistically borne out since indicators of at least four different dimensions of performance are linked to the other dimensions, which means that loadings of the second order construct 'performance' are not purely separate (as in the case of other second order constructs as well).

As far as the relationship between performance and the two mediators of product attributes and SPD processes is concerned, it is seen that processes affect performance clearly to a greater degree as compared to product attributes (which has been discussed in detail in the sections above). The indirect effect of strategic orientation on performance is of a substantial magnitude, according to the a-priori model (0.6086).This is a logical finding, considering that the strategic orientation and the performance goals of an organization would normally be in sync, assuming that the operations of the organization are going well. 


\section{Hypothesis Testing Compared}

The results of the hypothesis testing with respect to the a-priori model and the subset model are presented in table 9.2 for a comparative assessment of the implications of both in order to make a final decision on whether to accept or reject.

The nebulous nature of the relationship between product attributes and performance is primarily highlighted, in the results from testing Hypotheses 13, 14 and 15. The final decision is based on the discussion conducted above, which means that the a-priori was examined in tandem with the model subsets from a theoretical perspective before a conservative decision was made in accepting or rejecting a hypothesis.

\begin{tabular}{|c|c|c|c|}
\hline Hypotheses & $\begin{array}{l}\text { A-Priori } \\
\text { Model }\end{array}$ & $\begin{array}{l}\text { Subset } \\
\text { Models }\end{array}$ & $\begin{array}{c}\text { Final } \\
\text { Decision }\end{array}$ \\
\hline $\begin{array}{l}\text { H1: the composite market orientation is positively related to } \\
\text { sustainable product development processes. }\end{array}$ & $\begin{array}{l}\text { Accept, } \\
\text { relationship } \\
\text { has potential } \\
\text { issues with } \\
\text { negative } \\
\text { signs }\end{array}$ & Accept & Accept \\
\hline $\begin{array}{l}\text { H2: competitor orientation is positively related to sustainable } \\
\text { product development processes. } \\
\text { H2a: competitor orientation is positively related to } \\
\text { domain-specific knowledge integration. } \\
\text { H2b: competitor orientation is positively related to } \\
\text { procedural knowledge integration. } \\
\text { H2c: competitor orientation is positively related to } \\
\text { flexible decision making. }\end{array}$ & $\begin{array}{l}\text { Accept } \\
\mathrm{H} 2 \mathrm{a}-\mathrm{c}\end{array}$ & Accept & Accept \\
\hline $\begin{array}{l}\text { H3: customer orientation is positively and significantly related } \\
\text { to sustainable product development processes. } \\
\text { H3a: customer orientation is positively related to } \\
\text { domain-specific knowledge integration. }\end{array}$ & $\begin{array}{l}\text { Accept } \\
\text { H3a-c }\end{array}$ & Accept & Accept \\
\hline
\end{tabular}




\begin{tabular}{|c|c|c|c|}
\hline $\begin{array}{l}\text { H3b: customer orientation is positively related to } \\
\text { procedural knowledge integration. } \\
\text { H3c: customer orientation is positively related to } \\
\text { flexible decision making. }\end{array}$ & & & \\
\hline $\begin{array}{l}\text { H4: interfunctional coordination is positively and significantly } \\
\text { related to sustainable product development processes. } \\
\text { H4a: interfunctional coordination is positively related } \\
\text { to domain-specific knowledge integration. } \\
\text { H4b: interfunctional coordination is positively related } \\
\text { to procedural knowledge integration. } \\
\text { H4c: interfunctional coordination is positively related } \\
\text { to flexible decision making. }\end{array}$ & $\begin{array}{l}\text { Accept } \\
\text { H4a-c }\end{array}$ & Accept & Accept \\
\hline $\begin{array}{l}\text { H5: technological orientation is positively and significantly } \\
\text { related to sustainable product development processes. } \\
\text { H5a: technological orientation is positively related to } \\
\text { domain-specific knowledge integration. } \\
\text { H5b: technological orientation is positively related to } \\
\text { procedural knowledge integration. } \\
\text { H5c: technological orientation is positively related to } \\
\text { flexible decision making. }\end{array}$ & $\begin{array}{l}\text { Accept } \\
\text { H5a-c }\end{array}$ & Accept & Accept \\
\hline $\begin{array}{l}\text { H6: sustainability orientation is positively and significantly } \\
\text { related to sustainable product development processes. } \\
\text { H6a: sustainability orientation is positively related to } \\
\text { domain-specific knowledge integration. } \\
\text { H6b: sustainability orientation is positively related to } \\
\text { procedural knowledge integration. } \\
\text { H6c: } \text { customer orientation is positively related to } \\
\text { flexible decision making. }\end{array}$ & $\begin{array}{l}\text { Accept } \\
\text { H6a-c }\end{array}$ & Accept & Accept \\
\hline $\begin{array}{l}\text { H7: integration of domain-specific knowledge and technical } \\
\text { know-how is positively and significantly related to } \\
\text { performance. } \\
\text { H7a: integration of domain-specific knowledge is } \\
\text { positively and significantly related to environmental } \\
\text { performance. } \\
\boldsymbol{H} 7 \boldsymbol{b} \text { : integration of domain-specific knowledge is } \\
\text { positively and significantly related to economic } \\
\text { performance. } \\
\boldsymbol{H} 7 \text { c: integration of domain-specific knowledge is } \\
\text { positively and significantly related to social } \\
\text { performance. } \\
\boldsymbol{H} 7 \text { : } \text { integration of domain-specific knowledge is } \\
\text { positively and significantly related to strategic } \\
\text { performance. }\end{array}$ & $\begin{array}{l}\text { Accept } \\
\text { H7a-d }\end{array}$ & Accept & Accept \\
\hline
\end{tabular}




\begin{tabular}{|c|c|c|c|}
\hline $\begin{array}{l}\text { H8: procedural knowledge integration is positively and } \\
\text { significantly related to performance. } \\
\text { H8a: integration of procedural knowledge is positively } \\
\text { and significantly related to environmental } \\
\text { performance. } \\
\text { H8b: integration of procedural knowledge is positively } \\
\text { and significantly related to economic performance. } \\
\text { H8c: integration of procedural knowledge is positively } \\
\text { and significantly related to social performance. } \\
\text { H8d: integration of procedural knowledge is positively } \\
\text { and significantly related to strategic performance. }\end{array}$ & $\begin{array}{l}\text { Accept } \\
\text { H8a-d }\end{array}$ & Accept & Accept \\
\hline $\begin{array}{l}\text { H9: flexible (strategic) decision-making is positively and } \\
\text { significantly related to performance. } \\
\text { H9a: flexible decision-making is positively and } \\
\text { significantly related to environmental } \\
\text { performance. } \\
\text { H9b: flexible decision-making is positively and } \\
\text { significantly related to economic performance. } \\
\text { H9c: flexible decision-making is positively and } \\
\text { significantly related to social performance. } \\
\text { H9d: flexible decision-making is positively and } \\
\text { significantly related to strategic performance. }\end{array}$ & $\begin{array}{l}\text { Accept } \\
\text { H9a-d }\end{array}$ & Accept & Accept \\
\hline $\begin{array}{l}\text { H10: Product fecundity is positively and significantly related to } \\
\text { the three attributes of sustainable products } \\
\text { H10a: Domain-specific knowledge integration is } \\
\text { positively related to product fecundity } \\
\text { H10b: Procedural knowledge integration is } \\
\text { positively related to product fecundity } \\
\text { H10c: Flexible decision-making is positively } \\
\text { related to product fecundity }\end{array}$ & Accept & NA & Accept \\
\hline $\begin{array}{l}\text { H11: Product fidelity is positively and significantly } \\
\text { related to the three attributes of sustainable products } \\
\text { H11a: Domain-specific knowledge integration is } \\
\text { positively related to product fidelity } \\
\text { H11b: Procedural knowledge integration is }\end{array}$ & Accept & NA & Accept \\
\hline
\end{tabular}




\begin{tabular}{|c|c|c|c|}
\hline $\begin{array}{l}\text { positively related to product fidelity } \\
\text { H11c: Flexible decision-making is positively } \\
\text { related to product fidelity }\end{array}$ & & & \\
\hline $\begin{array}{l}\text { H12: Product longevity is positively and significantly } \\
\text { related to the three attributes of sustainable products } \\
\qquad \begin{array}{l}\text { H12a: Domain-specific knowledge integration is } \\
\text { positively related to product longevity } \\
\text { H12b: Procedural knowledge integration is } \\
\text { positively related to product longevity } \\
\text { H12c: Flexible decision-making is positively } \\
\text { related to product longevity }\end{array}\end{array}$ & Accept & NA & Accept \\
\hline $\begin{array}{l}\text { H13: Product fecundity positively and significantly impacts } \\
\text { performance. } \\
\text { H13a: Product fecundity positively and significantly } \\
\text { impacts environmental performance. } \\
\text { H13b: Product fecundity positively and significantly } \\
\text { impacts economic performance. } \\
\text { H13c: Product fecundity positively and significantly } \\
\text { impacts social performance. } \\
\text { H13d: Product fecundity positively and significantly } \\
\text { impacts strategic performance. }\end{array}$ & $\begin{array}{c}\text { Cautiously } \\
\text { Accept } \\
\text { H13a-d } \\
\text { Relationship } \\
\text { partially not } \\
\text { significant }\end{array}$ & $\begin{array}{c}\text { Cautiously } \\
\text { Accept } \\
\text { H13a-d } \\
\text { Relationship } \\
\text { partially not } \\
\text { significant }\end{array}$ & $\begin{array}{l}\text { Cautiously } \\
\text { Accept } \\
\text { H13a-d } \\
\text { Relationsh } \\
\text { ip partially } \\
\text { not } \\
\text { significant }\end{array}$ \\
\hline $\begin{array}{l}\text { H14: Product fidelity positively and significantly impacts } \\
\text { performance. } \\
\text { H14a: Product fidelity positively and significantly } \\
\text { impacts environmental performance. } \\
\text { H14b: Product fidelity positively and significantly } \\
\text { impacts economic performance. } \\
\text { H14c: Product fidelity positively and significantly } \\
\text { impacts social performance. } \\
\text { H14d: Product fidelity positively and significantly } \\
\text { impacts strategic performance. }\end{array}$ & $\begin{array}{c}\text { Cautiously } \\
\text { Accept } \\
\text { H14a-d } \\
\text { Relationship } \\
\text { partially not } \\
\text { significant }\end{array}$ & $\begin{array}{c}\text { Cautiously } \\
\text { Accept } \\
\text { H14a-d } \\
\text { Relationship } \\
\text { partially not } \\
\text { significant }\end{array}$ & $\begin{array}{c}\text { Cautiously } \\
\text { Accept } \\
\text { H14a-d } \\
\text { Relationsh } \\
\text { ip partially } \\
\text { not } \\
\text { significant }\end{array}$ \\
\hline $\begin{array}{l}\text { H15: Product longevity positively and significantly impacts } \\
\text { performance. } \\
\text { H15a: Product longevity positively and } \\
\text { significantly impacts environmental performance. } \\
\text { H15b: Product longevity positively and }\end{array}$ & $\begin{array}{l}\text { Cautiously } \\
\text { Accept } \\
\text { H15a-d } \\
\text { Relationship }\end{array}$ & $\begin{array}{l}\text { Cautiously } \\
\text { Accept } \\
\text { H15a-d } \\
\text { Relationship }\end{array}$ & $\begin{array}{l}\text { Cautiously } \\
\text { Accept } \\
\text { H15a-d } \\
\text { Relationsh }\end{array}$ \\
\hline
\end{tabular}




\begin{tabular}{|l|c|c|c|}
\hline $\begin{array}{l}\text { significantly impacts economic performance. } \\
\text { H15c: Product longevity positively and } \\
\text { significantly impacts social performance. }\end{array}$ & $\begin{array}{c}\text { partially not } \\
\text { significant }\end{array}$ & $\begin{array}{c}\text { partially not } \\
\text { significant }\end{array}$ & $\begin{array}{c}\text { ip partially } \\
\text { not } \\
\text { significant }\end{array}$ \\
$\begin{array}{l}\text { H15d: } \text { Product longevity positively and } \\
\text { significantly impacts strategic performance. }\end{array}$ & & \\
\end{tabular}

\section{Table 9.2 Summary of the Tested Hypotheses}

\section{Stage 1 and Stage 2, Focal Points}

A number of important findings are corroborated by stage 2 (empirical testing, Chapter 8 ) that have been mentioned in stage 1 (qualitative interview-based, Chapter 5) of the research. This section touches on the most important points that are clearly seen across both types of analyses.

First, with respect to strategic orientation, it is seen that most organizations have begun to proactively create a sustainability orientation, not only due to customer demand but because they find that an orientation towards sustainability actually provides an advantage in their particular case, either at the strategic level, the process level or the product level. This advantage then runs through the course of product development and commercialisation to product performance. This finding is much in line with the recommendations put forth by Boons et al. (2013):

“...where sustainability considerations (environmental, social, and financial) are integrated into company systems from idea generation through to research and development $(R \& D)$ and commercialization. This applies to products, services and technologies, as well as to new business and organizational models" 
However (and second), it is also found that this orientation in some way obscured when the organization assumes that the customer is either unaware, does not prioritise such considerations or is unable/unwilling to pay for a potential added premium that comes with the sustainability "tag". In this case, as interviewees point out, the organization simply does not point out that sustainability is built into the product via organizational processes, materials and/or imposed stringent regulations.

Also (third), it is difficult to quantify or assess the scale of sustainability that an organization or even product offers as yet since such mechanisms are not yet as pervasive worldwide or across industries. As Hallstedt et al. (2013) state, that some kind of environmental impact assessment (also known as EIA) or lifecycle analysis (also known as LCA) is required for this information to be accessed, objectively collected and assessed in a meaningful way. It is also a concern that organizations have the capacity or will to systematically conduct these analyses.

Fourth, there is an indication though, from both the data collection stages of this study that organizations are willing to move past the traditional outlook that sustainability is an added burden and focus on the elements that render sustainability a win-win situation with superior returns. Empirically, this is borne out from the fact that the SPD processes have a strong positive relationship with each of the dimensions of organizational performance.

Fifth, a strong agreement is seen in the case of sustainable product development processes being at the heart of creating sustainable products. Not only were these processes ranked consistently highly by all the interviewees, they were also seen to load very well in both the structural models examined. For example, knowledge integration, at the domain and procedural levels are seen as critical starting points and that flexible decision-making is what keeps the organization moving forward on track strategically. 
Sixth, product attributes and their place in the organizational ecosystem has been a complex concept at both stages of data collection. While there is strong agreement that the attributes are important and also are connected to the organizational levels of orientation as well as organizational performance, a lack of codified methods to assess the impact of sustainable products (discussed above) leads to an understandably ambiguous impact of the product attributes within the full ecosystem under study (elucidated previously).

Finally (seventh), the performance of an organization was seen in both stages of the research to be strongly affected by the SPD processes as well as the strategic orientation of the organization, while product attributes provided a more complex addition to the mix. However, it should be noted that the triple bottom line was collectively represented strongly as a performance requirement and the strong relationship as well as the loading of the construct itself proved that the organizational ecosystem, from the beginning to the end, provides entrenched considerations for sustainable products.

In summation, this chapter discusses the interpretation of the a-priori model and breaks down parts of the model into subsets to further understand the relationships posited by this research. The research questions are revisited and the findings of both stage of the research are compared. The next chapter explains the benefits and contributions of this study in the academic and managerial contexts along with outlining the limitations of the study. Future areas for potential research are also discussed. 


\section{Chapter 10 Conclusion}

The idea that sustainability can reach beyond an impractical regulatory burden to palpably uplift the performance of an organization and its products has recently and slowly been taking root in the business arena (Boons et al., 2013; Hallstedt et al., 2015; Kuhl et al., 2016). The core idea behind this study was to explore to what extent the idea of sustainability can be meaningfully embedded into the core operations of an organization. In other words, this research empirically explores whether there is an advantage (or a lack of disadvantage) in creating an organizational ecosystem that caters to sustainability considerations, from strategy, to processes, to products, to performance.

Being the concluding piece of this document, this chapter outlines the academic contributions and managerial implications resulting from this research. Then the limitations of the study are enumerated followed by a discussion of the potential for future study stemming from this research.

\subsection{Academic Contributions}

First, and what is the single most important contribution of this study is that it is the first of its kind to incorporate multiple different areas of operations strategy, new product development, innovation and sustainability in one academically vetted and coherent discourse to examine to the effects of producing sustainable products in the context of the organization. The study conducts a complex systematic assessment across the three strategic levels, namely that of the organization, 
process/decision-making and product, making this novel contribution indispensable from a theory-building perspective.

Second, the study successfully as well as meaningfully transplants (and examines) the concept of social contagion from new product development literature to the context of sustainable products. Attributes intrinsic to products that affect how popular these products are in the market can potentially assist in the understanding of many theoretical puzzles in the areas of product development and sustainable operations, such as whether products can be socially desirable based on intrinsic characteristics, or how alternate product lifecycles can change the current paradigm of disposable consumerism supported by regulations, or whether various modularised families of products can be introduced in the market that cater to segment-specific long-term needs. This contribution is also important from the point of view of theory development in the subject area since social contagion is yet to be absorbed as a phenomenon related to sustainability in products.

Third, this research successfully empirically tests the scales taken from new product literature in the context of sustainable products and provides a number of interesting insights into both the theoretical aspects as well as the applicability of the components of the scales as they apply to this study and area of management. For example, the fit of the NPD and sustainability scales in the context of sustainable products is seen to be very appropriate, however, further research may benefit from augmentation of these adopted scales, especially where items related to processes or performance dimensions are concerned. This study provides a strong base for further augmentation or re-specification of the scales in order to discover whether other potential dimensions of the constructs ${ }^{8}$ used can also be contextualised differently.

\footnotetext{
${ }^{8}$ For example, performance along the lines of a quality framework or lean manufacturing, or processes specifically taking into account modularised product families and to what extend modularisation is utilised.
} 
Fourth, this research tests and finds ample support for the four second order constructs of strategic orientation, sustainable product development processes, product attributes and performance. Understanding these constructs conceptually as being multi-dimensional in nature provides not only a more holistic capture of data but also better interpretation from a theoretical perspective. The support found from the data proves that the manner in which these constructs are modeled indeed offers an explanation that respects the integrity and complexity of the phenomena being examined in the form of multi-dimensional second order constructs(as compared to a set of unrelated component constructs).

\subsection{Managerial Implications}

The results from this study have some interesting insights to offer managers in the field. Here, only the overarching conclusions are briefly enumerated, since there are potentially more ramifications that may be specific to various positions of responsibility.

First, the most important implication is that the incorporation of sustainability into the structure of the organization from beginning to end for medium-large and large organizations with a substantial technology component (high-tech firms) provides benefits ${ }^{9}$ to a significant extent. This appears to be because sustainable products, i.e. products created with sustainable processes and keeping in mind sustainability goals can now be manufactured in a manner that

\footnotetext{
${ }^{9}$ These perceived benefits include, but are not limited to eventual decrease in costs, especially due to noncompliance and outdated systems, forced change in systems due to regulation enforcement, increased quality due to stringent standards, increased consumer base and thus an increase in profits (source: Chapter 9, discussion of findings from stage 1 and 2 of this study. ).
} 
renders them competitively at par with other products, at least where economies of scale are present.

Second, results imply that a structured review and assessment system would potentially be helpful in creating more performance-oriented sustainability practices and products, bettering organizational well-being in the long run. This is especially true since the triple bottom line of performance was considered equally important throughout the empirical data sample.

Third, it should be noted that the complex relationship between product attributes and performance implies that managers cannot rely on an organization's already established strategic orientation and development processes to carry a product's performance for an organization. Individual focus on each product's potential attributes and establishing the best possible fit between the attributes and the orientation and processes ensures that total organizational performance is capitalised on (in other words optimised) for each product offering.

Fourth, the results of both stages, but especially stage 1, imply that incorporating sustainability goals is more fruitful in the long-run, even if this is not advertised to the consumer interim. Following stringent regulations and additional resources deployed to produce better products may sometimes lead to a marginal increase in costs, but this is more-often-than-not offset by the willingness of the customer to pay for a superior product offering. In other cases, having assessment tools handy such as lifecycle analysis make a desirable selling point for the initiated and help tap into a wider customer base.

Fifth, taking into consideration that research is at a nascent stage at this point, the strategic level incorporation of sustainability orientation and goals appears to provide a significant benefit in cost-saving (when performance benefits are holistically weighed against costs of implementing sustainability) alone for larger organizations. It is expected that other dimensions of performance, 
when measured, as well as introduction of sustainability-specific attributes on a product and process level may increase the advantages of introducing sustainable offerings for an organization.

\subsection{Limitations}

As with most research in the social sciences, where human responses populate data points, there are a number of limitations that are admittedly a part of this study. One limitation of this study could be the nature of its data collection in the both stages of this study. The snowball sampling technique used in stage 1 to gain interviews may limit the applicability of this study's findings, since there may be a bias associated with the possibility that the researcher(s) interviewed within a particular social or professional network. However, it can be noted that executives are generally seen to be hard to interview and/or survey and thus the sampling technique is generally held acceptable for an exploratory study (Cycyota and Harrison, 2006; Lee et al., 1999). Also, considering the geographic and industry spread of the sample, generalizability need not be highly curtailed.

Data collection in stage 2 of the study also may be subject to certain biases. For example, bias due to respondents being the single source of data for most organizations (or geographically distinct operations of the same), or bias related to social desirability. Even though triangulation using multiple respondents would have eliminated single source bias, it would have defeated the purpose of the study and limited the scope of analysis of the results because resource constraints would have led to a very small and segmented sample, leading to difficulties with interpretation and generalisation. To lessen the impact of this trade off, the common method bias test was 
conducted, to ensure that the sample was admissible for the purposes of the study. The respondents also had complete anonymity and confidentiality, which would substantially lessen the impact of socially desirable answers.

Another possible limitation might be that the results of the study might not be generalizable when considering applicability to disparate economies compared to the sample analysed. Therefore, there might be other contingent factors ${ }^{10}$ which affect the system under observation, which might change how results are interpreted.

Yet another limitation of this study is nature of the target population. Empirical data was collected from large or near-large organizations with technology-intensive operations (high-tech firms) across North America and India. These results should be interpreted with caution for other geographical and industrial segments and may not be applicable to smaller firms. As mentioned before, the wide spread of industry in the data sample guards against highly inapplicable results. The study also has three limitations related to the fact that it is a preliminary exploration into a nearly uncharted area. First, the novelty of the subject area means that quantification of levels of sustainability such as along a scale, or incorporation of the impact of product lifecycles was missing, simply because such data is neither available nor adequately measurable/interpretable at this time.

In addition to this, this particular research was focused on the ecosystem intrinsic to the organization, so the effect of external factors was not considered or assessed. Lastly, this research offers a snapshot of the state of organizations at a particular space in time. Though most of the

\footnotetext{
${ }^{10}$ Many diverse factors can be contingent in such a situation, depending on the kind of economy under observation. For example, in the case of China, stringent social and economic regulations come into play as well as the gigantic scale of production at all levels of quality. This is only one aspect of how China as an economy is different from others. Depending on the kind of study being conducted, the external factors will change, in some cases to a very great extent.
} 
focus of the research is at the strategic level, the static nature of the study may not take into consideration factors that come into play over time.

\subsection{Future Directions}

Since this area is extremely underexplored, there is huge potential for future research. The suggestions listed below more specifically pertain to the findings resulting from this study. Of course, perhaps the first suggestion for future research would be conducting a longitudinal analysis and integrating factors ${ }^{11}$ that affect the organization and its product offerings over time. Yet another simple extension of this study would be observing the behaviour of the posited research models with other datasets, perhaps with a smaller firm size, or other countries, or other industries such as fast-moving consumer goods (FMCG). The effect of having (or not having) certification such as ISO 14000, for example, can be checked on the tested model. If resources exist to collect a larger data set, subgroup differences can also be tested to analyse in further detail whether the results currently obtained are truer for certain groups or segments (such as differences across developed and developing countries, various industries, organization sizes) of the target population.

A more substantial suggestion for future research would be based on the approach to the research question. Since the ecosystem explored was intrinsic to the organization, external factors such as drivers of market success or performance may be a good starting point. An idea of

\footnotetext{
${ }^{11}$ There are potentially a lot of factors that can come into play in a case such as this. Some include the performance of a product over time, the change in organizational strategy and orientations, the changes in regulation and other dynamic aspects.
} 
how the organizational ecosystem changes with external influences or pressure would be interesting to observe. Alternatively, analysing a greater network of effects by creating a variation of the current model such as a non-recursive model, such as in the case of building in a feedback loop might be a more challenging exploration, but would yield more nuanced rewards. Another appealing research direction is concerned with the product attributes and their effects in the context of sustainable products. Further research may be conducted into other strata of management studies to unearth whether other attributes exist to enhance or theoretically augment the current fit in the sustainable organization, process and product ecosystem.

Yet another considerable area for future exploration relates to that of the level of product sustainability, i.e. the quantification of sustainability as a scale and the assessment of lifecycles or environmental impacts of such products. Work in this area excludes policy-oriented research and environmental rankings and scales (such as those developed by third-party IGOs) that do not specifically address core business operations and offerings. Since literature on these areas is currently not developed to a stage where it can be convincingly coalesced with sustainability within the organization, such work would indeed be an avenue for future research. 


\section{References}

Acur, N., Kandemir, D., \& Boer, H. (2012). Strategic Alignment and New Product Development: Drivers and Performance Effects. Journal of Product Innovation Management,29(2), 304-318.

Akgün, A. E., Keskin, H., \& Byrne, J. (2012).Antecedents and Contingent Effects of Organizational Adaptive Capability on Firm Product Innovativeness. Journal of Product Innovation Management,29(S1), 171-189.

Akgün, A. E., Byrne, J., Keskin, H., Lynn, G. S. \& Salih, Z. I. (2005). Knowledge networks in new product development projects: A transactive memory perspective. Information \& Management, 42, 1105-1120

Aldrich, H.E., \& Fiol, C.M. (1994). Fools rush in? The institutional context of industry creation. Academy of Management Review, 19 (4), 645-670.

Anderson, J. R. (1983). The architecture of cognition. Cambridge, MA: HBS Press.

Ansoff, H. I. (1975). Managing strategic surprise by response to weak signals. California Management Review, 18 (2), 21-33.

Armstrong, J. S., \& Collopy, F. (1996). Competitor orientation: Effects of objectives and information on managerial decisions and profitability. Journal of Marketing Research, 13 (May), 188-199.

Atuahene-Gima, K. (1995). An exploratory analysis of the impact of market orientation on new product performance. Journal of Product Innovation Management, 12, 275-293.

Atuahene-Gima, K. (2003). The effects of centrifugal and centripetal forces on product development speed and quality: How does problem solving matter? Academy of Management Journal,46 (3), 359-373.

Atuahene-Gima, K., \& Li, H. (2004).Strategic decision comprehensiveness and new product development outcomes in new technology ventures. Academy of Management Journal, 47 (4), 583-597. 
Atuahene-Gima, K., S. F. Slater, \& E. M. Olson. (2005). The contingent value of responsive and proactive market orientations for new product program performance. Journal of Product Innovation Management, 22(6), 464-482.

Azar, C., Holmberg, J., \& Lindgren, K. (1996). Socio-ecological indicators for sustainability. Ecological Economics, 18, 89-112.

Baker, W. E., \& Sinkula. J. M. (2005). Market orientation and the new product paradox. Journal of Product Innovation Management,22, 483-502.

Barney, J. B. (1991). Firm resources and sustained competitive advantage. Journal of Management, 17 (1), 99-120.

Bansal, P., \& Roth, K. (2000) Why companies go green: a model of ecological responsiveness. Academy of Management Journal, 43(4), 717-736.

Bauer, R. A. (1960). Consumer behavior as risk taking. In R. S. Hancock (ed.), Dynamic marketing for a changing world (pp. 389-398). Chicago, IL: American Marketing Association.

Belz, F., \& Peattie, K. (2009).Sustainability Marketing: A Global Perspective, Glasgow, UK: Wiley.

Bennett, R., \& Cooper, R. (1981).Beyond the marketing concepts. Business Horizons , 22 (June), 76-83.

Bennett, S.J. (1991). The Complete Guide to Small Business Opportunities from the Environmental Revolution. New York, NY: Wiley.

Bentler, P. M. (1990). Comparative fit indexes in structural models. Psychological Bulletin, $107,238-246$.

Bereketli, I., \& Genevois, M. E. (2013). An integrated QFDE approach for identifying improvement strategies in sustainable product development. Journal of Cleaner Production, 54, 188-198.

Berle, G., (1991). The Green Entrepreneur: Business Opportunities that Can Save the Earth and Make You Money. Blue Ridge Summit, PA: Liberty Hall Press 
Bharadwaj, S. G., Varadarajan, P. R., \& Fahy, J. (1993). Sustainable competitive advantage in service industries: A conceptual model and research propositions. Journal of Marketing, 57 (October), 83-99.

Boons, F., \& Lüdeke-Freund, F. (2013). Business models for sustainable innovation: state-ofthe-art and steps towards a research agenda. Journal of Cleaner Production, 45, 9-19.

Boons, F., Montalvo, C., Quist, J., \& Wagner, M. (2013). Sustainable innovation, business models and economic performance: an overview. Journal of Cleaner Production, 45, 1-8.

Boons, F.A.A. (2009).Creating Ecological Value. An Evolutionary Approach to Business Strategies and the Natural Environment. Cheltenham, UK: Elgar.

Brenner, M. J., \& Tushman, M. L. (2003). Exploitation, exploration, and process management: The productivity dilemma revisited. Academy of Management Review, 28, 238256.

Brockman, B. K., \& Morgan, R. M. (2003).The role of existing knowledge in new product innovativeness and performance. Decision Sciences, 34(2), 385-419.

Bruyere, B., \& Rappe, S. (2007). Identifying the motivations of environmental volunteers. Journal of Environmental Planning and Management, 50 (4), 503-516.

Bullard, O., \& Manchanda, R. V. (2013). Do sustainable products make us prevention focused? Marketing Letters, 24, 77-189. DOI 10.1007/s11002-012-9221-2

Byrne, B. M. (1998). Structural Equation Modeling with LISREL, PRELIS, and SIMPLIS: Basic Concepts, Applications, and Programming. Mahwah, N.J.: Lawrence Erlbaum Associates. ISBN: 0-8058-2924-5.

Calantone, R. J., Chan, K., \& Cui, A. S. (2006). Decomposing product innovativeness and its effects on new product success. Journal of Product Innovation Management, 23 (5), 408421.

Campbell, D. J., \& Furrer, D. W. (1995). Goal setting and competition as determinants of task performance. Journal of Organizational Behavior, 16 (4), 377-389.

Carbonell, P., \& Rodriguez A. I. (2006).The impact of market characteristics and innovation speed on perceptions of positional advantage and new product performance. International Journal of Research in Marketing, 23, 1-12. 
Carrillo-Hermosilla, J., del Río, P., \& Könnölä, T. (2010). Diversity of eco-innovations: reflections from selected case studies. Journal of Cleaner Production, 18, 1073-1083.

Chen, C, Zhu, J., Yu, J., \& Noori, H. (2012).A new methodology for evaluating sustainable product design performance with two-stage network data envelopment analysis. European Journal of Operational Research, 221, 348-359.

Chen, Y. S., Lai, S. B., \& Wen, C. T. (2006). The influence of green innovation performance on corporate advantage in Taiwan. Journal of Business Ethics, 67, 331-339.

Chesbrough, H. (2003). Open innovation: The new imperative for creating and profiting from technology. Boston: HBS Press.

Chesbrough, H. (2007). The market for innovation: Implications for corporate strategy. California Management Review, 49 (3), 45-66.

Chesbrough, H., \& Schwartz, K. (2007). Innovating business models with co-development partnerships. Research Technology Management, 50 (1), 55-59.

Christensen, C. M., \& Bower, J. L. (1996).Customer power, strategic investment, and the failure of leading firms. Strategic Management Journal, 17, 197-218.

Christensen, J. F., Olesen, M. H., \& Kjaer, J. S. (2005). The industrial dynamics of open innovation-evidence from the transformation of consumer electronics. Research Policy, 34 (10), 1533-1549.

Chung, Y., \& Tsai, C. (2007). The effect of green design activities on new product strategies and performance: An empirical study among high-tech companies. International Journal of Management, 24 (2), 276-288.

Clark, K. B., \& Fujimoto, T. (1991).Product development performance: Strategy, organization and management in the world auto industry. Boston, MA: HBS Press.

Cohen, B., \& Winn, M.I. (2007).Market imperfections, opportunity and sustainable entrepreneurship. Journal of Business Venturing, 22, 29-49.

Cohen, W. M., \& Levinthal, D. A. (1990). Absorptive capacity: A new perspective on learning and innovation. Administrative Science Quarterly, 42, 1-34. 
Cohen, W. M. (1991). Individual learning and organizational routine: Emerging connections. Organization Science, 2, 135-139.

Cohen, W. M., \& Levinthal, D. A. (1989). Innovation and learning: The two faces of R\&D. Economic Journal, 99, 569-596.

Colazo, J. A. (2010). Collaboration structure and performance in new software development: Findings from the study of open source projects. International Journal of Innovation Management, 14(5), 735-758.

Collis, D. J., \& Montgomery, C. A. (1995). Competing on resources: Strategy in the 1990s. Harvard Business Review,73 (4), 118-128.

Cooper, R. G. (1979). The dimensions of industrial new product success and failure. Journal of Marketing, 43, 93-103.

Cooper, R. G. (1985). Industrial firms' new product strategies. Journal of Business Research, $13,107-121$.

Cooper, R. G., \& Kleinschmidt, E. J. (1987). Success factors in product innovation. Industrial Marketing Management, 16, 215-223.

Curran, R.G., West, S.G., \& Finch, J. F. (1996). The Robustness of Test Statistics to NonNormality and Specification Error in Confirmatory Factor Analysis. Psychological Methods, 116-29.

Cycyota, C. S., \& Harrison, D. A. (2006). What (not) to expect when surveying executives: A meta analysis of top manager response rates and techniques over time. Organizational Research Methods, 9(2), 133-160.

Dangelico, A., Pontrandolfo, P., \& Pujari, D. (2013). Developing Sustainable New Products in the Textile and Upholstered Furniture Industries: Role of External Integrative Capabilities. Journal of Product Innovation Management,30(4), 642-658.

Dawkins, R. (1976). The selfish gene. Oxford, UK: Oxford University Press.

Day, G. S. (1990). Market-driven strategy: Processes for creating value. New York: The Free Press. 
De Toni, A., \& Nassimbeni, G. (2001). A method for the evaluation of suppliers co-design effort. International Journal of Production Economics, 72,169-180.

de Medeiros, J. F., Ribeiro, J. L. D., Cortimiglia, M. N. (2014). Success factors for environmentally sustainable product innovation: a systematic literature review. Journal of Cleaner Production, 65, 76-86.

Dean, T.J., \& McMullen, J.S. (2007). Toward a theory of sustainable entrepreneurship: reducing environmental degradation through entrepreneurial action. Journal of Business Venturing,22, 50-76.

Debruyne, M., Rudy, M., Griffin, A., Hart, S., Hultink, E. J., and Robben, H. (2002). The impact of new product launch: Strategies on competitive reaction in industrial markets. Journal of Product Innovation Management, 19 (2), 159-170.

Delmar, F., \& Shane, S. (2004). Legitimating first: organizing activities and the survival of new ventures. Journal of Business Venturing, 19 (3), 385-410.

Dennett, D. C. (1995). Darwin's dangerous idea: Evolution and the meanings of life. New York, NY: Simon and Schuster.

Deshpandé, R., Farley, J. U., \& Webster, F. E. (1993). Corporate culture, customer orientation, and innovativeness in Japanese firms: A quadrad analysis. Journal of Marketing,57, 23-37.

Dess, G. G., \& Lumpkin, G. T. (2005). The role of entrepreneurial orientation in stimulating effective corporate entrepreneurship. Academy of Management Executive, 19 (1), 147-156.

Dillman, D. A. (2000).Mail and internet surveys: The tailored design method. New York, NY: John Wiley \& Sons.

Dillman, D., Smyth, J. \& Christian, L. (2009).Internet, Mail, and Mixed-Mode Surveys: The Tailored Design Method, New York: Wiley.

Dissanayake, D., Tilt, C. \& Xydias-Lobo, M. (2016). Sustainability reporting by publicly listed companies in Sri Lanka. Journal of Cleaner Production, 129, 169-182.

Dougherty, D. (1992). Interpretive barriers to successful product innovation in large firms. Organization Science, 3 (2), 179-202. 
Dyllick, T., \& Hockerts, K. (2002). Beyond the business case for corporate sustainability. Business Strategy and the Environment, 11 (2), 130-141.

Eisenhardt, K. (1989). Building theories from case study research. Academy of Management Review, 14, 532-550.

Eisenhardt, K. M. (1990). Speed and strategic choice: How managers accelerate decisionmaking. California Management Review, 32 (3), 39-54.

Elbanna, S. (2006). Strategic decision-making: Process perspectives. International Journal of Management Reviews, 8 (1), 1-20.

Elkington, J., (1997). Cannibals with Forks: The Triple Bottom Line of 21st Century Business. Oxford, UK: Capstone Publishing.

Enkel, E., Gassmann, O., \& Chesbrough, H. (2009). Open R\&D and open innovation: Exploring the phenomenon. R\&D Management, 39 (4), 311-316.

Enkel, E., Kausch, C., and Gassmann, O. (2005). Managing the risk of customer integration. European Management Journal,33 (2), 203-213.

Eppink, D. J. (1978).Planning for strategic flexibility. Long Range Planning, 11 (August), 915.

Evans, J. S. (1991). Strategic flexibility for high technology manoeuvres: A conceptual framework. Journal of Management Studies, 28 (1), 69-89.

Fishbein, M., \& Ajzen, I. (1975).Belief, attitude, intention, and behavior: An introduction to theory and research. Reading, MA: Addison-Wesley.

Fleischmann, M., Bloemhof-Ruwaard, J.M., Dekker, R., Van der Laan, E.A., Van Nunen, J.A.E.E., \& Van Wassenhove, L.N. (1997). Quantitative models for reverse logistics: a review. European Journal of Operational Research,103, 1-13.

Franceschini, S, Faria, L.G.D., \& Jurowetzki, R. (2016). Unveiling scientific communities about sustainability and innovation. A bibliometric journey around sustainable terms. Journal of Cleaner Production, 127, 72-83. 
Frishammar, J., Lichtenthaler, U., \& Rundquist, J. (2012). Identifying Technology Commercialization Opportunities: The Importance of Integrating Product Development Knowledge. Journal of Product Innovation Management,29(4), 573-589.

Fornell, C. \& Larcker, D. F. (1981). Evaluating Structural Equation Models with Unobservable Variables and Measurement Error. Journal of Marketing Research, 18(1), 3950 .

Gassmann, O., \& von Zedtwitz, M. (2003).Trends and determinants of managing virtual R\&D teams. $R \& D$ Management, 33(3), 243-262.

Gatignon, H., \& Xuereb, J.M. (1997). Strategic orientation of the firm and new product performance. Journal of Marketing Research, 34 (February), 77-90.

Gaziulusoy, A. I., \& Boyle, C. (2013).Proposing a heuristic reflective tool for reviewing literature in transdisciplinary research for sustainability. Journal of Cleaner Production, 48, 139-147.

Gaziulusoy, A. I., Boyle, C., \& McDowall, R. (2013). System innovation for sustainability: a systemic double-flow scenario method for companies. Journal of Cleaner Production, 45, 104-116.

Genç, E., \& Di Benedetto, C. A. (2015). Cross-functional integration in the sustainable new product development process: The role of the environmental specialist. Industrial Marketing Management, 50, 150-161.

Gertsakis, J., Lewis, H., \& Ryan,C. (1997). A Guide to Eco ReDesign. National Centre for Design at RMIT, Melbourne GPO Box 2476V Melbourne 3001, Australia.

Gerwin, D. (1993). Manufacturing flexibility: A strategic perspective. Management Science, 39 (4), 395-410.

Gerbing, D.W., \& Anderson, J.C. (1993). Monte Carlo evaluations of goodness-of-fit indices for structural equation models. In K.A. Bollen, \& J.S. Long (eds.), Testing structural equation models. Newbury Park, CA: Sage.

Gladwin, T.N., Kennelly, J.J., \& Krause, T. (1995).Shifting Paradigms for Sustainable Development: Implications for Management Theory and Research. Academy of Management Review, 20(4), 874-907. 
Glavic, P., \& Lukman, R. (2007). Review of sustainability terms and their definitions. Journal of Cleaner Production, 15 (18), 1875-1885.

Goldenberg, J., Lehmann, D. R., \& Mazursky, D. (2001).The idea itself and the circumstances of its emergence as predictors of new success. Management Science, 47 (1), $69-84$.

Govindan K., Khodaverdi, R, \& Jafarian, A. (2013). A fuzzy multi criteria approach for measuring sustainability performance of a supplier based on triple bottom line approach. Journal of Cleaner Production, 47, 345-354.

Grewal, R., \& Tansuhaj, P. (2001).Building organizational capabilities for managing economic crisis: The role of market orientation and strategic flexibility. Journal of Marketing, 65 (2), 67-80.

Griffin, A., \& Page, A. L. (1996). PDMA success measurement project: Recommended measures for product development success and failure. Journal of Product Innovation Management, 13, 478-496.

Grin, J., Rotmans, J., \& Schot, J. (2010). Transitions to Sustainable Development: New Directions in the Study of Long Term Transformative Change. New York, NY: Routledge.

Groves, R. M., Fowler, F. J. Jr., Couper, M. P., Lepkowski, J. M., Singer, E., \& Tourangeau, R. (2009).Survey Methodology, $2^{\text {nd }}$ Ed. Somerset, NJ: John Wiley\& Sons.

Gunasekaran, A., \& Gallear, D. (2012). Editorial: Special Issue on Sustainable development of manufacturing and services. International Journal of Production Economics, 140, 1-6.

Guo, L. (2008). Perspective: An analysis of 22 years of research in JPIM. Journal of Product Innovation Management, 25 (3), 249-260.

Hallstedt, S. I., Bertoni, M., \& Isaksson, O. (2015). Assessing sustainability and value of manufacturing processes: a case in the aerospace industry. Journal of Cleaner Production, 108, 169-182.

Hallstedt, S. I., Thompson, A. W., \& Lindahl, P. (2013). Key elements for implementing a strategic sustainability perspective in the product innovation process. Journal of Cleaner Production, 51, 277-288. 
Hallstedt, S., Ny, H., Robèrt, K.H., \& Broman, G. (2010). An approach to assessing sustainability integration in strategic decision systems. Journal of Cleaner Production, 18, 703-712.

Han, J. K., Kim, N., \& Srivastava, R. K. (1998). Market orientation and organizational performance: Is innovation a missing link? Journal of Marketing, 62, 30-45.

Hargadon, A., \& Fanelli, A. (2002). Action and possibility: Reconciling dual perspectives of knowledge in organizations. Organization Science, 13 (3), 290-302.

Havlena,W. J., \& DeSarbo, W. S. (1991). On the measurement of perceived consumer risk. Decisions Sciences, 22 (4), 927-939.

Henard, D. H., \& Szymanski, D. M. (2001). Why some new products are more successful than others. Journal of Marketing Research, 38 (3), 362-375.

Henderson, R. M., \& Clark, K. B. (1990). Architectural innovation: The reconfiguration of existing product technologies and the failure of established firms. Administrative Science Quarterly,35, 9-30.

Hayes, A. F. (2013). Introduction to mediation, moderation, and conditional process analysis. New York: The Guilford Press.

Heylighen, F. (1998). What makes a meme successful? Selection criteria for cultural evolution.15th International Congress on Cybernetics, August 24-28, Namur, Belgium.

Higgins, C. \& Coffey, B. (2016). Improving how sustainability reports drive change: a critical discourse analysis. Journal of Cleaner Production, In Press, 1-12.

Hill, C. E., Knox, S., Thompson, B. J., Williams, E. N., Hess, S. A., \& Ladany, N. (2005). Consensual qualitative research: An update. Journal of Counseling Psychology, 52, 196-205.

Hitt, M. A., Keats, B. W., \& de Marie, S. M. (1998).Navigating in the new competitive landscape: Building strategic flexibility and competitive advantage in the 21 st century. Academy of Management Executive, 12 (4), 22-42.

Holmberg, J., \& Robèrt, K.H. (2000).Backcasting e a framework for strategic planning. International Journal of Sustainable Development and World Ecology, 7 (4), 291-308. 
Hoopes, D. G., \& Postrel, S. (1999). Shared knowledge, "glitches," and product development performance. Strategic Management Journal, 20, 837-65.

Hopkins, M. (2010). How sustainability fuels design innovation. Interview with Steven Eppinger. MIT Sloan Management Review,52 (1), 75-81.

Houston, F. S. (1986). The marketing concept: What it is and what it is not. Journal of Marketing,50 (April), 81-87.

Hu, L., \& Bentler, P. M. (1999). Cutoff criteria for fit indexes in covariance structure analysis: Conventional criteria versus new alternatives. Structural Equation Modeling, 6, 155 .

Hutchins, M.J., \& Sutherland, J.W. (2008).An exploration of measures of social sustainability and their application to supply chain decisions. Journal of Cleaner Production, 16, 16881698.

Hunt, S. D., \& Morgan, R. M. (1995). The comparative advantage theory of competition. Journal of Marketing, 59 (April), 1-15.

Hurley, S., \& Chater, N. (2005).Perspectives on imitation: From cognitive neuroscience to social science. Cambridge, MA: MIT Press.

Inigo, E. A., \& Albareda, L. (2016). Understanding sustainable innovation as a complex adaptive system: a systemic approach to the firm. Journal of Cleaner Production, 126, 1-20.

Jaehn, F. (2016). Sustainable Operations. European Journal of Operational Research, 253, 243-264.

Jaworski, B. J., \& Kohli, A. K. (1993). Market orientation: Antecedents and consequences. Journal of Marketing, 57 (3), 53-70.

Jennings, P.D., \& Zandbergen, P.A. (2005). Ecologically Sustainable Organizations: An Institutional Approach. Academy of Management Review, 20(4), 1015-1052.

Jeong, I., J. H., Pae, \& Zhou, D. (2006). Antecedents and consequences of the strategic orientations in new product development: The case of Chinese manufacturers. Industrial Marketing Management, 35, 348-358. 
Jin, L., \& Sun, H. (2010). The effect of researchers' interdisciplinary characteristics on team innovation performance: Evidence from university $\mathrm{R} \& \mathrm{D}$ teams in china. International Journal of Human Resource Management, 21(13), 2488-2502.

Johnson, J. L., Lee, R. P., Saini, A., \& Grohmann, B. (2003). Market-focused strategic flexibility: Conceptual advances and an integrative model. Journal of the Academy of Marketing Science, 31 (1), 74-89.

Johnston, P., Everard, M., Santillo, D., \& Robèrt, K.H. (2007). Reclaiming the definition of sustainability. Environmental Science and Pollution Research,14 (1), 60-66.

Kahn, K. B. (2001). Market orientation, interdepartmental integration, and product development performance. Journal of Product Innovation Management, 18 (5), 314-323.

Kandemir, D., \& Acur, N. (2012). Examining Proactive Strategic Decision-making Flexibility in New Product Development. Journal of Product Innovation Management,29(4), 608-622.

Kaplowitz, M. D., Hadlock, T. D. \& Levine, R. (2004).A Comparison Of Web And Mail Survey Response Rates. Public Opinion Quarterly, 68(1), 94-101.

Keskin, D., Diehl, J. C., \& Molenaar, N. (2013). Innovation process of new ventures driven by sustainability. Journal of Cleaner Production, 45, 50-60.

Kessler, E. H., \& Bierly P. H. (2002). Is faster really better? An empirical test of the implications of innovation speed. IEEE Transactions on Engineering Management, 49, 2-12.

Kim, B., \& Kim, J. (2009). Structural factors of NPD (new product development) team for manufacturability. International Journal of Project Management, 27, 690-702.

Kim, N., Im, S., \& Slater, S. F. (2013). Impact of Knowledge Type and Strategic Orientation on New Product Creativity and Advantage in High-Technology Firms. Journal of Product Innovation Management,30(1), 136-153.

Kenny, D. A., \& Judd, C. M. (2014). Power anomalies in testing mediation. Psychological Science, 25, 334-339.

Kline, R. B. (2005). Principles and Practice of Structural Equation Modeling (2nd ed.). New York: Guilford. ISBN 978-1-57230-690-5 
Kleindorfer, P. R., Singhal, K., \& Van Wassenhove, L. N.(2005). Sustainable Operations Management. Production and Operations Management, 14(4), 482-492.

Kleinschmidt, E. J., de Brentani, U., \& Salomo, S. (2007). Performance of global new product development programs: A resource-based view. Journal of Product Innovation Management, 24 (5), 419-41.

Kohli, A. K., \& Jaworski, B. J. (1990). Market orientation: The construct, research propositions, and managerial implications. Journal of Marketing, 54 (April), 1-18.

Koschatzky, K. (2001). Networks in innovation research and innovation policy-An Introduction. In Koschantzky, K., Kulicke, M., \& Zenker, A. (Eds.), Innovation networks: Concepts and challenges in the European perspective (pp. 3-23). Heidelberg: PhySNIa Verlag.

Koufteros, X., Babbar, S., \& Kaighobadi, M., (2009). A Paradigm for Examining SecondOrder Factor Models Employing Structural Equation Modeling. International Journal of Production Economics, 120(2), 633-652.

Kuckertz, A., \& Wagner, M. (2010). The influence of sustainability orientation on entrepreneurial intentions - Investigating the role of business experience. Journal of Business Venturing, 25, 524-539.

Küçüksayraç, E. (2015). Design for sustainability in companies: strategies, drivers and needs of Turkey's best performing businesses. Journal of Cleaner Production, 106, 455-465.

Kuhl, M. R., da Cunha, J. C., Maçaneiro, M. B., \& da Cunha, S. K. (2016). Collaboration for Innovation and Sustainable Performance: Evidence of Relationship in Electro-Electronic Industry. Brazilian Business Review, 13(3), 1-25.

Kumar, V., \& Boyle, T. (1999). Status of Research on Quality and Quality Management in R\&D. In: Proceedings of the $27^{\text {th }}$ Annual Conference of the Administrative Sciences Association of Canada, 20(7).

Lambert, S. C., \& Davidson, R. A. (2013). Applications of the business model in studies of enterprise success, innovation and classification: An analysis of empirical research from 1996 to 2010. European Management Journal, 31(6), 668-681. 
Langerak, F., Hultink, E. J., \& Robben, H. S. J. (2004).The impact of market orientation, product advantage, and launch proficiency on new product performance and organizational performance. Journal of Product Innovation Management, 21, 79-94.

Langley, D. J., Pals, N., \& Ortt, J. R. (2005). Adoption of behaviour: Predicting success for major innovations. European Journal of Innovation Management, 8 (1), 56-78

Langley, D. J., Bijmolt, T. H. A., J. Ortt, R., \& Pals, N. (2012). Determinants of Social Contagion during New Product Adoption. Journal of Product Innovation Management, 29(4), 623-638.

Laursen, K., \& Salter, A. (2006). Open for innovation: The role of openness in explaining innovation performance among UK manufacturing firms. Strategic Management Journal, 27 (2), 131-150.

Lawrence, P., \& Lorsch, J. (1967). Organization and environment. Boston, MA: Harvard School of Business Administration Press.

Lee, T. W., Mitchell, T. R., \& Sablynski, C. J. (1999). Qualitative research in organizational and vocational psychology, 1979 -1999. Journal of Vocational Behavior, 55, 161-187.

Linton, J. D., Klassen, R., \& Jayaraman, V. (2007). Sustainable Supply Chains: An Introduction. Journal of Operations Management, 25(6), 1075-1082.

Little, R., \& Rubin, D. B. (1989). The analysis of social science data with missing values. Sociological Methods and Research, 18(2), 292-326.

Little, T. D., Card, N. A., Bovaird, J. A., Preacher, K. J., \& Crandall, C. S. (2007). Structural equation modeling of mediation and moderation with contextual factors. In T. D. Little, J. A. Bovaird, \& N. A. Card (Eds.), Modeling contextual effects in longitudinal studies (pp. 207230). Mahwah, NJ: Lawrence Erlbaum Associates.

Löbler, M. L., da Silva, B. G., Pozzobon, D. M., \& Gomes, C. M. (2012). Strategic Orientation Towards Sustainable Innovation: A Case Study in a Brazilian University. Journal of Technology Management and Innovation, 7(2), 196-205.

Locke, R. M. (2003). The Promise and Perils of Globalization: The Case of Nike. MIT IPC Working Paper 02-008. Cambridge, MA: MIT Press. 
Lockrey, S., \& Johnson, K. B. (2013). Designing pedagogy with emerging sustainable technologies. Journal of Cleaner Production, http://dx.doi.org/10.1016/j.jclepro.2013.05.005

Loorbach, D., \& Wijsman, K. (2013). Business transition management: exploring a new role for business in sustainability transitions. Journal of Cleaner Production, 45, 20-28.

Low, M.K., Williams, D. J., \&Dixon, A. C. (1996). Design practices for improving the endof-life disposal of telecommunications equipment. Engineering Science \& Education Journal, 5(4), 153-158.

Low, M.K., \& Williams, D.J. (1998). Manufacturing products with end-of-life considerations: an economic assessment to the routes of revenue generation from mature products. IEEE Transactions on Components, Packaging, and Manufacturing TechnologyPart $C 21(1)$.

Lukas, B. A., \& Ferrell, O. C. (2000). The effect of market orientation on product innovation. Journal of the Academy of Marketing Science, 28(2), 239-247.

Manda, B. M. K., Bosch, H., Karanam, S., Beers, H., Bosman, H., Rietveld, E., Worrell, E., \& Patel, M. K. (2016). Value creation with life cycle assessment: an approach to contextualize the application of life cycle assessment in chemical companies to create sustainable value. Journal of Cleaner Production, 126, 337-351.

Mann, H., Kumar, U., Kumar, V. \& Mann, I.J.S. (2010).Drivers of Sustainable Supply Chain Management. The IUP Journal of Operations Management, 9(4), 52 -63.

Mariadoss, B. J., Chi, T., Tansuhaj, P., \& Pomirleanu, N. (2016). Influences of Firm Orientations on Sustainable Supply Chain Management. Journal of Business Research, 69, 3406-3414.

Mascle, C. (2013). Design for rebirth (DFRb) and data structure. International Journal of Production Economics, 142, 235-246.

Mascle, C., \& Zhao, H. P. (2008). Integrating environmental consciousness in product/process development based on life-cycle thinking. International Journal of Production Economics, 112, 5-17.

Matsushita, (2002). Environmental Sustainability Report. Matsushita Electric Industrial Co., Ltd., Osaka, Japan. 
McAloone, T., \& Tan, A. (2005). Sustainable product development through a life-cycle approach to product and service creation: an exploration of the extended responsibilities and possibilities for product developers. In: Proceedings of Eco-X Conference: Ecology and Economy in Electronix, 1-12.

Melnyk, V., van Herpen, E., Fischer, A. R. H., \& van Trijp, H. C. M. (2013). Regulatory fit effects for injunctive versus descriptive social norms: Evidence from the promotion of sustainable products. Marketing Letters, 24, 191-203. DOI 10.1007/s11002-013-9234-5

Mercier-Laurent, E. (2009). Les écosystems de l'innovation. Lavoisier, ISBN 978-2-74622117-8.

Metta, H., \& Badurdeen, F. (2013). Integrating Sustainable Product and Supply Chain Design: Modeling Issues and Challenges. IEEE Transactions on Engineering Management, 60(2), 438-445.

Millar, M.M., \& Dillman, D.A. (2011). Improving Response to Web and Mixed-Mode Surveys. Public Opinion Quarterly, 75(2), 249-269.

Montalvo, C., Diaz-Lopez, F., Brandes, F. (2011). Eco-innovation Opportunities in Nine Sectors of the European Economy. European Sector Innovation Watch. European Commission, Directorate General Enterprise and Industry, Brussels

Montoya-Weiss, M. M., \& Calantone, R. (1994). Determinants of new product performance: A review and meta-analysis. Journal of Product Innovation Management, 11 (5), 397-417.

Moore, G. A. (2002). Crossing the chasm. New York, NY: Collins.

Moorman, C., \& Rust, R. T. (1999). The role of marketing. Journal of Marketing, 63, 180197.

Moon, S., Bergey, P. K., Bove, L. L., \& Robinson, S. (2016). Message framing and individual traits in adopting innovative, sustainable products (ISPs): Evidence from biofuel adoption. Journal of Business Research, 69, 3553-3560.

Mukherjee, A., \& Hoyer W. D. (2001). The effect of novel attributes on product evaluation. Journal of Consumer Research, 28 (3), 462-472. 
Narver, J. C., Slater, S. F., \& MacLachlan, D. L. (2004). Responsive and proactive market orientation and new-product success. Journal of Product Innovation Management, 21, 334347.

Narver. J. C., \& Slater, S. F. (1990). The Effect of a Market Orientation on Business Profitability. Journal of Marketing, 54 (October), 20-35.

Nattrass, B., \& Altomare, M. (2002). Dancing with the Tiger, Gabriola Island, British Columbia, Canada: New Society Publishers

Ngo, L. V., \& O'Cass, A. (2012). In Search of Innovation and Customer-related Performance Superiority: The Role of Market Orientation, Marketing Capability, and Innovation Capability Interactions. Journal of Product Innovation Management, 29(5), 861-877.

Nishant, R., Goh, M., \& Kitchen, P. J. (2016). Sustainability and differentiation: Understanding materiality from the context of Indian firms. Journal of Business Research,69, 1892-1897.

Nonaka, I., \& Takeuchi, H. (1995). The knowledge creating company. New York: Oxford University Press.

Nunnally, J. C. (1967). Psychometric theory. 1st edition. New York: McGraw-Hill.

Nunnally, J. C. (1978). Psychometric theory. 2nd edition. New York: McGraw-Hill.

Nunnally, J. C., \& Bernstein, I. H. (1994). Psychometric theory. NewYork, NY: McGrawHill.

Olivera, F. (2000). Memory systems in organizations: An empirical investigation of mechanisms for knowledge collection, storage, and access. Journal of Management Studies, 37 (6), 811-832.

Oppenheimer, M. (2006). Science and environmental policy: the role of nongovernmental organizations. Social Research,73 (3), 881-890.

Ostlund, L. E. (1974). Perceived innovation attributes as predictors of innovativeness. Journal of Consumer Research, 1 (September), 23-29. 
Pagell, M., \& Gobeli, D. (2009). How Plant Managers' Experiences and Attitudes Toward Sustainability Relate to Operational Performance. Production and Operations Management, $18(3), 278-299$.

Pagell, M., \& Wu, Z. (2009). Building a More Complete Theory of Sustainable Supply Chain Management Using Case Studies Of 10 Exemplars. Journal of Supply Chain Management, 45(2), 37-56.

Paladino, A. (2007). Investigating the drivers of innovation and new product success: A comparison of strategic orientations. Journal of Product Innovation Management, 24, 534553.

Paladino, A. (2008). Analyzing the effects of market and resource orientations on innovative outcomes in times of turbulence. Journal of Product Innovation Management, 25, 577-592.

Petala, E., Wever, R., Dutilh, C., \& Brezet, H. (2010). The role of new product development briefs in implementing sustainability: a case study. Journal of Engineering and Technology Management,27(34), 172-182.

Petrick, I. J., \& Echols, A. E. (2004). Technology roadmapping in review: A tool for making sustainable new product development decisions. Technological Forecasting and Social Change, 71, 81-100.

Ping Jr., R. A. (2004). On Assuring Valid Measures for Theoretical Models using Survey Data. Journal of Business Research, 57(2), 125-141.

Podsakoff, P.M., MacKenzie, S. B., \& Lee, J. (2003). Common Method Biases in Behavioral Research: A Critical Review of the Literature and Recommended Remedies. Journal of Applied Psychology, 88(5), 879-903.

Pornpitakpan, C. (2004). The persuasiveness of source credibility: A critical review of five decades' evidence. Journal of Applied Social Psychology, 34 (2), 243-281.

Porter, M., \& van der Linde, C. (1995). Green and competitive: Ending the stalemate. Harvard Business Review, September-October, 120-133.

Pujari, D. (2006). Eco-innovation and new product development: Understanding the influences on market performance. Technovation, 26 (1), 76-85. 
Rajagopalan, N., Rasheed, A. M., \& Datta., D. K. (1993). Strategic decision processes: Critical review and future directions. Journal of Management, 19 (2), 349-384.

Ramesh, B., \& Tiwana, A. (1999). Supporting collaborative process knowledge management in new product development teams. Decision Support Systems, 27, 213-235.

Rashid, A., Asif, F. M. A., Krajnik, P., \& Nicolescu, C. M. (2013). Resource Conservative Manufacturing: an essential change in business and technology paradigm for sustainable manufacturing. Journal of Cleaner Production. 57, 166-177.

Rauniar, R., \& Rawski, G. (2011). Organizational structuring and project team structuring in integrated product development project International Journal of Production Economics, 135, 939-952.

Raykov, T. (1997). Estimation of composite reliability for congeneric measures. Applied Psychological Measurement,21(2), 173-184.

Raykov, T. (2004). Behavioral scale reliability and measurement invariance evaluation using latent variable modeling. Behavior Therapy,35(2), 299-331.

Raykov, T. (2005). Bias-corrected estimation of noncentrality parameters of covariance structure models. Structural Equation Modeling, 12, 120-129.

Raykov, T., \& Marcoulides. G.A. (2011). Introduction to Psychometric Theory. Abingdon, Oxon: Routledge.

Raykov, T., Lee, C. L., Marcoulides, G. A., \& Chang, C. (2013). A Commentary on the Relationship Between Model Fit and Saturated Path Models in Structural Equation Modeling Applications. Educational and Psychological Measurement, 73(6), 1054-1068.

Reid, R., \& DeFilippi, R. J. (1990).Causal ambiguity, barriers to imitation, and sustainable competitive advantage. Academy of Management Review, 15 (1), 88-102.

Rogers, E. M. (2003). Diffusion of innovations. New York, NY: The Free Press.

Rose, C.M., Stevels, A., \& Ishii,K. (2000). A new approach to end-of-life design advisor (ELDA). In: Proceedings of the IEEE International Symposium on Electronics and the Environment, SanFrancisco, 99-104.

Rubin, D. B. (1976). Inference and Missing Data, Biometrika, 63(3), 581-592. 
Rubio, S., Chamorro, A., \& Miranda, F. J. (2008). Characteristics of the research on reverse logistics (1995-2005). International Journal of Production Research, 46(4), 1099-1120

Sabherwal, R. \& Fernandez, I. B. (2003). An empirical study of the effect of knowledge management processes at individual, group, and organizational levels. Decision Sciences, 34(2), 225-260.

Sanchez, R. (1995). Strategic flexibility in product competition. Strategic Management Journal, 16, 135-159.

Santamaria, L., Escobar-Tello, C., \& Ross, T. (2016). Switch the channel: using cultural codes for designing and positioning sustainable products and services for mainstream audiences. Journal of Cleaner Production, 123, 16-27.

Scott's Directories. (2014). Business \& Industrial Online Directory. http:/www.scottsinfo.com. [accessed Jan 2014].

Seuring, S., \& Müller, M. (2008), From a literature review to a conceptual framework for sustainable supply chain management. Journal of Cleaner Production, 16, 1699-1710.

Sharfman, M. P., \& Dean, J. W. (1997). Flexibility in strategic decision making: Informational and ideological perspectives. Journal of Management Studies, 34 (2), 191-217.

Sharma, S. (2000). Managerial interpretations and organizational context as predictors of corporate choice of environmental strategy. Academy of Management Journal, 43(4), 681697.

Shay, J. P., \& Baack, S. A. (2004). Expatriate assignment, adjustment and effectiveness: An empirical examination of the big picture. Journal of International Business Studies, 35(3), 216-232.

Shrivastava, P. (1995). Environmental technologies and competitive advantage. Strategic Management Journal, 16 (Special Issue), 183- 200.

Slater, S. F., \& Narver. J. C. (1995). Customer-led and market-oriented: Let's not confuse the two. Strategic Management Journal, 19 (10), 1001-1006.

Song, X. M., \& Parry, M. E. (1997). A cross-national comparative study of new product development processes: Japan and the United States. Journal of Marketing, 61, 1-18. 
Souder, W. E., Sherman, J. D., \& Davis-Cooper, R. (1993).Environmental organizational integration and new product development effectiveness. A test of contingency theory. Journal of Product Innovation Management, 15 (November), 520-533.

Spanjol, J., Mühlmeier, S., \& Tomczak, T. (2012). Strategic Orientation and Product Innovation: Exploring a Decompositional Approach. Journal of Product Innovation Management, 29(6), 967-985.

Sriboonlue, P., Ussahawanitchakit, P., \& Raksong, S. (2016). Strategic innovation capability and firm sustainability: Evidence from auto parts businesses in Thailand. Journal of Business and Retail Management Research, 10(2), 11-29

Staffiere, D.T. (1995). Designing product for the environment. In: IEEE Applied Power Electronics Conference and Exposition-APEC, 1, 76-77.

Starik, M., \& Rands G. P. (1995). Weaving and integrated web: Multilevel and multisystem perspectives of ecologically sustainable organizations. Academy of Management Review, 20(4), 908-935.

Starr, J.A., \& Macmillan, I.A. (1990). Resource cooptation via social contracting: resource acquisition strategies for new ventures. Strategic Management Journal, 11, 79-92.

Statistics Canada. (2003). Survey Methods and practices. National Library of Canada ISBN 0-660-19050-8: CS12-587-XPE

Statistics Canada.(2011). Employment Size Category, Glossary of Terms. https://www.ic.gc.ca/eic/site/cis-sic.nsf/eng/h_00005.html\#employment_size_category [accessed Jan 2014].

Stevens, J. (2002). Applied multivariate statistics for the social sciences (4th ed.) Mahwah, NJ: Lawrence Erlbaum Associates.

Stewart, K. A., \& Segars, A.H. (2002). An Empirical Examination of the Concern for Information Privacy Instrument, Information Systems Research,13(1), 36-49.

Suchman, M.C. (1995). Managing legitimacy: strategic and institutional approaches. Academy of Management Review, 20(3), 571-610. 
Sutton, R.I., \& Staw, B.M. (1995). What Theory is Not. Administrative Science Quarterly, 40(3), 371-84.

Tabachnick, B.G., \& Fidell, L.S. (2007). Using Multivariate Statistics (5th Ed.). Boston: Pearson.

Tanaka, J.S. (1993). Multifaceted conceptions of fit in structural equation models. In K.A. Bollen, \& J.S. Long (eds.), Testing structural equation models. Newbury Park, CA: Sage.

Teece, D. J. (1988). Capturing value from technological innovation: Integration, strategic partnering, and licensing decisions. Interfaces, 18(3), 46-61.

Teece, D. J. (2010). Business Models, Business Strategy and Innovation. Long Range Planning, 43, 172-194.

Tibben-Lembke, R. S. (2002). Life after Death: reverse logistics and the product life cycle. International Journal of Physical Distribution and Logistics, 32(3), 223-244.

Trotta, M. G. (2010). Product Lifecycle Management: Sustainability and knowledge management as keys in a complex system of product development. Journal of Industrial Engineering and Management, 3(2), 309-322.

Tukker, A., \& Jansen, B. (2006). Environmental impacts of products: a detailed review of studies. Journal of Industrial Ecology, 10(3), 159-182.

Tukker, A., Emmert, S., Charter, M., Vezzoli, C., Sto, E., Andersen, M., Geerken, T., Tischner, U., \& Lahlou, S. (2008). Fostering change to sustainable consumption and production: an evidence based view. Journal of Cleaner Production, 16(11), 1218-1225.

Ullman, J. B. (2001). Structural equation modeling. In B. G. Tabachnick \& L. S. Fidell (Eds.), Using Multivariate Statistics (4th ed.) (pp. 653-771). Needham Heights, MA: Allyn \& Bacon.

Ullman, D. G. (2010). The mechanical design process. Boston: McGraw-Hill.

United Nations Economic Commission for Europe. (2004). Sustainable development concept and action, http://www.unece.org/oes/nutshell/20042005/focus_sustainable_development.html [Accessed January 2014]. 
van Weenen, J. C. (1995). Toward Sustainable Product Development. Journal of Cleaner Production,3(1-2), 95-100.

Verganti, R. (1999). Planned flexibility: Linking anticipation and reaction in product development projects. Journal of Product Innovation Management, 16(4), 363-376

Verona, G. (1999). A resource-based view of product development. Academy of Management Review, 24(1), 132-142.

Veryzer, R. W. (1998). Key factors affecting customer evaluation of discontinuous new products. Journal of Product Innovation Management, 15(2), 136-150.

Wang, J., \& Wu, L. (2016). The impact of emotions on the intention of sustainable consumption choices: evidence from a big city in an emerging country. Journal of Cleaner Production, 126, 325-336.

Wang, Q. (1997). R\&D/marketing interface in a firm's capability-building process: Evidence from pharmaceutical firms. International Journal of Innovation Management, 1(1), 23-52.

Wells, W. D., Moriarty, S., \& Burnett, J. (2005). Advertising: Principles and practice. Englewood Cliffs, NJ: Prentice Hall.

Williams, R. (2002). Memetics: A new paradigm for understanding customer behaviour? Marketing Intelligence \& Planning, 20(3), 162-167.

Wright, S. (1918). On the Nature of Size Factors. Genetics, 3, 367-74.

Wright, S. (1934). The Method of Path Coefficients. Annals of Mathematical Statistics, 5, 161-215.

Yang, H. D., Kang, H. R., \& Mason, R. M., (2008). An exploratory study on meta skills in software development teams: Antecedent cooperation skills and personality for shared mental models.European Journal of Information Systems, 17(1), 47-61.

Yang, Y., Wang, Q., Zhu, H., \& Wu, G. (2012) What Are the Effective Strategic Orientations for New Product Success under Different Environments? An Empirical Study of Chinese Businesses.Journal of Product Innovation Management, 29(2), 166-179. 
Yannopoulos, P., Auh, S., \& Menguc, B. (2012).Achieving Fit between Learning and Market Orientation: Implications for New Product Performance. Journal of Product Innovation Management,29(4), 531-545.

Younesi, M., \& Roghanian, E. (2015). A framework for sustainable product design: a hybrid fuzzy approach based on Quality Function Deployment for Environment. Journal of Cleaner Production, 108, 385-394.

Zahra, S.A., Gedajlovic, E., Neubaum, D.O., \& Shulman, J.M. (2009). A typology of social entrepreneurs: motives, search processes and ethical challenges. Journal of Business Venturing,24(5), 519-532.

Zhang, F., \& Zwolinski, P. (2011). Optimized navigation system for eco-design management.12e Colloque National AIP PRIMECA, Le Mont Dore. 29 March - 01 April, 2011.

Zhang, F., Rio, M., Allais, R., Zwolinski, P., Carrillo, T. R., Roucoules, L., Mercier-Laurent, E., \& Buclet, N. (2013). Toward an systemic navigation framework to integrate sustainable development into the company. Journal of Cleaner Production, 54, 199-214.

Zimmerman, M., \& Zeitz, G.J. (2002).Beyond survival: achieving new venture growth by building legitimacy. Academy of Management Review, 27(3), 414-431. 


\section{Appendices}

\section{Appendix 1.0: List of Abbreviations Used}

3BL Triple Bottom Line

AHP Analytical Hierarchy Process

D4S Design for Sustainability

DFD Design For Disassembly

DfE Design for Environment

DFR Design For Recyclability

DFRb Design for Rebirth

DFRM Design For Remanufacturability

DFRU Design For Reusability

FAHP Fuzzy Analytical Hierarchy Process

IP Intellectual Property

KI Knowledge Integration

LCA Life Cycle Assessment/Analysis

NPD New Product Development

QFD Quality Function Deployment

QFDE Quality Function Deployment for Environment

S-PD Sustainable Product Development

SPDP Sustainable Product Development Processes 


\section{Appendix 2.0: Draft Questions prepared for Semi Structured Interviews}

1. Based on your experience(s) in product development as related to a sustainable product, please discuss any one specific example which is most particularly familiar to you. Please describe, in detail:

a. The strategic orientations that assisted in the conceptualisation and development of the sustainable product (please rank)

b. The strategic development processes, especially knowledge related, that were useful for the development of the sustainable product (please rank)

c. If the processes of developing sustainable products were seen to differ from developing other products

2. After the example has been described and discussed; the interviewee will be provided the following:

a. The definition of sustainable products put forth in Chapter 1, from Belz and Peattie (2009)

b. The list of characteristics of sustainable products discussed in Chapter 1 from Belz and Peattie (2009)

c. The list of three attributes discussed in Chapter 2 and their definitions.

The interviewee will then be asked if (s)he agrees that these characteristics and attributes apply to sustainable products in his/her experience, they will also be asked to rank the relative importance of these attributes. 
3. Then, the interviewee will be asked what characteristics or attributes (s)he deems to be most important in a sustainable product; based on the definition put forth in Chapter 1, which will be provided again. Probing questions will be asked related to why these characteristics/attributes are deemed important in his/her experience, such as:

a. Why do you think this is important?

b. Could you provide more detail with respect to this attribute?

c. Could you associate this attribute to your previous example?

d. Other questions will be asked as the situation requires.

4. After this, the interviewee will be asked whether these development processes and product attributes were seen to affect organization performance in any way. Questions will be asked as follows:

a. Do you think these processes or the product attributes affected the strategic performance of your organization?

b. Do you think these processes or the product attributes affected the corporate social performance of your organization?

c. Do you think these processes or the product attributes affected the environment related performance of your organization?

d. Do you think these processes or the product attributes affected the economic (financial) performance of your organization?

e. In your opinion, was there any other type of performance affected by either these development processes or the product attributes, can you please rank the various 
performance aspects discussed above according to their importance to your organization?

5. Lastly, interviewees will be asked if they feel that there is any other important point they would like to add which has not been discussed within this context. If yes, they will be asked to elaborate and discuss the applicability and potential importance in this context. 


\section{Appendix 3.0 Cover Letter for Survey Draft}

September $01^{\text {st }}, 2014$

Dear

SUBJECT: Carleton University Research Study - Development of Sustainable Products and $\underline{\text { Performance }}$

My name is Hanuv Mann, a PhD student at the Eric Sprott School of Business, Carleton University in Ottawa. I am currently conducting an investigation into the development of sustainable products in various high-technology organizations in the North America and Asia under the supervision of Dr. Uma Kumar, also at the Sprott School of Business.

The goal of this survey is to get a better understanding of what processes enable organizations to develop sustainable products in practice and how the development of those products affects organizational performance. The resultant rubric should help firms identify what strategic orientation and development processes assist in the creation or enhancement of sustainable products at an immediate as well as a strategic level. The proposed survey has been reviewed by and has received the clearance of the university Research Ethics Committee. 
I am writing to request your invaluable participation in the study by filling out the online survey which I am sending you. The survey only takes $\mathbf{0 6}$ minutes and can be accesses by clicking on the following link :

http://fluidsurveys.com/surveys/hmann/sustain/

Also, I would very much appreciate it if you, optionally, might be able to refer two colleagues in the same industry who might be qualified to respond to the survey. Please note that are not requesting any confidential or sensitive information in the questionnaire. However, any information you provide will be treated both anonymously as well as confidentially, which is to say that it will not be attributed to your name or that of your company. This is a webhosted questionnaire and therefore a non-secure form of communication. Should you wish to obtain a summary of the findings, I would be pleased to provide you with the results if you enter your contact email at the section at the beginning of the questionnaire that is sent to you.

If you have any questions or comments about the survey, I would be happy to reply to them. My email address is hmann@connect.carleton.ca. Any concerns about this research should be directed to the advising Professor, Dr. Uma Kumar, or the Chair of the Carleton University Research Ethics Board, whose contact information is provided below.

Thanking you for your co-operation and interest.

Sincerely,

Hanuv Mann

PhD Student

Eric Sprott School of Business 
Carleton University

Ottawa, Ontario, Canada

$613-520-2600 \times 6703$

Email: hmann@connect.carleton.ca

Research Ethics Board Chair:

Prof. Andy Adler

Chair, Carleton University Research Ethics

Board

Office of Research Services

3125 Dunton Tower

Carleton University

Tel: 613-520-2517

E-mail: ethics@carleton.ca
Advising Professor:

\section{Dr. Uma Kumar}

Professor of Innovation and Technology Management Director, Research Center for Technology Management Eric Sprott School of Business, Carleton University, Ottawa, Ontario, Canada K1S 5B6 Phone (613)520 6601 Fax (613)520 4427

Email: uma.kumar@carleton.ca 


\section{Appendix 4.0 Ethics Statement Draft}

Date: April 01 ${ }^{\text {st }}, 2014$

The conduct for this research will be governed by the Tri-Council Policy Statement: Ethical Conduct for Research Involving Humans. This policy may be reviewed at: http://www.nserc.ca/programs/ethics/english/policy.htm

\section{Project Lay Summary}

This research is an investigation into the development of sustainable products in various organizations.

The goal of this survey is to get a better understanding of what processes allow organizations to develop sustainable products in practice and how the development of those products affects organizational performance. The focus will be on examining the responses of a select set of executives from high-technology organizations. The resultant rubric should help firms identify what strategic orientation and development processes assist in the creation or enhancement of sustainable products at an immediate as well as a strategic level.

\section{Methodology and Procedures:}

\section{Research Problem}

The research problem can be stated as:

What strategic orientations and product development processes lead to the development of sustainable products in high technology organization and what is their effect on performance. 
2. The data to analyze this research problem would be gathered in two stages, through face-to-face interviews and a questionnaire designed to determine what product development processes lead to sustainable products and their effect on organizational performance.

The method of data collection will be done with a hybrid data collection method of consecutive and snowball sampling. The list of executives for the survey would be obtained from Scott's Directories in Canada, Hoovers in USA and the CII (Confederation of Indian Industry) database in India.

3. The researchers have designed a questionnaire to be completed by individual executives within high-technology organizations. The output of this questionnaire will allow the researchers to identify what orientations and development processes lead to making sustainable products and how these affect the performance of organizations. Some of the measurement techniques that we will focus on include:
a. A modified version of the 7-point Likert Scale.
b. Fixed-questions.

4. Once the researchers have collected the data, the questionnaires will be checked for omissions before the data is input for quantitative analysis.

5. The qualitative data from the interviews will be input into a computer database for analysis of trends and information. The obtained information will be used to adjust the survey questionnaire if required.

6. The quantitative data from the questionnaires will be input into a computer database for statistical analysis. 
7. Based on the results of the analysis of the quantitative and qualitative data, the researchers will make conclusions regarding the strategic orientation and processes that make actual significant contribution to developing sustainable products in organizations.

8. Based on the conclusions, a rubric will be established for what orientations and processes are most useful for the development of sustainable products. Also, an estimate will be presented with respect to how particular processes or product attributes can affect performance for the same organizational profiles.

\section{Description of the Participants:}

As mentioned above, the participants would include all those on the list supplied by the Scott's Directories databases. For the interviews, the participants will be called more than 24 hours in advance of the interview to request their participation and state the purpose of the interview. For the survey questionnaires, a cover letter would be provided to the participants stating the purpose of the survey and importance of their participation, as well as an assurance of their right to anonymity and confidentiality. There will be no additional statement of consent requested from the participants.

\section{Recruitment Process:}

The incubation cell in IIT has consented to support the data collection for the interviews. After the university research ethics board committee has approved the research, initial contact with the respondents will be through the researcher directly. For the survey stage, the contact information for respondents for the questionnaire would be collected from Scott's Directories in Canada, Hoovers in USA and the CII (Confederation of Indian Industry) database in India. The respondents will be interviewed/surveyed on a voluntary basis which will be determined by 1) the consent of the potential interviewee when called and requested for their time for the interview 
and 2) what responses are received after the introductory covering letter (email) is sent to the initial sample for survey.

\section{Risks:}

There is no foreseen risk to any participants. No respondent will be adversely affected as a result of his/her answers or due to the surveying process. The research will not involve any process by which the informant will be put in a position that would appear possibly as threatening to or seen as compromising their (personal as well as organizational) interests. The interviews and survey will be conducted in strict accordance with the specifications of the Tri-Council Policy Statement.

\section{Benefits:}

The benefits of this study are two-fold. The researchers will get an approximation of what strategic orientations and product development processes are actually useful for creating or modifying sustainable products and also would get specific feedback if these differ from those mentioned in academic literature. It would also help firms identify, in practice, what combination strategic orientation and development processes assist in the creation or enhancement of sustainable products at an immediate as well as a strategic level.

\section{Informed Consent:}

Please refer to Appendix 5 for the Letter of Information.

\section{Anonymity of Participants:}

All the information provided by the respondents for the research will be held in strict confidentiality. No response in the survey will be linked in any way to an identifiable respondent. 
The anonymity of the respondents will be respected. It is also ensured that any documentation of the survey results will not include any quotes or distort any facts or findings of the survey. The participants are not required to leave any of their personal contact information on the questionnaire itself, however if they express interest in receiving results, they may voluntarily leave their contact information.

\section{Security of Data:}

Once the data is tabulated from each questionnaire, the questionnaires will be shredded/ deleted. Only the processed (statistically treated) results will be consolidated into a report. All data will be stored in a computer database in the Carleton University which will be accessed only by the researchers involved in this study/ project.

\section{Research Instrument:}

Please refer to the copy of the questionnaire to be used.

\section{Dissemination:}

The research findings will be presented in academic conference(s) and will be documented in the form of publication(s) in established academic journal(s) with due consideration to the various findings and their implications. Moreover, the results would be forwarded to those participants of the study who indicate an interest in the final findings of the research project. 


\section{Appendix 5.0 Letter of InformationDraft}

September $01^{\text {st }}, 2014$

\section{To Whom It May Concern,}

My name is Hanuv Mann and I am writing to you for my research at the Eric Sprott School of Business, Carleton University. We are conducting an investigation into the development of sustainable products in various high-technology organizations in the North America and Asia.

The contact information for the principle researcher and supervising professor is provided below:

(M) 613-620-6543

Hanuv Mann $\quad \underline{\text { hmann@connect.carleton.ca }}$

(W) 520-2600x6703

Dr. Uma Kumar

uma.kumar@,carleton.ca

Work: 613-520-6601

The goal of this survey is to get a better understanding of what processes enable organizations to develop sustainable products in practice and how the development of those products affects organizational performance. The resultant rubric should help firms identify what strategic 
orientation and development processes assist in the creation or enhancement of sustainable products at an immediate as well as a strategic level. The proposed survey has been reviewed by and has received the clearance of the university Research Ethics Committee.

There are 78 questions on this questionnaire and the anticipated time for filling out this questionnaire is about $\mathbf{0 6}$ minutes. There is no personal or professional, psychological or physical risk to you or your organization in taking part in this survey. Your organization may benefit indirectly from this survey's results and the results of the research will contribute to the ongoing research on developing sustainable products in organizations.

\begin{abstract}
All the information provided by you for the research will be held in strict confidence and anonymity. No response in the survey will be linked in any way to you or your organization. By submitting the questionnaire, you are consenting to take part in this research survey.You arenot required to leave any of yourpersonal contact information on the questionnaire itself, however if you are interestedin receiving theresults, youmay contact us via email to receive a copy of the results.
\end{abstract}

Once the data is tabulated from each questionnaire, the questionnaires will be shredded/ deleted. Only the processed (statistically treated) results will be consolidated into a report. All data will be stored in a computer database in the researcher's secure Carleton computer account and will be accessed only by the abovementioned researchers. All hard-copy data will be destroyed by the end of the year 2015. Only the aggregate data will be retained for further possible research purposes. 
This project has been reviewed and has received ethics clearance through the Carleton University Research Ethics Board and those participants with concerns or questions about their involvement in the study may contact the research ethics chair. The chair's information is as follows:

\author{
Prof. Andy Adler \\ Chair, Carleton University Research Ethics Board \\ Office of Research Services \\ 3125 Dunton Tower \\ Carleton University \\ Tel: 613-520-2517 \\ E-mail: ethics@carleton.ca
}

Should you wish to receive a summary of the findings of the study once completed, please do not hesitate to email me with your contact information.

Thank you very much for taking part in this survey.

Sincerely,

Hanuv Mann 


\section{Appendix 6.0 Follow Up Letter (email) for Survey Draft}

Date: September $01^{\text {st }}, 2014$

Dear

SUBJECT: Carleton University Research Study - Development of Sustainable Products and $\underline{\text { Performance }}$

My name is Hanuv Mann, a PhD student at the Eric Sprott School of Business, Carleton University in Ottawa. I am currently conducting an investigation into the development of sustainable products in various high-technology organizations in the North America and Asia under the supervision of Dr. Uma Kumar, Professor, Sprott School of Business.

Two weeks ago a survey, linked below, was sent to you to seeking your expert views on what processes assist in the development of sustainable products for organizations.

http://fluidsurveys.com/surveys/hmann/sustain/

The resultant rubric should help firms identify how to successfully enhance the development of sustainable products for best possible organizational performance. 
If you have already completed and submitted the survey, please accept my sincere thanks. If not, I would request you to please do so at your earliest convenience. Also, I would very much appreciate it if you, optionally, might be able to refer two colleagues in the same industry who might be qualified to respond to the survey. It is extremely important that your views be included in the study.

If by some chance you did not receive the survey, please call or email me at the information provided below so that I can send you another.

If you have any questions or comments about the survey, I would be happy to reply to them. Any concerns about this research should be directed to the advising professor, Dr. Uma Kumar, whose contact information is provided below.

Thanking you for your co-operation.

Sincerely,

Advising Professor:

Hanuv Mann

PhD Student

Eric Sprott School of Business

Carleton University

Ottawa, Ontario, Canada

613-520-2600 × 6703

hmann@,connect.carleton.ca
Dr. Uma Kumar

Professor of Innovation and Technology Management

Director, Research Center for Technology Management Eric Sprott School of Business, Carleton University, Ottawa, Ontario, Canada K1S 5B6

Phone (613)520 6601 Fax (613)520 4427

uma.kumar@carleton.ca 


\section{Appendix 7.0 Script for Interview Phonecall /Initial Email}

Hello

My name is Hanuv Mann, a PhD student at the Eric Sprott School of Business, Carleton University in Ottawa. I am currently conducting an investigation into the development of sustainable products in various high-technology organizations in the North America and Asia under the supervision of Dr. Uma Kumar, also at the Sprott School of Business.

I was given to understand by that you have experience

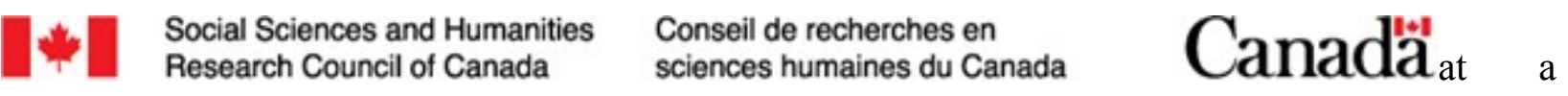

senior executive position in the high-tech area. I would be grateful if you might be able to take some time out for an interview with me regarding how your organization works in this context.

The goal of this survey is to get a better understanding of what processes enable organizations to develop sustainable products in practice and how the development of those products affects organizational performance.

If you would consider an interview, I would be happy to schedule a time and place of your convenience. If you have any specific requirements, such as a time limitation, please do let me know.

I would also require signed consent from you for research ethics purposes. Your anonymity and the confidentiality of the interview would be paramount considerations for me at all times. If you require additional information, details on the study, or contact information for my supervisor and research ethics board chair, I would be happy to provide a print copy of the same at our meeting.

Thank you for your time! 


\section{Appendix 8.0 Conceptual Primer for Interviewees}

\section{Product Life Cycle}

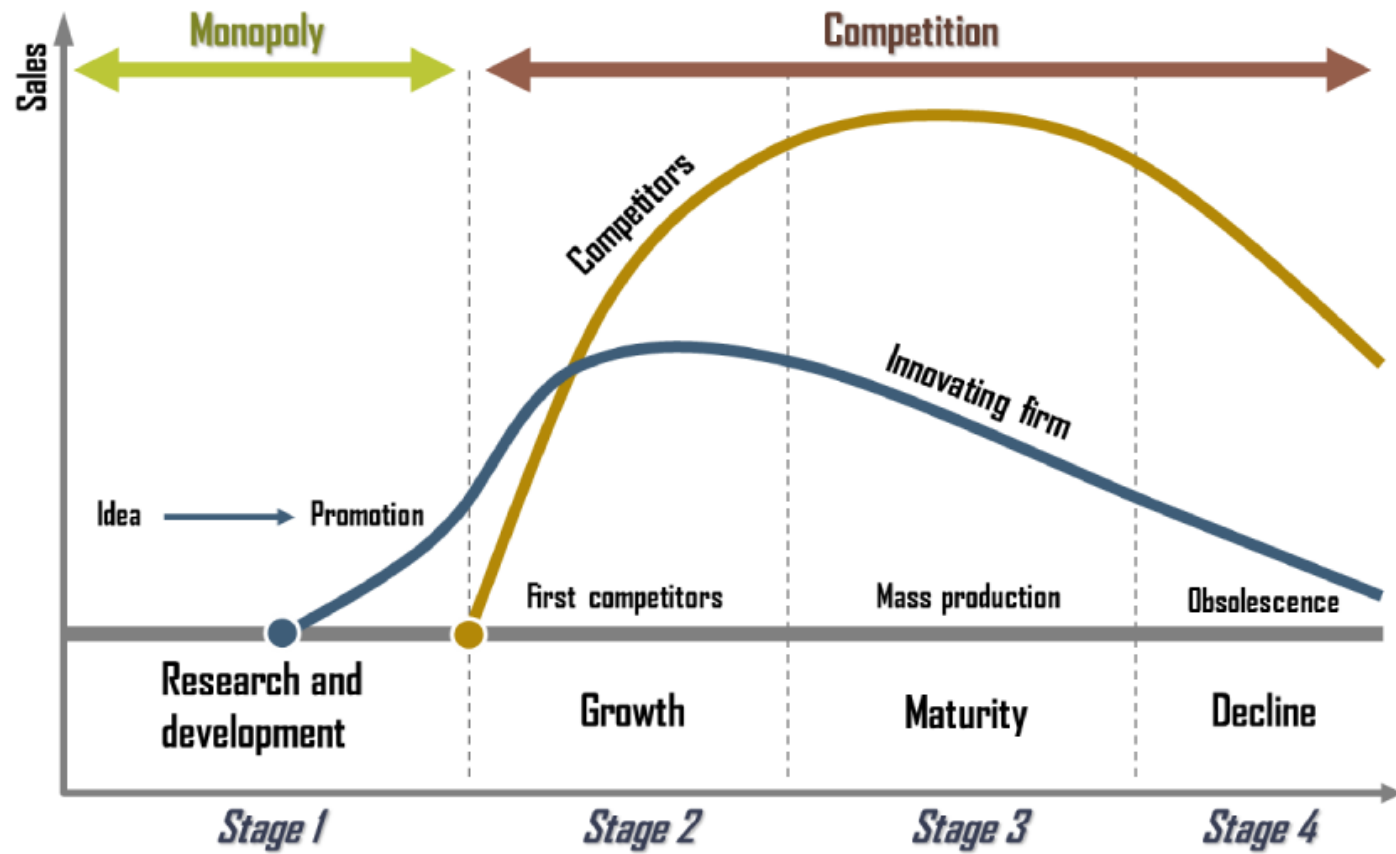

Sustainable Product Cradle-to-cradle life cycle

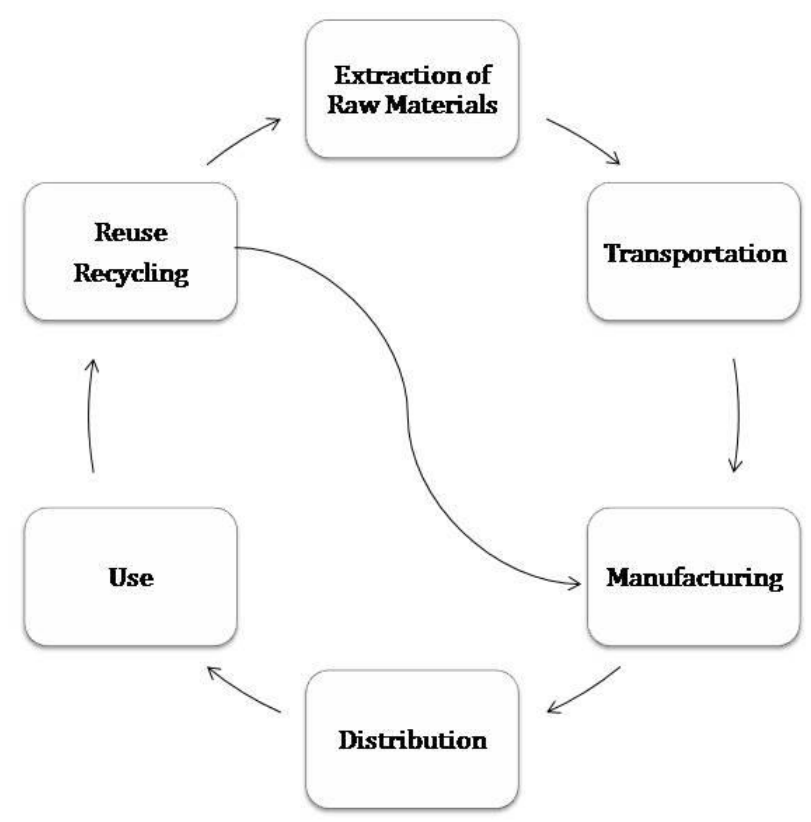




\section{Definition of a sustainable product}

a 'sustainable product' (or service) as defined by Belz and Peattie (2009, p. 154) satisfies "customer needs and significantly improve[s] the social and environmental performance along the whole life cycle in comparison to conventional or competing offers."

\section{Six Characteristics of a sustainable product}

7. Customer Satisfaction. Belz and Peattie (2009) find that this is the most important criteria for a product's survival in the market.

8. Dual Focus. The product should have a social as well as an ecological focus.

9. Life-cycle orientation. The entire life-cycle from the cradle (sourcing and raw materials) to the grave (post-use) should be considered. In this research, as previously discussed (and further considered in Section 2.1), the life-cycle of the product is essential to the degree of its 'sustainability'.

10. Significant improvements. a product should contribute either on a global socio-ecological scale or at the very least provide some indication of its socio-ecological performance throughout its life-cycle.

11. Continuous improvement. deals with the changing nature of the market and hence the requirement of products to change with time.

12. Competing offers. a sustainable product may sometimes lag behind in providing competing offers since it has to incorporate costs associated with socio-ecological impacts. Therefore, the authors suggest considering performance at social, environmental and economic levels. 


\section{Three Attributes related to the Use of a Sustainable Product}

1. Fecundity: potential consumers are stimulated to begin to express a new, sustainabilityrelated behaviour such that it is copied many times.

2. Fidelity: the accuracy with which one person copies another so that consumers are able to carry out the sustainability product-related behaviour.

3. Longevity: people are stimulated to keep on using a product or its components over a long period of time due to sustainability-related design and compatibility superiority.

Strategic Orientations: strategic choices or decisions made on an organization's performance goals

1. Customer Orientation

2. Technological Orientation

3. Competitor Orientation

4. Interfunctional Coordination

5. Sustainability Orientation

\section{Three PD Processes}

1. Domain Specific Knowledge Integration incl. Acquisition of Technical Know-how

2. Procedural Knowledge Integration

3. Flexible Strategic Decision-Making

\section{Performance}

1. Strategic Performance

2. Environmental Performance

3. Social Performance (eg. CSR)

4. Financial Performance 


\title{
Appendix 9.0 Survey Questionnaire
}

\author{
ACADEMIC RESEARCH SURVEY \\ Sustainable Product Development and its effect on Performance
}

\section{ANTECEDENTS OF SUSTAINABLE NEW PRODUCT DEVELOPMENT}

Please indicate the level of the following items in your organization over the past 3 years. (Please circle the number)

1. Customer Orientation

Strongly

Strongly

Disagree

Agree

1. We meet with customers frequently to find out what products or services they $\begin{array}{lllllll}1 & 2 & 3 & 4 & 5 & 6 & 7\end{array}$ will need in the future.

2. We conduct customer satisfaction surveys frequently with our end users.

$\begin{array}{lllllll}1 & 2 & 3 & 4 & 5 & 6 & 7\end{array}$

3. We carry out a great deal of market research to understand customer needs.

$\begin{array}{lllllll}1 & 2 & 3 & 4 & 5 & 6 & 7\end{array}$ 
1. Our new products always apply state of the art technology

2. Compared to competitors, our input in $R \& D$ is more aggressive.

3. Compared to competitors, we take the lead in using sophisticated technologies in new product development

4. We are forward-looking in building new technology solutions to meet customer needs

\section{Competitor Orientation}

1. We collect information on competitors systematically.

2. We usually consider competitors' actions before determining the action plan.

3. We know of competitors' new product launches in advance.

4. We respond to competitors' actions in time $\begin{array}{lllllll}1 & 2 & 3 & 4 & 5 & 6 & 7\end{array}$

$\begin{array}{lllllll}1 & 2 & 3 & 4 & 5 & 6 & 7\end{array}$

$\begin{array}{lllllll}1 & 2 & 3 & 4 & 5 & 6 & 7\end{array}$

$\begin{array}{lllllll}1 & 2 & 3 & 4 & 5 & 6 & 7\end{array}$ 

new product development

3. Different functional departments often collaborate together in the development of new products

4. Different functional departments often share their experiences in product $\quad \begin{array}{llllllll} & 1 & 2 & 3 & 4 & 5 & 6 & 7\end{array}$ development

\section{SUSTAINABLE NEW PRODUCT DEVELOPMENT}


Please indicate the level of the following items in your organization over the past 3 years. (Please circle the number)

1. We have systems and methods to acquire thematic knowledge from product development projects.

2. We have systems and methods to share thematic knowledge from product development projects within the firm.

3. We use, acquire or share thematic knowledge from product development projects in upcoming product development projects. 
1. We have systems and methods to acquire procedural knowledge from product development projects

2. We have systems and methods to share procedural knowledge from product development projects within the firm.

3. We use, acquire or share procedural knowledge from product development projects in upcoming product development projects.

1. We are able to forecast future requirements based on feasibly committed product development decisions.

2. We are able to adjust our NPD decision-making process to future requirements.

3. We can estimate future requirements on the speed of our decision-making $\quad \begin{array}{llllllll}1 & 2 & 3 & 4 & 5 & 6 & 7\end{array}$ process for product development.

4. As required, we are able to adjust how to translate product development $\quad \begin{array}{lllllllll} & 1 & 2 & 3 & 4 & 5 & 6 & 7\end{array}$ decisions into actions. 
5. We can estimate future requirements based on our total development time. $\begin{array}{llllllll}1 & 2 & 3 & 4 & 5 & 6 & 7\end{array}$

For Qns 5-8, Please use one sustainable product developed within the last 1 year as your reference point.

5. Product Fecundity

Strongly

Strongly

Disagree

Agree

1. Our product has the ability to reach a large number of potential customers. $\quad \begin{array}{llllllll}1 & 2 & 3 & 4 & 5 & 6 & 7\end{array}$

2. Our product can be clearly perceived and understood with the aid of one $\quad \begin{array}{llllllll}1 & 2 & 3 & 4 & 5 & 6 & 7\end{array}$ or more of the five senses.

3. Our product has/have the ability to encourage its own use via built-in

$\begin{array}{lllllll}1 & 2 & 3 & 4 & 5 & 6 & 7\end{array}$ functions.

4. Our product is new and original as compared with existing products in the $\begin{array}{lllllll}1 & 2 & 3 & 4 & 5 & 6 & 7\end{array}$ market.

6. Product Fidelity

Strongly

Strongly

Disagree

Agree

1. Potential users can try our product with ease.

$\begin{array}{lllllll}1 & 2 & 3 & 4 & 5 & 6 & 7\end{array}$ 
2. The use and functions of our product can be learnt without difficulty or $\quad \begin{array}{lllllllll} & 1 & 2 & 3 & 4 & 5 & 6 & 7\end{array}$ frustration.

3. The misuse of our product does not cause significant damage or is not $\begin{array}{lllllll}1 & 2 & 3 & 4 & 5 & 6 & 7\end{array}$ dangerous to the user.

7. Product Longevity

Strongly

Strongly

Disagree

Agree

1. Our product is compatible with / is supported by / can support a fair range $\quad \begin{array}{llllllll}1 & 2 & 3 & 4 & 5 & 6 & 7\end{array}$ of applications or other products.

2. Our product performs consistently over time.

$\begin{array}{lllllll}1 & 2 & 3 & 4 & 5 & 6 & 7\end{array}$

3. Our product offers a unique financial advantage to its users.

$\begin{array}{lllllll}1 & 2 & 3 & 4 & 5 & 6 & 7\end{array}$

4. The use of our product is socially supported and encouraged.

$\begin{array}{lllllll}1 & 2 & 3 & 4 & 5 & 6 & 7\end{array}$

5. Our product has a potentially long life-span not curtailed by built-in $\begin{array}{lllllll}1 & 2 & 3 & 4 & 5 & 6 & 7\end{array}$ limitations.

8. Our product is: $\quad \square$ Incrementally new (new version) $\quad \square$ New to our company

$\square$ New to our country of operations $\quad \square$ New to the world 
9. Our product is: $\quad$ पThe only product our company offers in total

$\square$ One of multiple sustainable products our company offers

$\square T h e$ only sustainable product our company offers (along with other, regular products)

10. We introduced this product: $\quad \square$ Less than 1 year ago $\square 1-2$ years ago

$\square$ 2-3 years ago $\square$ 3-4 years ago $\square 4-5$ years ago

$\square$ More than 5 years ago

11. The current product version or iteration is: $\square$ Version $1 \quad \square$ Version 2

aVersion $3 \quad \square$ Version $4 \quad \square$ Version 5 or more

PERFORMANCE 
Please indicate the level of the following items in your organization. (Please circle the number)

1. Environmental performanceover the past 3 years

1. There has been significant reduction of air emission over the past 3 years.

2. There has been significant reduction of waste water over the past 3

$\begin{array}{lllllll}1 & 2 & 3 & 4 & 5 & 6 & 7\end{array}$
years.

3. There has been significant reduction of solid wastes over the past 3

$\begin{array}{lllllll}1 & 2 & 3 & 4 & 5 & 6 & 7\end{array}$
years.

4. There has been significant decrease in consumption for

$\begin{array}{lllllll}1 & 2 & 3 & 4 & 5 & 6 & 7\end{array}$
hazardous/harmful/toxic materials over the past 3 years.

5. There has been significant decrease in frequency for environmental $\begin{array}{lllllll}1 & 2 & 3 & 4 & 5 & 6 & 7\end{array}$ accidents over the past 3 years.

6. There has been significant improvement of our organization's $\begin{array}{lllllll}1 & 2 & 3 & 4 & 5 & 6 & 7\end{array}$ environmental situation over the past 3 years.

2. Economic Performance over the past 3 years 
1. There has been significant decrease of cost for materials purchasing over $\quad \begin{array}{llllllll}1 & 2 & 3 & 4 & 5 & 6 & 7\end{array}$ the past 3 years.

2. There has been significant decrease of cost for energy consumption over $\begin{array}{lllllllll}1 & 2 & 3 & 4 & 5 & 6 & 7\end{array}$ the past 3 years.

3. There has been significant decrease of fee for waste treatment over the $\begin{array}{llllllll}1 & 2 & 3 & 4 & 5 & 6 & 7\end{array}$ past 3 years.

4. There has been significant decrease of fee for waste discharge over the $\quad \begin{array}{llllllll}1 & 2 & 3 & 4 & 5 & 6 & 7\end{array}$ past 3 years.

5. There has been significant decrease of fine for environmental accidents $\quad \begin{array}{lllllllll}1 & 2 & 3 & 4 & 5 & 6 & 7\end{array}$ over the past 3 years.

3. Strategic Performance over the past 3 years

1. Our current development projects include new product market options. $\quad \begin{array}{llllllll}1 & 2 & 3 & 4 & 5 & 6 & 7\end{array}$

2. Our organization has been successful in opening new markets in the past $\begin{array}{llllllll}1 & 2 & 3 & 4 & 5 & 6 & 7\end{array}$ 3 years.

3. Sustainable product development is successful in leading our organization into new product areas in the past 3 years. 
4. Sustainable product development has led to activities open new

$\begin{array}{lllllll}1 & 2 & 3 & 4 & 5 & 6 & 7\end{array}$ technologies over the past 3 years.

5. We incorporate unarticulated customer needs in our new products. $\quad \begin{array}{llllllll} & 1 & 2 & 3 & 4 & 5 & 6 & 7\end{array}$

6. In our organization there has been significant increase in product line $\quad \begin{array}{llllllll}1 & 2 & 3 & 4 & 5 & 6 & 7\end{array}$ over the past 3 years.

4. Corporate Social Performance over the past 3 years

1. There has been significant increase in days of vocational training over $\quad \begin{array}{lllllllll}1 & 2 & 3 & 4 & 5 & 6 & 7\end{array}$ the past 3 years.

2. There has been significant increase in philanthropy as a share of profit $\quad \begin{array}{llllllll}1 & 2 & 3 & 4 & 5 & 6 & 7\end{array}$ over the past 3 years.

3. There has been significant increase in formalization of community $\quad \begin{array}{lllllllll} & 1 & 2 & 3 & 4 & 5 & 6 & 7\end{array}$ relations over the past 3 years.

4. There has been significant increase in number of internships offered $\quad \begin{array}{lllllllll}1 & 2 & 3 & 4 & 5 & 6 & 7\end{array}$ over the past 3 years.

5. There has been significant decrease in scrap rate over the past 3 years. $\quad \begin{array}{lllllllll}1 & 2 & 3 & 4 & 5 & 6 & 7\end{array}$ 
1. What type of industry is your organization in?

$\begin{array}{llll}\square \quad \text { General manufacturing } & \square & \text { Food Industry } \\ \square \quad \text { Electrical equipment, appliance, and } & \square & \text { Chemical manufacturing } \\ \text { component manufacturing } & & \\ \square \quad \text { Primary metal manufacturing } & \square & \text { Fabricated metal product manufacturing } \\ \square \quad \text { Machinery manufacturing } & \square & \text { Computer and electronic product manufacturing } \\ \square \quad \text { Transportation equipment } & \square & \text { Service } \\ \square \quad \text { Other (please specify) } & \end{array}$

2. Has your organization obtained the ISO 14000 certification?

$\square \quad$ Yes $\square \quad$ No

3. If your answer to question 3 is YES, for the last how many years has your organization maintained the ISO 14000 certification?

$\square \quad$ Less than 3 years $\quad \square \quad$ More than 3 years 
4. Choose the title which most closely reflects your current position?

$\begin{array}{ll}\square \text { General Manager } & \square \text { Director } \\ \square \text { President } & \square \text { Vice President } \\ \square \text { Owner/Co-Owner } & \square \text { Founder/Co-founder }\end{array}$

$\square$ Member, Board of Directors

$\square \mathrm{CEO} \quad \square \mathrm{COO}$
$\square \mathrm{CTO}$

$\begin{array}{ll}\square \text { Head of Operations } & \square \text { Head of Business Unit } \\ \square \text { Head of R\&D } & \square \text { Senior Scientist } \\ \square \text { Partner } & \square \text { Senior Manager } \\ \square \text { Consultant } & \square \text { Advisor }\end{array}$

5. Which area is within your firm's current scope of business operations?
$\square$ Canada
$\square$ Asia
$\square$ The United States $\square$ Europe 

$\square$ Oceania
Africa
$\square$ South America $\quad \square$ Global

$\square$ Other (please specify)

6. Which of the following describes your firm?

$\square$ Privately owned

$\square$ Publicly owned

7. Summary of Research Findings

Would you like to receive a free copy of summary of research findings?

$\square \quad$ Yes, at my email address:

No

\section{Appendix 10.0 Survey Data Response Trend}




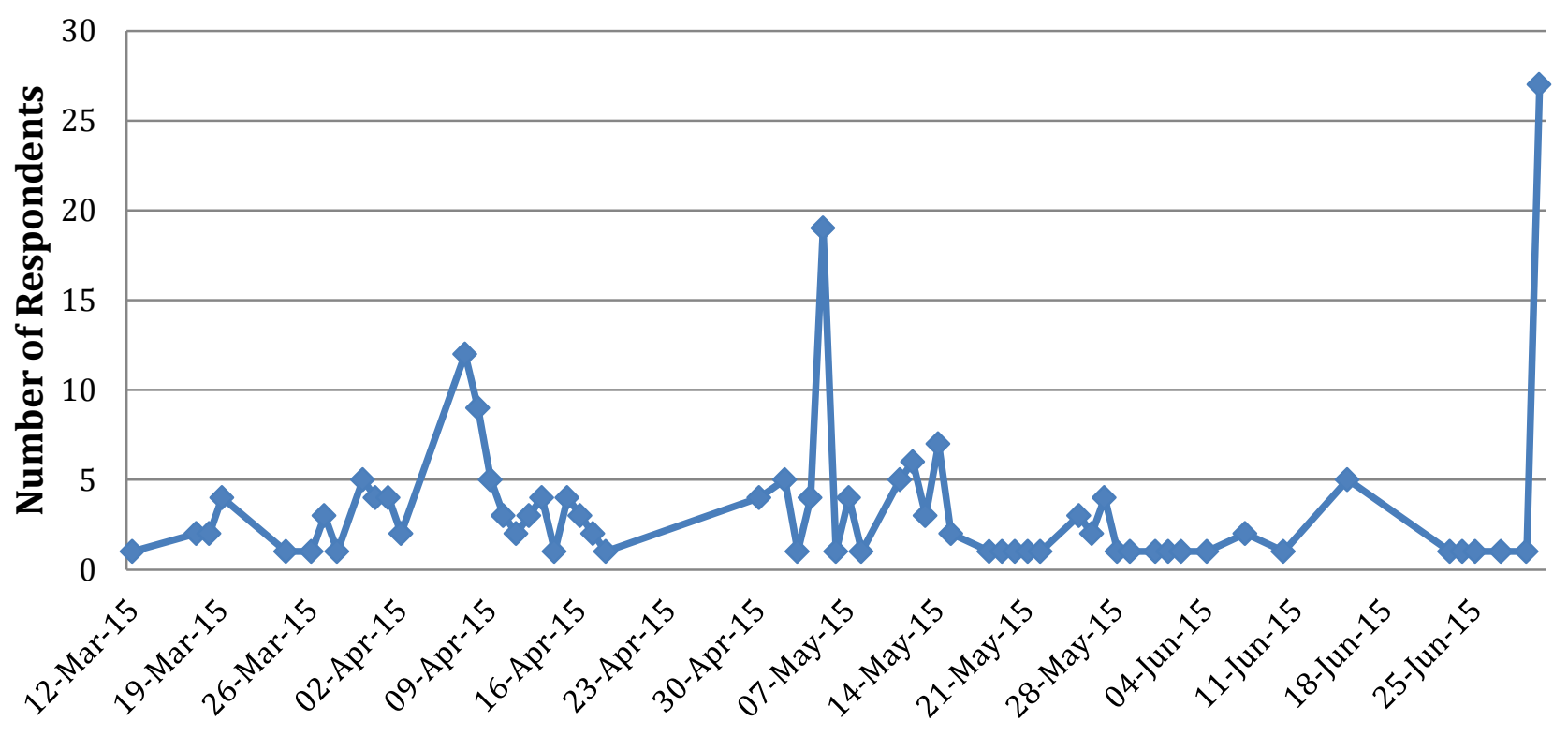




\section{Appendix 11.0 Skewness and Kurtosis Values for all Items}

\section{Descriptive Statistics}

\begin{tabular}{|c|c|c|c|c|c|c|c|}
\hline & $\mathrm{N}$ & Mean & $\begin{array}{c}\text { Std. } \\
\text { Deviation }\end{array}$ & Skev & less & Kur & \\
\hline & Statistic & Statistic & Statistic & Statistic & Std. Error & Statistic & Std. Error \\
\hline CUST1 & 201 & 5.17 & 1.376 & -.678 & .172 & .118 & .341 \\
\hline CUST2 & 201 & 4.79 & 1.536 & -.655 & .172 & -.160 & .341 \\
\hline CUST3 & 201 & 4.83 & 1.433 & -.596 & .172 & -.170 & .341 \\
\hline TECH1 & 201 & 5.15 & 1.318 & -.622 & .172 & .262 & .341 \\
\hline TECH2 & 201 & 5.10 & 1.308 & -.755 & .172 & .719 & .341 \\
\hline TECH3 & 201 & 5.10 & 1.243 & -.595 & .172 & .199 & .341 \\
\hline TECH4 & 201 & 5.40 & 1.184 & -.898 & .172 & 1.124 & .341 \\
\hline COMP1 & 201 & 4.79 & 1.351 & -.559 & .172 & -.206 & .341 \\
\hline COMP2 & 201 & 4.37 & 1.501 & -.424 & .172 & -.431 & .341 \\
\hline COMP3 & 201 & 3.99 & 1.483 & -.234 & .172 & -.629 & .341 \\
\hline COMP4 & 201 & 4.47 & 1.323 & -.505 & .172 & .322 & .341 \\
\hline SUSO1 & 201 & 4.93 & 1.445 & -.611 & .172 & .193 & .341 \\
\hline SUSO2 & 201 & 5.11 & 1.297 & -.618 & .172 & .610 & .341 \\
\hline SUSO3 & 201 & 5.13 & 1.299 & -.640 & .172 & .513 & .341 \\
\hline SUSO4 & 201 & 4.49 & 1.591 & -.280 & .172 & -.522 & .341 \\
\hline IFC1 & 201 & 5.37 & 1.093 & -1.006 & .172 & 2.401 & .341 \\
\hline IFC2 & 201 & 5.47 & 1.072 & -1.143 & .172 & 2.442 & .341 \\
\hline IFC3 & 201 & 5.50 & 1.209 & -1.186 & .172 & 2.025 & .341 \\
\hline IFC4 & 201 & 5.38 & 1.211 & -.914 & .172 & 1.183 & .341 \\
\hline DSKI1 & 201 & 4.61 & 1.326 & -.309 & .172 & -.137 & .341 \\
\hline DSKI2 & 201 & 4.63 & 1.351 & -.377 & .172 & -.110 & .341 \\
\hline DSKI3 & 201 & 4.65 & 1.284 & -.456 & .172 & .052 & .341 \\
\hline ACQTEC1 & 201 & 4.67 & 1.401 & -.512 & .172 & -.133 & .341 \\
\hline ACQTEC2 & 201 & 4.63 & 1.405 & -.579 & .172 & .225 & .341 \\
\hline ACQTEC3 & 201 & 5.00 & 1.330 & -.798 & .172 & .773 & .341 \\
\hline PKI1 & 201 & 4.84 & 1.330 & -.520 & .172 & -.041 & .341 \\
\hline PKI2 & 201 & 4.90 & 1.302 & -.546 & .172 & .192 & .341 \\
\hline PKI3 & 201 & 4.95 & 1.276 & -.811 & .172 & .765 & .341 \\
\hline FDM1 & 201 & 4.64 & 1.282 & -.661 & .172 & .284 & .341 \\
\hline FDM2 & 201 & 4.89 & 1.363 & -.805 & .172 & .397 & .341 \\
\hline FDM3 & 201 & 4.58 & 1.336 & -.764 & .172 & .241 & .341 \\
\hline FDM4 & 201 & 4.96 & 1.193 & -.752 & .172 & .762 & .341 \\
\hline FDM5 & 201 & 4.76 & 1.255 & -.510 & .172 & .084 & .341 \\
\hline FEC1 & 201 & 5.63 & 1.408 & -1.460 & .172 & 2.045 & .341 \\
\hline FEC2 & 201 & 5.55 & 1.442 & -1.313 & .172 & 1.519 & .341 \\
\hline FEC3 & 201 & 5.21 & 1.639 & -1.022 & .172 & .457 & .341 \\
\hline FEC4 & 201 & 5.11 & 1.445 & -.906 & .172 & .688 & .341 \\
\hline
\end{tabular}




\begin{tabular}{|l|l|l|l|r|r|r|r|} 
FID1 & 201 & 5.35 & 1.574 & -1.142 & .172 & .906 & .341 \\
FID2 & 201 & 5.36 & 1.346 & -1.046 & .172 & 1.216 & .341 \\
FID3 & 201 & 5.04 & 1.713 & -.866 & .172 & -.105 & .341 \\
LONG1 & 200 & 4.81 & 1.541 & -.783 & .172 & .132 & .342 \\
LONG2 & 201 & 5.83 & 1.119 & -1.371 & .172 & 3.246 & .341 \\
LONG3 & 201 & 5.27 & 1.337 & -.921 & .172 & .865 & .341 \\
LONG4 & 201 & 5.00 & 1.404 & -.789 & .172 & .632 & .341 \\
LONG5 & 201 & 5.34 & 1.451 & -1.004 & .172 & .850 & .341 \\
ENVPERF1 & 201 & 4.29 & 1.542 & -.147 & .172 & -.314 & .341 \\
ENVPERF2 & 201 & 4.29 & 1.577 & -.231 & .172 & -.483 & .341 \\
ENVPERF3 & 201 & 4.37 & 1.524 & -.221 & .172 & -.329 & .341 \\
ENVPERF4 & 201 & 4.49 & 1.530 & -.319 & .172 & -.370 & .341 \\
ENVPERF5 & 201 & 4.71 & 1.577 & -.501 & .172 & -.128 & .341 \\
ENVPERF6 & 201 & 4.87 & 1.532 & -.606 & .172 & .062 & .341 \\
ECONPERF1 & 201 & 3.97 & 1.471 & -.196 & .172 & -.413 & .341 \\
ECONPERF2 & 201 & 3.86 & 1.597 & .074 & .172 & -.483 & .341 \\
ECONPERF3 & 201 & 3.79 & 1.503 & .165 & .172 & -.393 & .341 \\
ECONPERF4 & 201 & 3.74 & 1.531 & .182 & .172 & -.356 & .341 \\
ECONPERF5 & 201 & 4.27 & 1.658 & -.211 & .172 & -.455 & .341 \\
STRPERF1 & 201 & 5.12 & 1.413 & -.955 & .172 & 1.097 & .341 \\
STRPERF2 & 201 & 5.09 & 1.434 & -.990 & .172 & 1.090 & .341 \\
STRPERF3 & 201 & 4.87 & 1.429 & -.735 & .172 & .473 & .341 \\
STRPERF4 & 201 & 4.78 & 1.376 & -.450 & .172 & .357 & .341 \\
STRPERF5 & 201 & 5.08 & 1.317 & -.719 & .172 & .401 & .341 \\
SOCPERF1 & 201 & 4.26 & 1.401 & -.349 & .172 & .004 & .341 \\
SOCPERF2 & 201 & 3.80 & 1.549 & .052 & .172 & -.527 & .341 \\
SOCPERF3 & 201 & 4.10 & 1.503 & -.180 & .172 & -.424 & .341 \\
SOCPERF4 & 201 & 4.13 & 1.522 & -.272 & .172 & -.440 & .341 \\
SOCPERF5 & 201 & 4.31 & 1.433 & .000 & .172 & -.231 & .341 \\
Valid N (listwise) & 200 & & & & & & \\
\hline & & & & & & \\
\\
EN
\end{tabular}


Appendix 12.0Models A to D for the Second Order Constructs

\section{Strategic Orientation}

\section{Model A}

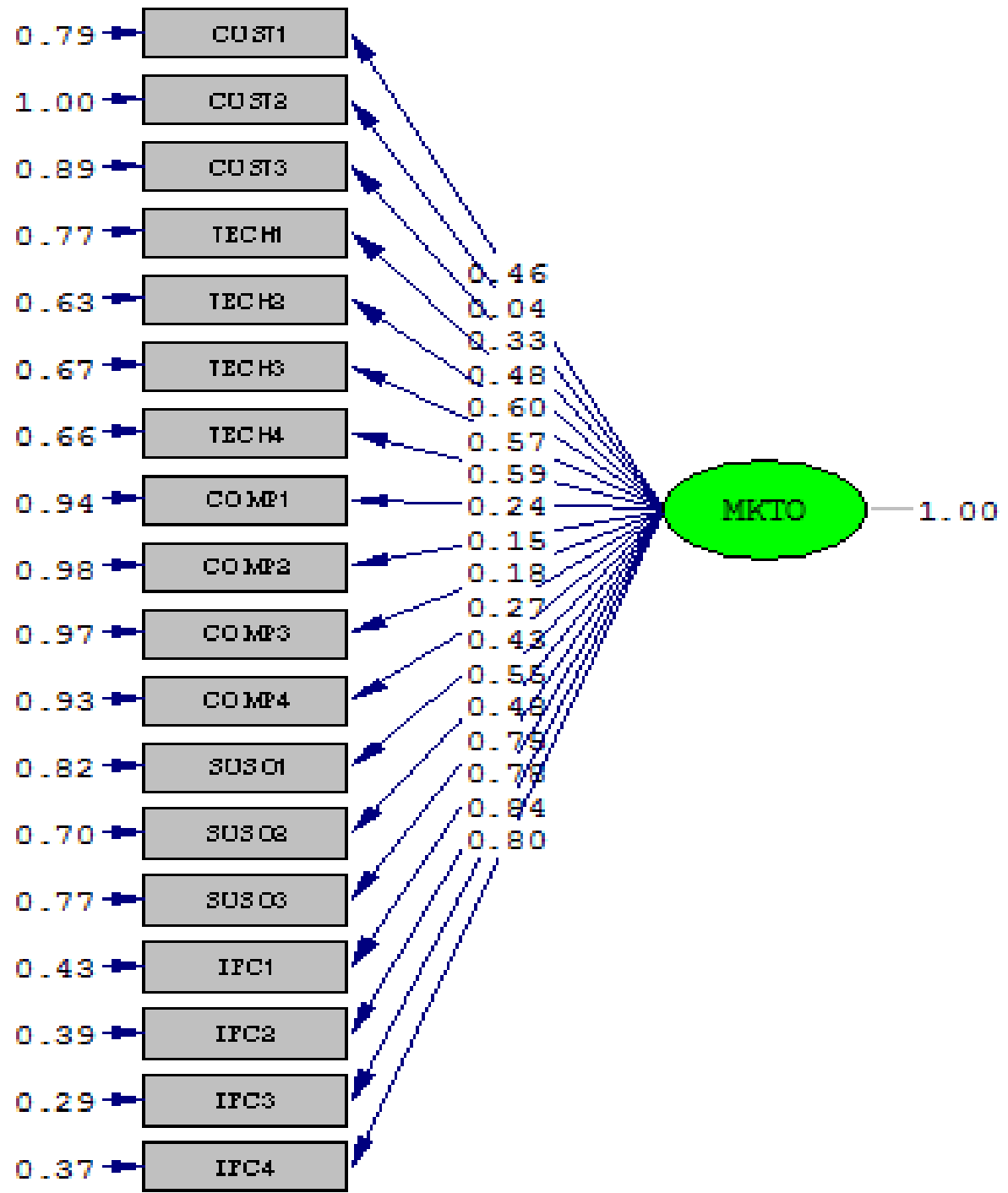




\section{Model B}

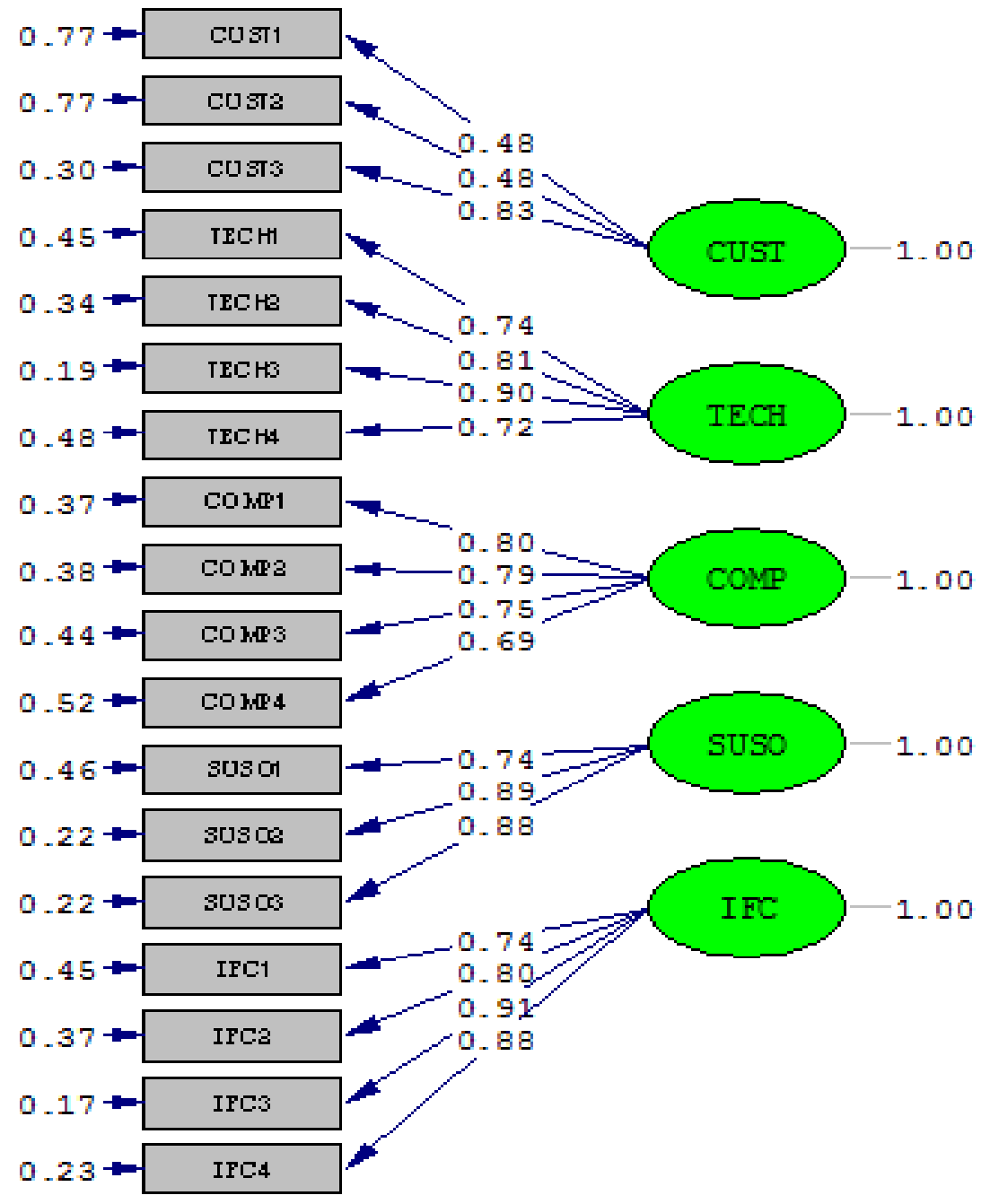




\section{Model C}

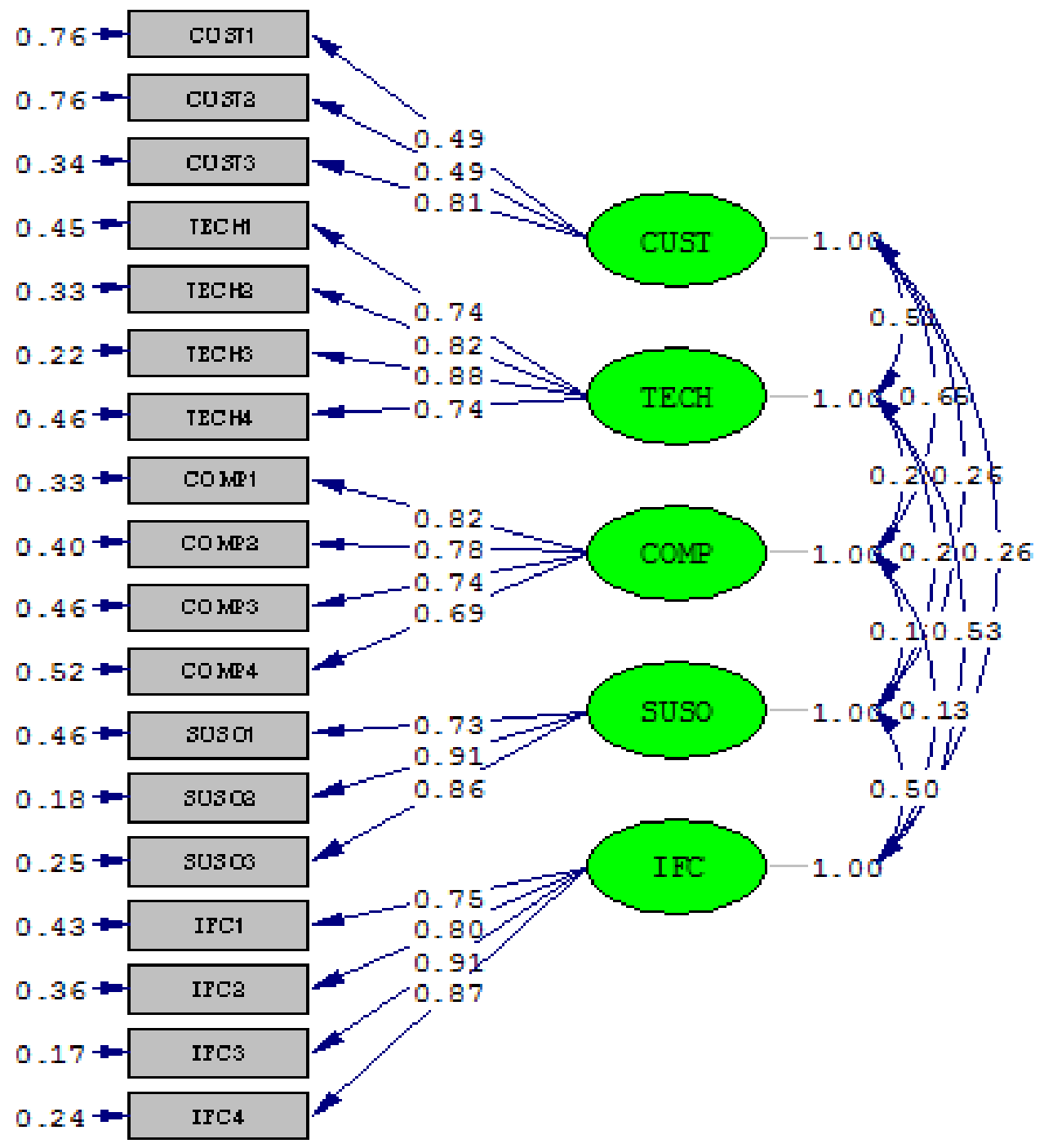




\section{Model D}

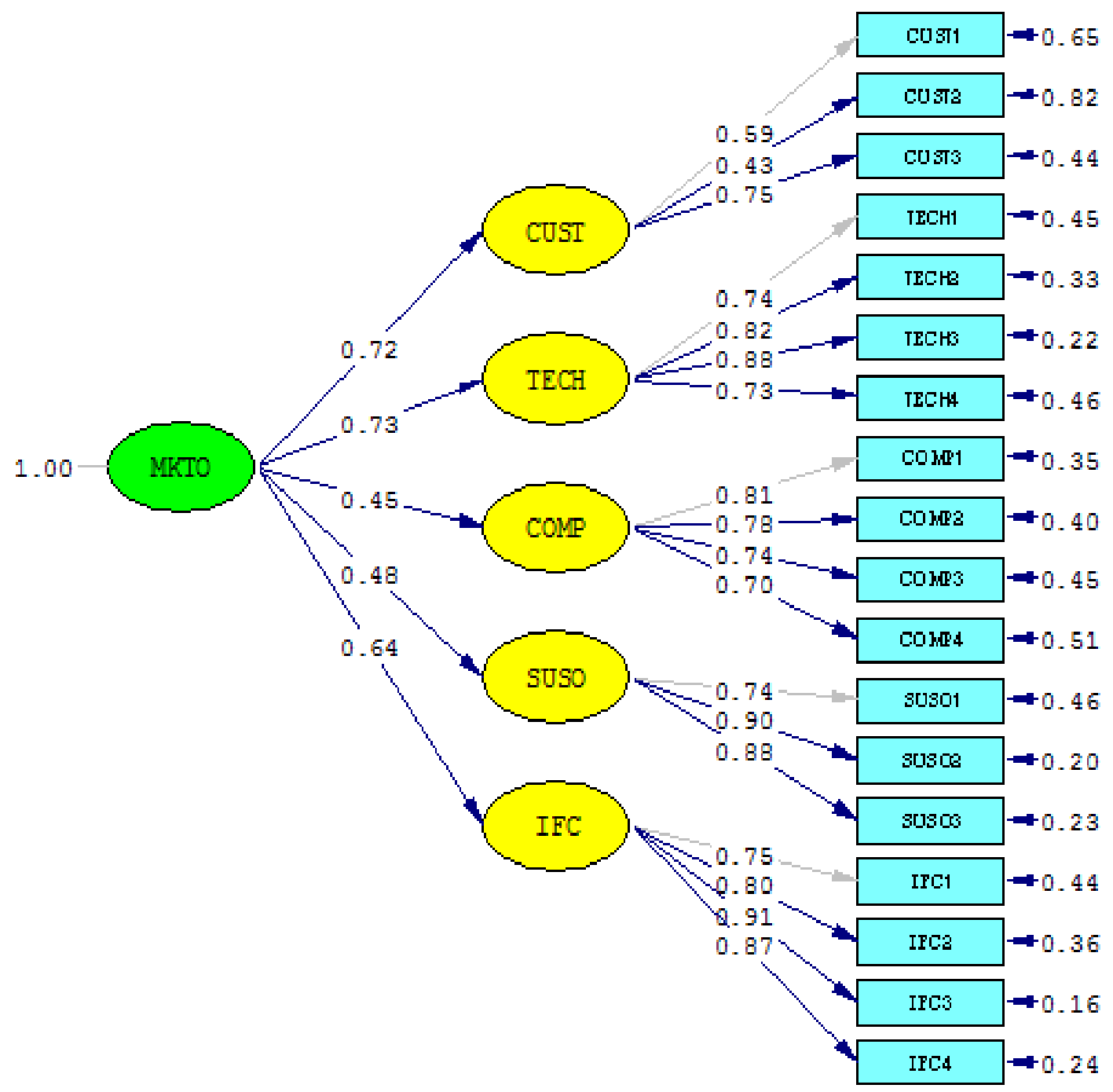




\section{Model A}

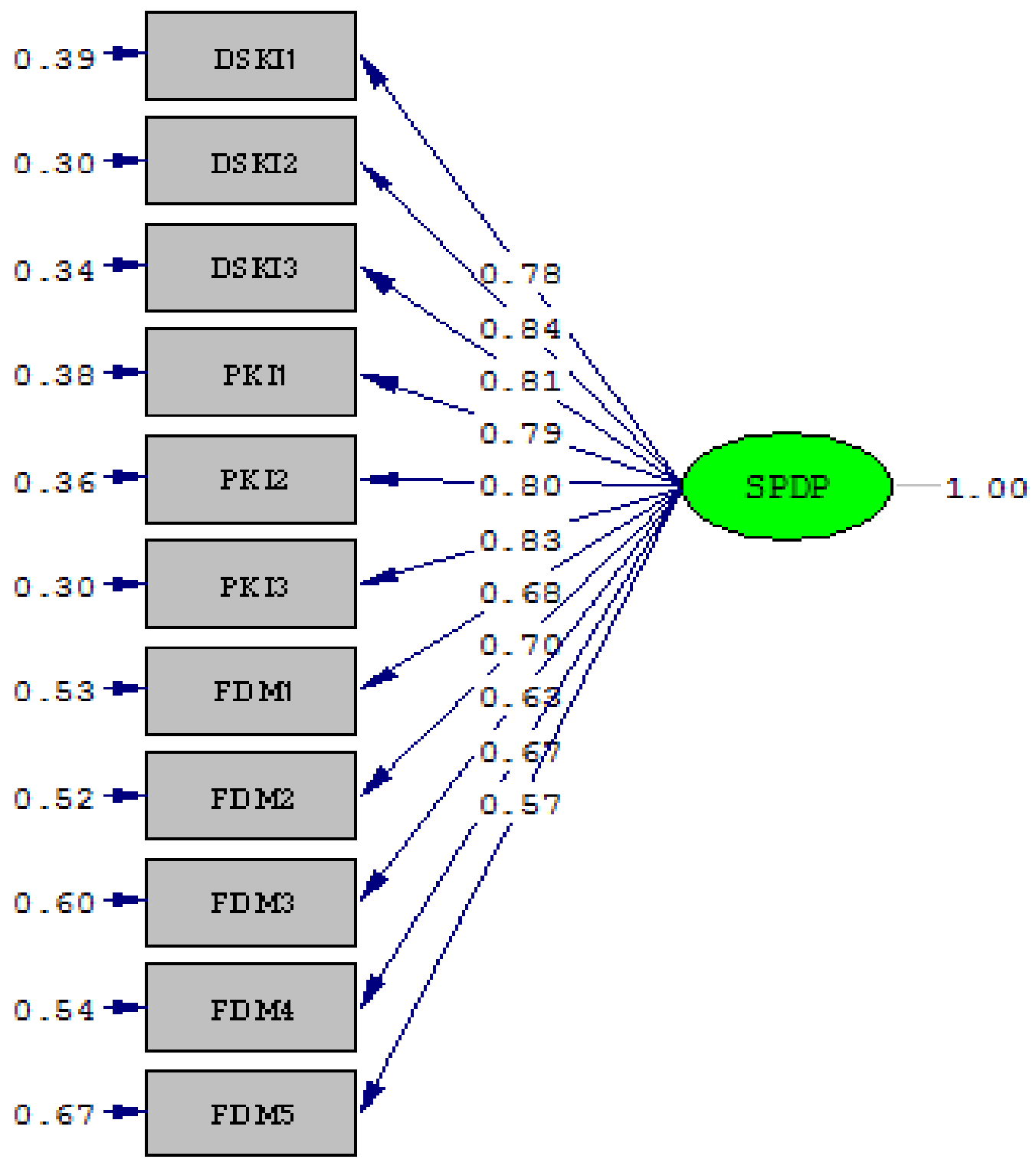




\section{Model B}
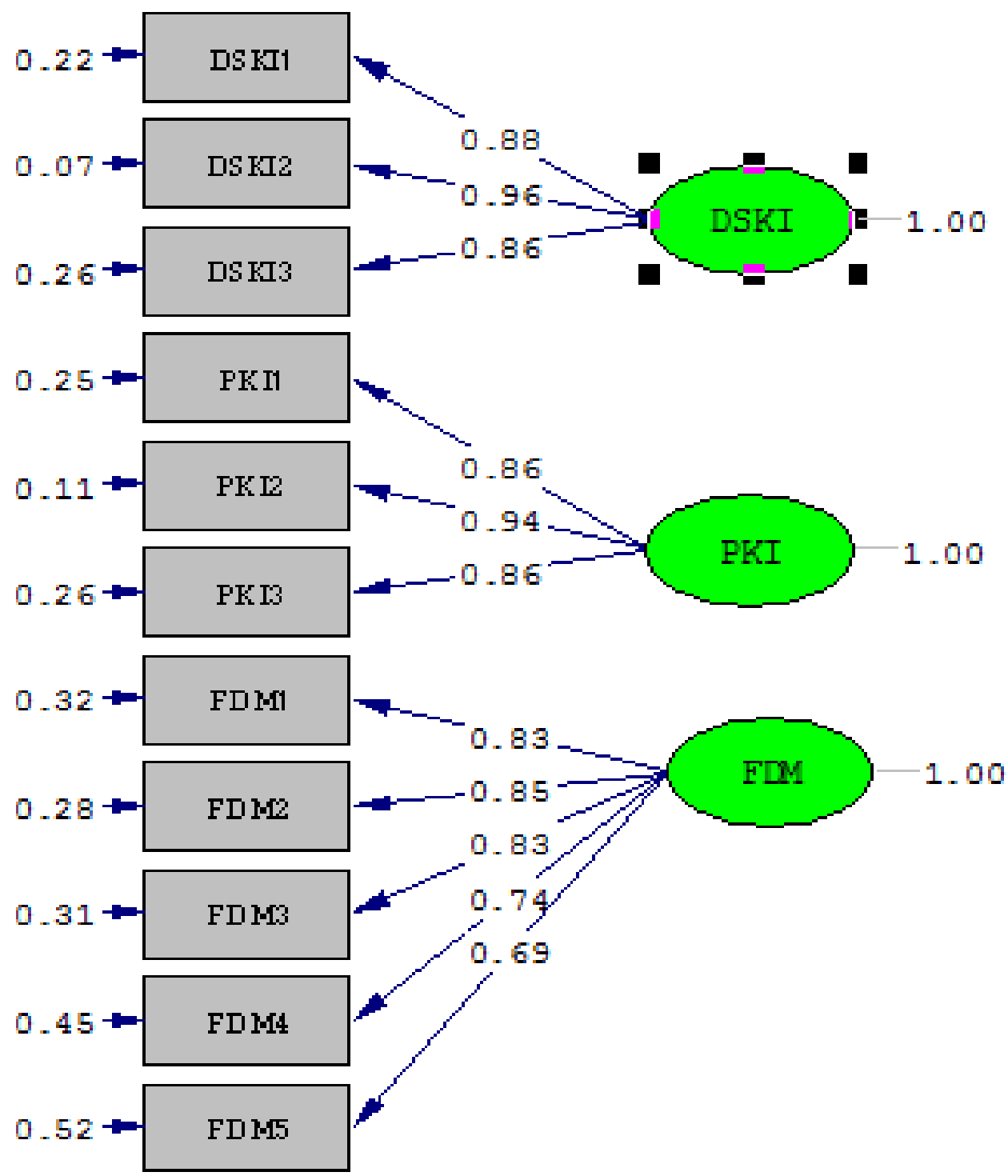


\section{Model C}

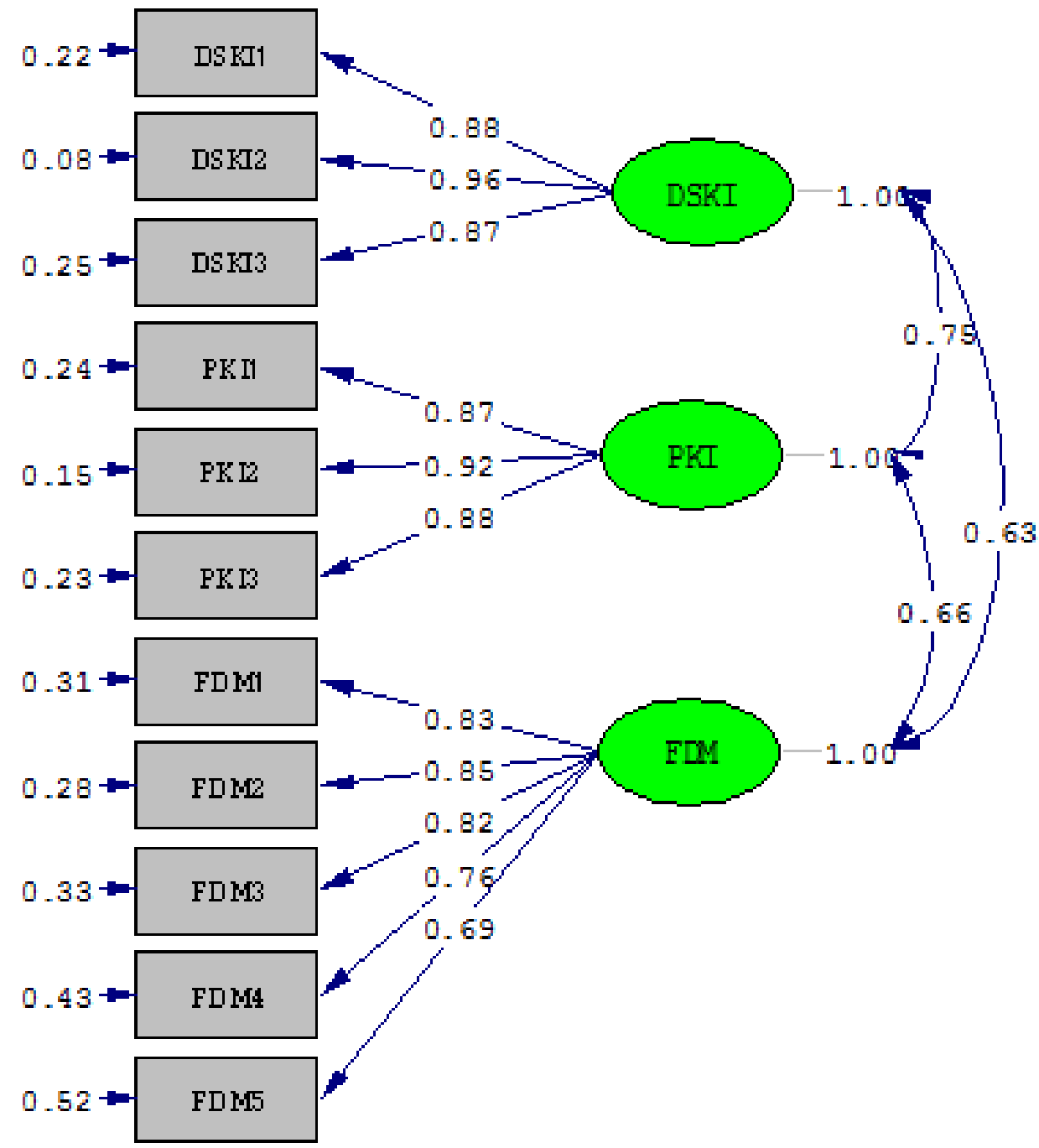




\section{Model D}

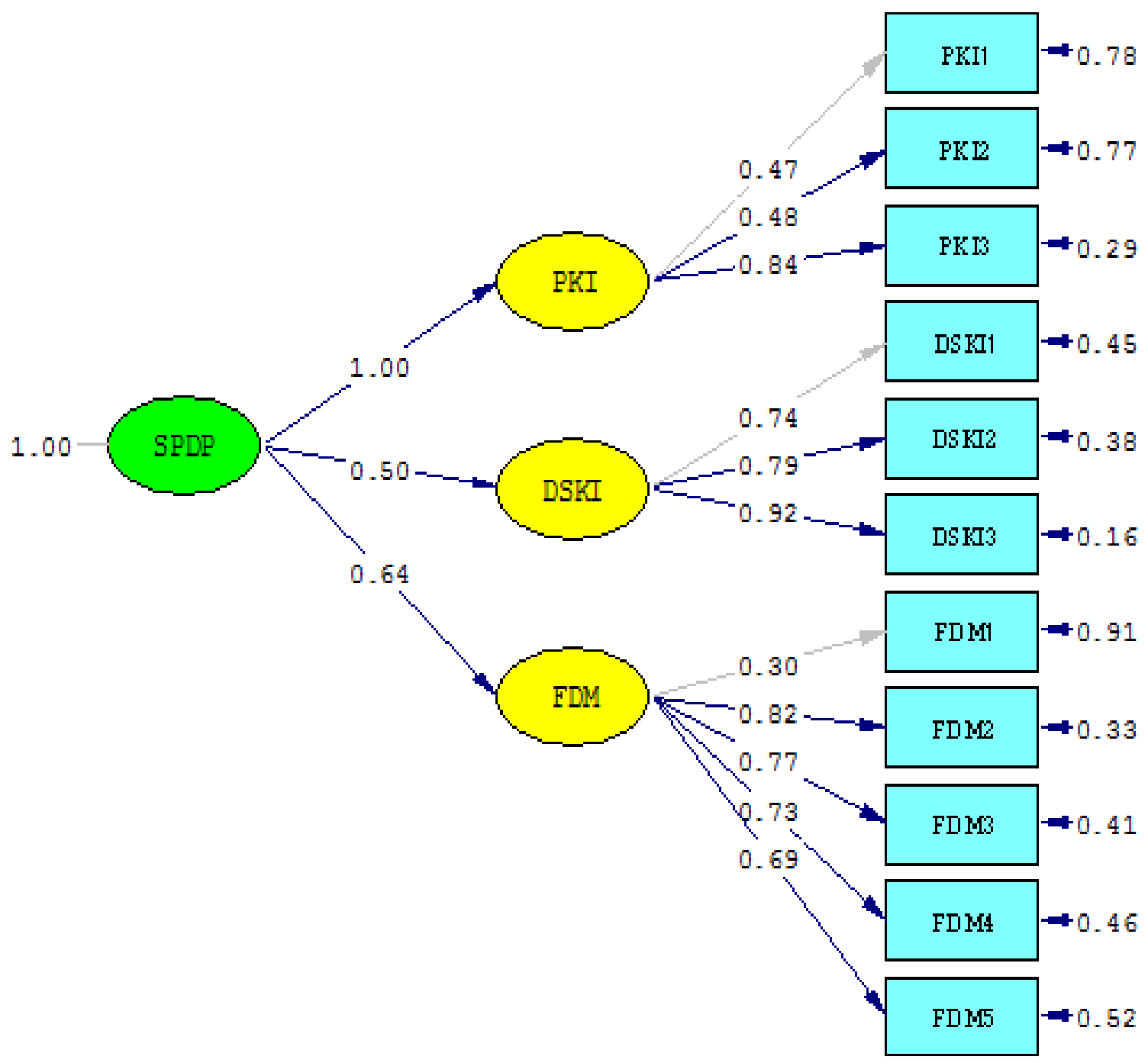




\section{Product Attributes}

\section{Model A}

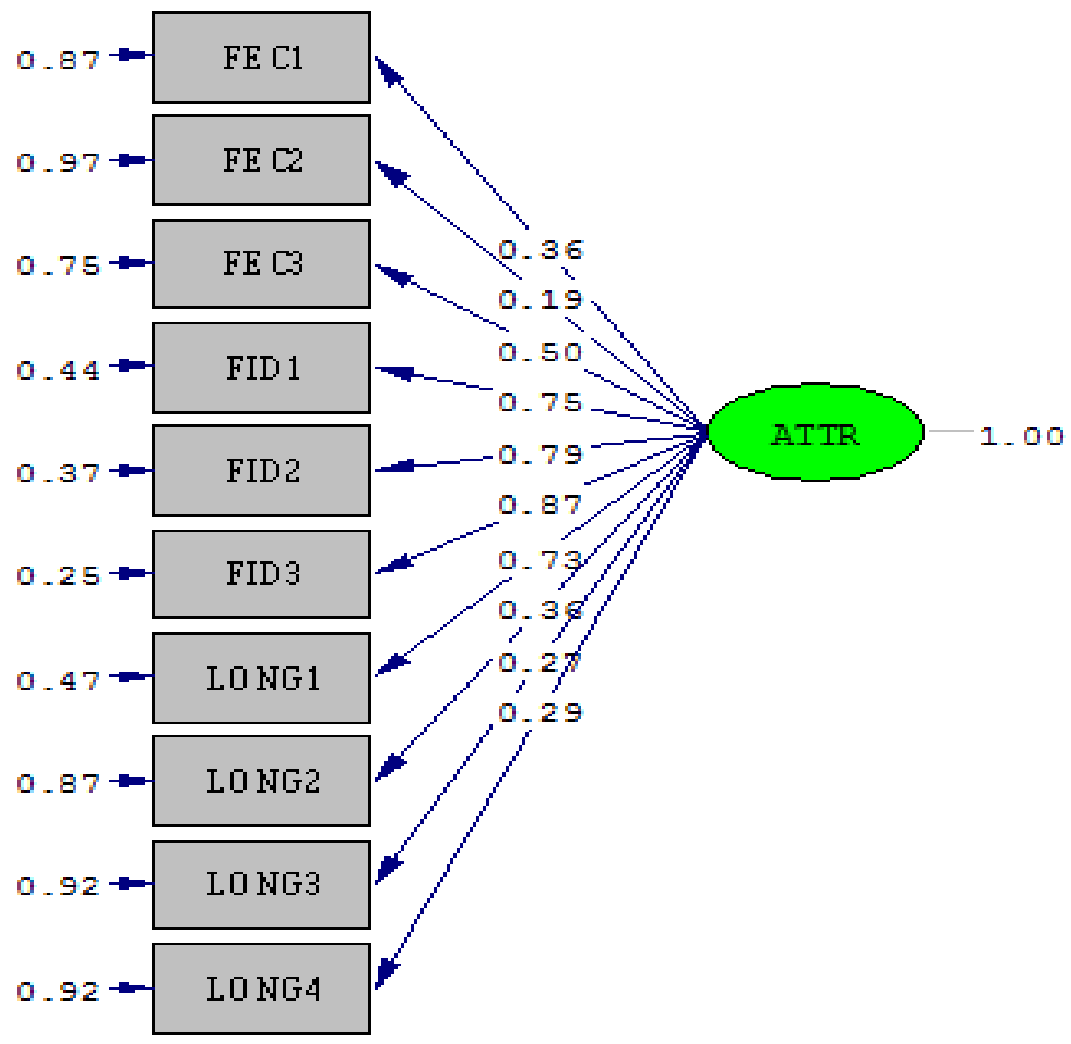




\section{Model B}

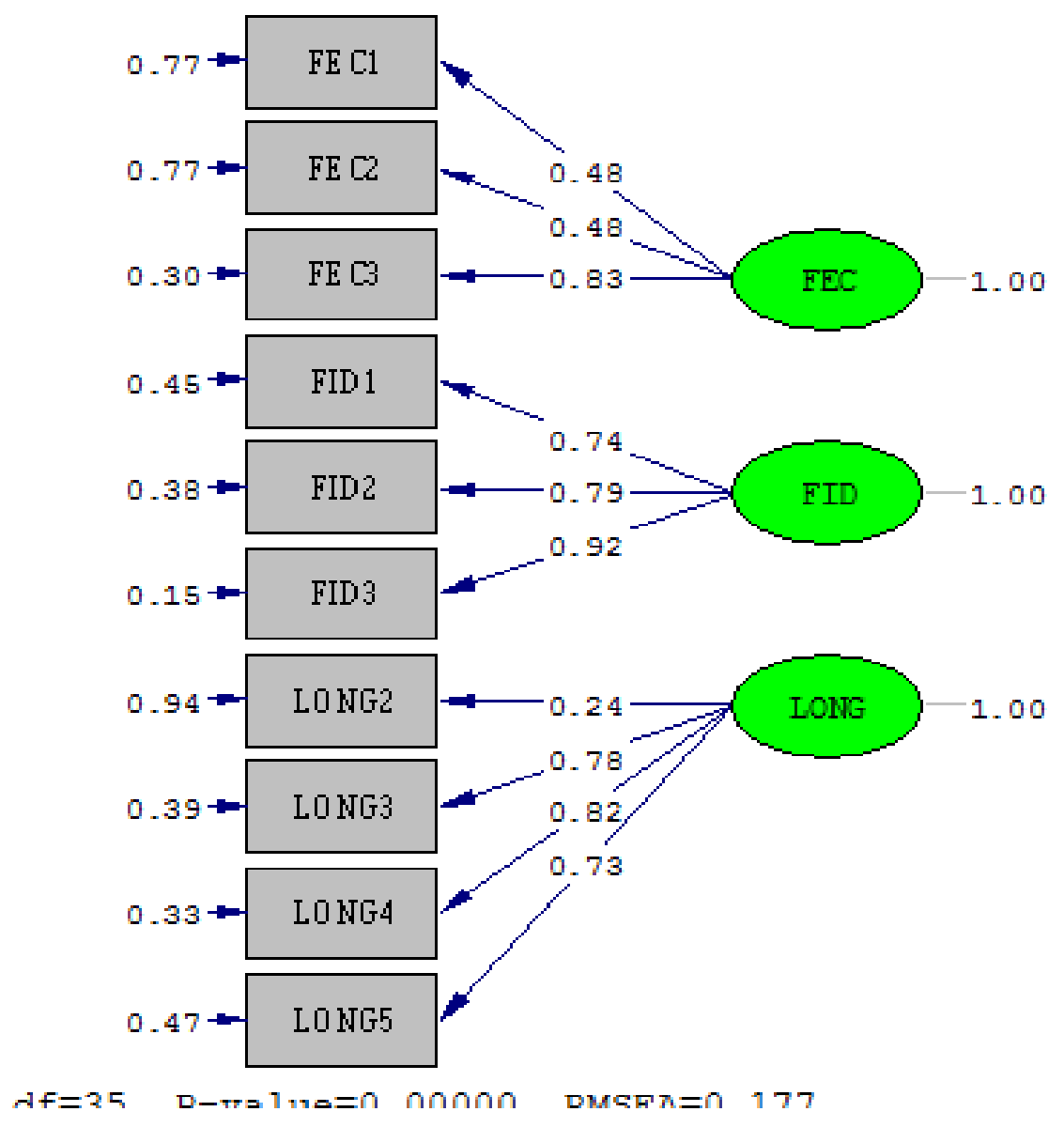




\section{Model C}

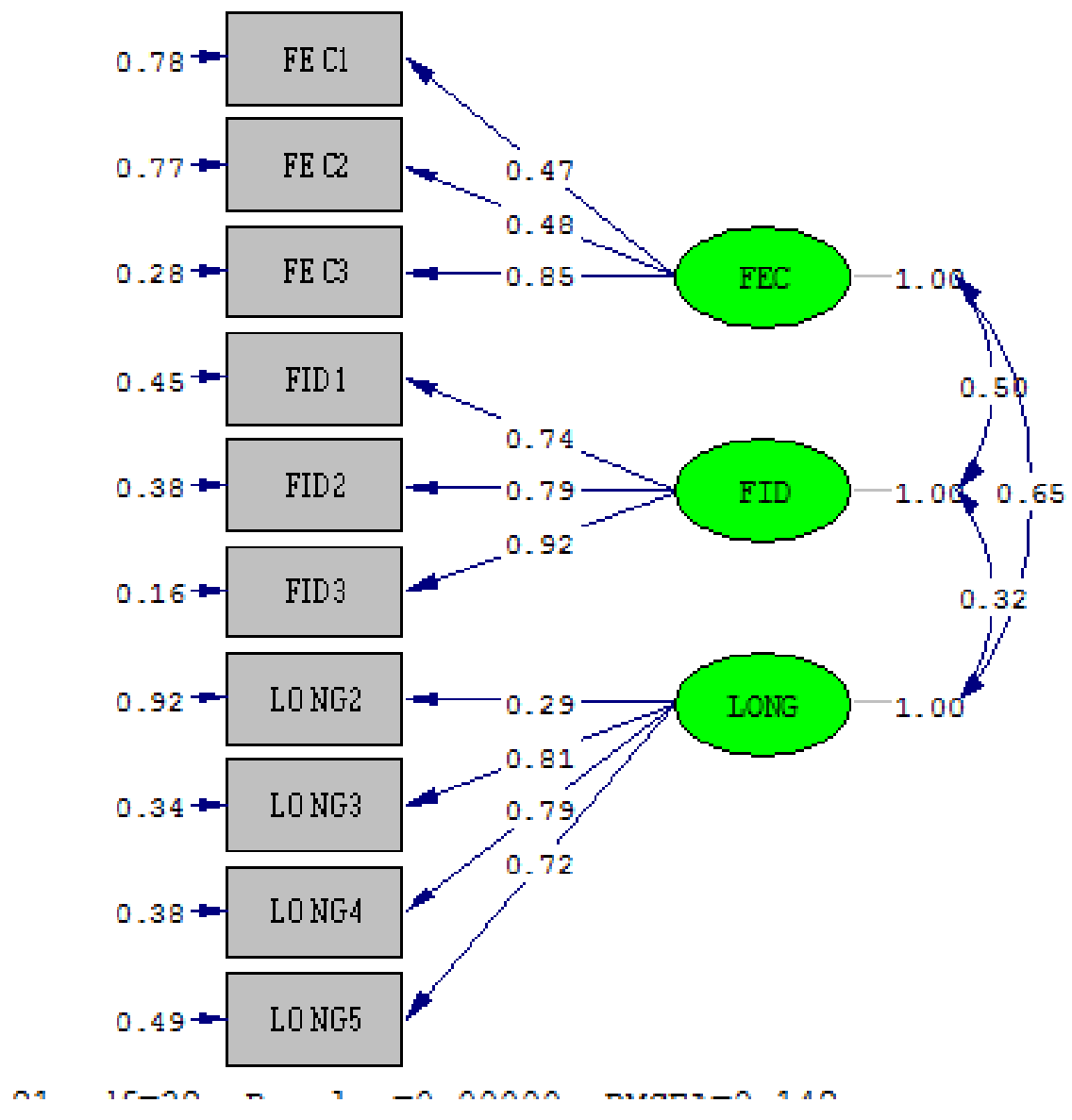




\section{Model D}

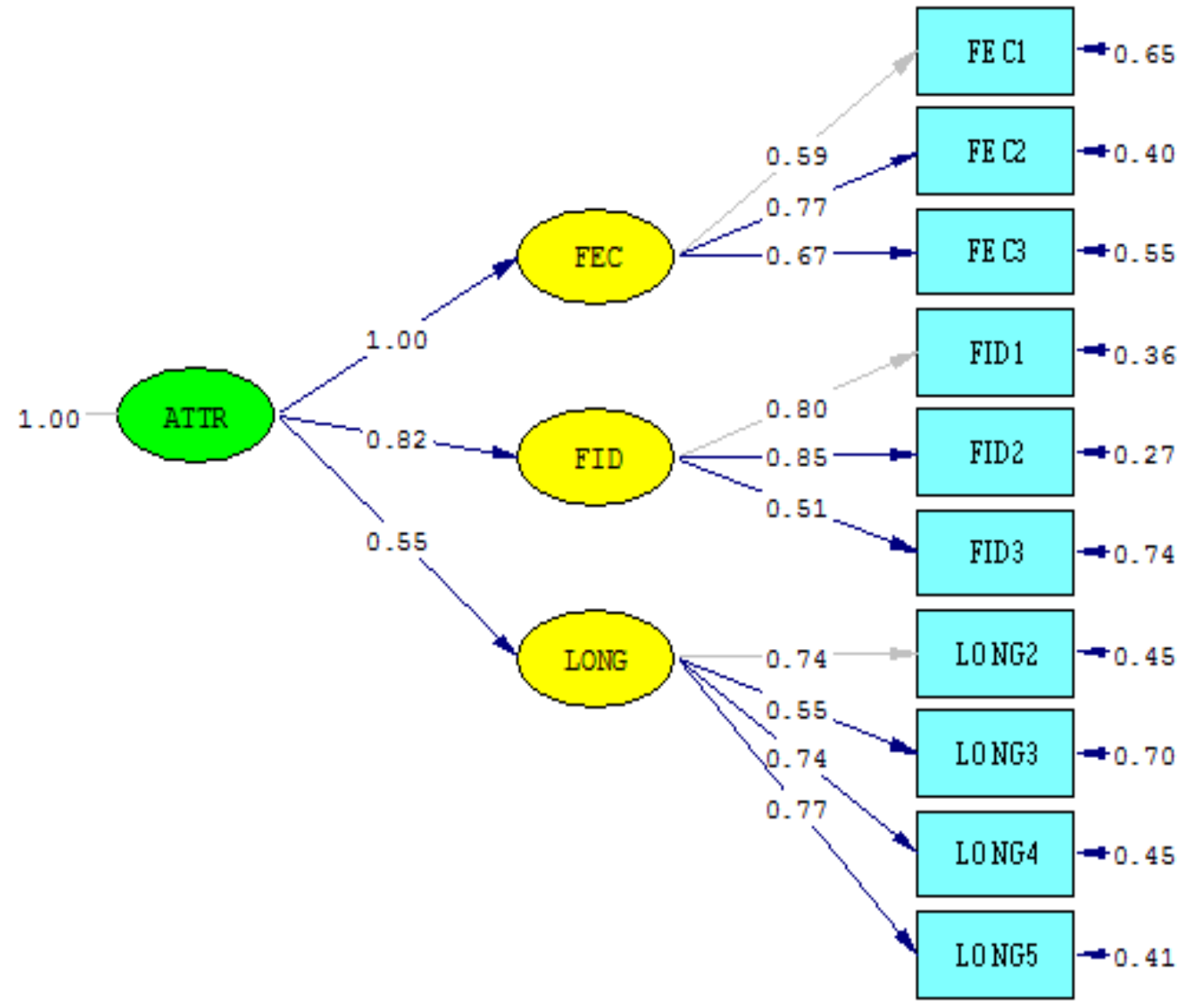

Chi-Square $=98.29, \mathrm{df}=32, \mathrm{P}-\mathrm{value}=0.00000, \mathrm{RMSEA}=0.102$ 


\section{Performance}

\section{Model A}

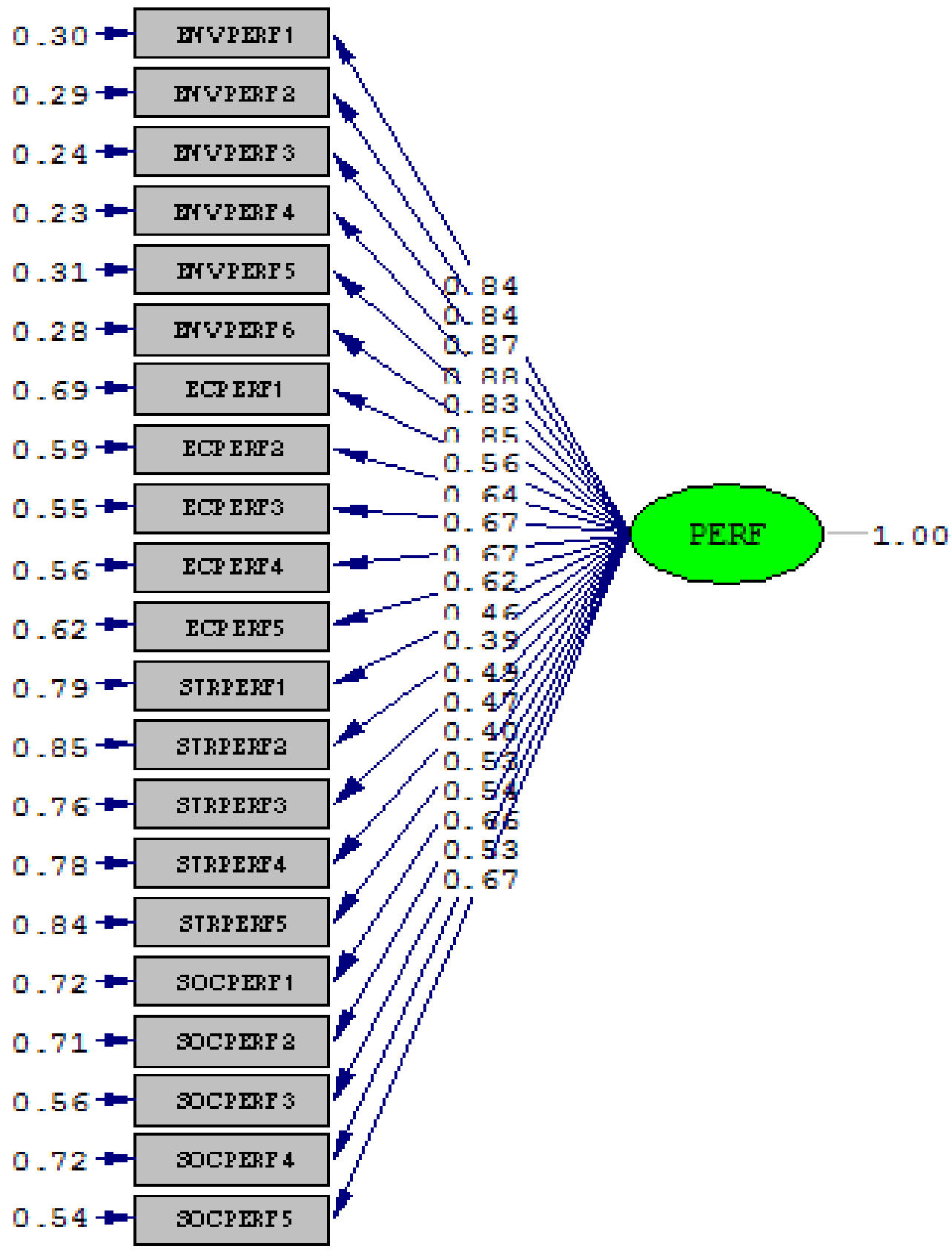




\section{Model B}

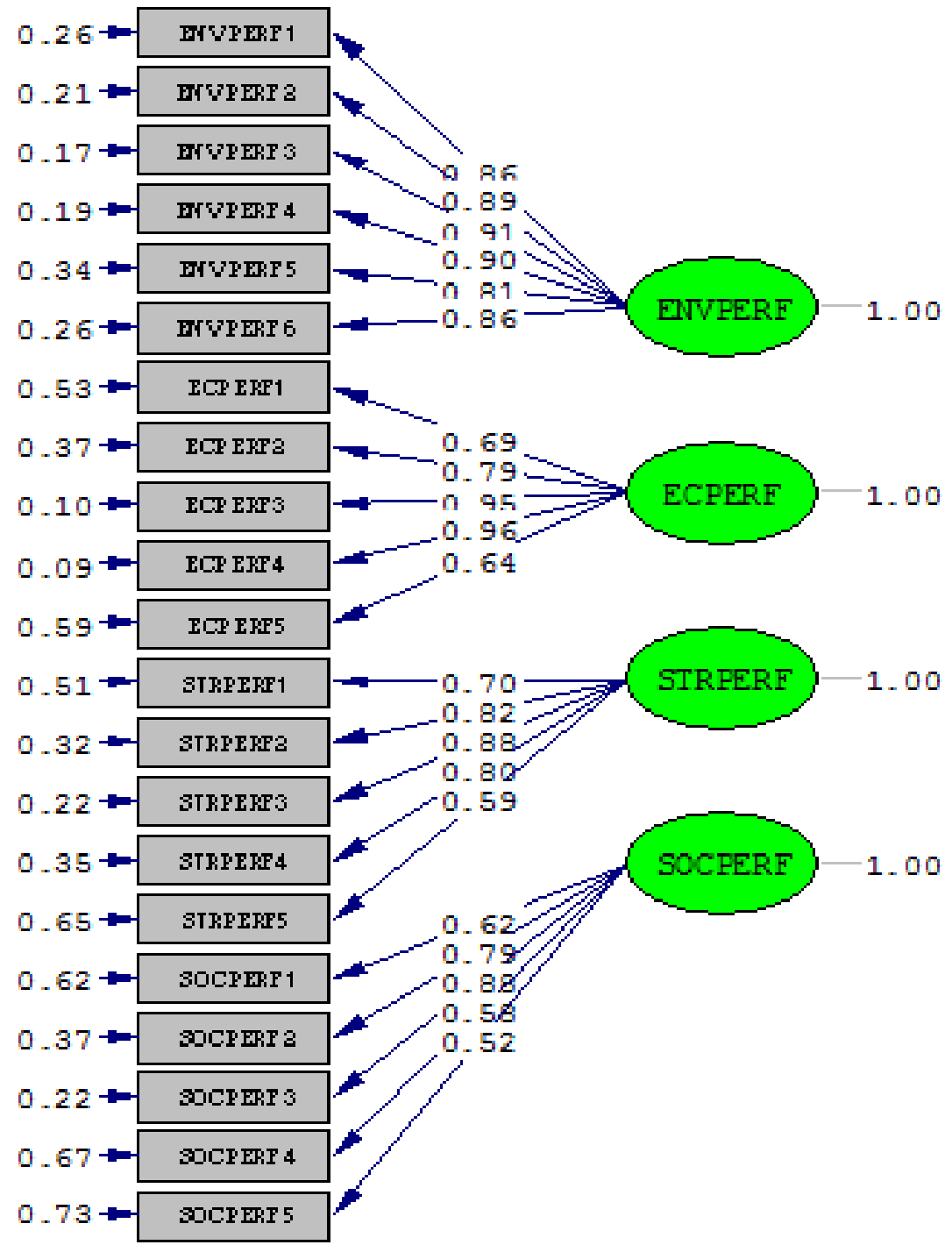




\section{Model C}

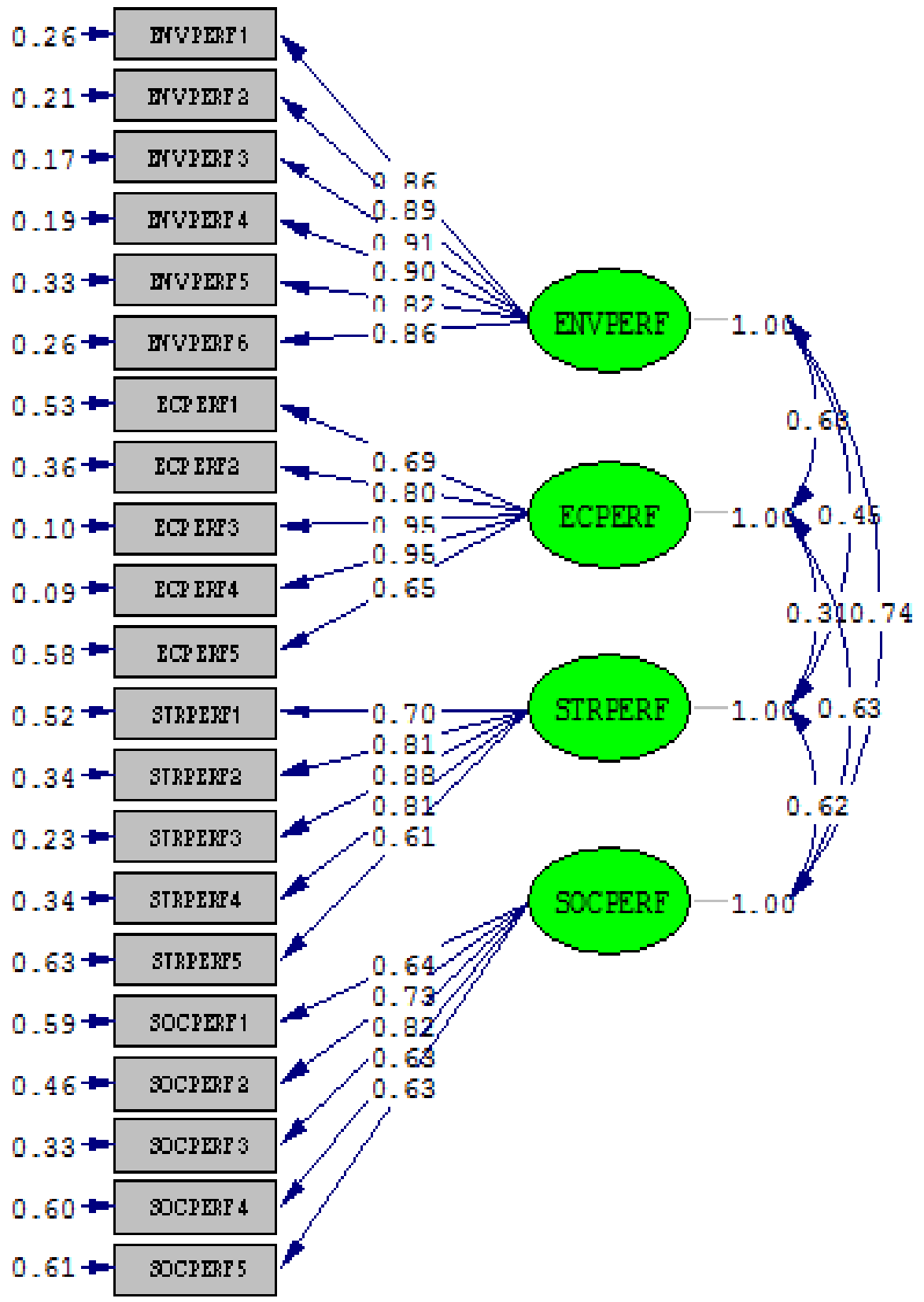


Appendix 13.0 LISREL Output for $X$ on Eta Total and Indirect Effects

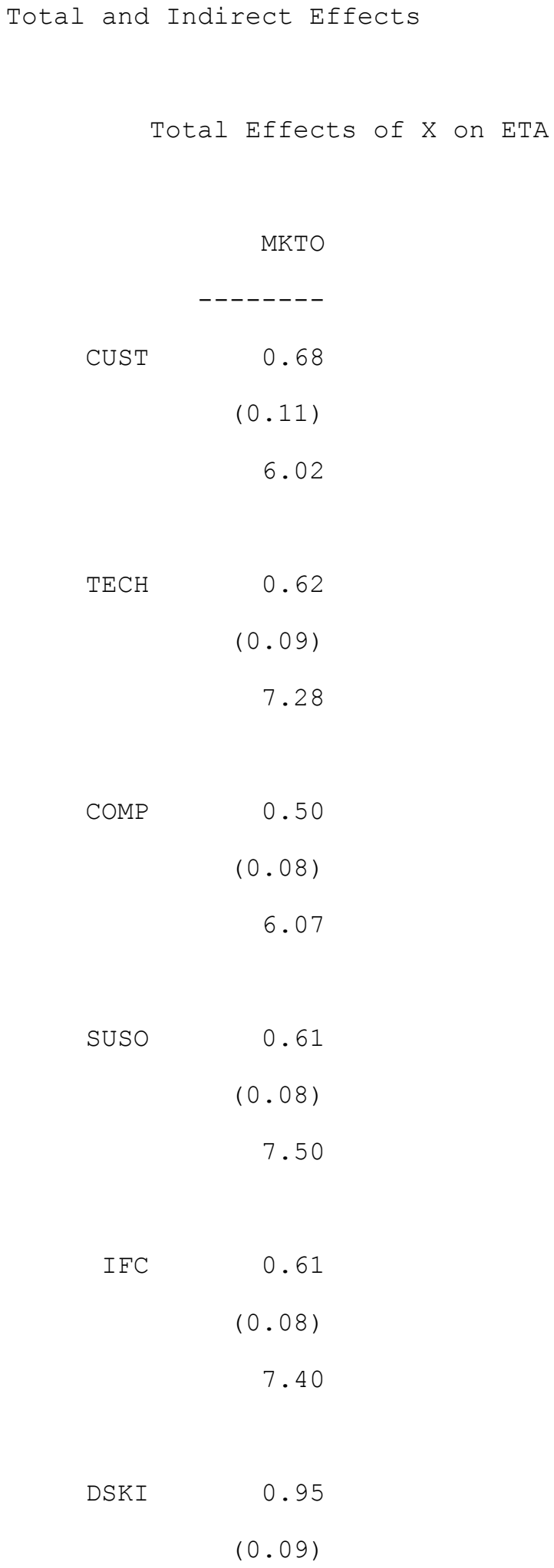


10.72

PKI 1.46

$(0.14)$

10.50

FDM 2.19

$(0.27)$

8.07

FEC $\quad 0.54$

$(0.09)$

5.85

FID $\quad 0.46$

$(0.08)$

6.00

LONG $\quad 0.37$

$(0.07)$

5.40

$\begin{array}{ll}\text { ENVPERF } & 0.48\end{array}$

$(0.07)$

7.00

ECPERF 0.40

$(0.07)$

5.88 


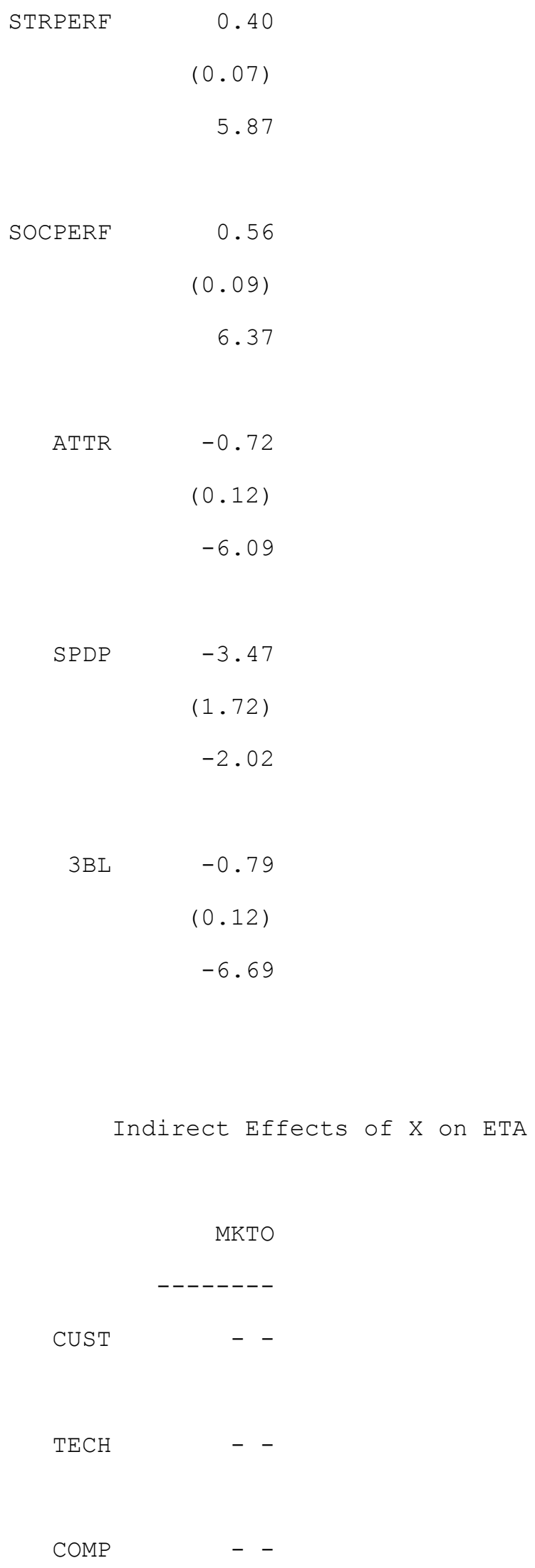




\begin{tabular}{|c|c|}
\hline SUSO & - \\
\hline IFC & - \\
\hline \multirow[t]{3}{*}{ DSKI } & 0.95 \\
\hline & $(0.09)$ \\
\hline & 10.72 \\
\hline \multirow[t]{3}{*}{$\mathrm{PKI}$} & 1.46 \\
\hline & $(0.14)$ \\
\hline & 10.50 \\
\hline \multirow[t]{3}{*}{ FDM } & 2.19 \\
\hline & $(0.27)$ \\
\hline & 8.07 \\
\hline \multirow[t]{3}{*}{$\mathrm{FEC}$} & 0.54 \\
\hline & $(0.09)$ \\
\hline & 5.85 \\
\hline \multirow[t]{3}{*}{ FID } & 0.46 \\
\hline & $(0.08)$ \\
\hline & 6.00 \\
\hline \multirow[t]{3}{*}{ LONG } & 0.37 \\
\hline & $(0.07)$ \\
\hline & 5.40 \\
\hline
\end{tabular}

$\begin{array}{ll}\text { ENVPERF } & 0.48\end{array}$ 


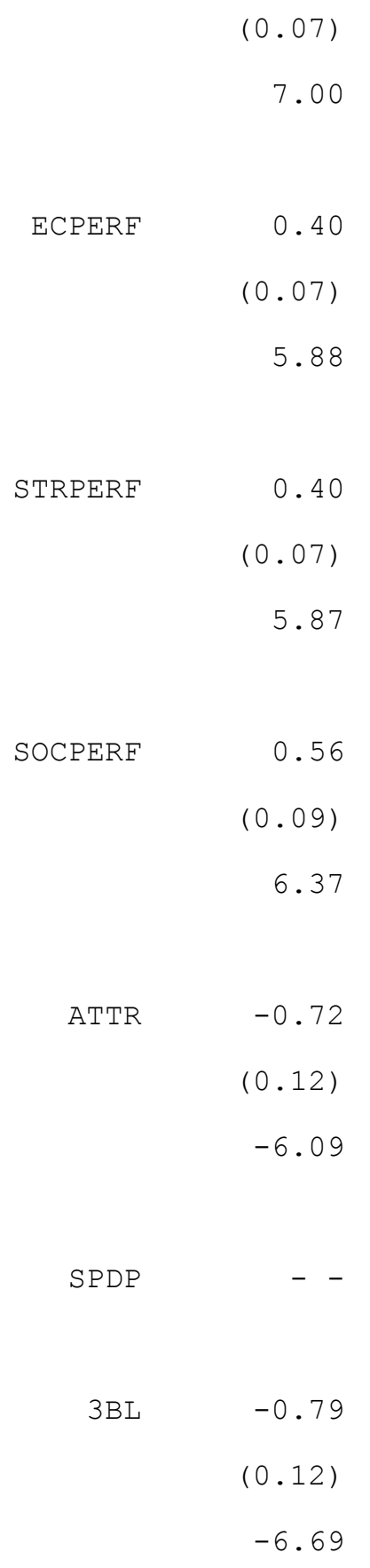




\section{Appendix 14.0 SUB A}

\section{Effect of Product Attributes on Performance}

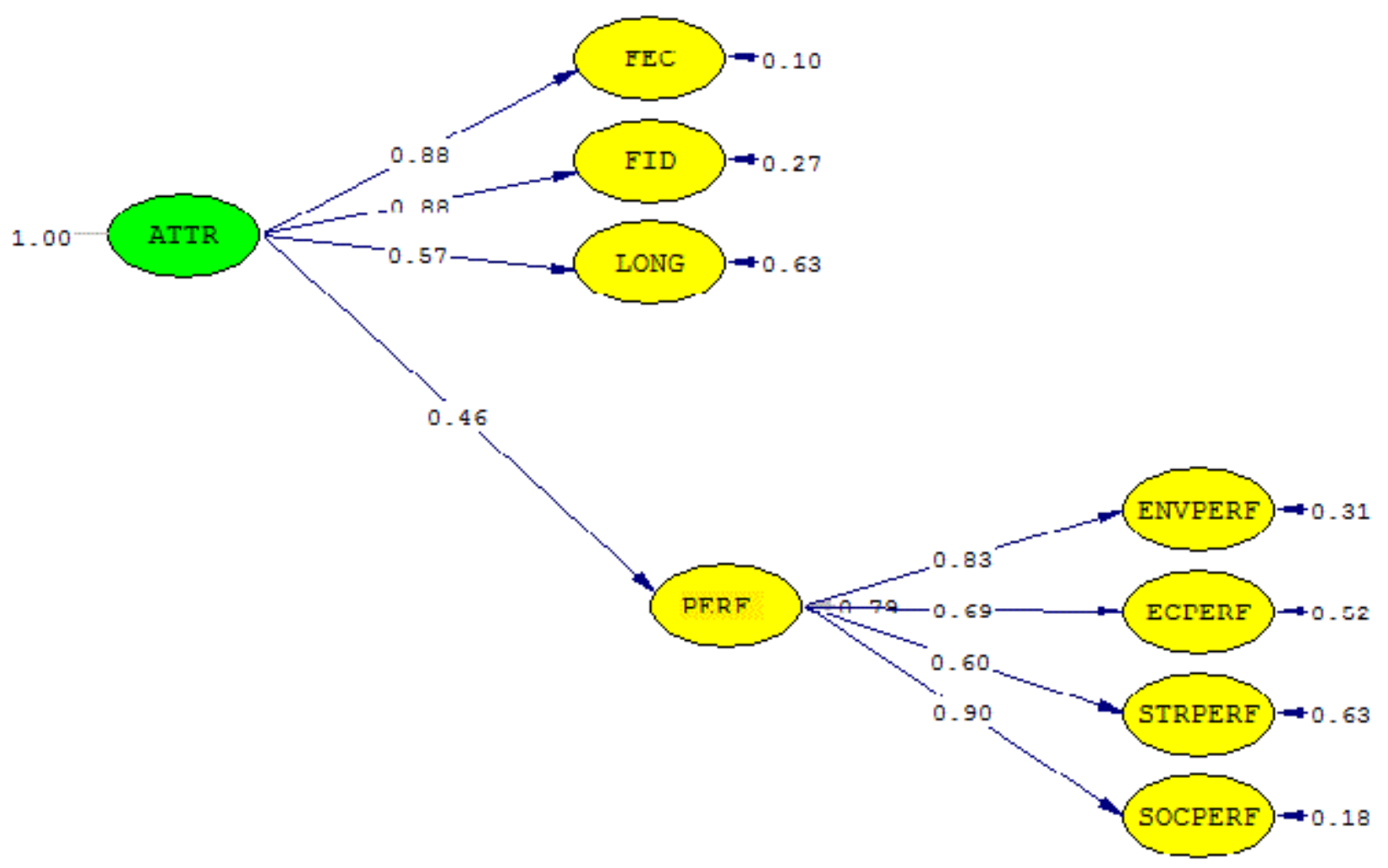




\section{Appendix 14 SUB B}

Effect of Strategic Orientation on Product Attributes and the effect on Performance

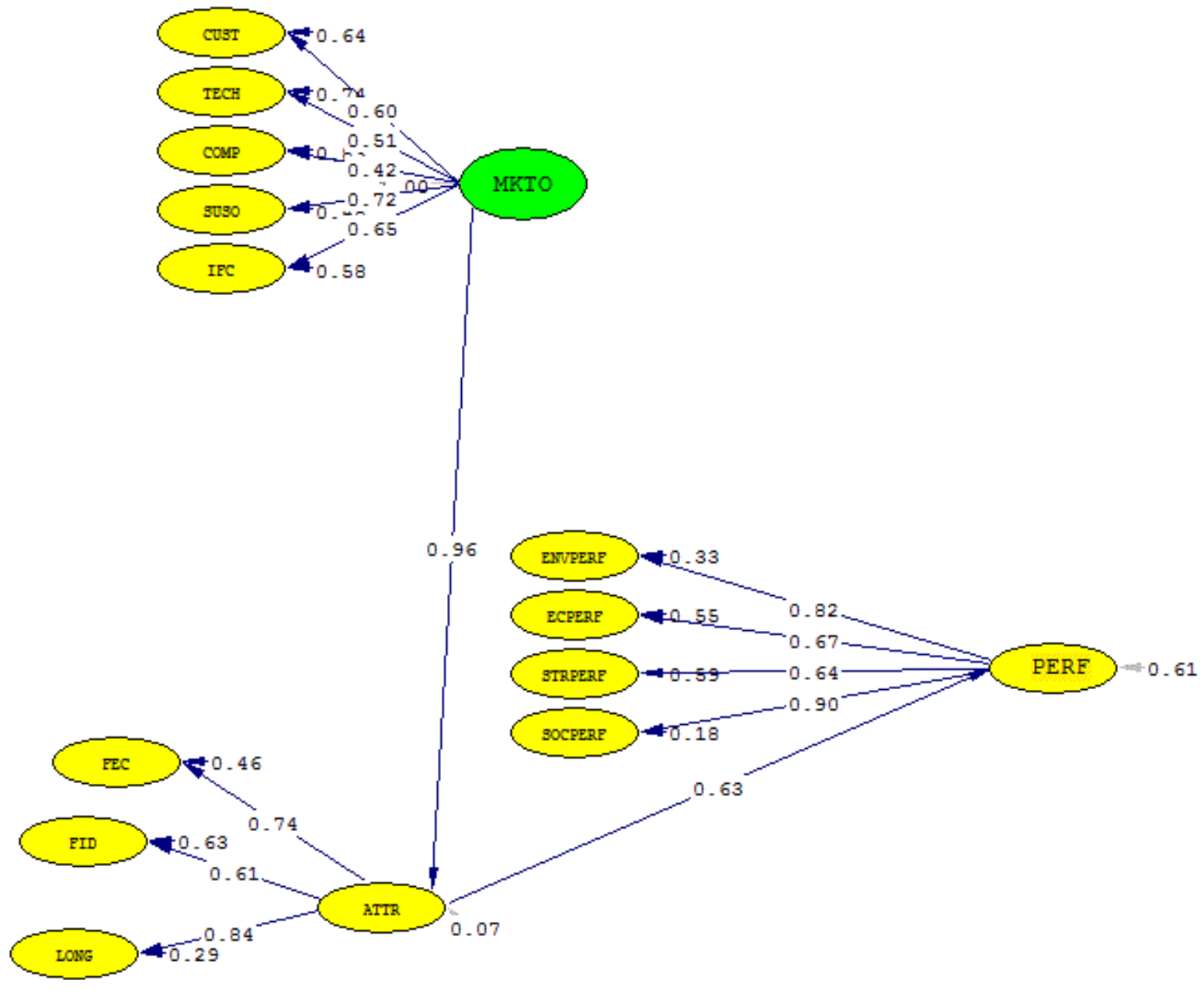




\section{Appendix 14 SUB C}

Effect of Strategic Orientation on Sustainable product development processes and

\section{Performance}

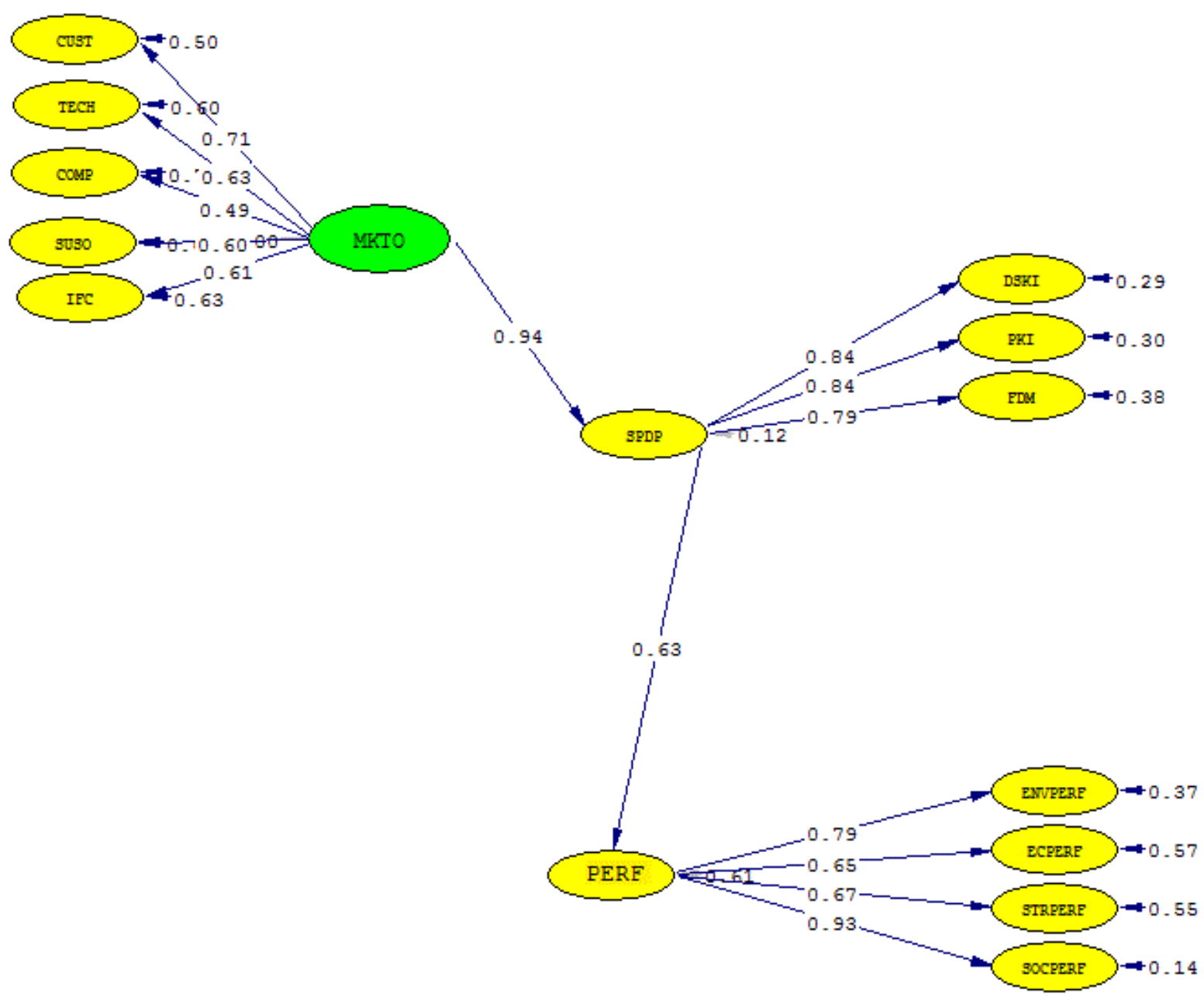




\section{Appendix 14 SUB D}

Effect of Sustainable product development processes on Product attributes and

\section{Performance}

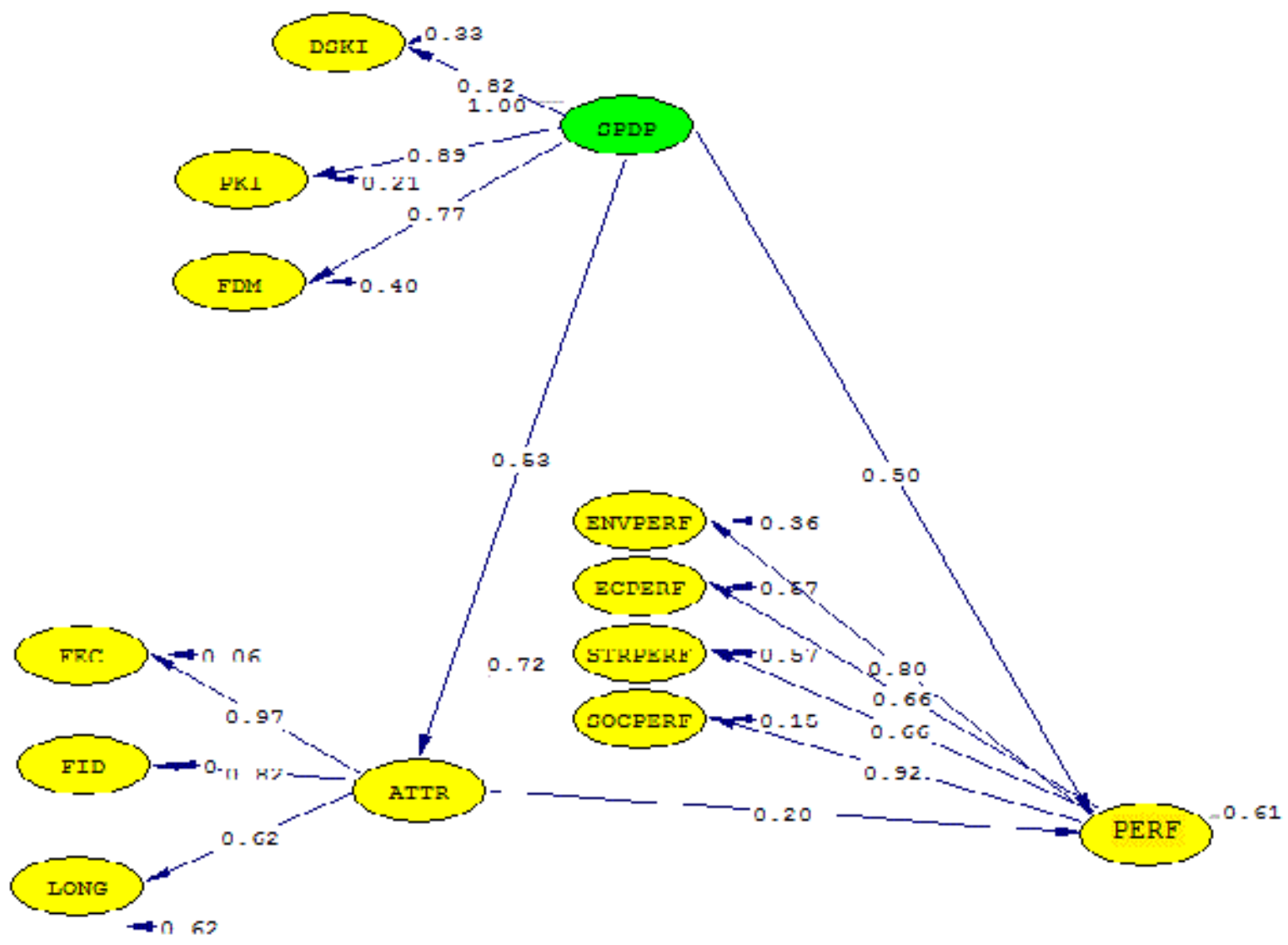




\section{Appendix 15 SIMPLIS code for a-priori model}

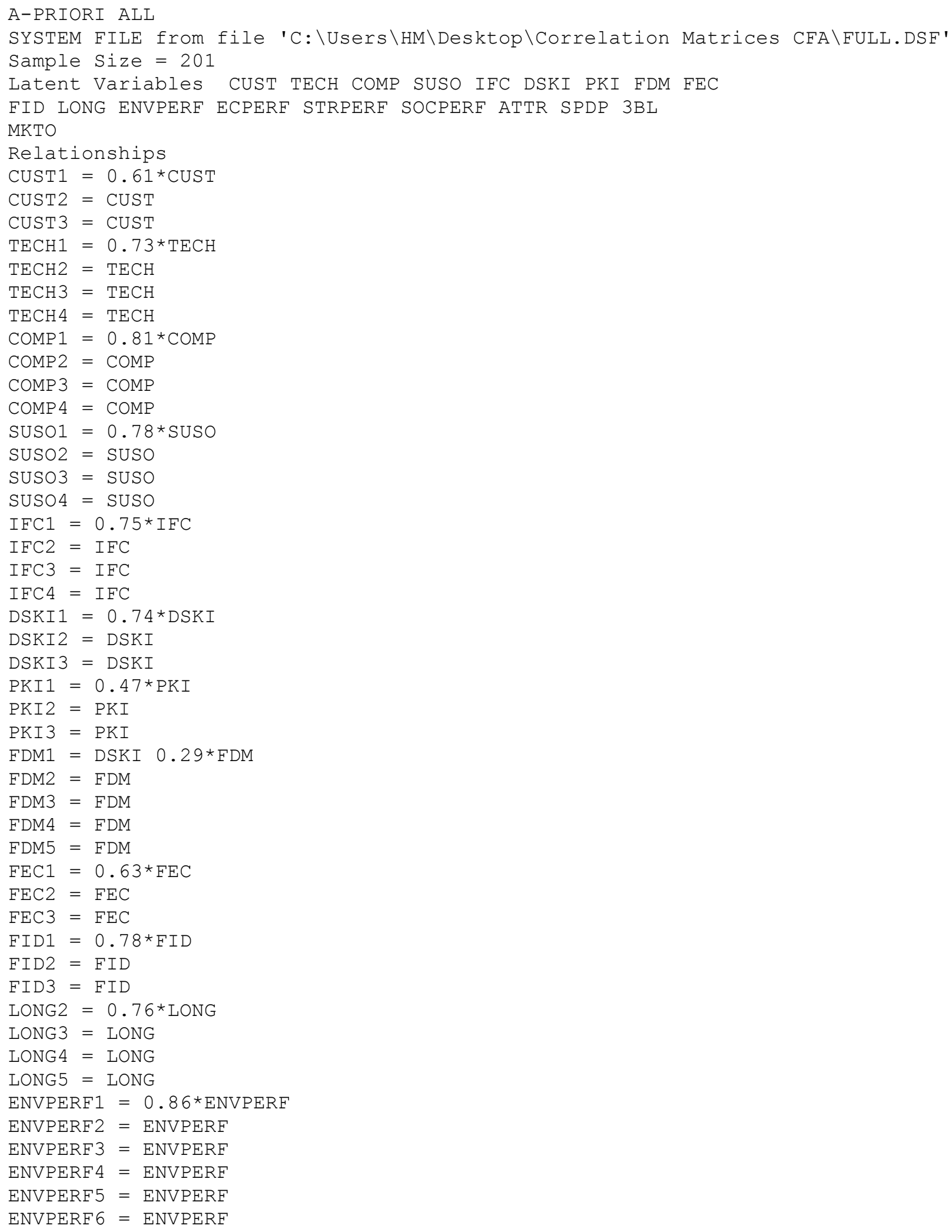




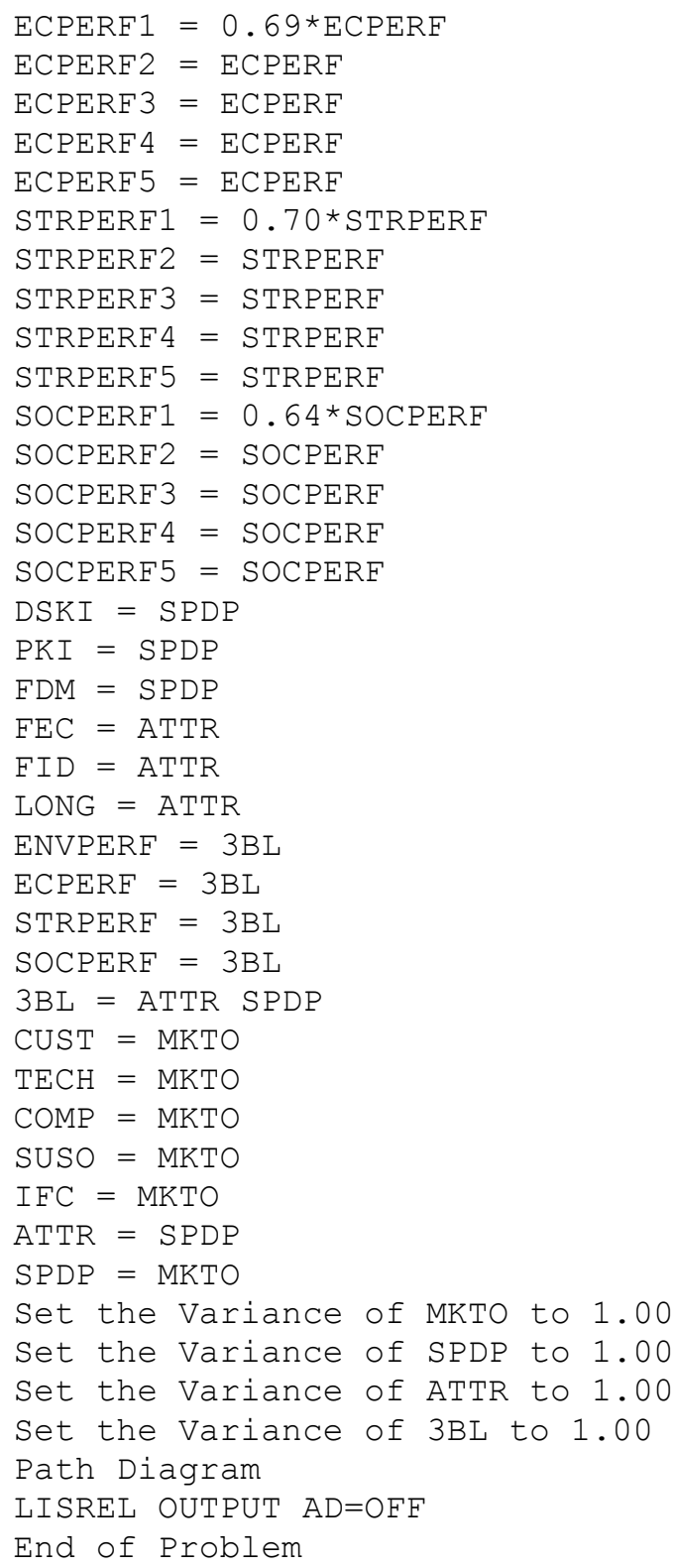




\section{Appendix 16 Items Removed from Analysis}

\begin{tabular}{|c|c|c|}
\hline Item ID & Loading Value & Theoretical Reason Itemswere Removed \\
\hline ACQTEC1 & 0.43 & $\begin{array}{l}\text { All three ACQTEC items were considered a potential match with the } \\
\text { context of sustainable products and thus the items were included in } \\
\text { domain-specific knowledge integration. }\end{array}$ \\
\hline ACQTEC2 & 0.37 & $\begin{array}{l}\text { However, data showed that organizations do not necessarily consider } \\
\text { that installing new machinery, or hiring new people, or new training } \\
\text { results in product and process sustainability. }\end{array}$ \\
\hline ACQTEC3 & 0.44 & Thus these items were feasibly dropped from the study. \\
\hline & & $\begin{array}{l}\text { The question whether a product can support or is compatible with a } \\
\text { range of other products is something that is hypothesized to exist } \\
\text { once the sustainability market matures (Boons et al., 2013; Kuhl et } \\
\text { al., 2016). } \\
\text { Perhaps the idea that modularisation of products is one of the routes } \\
\text { to sustainability and what is the value of such, is not as pervasive as } \\
\text { was theorised (Hallstedt et al., 2015; Mascle, 2013). }\end{array}$ \\
\hline LONG1 & 0.45 & Thus the item was feasibly dropped from the study. \\
\hline
\end{tabular}




\section{Appendix 17 Modification Indices Appliedand Reasons}

\begin{tabular}{|c|c|c|}
\hline $\begin{array}{l}\text { Second } \\
\text { order Model }\end{array}$ & Modification Indices Applied & Reason \\
\hline $\begin{array}{l}\text { Strategic } \\
\text { Orientation }\end{array}$ & $\begin{array}{l}\text { COMP1 to CUST; } \\
\text { - CUST3 to TECH; } \\
\text { - CUST2 \& CUST3 to COMP; } \\
\text { - CUST1 to SUSO; } \\
\text { - CUST1, CUST2, CUST3 \& } \\
\text { SUSO2 to IFC }\end{array}$ & $\begin{array}{l}\text { Collection of information on competition also } \\
\text { includes their attitude and orientation towards the } \\
\text { customer base. } \\
\text { Market research to understand customer needs } \\
\text { also includes the technology needs of the } \\
\text { customer. } \\
\text { Market research and customer satisfaction may be } \\
\text { considered relative to the products from } \\
\text { competitors in the market. } \\
\text { Satisfaction surveys would also include the } \\
\text { satisfaction with the sustainability aspects of the } \\
\text { product. } \\
\text { Meetings with customers to determine needs, } \\
\text { satisfaction surveys, market research into } \\
\text { customer needs and preventing waste during } \\
\text { production would all only be possible in various } \\
\text { functional groups within the organization } \\
\text { cooperated for the above requirements. }\end{array}$ \\
\hline $\begin{array}{l}\text { Sustainable } \\
\text { Product } \\
\text { Development } \\
\text { Processes }\end{array}$ & $\begin{array}{l}\text { - FDM1 to PKI; } \\
\text { - FDM1 to DSKI; }\end{array}$ & $\begin{array}{l}\text { Forecasting future requirements based on } \\
\text { committed product development decisions would } \\
\text { involve an estimation of both the procedural as } \\
\text { well as domain specific knowledge that would } \\
\text { need to be integrated for future purposes. }\end{array}$ \\
\hline $\begin{array}{l}\text { Product } \\
\text { Attributes }\end{array}$ & - $\quad$ LONG2 \& LONG5 to FEC; & $\begin{array}{l}\text { Product performance consistently over time as } \\
\text { well as life-span being not curtailed by in-built } \\
\text { limitations would directly impact fecundity since } \\
\text { the product may be rendered more attractive to the } \\
\text { consumer for the span of time it is usable without } \\
\text { limitations imposed by factors other than }\end{array}$ \\
\hline
\end{tabular}




\begin{tabular}{|c|c|c|}
\hline & $\begin{array}{l}\text { - LONG5 to FID; } \\
\text { - FID1 \& FEC1 to LONG; }\end{array}$ & $\begin{array}{l}\text { consumer choice. } \\
\text { It may be reasonably deduced that a product that } \\
\text { can function without in-built limitations would } \\
\text { also be able to function more "true-to-itself". } \\
\text { It may be reasonably deduced that if a product can } \\
\text { be tried out with great ease and can reach a large } \\
\text { number of people with ease, it may be used for a } \\
\text { longer time period. }\end{array}$ \\
\hline Performance & None Applied & NA \\
\hline
\end{tabular}


Appendix 18 Full Correlation Matrix from Data

\begin{tabular}{|c|c|c|c|c|c|c|c|c|}
\hline CUST1 & CUST2 & CUST3 & TECH1 & TECH2 & TECH3 & TECH4 & COMP1 & \\
\hline COMP2 & COMP3 & COMP4 & SUSO1 & SUSO2 & SUSO3 & SUSO4 & IFC1 & IFC3 \\
\hline DSKI & 1 DSKI2 DSKI3 & PKI2 & PKI3 FDM1 & FDM2 FDM3 & FDM4 FEC1 & FEC2 FEC3 & FID1 FID2 & FID3 \\
\hline LONG2 & LONG3 & LONG4 & LONG5 & ENVPERF1 & ENVPERF2 & ENVPERF3 & ENVPERF4 & \\
\hline ECPERF2 & ECPERF3 & ECPERF4 & STRPERF2 & STRPERF3 & STRPERF4 & SOCPERF1 & SOCPERF2 & \\
\hline OCPERF3 & SOCPERF4 & & & & & & & \\
\hline
\end{tabular}

CUST1 1

CUST2 $\quad 0.230570821 \quad 1$

$\begin{array}{llll}\text { CUST3 } & 0.400664104 & 0.400889724 & 1\end{array}$ 
$\begin{array}{lllll}\text { TECH1 } & 0.299762104 & 0.092407817 & 0.347256609 & 1\end{array}$

$\begin{array}{llllll}\mathrm{TECH} 2 & 0.282004301 & 0.122676005 & 0.313388581 & 0.583065762 & 1\end{array}$

$\begin{array}{lllllll}\mathrm{TECH} 3 & 0.208566624 & 0.077266256 & 0.408899622 & 0.680313267 & 0.725913646 & 1\end{array}$

$\begin{array}{llllllll}\text { TECH4 } & 0.321836186 & 0.050395006 & 0.286095914 & 0.525120054 & 0.616625653 & 0.637364995 & 1\end{array}$ 
$\begin{array}{lllllllll}\text { COMP1 } & 0.272346632 & 0.414387954 & 0.450929829 & 0.208465692 & 0.204226707 & 0.212570577 & 0.256024901 & 1\end{array}$

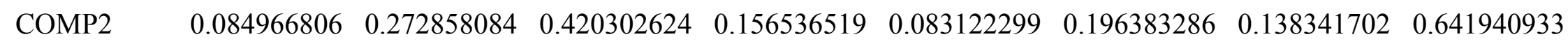
1

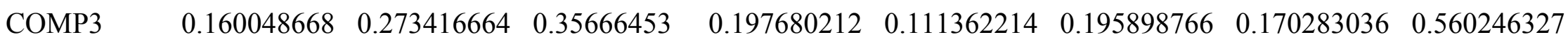
$0.607937787 \quad 1$

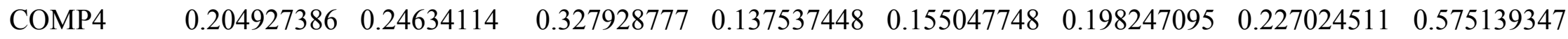
$\begin{array}{llll}0.494420539 & 0.552783463 & 1\end{array}$ 
$\begin{array}{lllllllll}\text { SUSO1 } & 0.368449354 & 0.015294351 & 0.136078679 & 0.100342941 & 0.167948917 & 0.071172728 & 0.116993876 & 0.089246738\end{array}$ $\begin{array}{llll}0.051894039 & 0.039298549 & 0.088937457 & 1\end{array}$

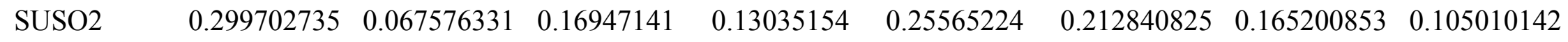
$\begin{array}{lllll}0.039889495 & 0.08637567 & 0.152253908 & 0.652723974 & 1\end{array}$

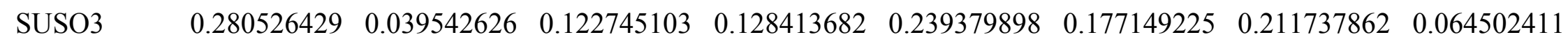
$\begin{array}{llllll}0.087340309 & 0.039630456 & 0.132033708 & 0.652546087 & 0.783418632 & 1\end{array}$

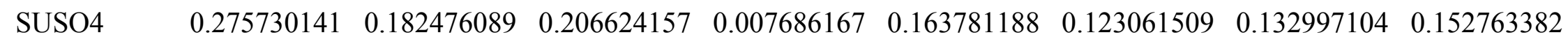
$\begin{array}{lllllll}0.118386239 & 0.095317844 & 0.039675175 & 0.685711491 & 0.602616621 & 0.64292606 & 1\end{array}$ 


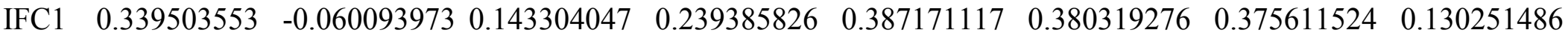 $\begin{array}{llllllll}0.069366837 & 0.06397905 & 0.222742369 & 0.334072834 & 0.464138672 & 0.370172002 & 0.292101939 & 1\end{array}$

$\begin{array}{rllllllllll}\text { IFC2 } & 0.303595539 & -0.084659582 & 0.160573724 & 0.296983307 & 0.408734171 & 0.357106108 & 0.39817718 & 0.057414157 \\ & 0.019853392 & 0.050089059 & 0.127005398 & 0.329030473 & 0.410698993 & 0.35311793 & 0.236484325 & 0.641724892 & 1\end{array}$

$\begin{array}{lllllllll}\text { IFC3 } & 0.353360316 & -0.012406782 & 0.200305609 & 0.335984189 & 0.43981953 & 0.38131545 & 0.442638063 & 0.12823651\end{array}$ $\begin{array}{llllllll}0.030814353 & 0.09201436 & 0.141425694 & 0.2874765 & 0.425974475 & 0.320276165 & 0.238525249 & 0.666980259\end{array}$ $0.718258459 \quad 1$ 


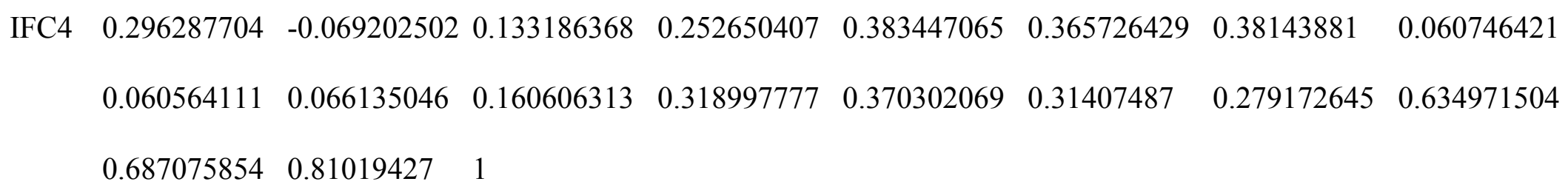

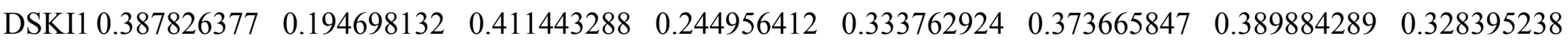
$\begin{array}{llllllll}0.210249145 & 0.239518429 & 0.303454829 & 0.386505188 & 0.380636863 & 0.372963792 & 0.358834339 & 0.288886838\end{array}$ $\begin{array}{llll}0.289953964 & 0.314415815 & 0.309781751 & 1\end{array}$

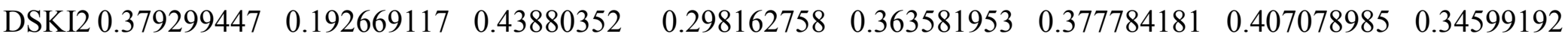
$\begin{array}{llllllll}0.206130438 & 0.272624229 & 0.319135437 & 0.37741996 & 0.364105266 & 0.376364656 & 0.341828201 & 0.306939494\end{array}$ $\begin{array}{lllll}0.321199234 & 0.359183267 & 0.364810929 & 0.850922877 & 1\end{array}$ 


$\begin{array}{cccccccccc}\text { PKI3 } & 0.306788863 & 0.173165643 & 0.306953023 & 0.25716395 & 0.380618752 & 0.325016927 & 0.446988133 & 0.269468381 \\ & 0.161030283 & 0.168853694 & 0.227157496 & 0.42095802 & 0.429580727 & 0.465752647 & 0.34716371 & 0.339633914 \\ & 0.378880427 & 0.434380856 & 0.377977758 & 0.5500586 & 0.639028512 & 0.654903591 & 0.740919096 & 0.809892357 & 1\end{array}$

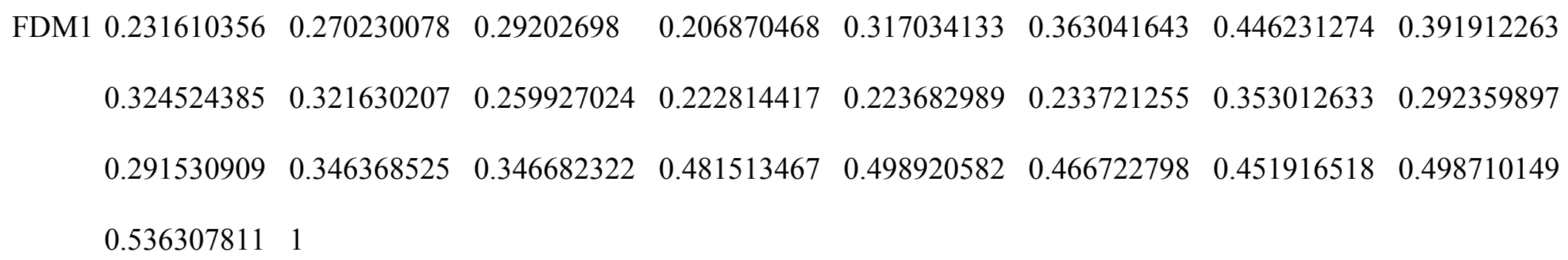

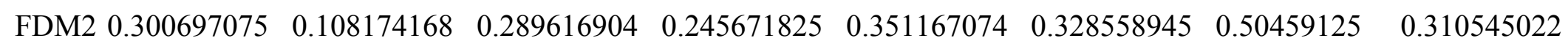
$\begin{array}{llllllll}0.229923447 & 0.308602239 & 0.294709813 & 0.2851317 & 0.23340221 & 0.338790104 & 0.308575506 & 0.33606352\end{array}$ $\begin{array}{llllllll}0.41484431 & 0.379149332 & 0.400827883 & 0.441083021 & 0.51261685 & 0.532428047 & 0.423168395 & 0.467000873\end{array}$ $0.586298152 \quad 0.721315098 \quad 1$ 


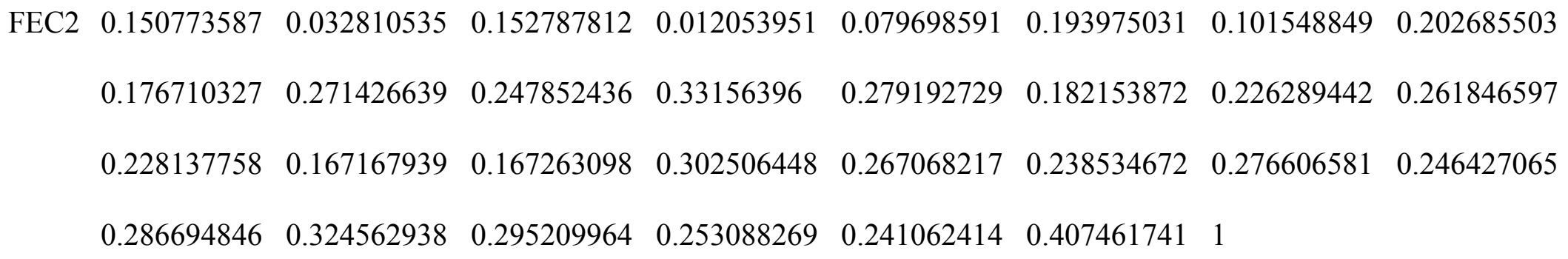

$\begin{array}{lllllllll}\text { FEC3 } & 0.099045306 & 0.162846232 & 0.177323548 & 0.068809037 & 0.048573833 & 0.134080959 & 0.116144286 & 0.128176517\end{array}$ $\begin{array}{llllllll}0.246979617 & 0.229171622 & 0.16455367 & 0.257770961 & 0.162773436 & 0.193452341 & 0.224953302 & 0.194161405\end{array}$ $\begin{array}{llllllll}0.160316431 & 0.176926044 & 0.204370379 & 0.235334775 & 0.209273333 & 0.186846637 & 0.238382323 & 0.244679533\end{array}$ $\begin{array}{llllllll}0.339787451 & 0.314826161 & 0.220674886 & 0.236913557 & 0.171043792 & 0.332401726 & 0.581883238 & 1\end{array}$

$\begin{array}{lllllllll}\text { FID1 } & 0.001871332 & 0.19433823 & 0.15553323 & -0.083003111 & 0.04380436 & 0.029872315 & 0.047727598 & 0.236515236\end{array}$ $\begin{array}{llllllll}0.245905283 & 0.322709284 & 0.24311948 & 0.112556643 & 0.178764377 & 0.057706745 & 0.112841161 & 0.08496875\end{array}$

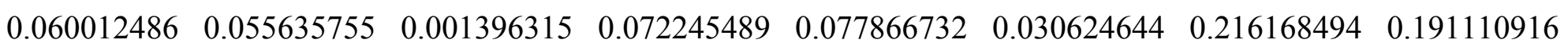

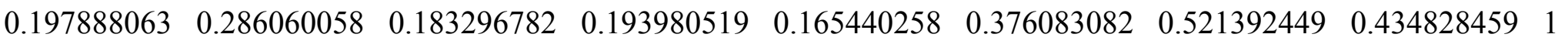




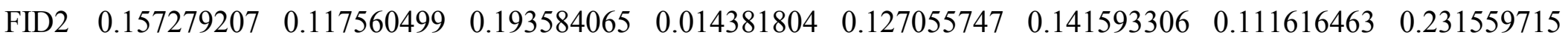
$\begin{array}{llllllll}0.309545513 & 0.369909044 & 0.266306054 & 0.232394135 & 0.308281167 & 0.249335977 & 0.238213574 & 0.217971275\end{array}$ $\begin{array}{llllllll}0.186519361 & 0.244813359 & 0.19444641 & 0.154951467 & 0.179351138 & 0.131407497 & 0.220624302 & 0.19868028\end{array}$ $\begin{array}{llllllll}0.27258368 & 0.317363829 & 0.324213348 & 0.269263974 & 0.302838575 & 0.445305988 & 0.515286422 & 0.432246855\end{array}$ 0.6926285721

$\begin{array}{lllllllll}\text { FID3 } & 0.119700651 & 0.070190048 & 0.096887193 & 0.050180577 & 0.069443822 & 0.159910607 & 0.028044881 & 0.099124167\end{array}$ $\begin{array}{llllllll}0.215255437 & 0.169458754 & 0.12753574 & 0.199294965 & 0.2385647 & 0.129907844 & 0.188217806 & 0.333174993\end{array}$ $\begin{array}{llllllll}0.140988359 & 0.21621479 & 0.261829648 & 0.130974585 & 0.147728892 & 0.116287922 & 0.134990105 & 0.051458084\end{array}$ $\begin{array}{llllllll}0.161220445 & 0.264870301 & 0.134907012 & 0.202786294 & 0.116016724 & 0.419365716 & 0.346396037 & 0.326202124\end{array}$ $0.379947882 \quad 0.409286624 \quad 1$

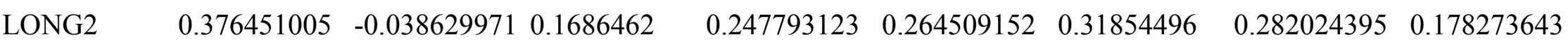
$\begin{array}{llllllll}0.144457737 & 0.143637213 & 0.280099581 & 0.418897354 & 0.592459396 & 0.51474845 & 0.344861425 & 0.472589582\end{array}$ $\begin{array}{llllllll}0.374692189 & 0.484092677 & 0.41658965 & 0.312812728 & 0.325290654 & 0.414890611 & 0.317411964 & 0.338099364\end{array}$ $\begin{array}{llllllll}0.449564661 & 0.298738205 & 0.387870756 & 0.252984652 & 0.425215467 & 0.423620316 & 0.414190729 & 0.25392587\end{array}$ 
$\begin{array}{llll}0.195472055 & 0.436105738 & 0.309346 & 1\end{array}$

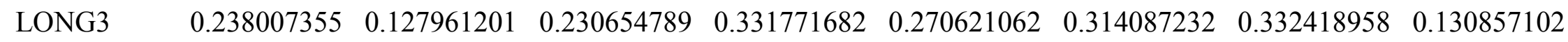
$\begin{array}{llllllll}0.139800488 & 0.172813263 & 0.149107517 & 0.240692596 & 0.339767152 & 0.436947524 & 0.292428431 & 0.240008915\end{array}$

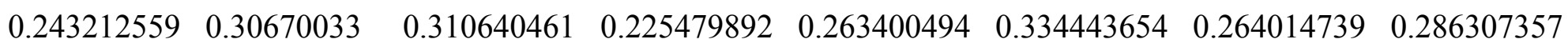
$\begin{array}{llllllll}0.444668614 & 0.238155573 & 0.348201538 & 0.187071834 & 0.364981742 & 0.262552234 & 0.078973087 & 0.241229987\end{array}$ $\begin{array}{lllll}0.150129943 & 0.262202612 & 0.127926773 & 0.421709947 & 1\end{array}$

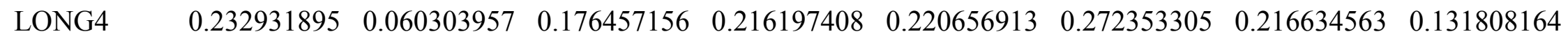

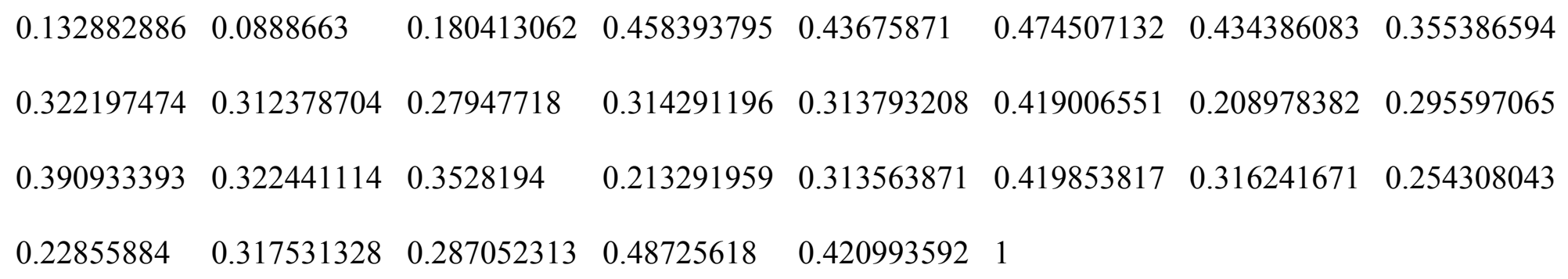

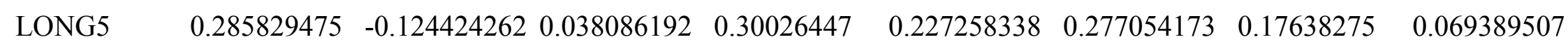
$\begin{array}{llllllll}0.032058043 & 0.055012914 & 0.15421166 & 0.291045454 & 0.364643125 & 0.357855495 & 0.196050607 & 0.331077298\end{array}$ 


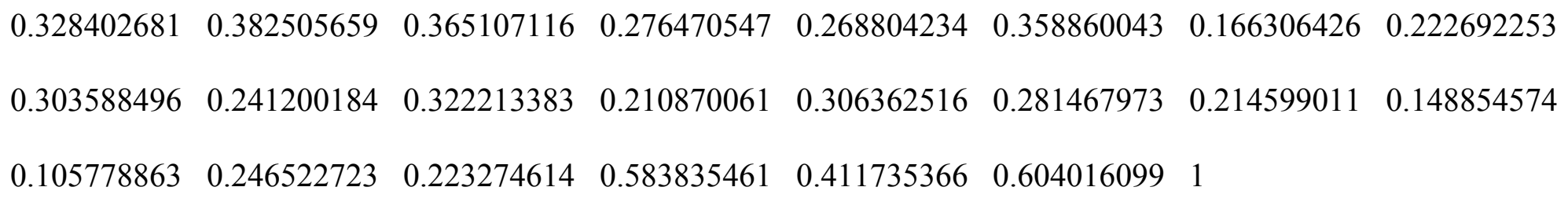

$\begin{array}{lllllllll}\text { ENVPERF1 } & 0.095929476 & 0.149073944 & 0.231331377 & -0.041334627 & 0.002799963 & 0.020444829 & 0.118361087 & 0.154335101\end{array}$

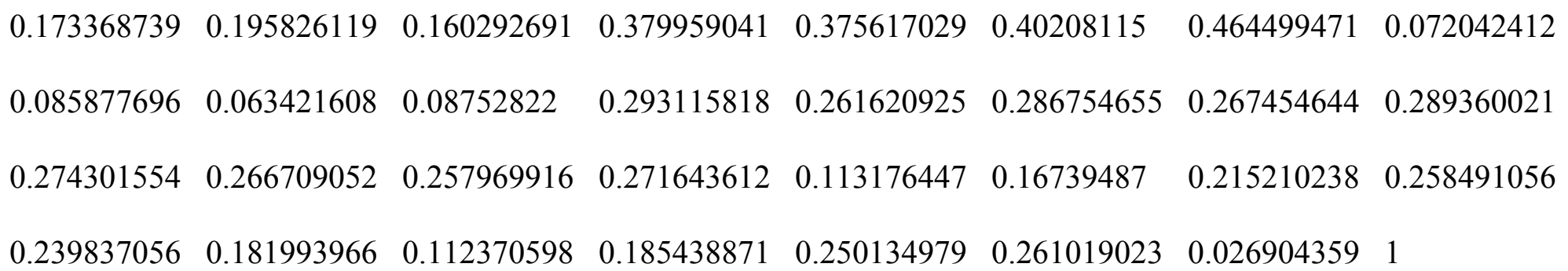

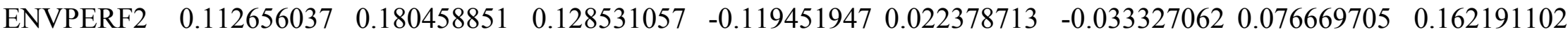
$\begin{array}{llllllll}0.164005774 & 0.191508115 & 0.145912106 & 0.430688783 & 0.431228168 & 0.430208867 & 0.489171987 & 0.080236804\end{array}$ $\begin{array}{llllllll}0.12085636 & 0.042349563 & 0.073504599 & 0.206849592 & 0.198671771 & 0.220322381 & 0.265964432 & 0.226721527\end{array}$

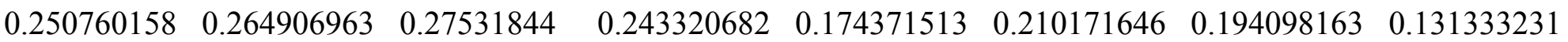

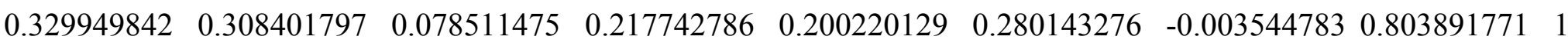




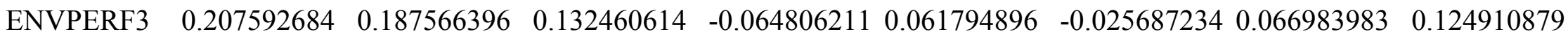

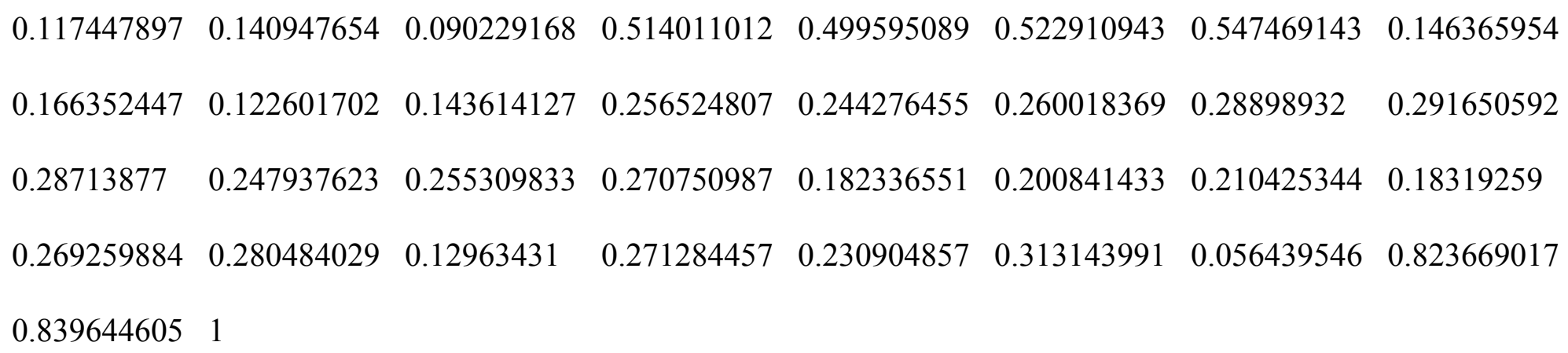

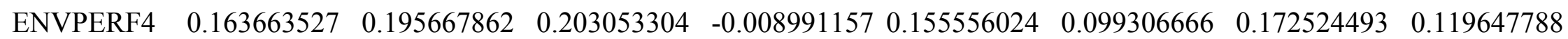

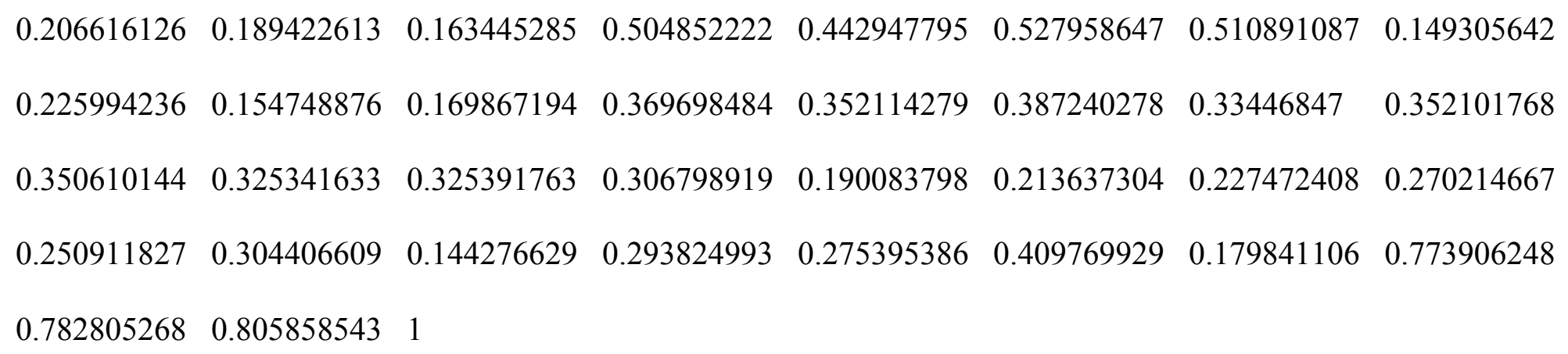

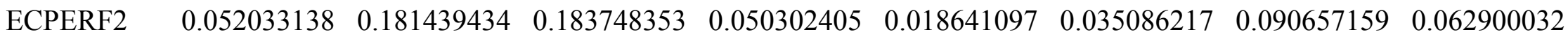
$\begin{array}{llllllll}0.142454498 & 0.16616854 & 0.038088342 & 0.138426203 & 0.208109751 & 0.235658875 & 0.257378842 & 0.041000394\end{array}$ $\begin{array}{llllllll}0.061580166 & 0.142268439 & 0.161818433 & 0.040451451 & 0.061534459 & 0.112788439 & 0.146937547 & 0.185399455\end{array}$ 


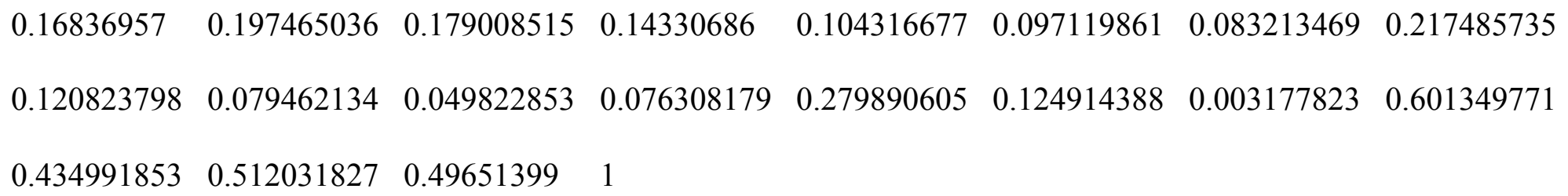

$\begin{array}{lllllllll}\text { ECPERF3 } & 0.165528461 & 0.175010333 & 0.17525642 & 0.069194148 & -0.027274592 & 0.001318629 & 0.048688589 & -0.00488679\end{array}$

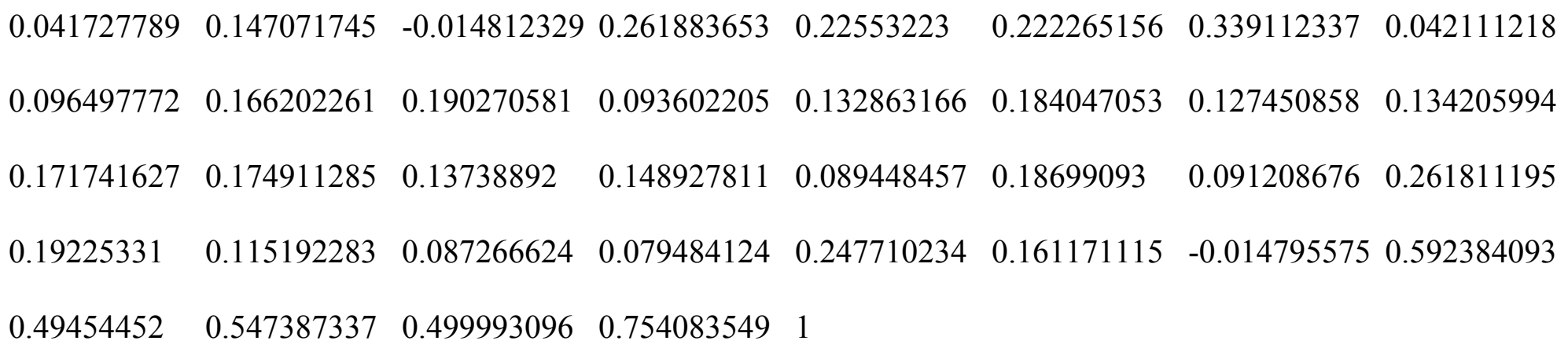

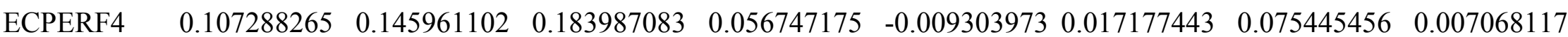

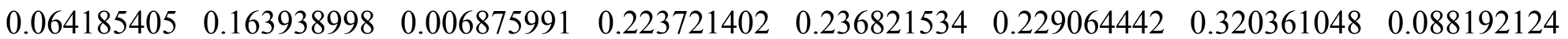

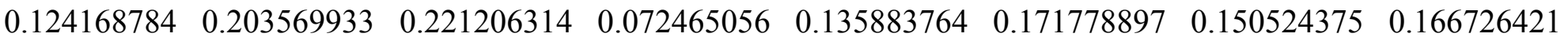
$\begin{array}{llllllll}0.210793897 & 0.175155249 & 0.158569743 & 0.145608477 & 0.083828066 & 0.193536093 & 0.067944228 & 0.235223652\end{array}$

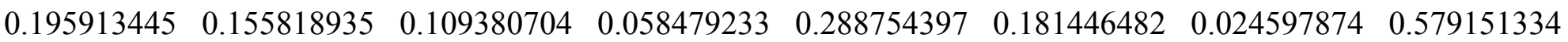
$\begin{array}{lllllll}0.478930152 & 0.508716488 & 0.481925587 & 0.749526704 & 0.907304601 & 1\end{array}$ 


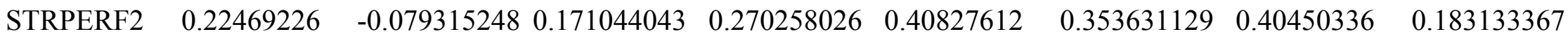

$\begin{array}{llllllllll}0.137053179 & 0.143856196 & 0.134727464 & 0.20847261 & 0.346391313 & 0.299217814 & 0.126337156 & 0.376612141 \\ 0.410047934 & 0.440047372 & 0.359428233 & 0.342810343 & 0.379662637 & 0.346634325 & 0.446149146 & 0.439339387 \\ 0.45358541 & 0.36160838 & 0.524639047 & 0.407216618 & 0.44096451 & 0.25499151 & 0.163488822 & 0.114954892 \\ 0.147046108 & 0.282583995 & 0.122470549 & 0.483855941 & 0.252721135 & 0.240987751 & 0.352277001 & 0.195407818 \\ 0.266518755 & 0.233335111 & 0.311623897 & 0.149887004 & 0.08135188 & 0.148031193 & 1 & & \end{array}$

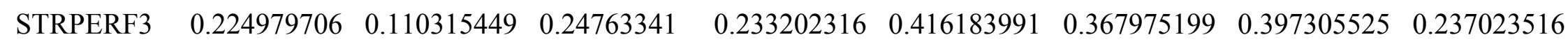

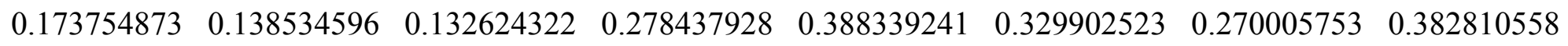
$\begin{array}{llllllll}0.385387229 & 0.430975549 & 0.377930778 & 0.411245291 & 0.433179613 & 0.463054727 & 0.428111934 & 0.438831957\end{array}$ $\begin{array}{llllllll}0.484514238 & 0.481900366 & 0.498247247 & 0.497426403 & 0.436438999 & 0.343789723 & 0.114576596 & 0.180204228\end{array}$ $\begin{array}{llllllll}0.204551235 & 0.206414008 & 0.175990038 & 0.361501914 & 0.321773425 & 0.306540778 & 0.30570208 & 0.264539307\end{array}$ $\begin{array}{llllllll}0.331654812 & 0.301913537 & 0.413055806 & 0.243951586 & 0.264007035 & 0.258443678 & 0.718332526 & 1\end{array}$

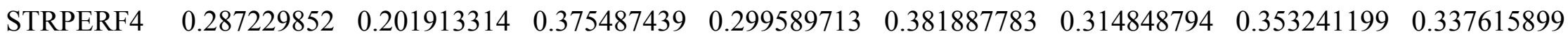
$\begin{array}{llllllll}0.197363872 & 0.172789536 & 0.148394623 & 0.265480611 & 0.339341098 & 0.310574676 & 0.237828467 & 0.311077985\end{array}$ 


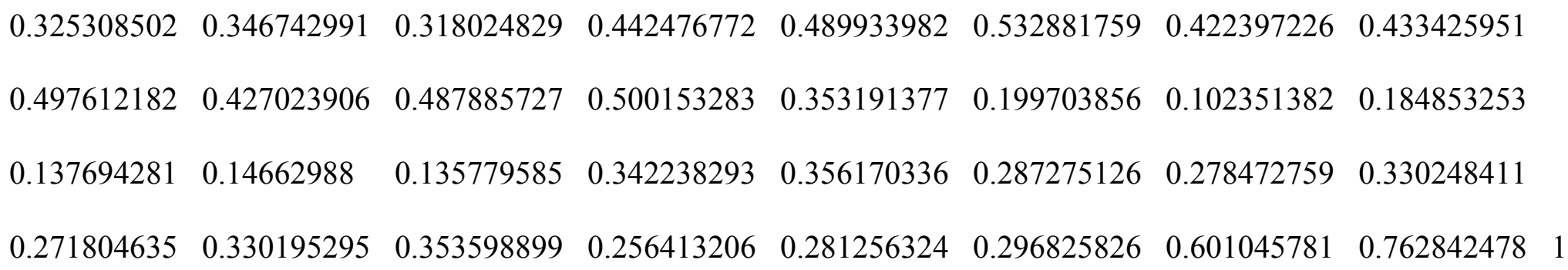

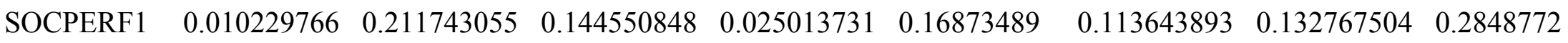

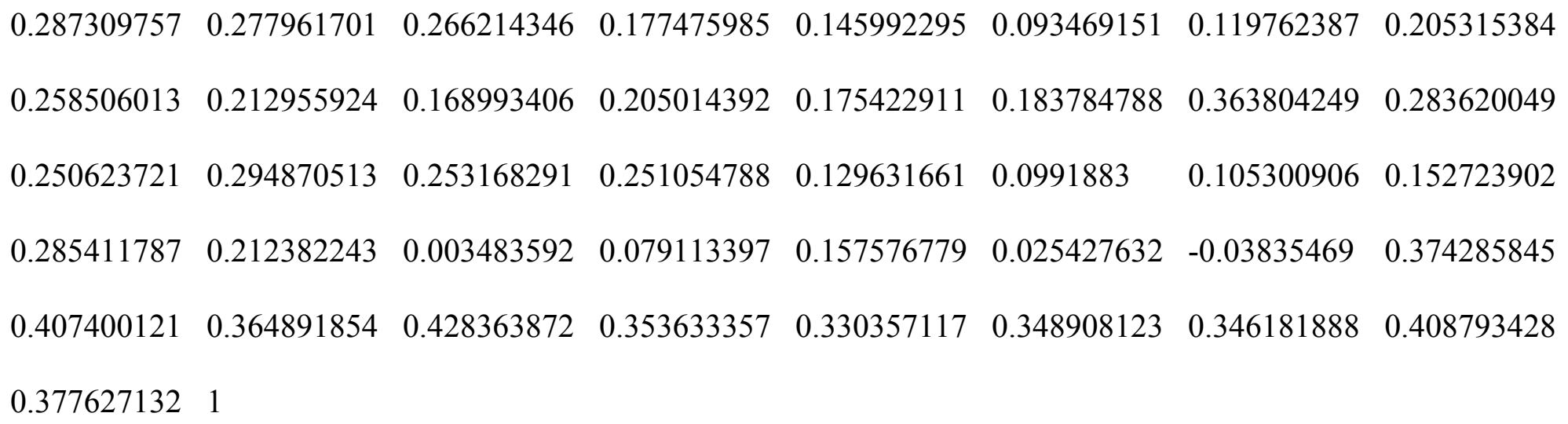

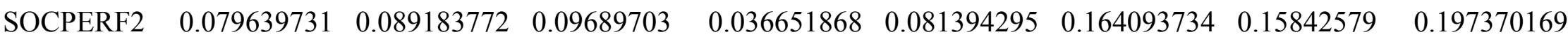
$\begin{array}{llllllll}0.162793718 & 0.153624967 & 0.194444752 & 0.245633096 & 0.349839273 & 0.249415601 & 0.202248505 & 0.265035543\end{array}$ $\begin{array}{llllllll}0.306061326 & 0.272057902 & 0.202887828 & 0.149614205 & 0.191293841 & 0.20128958 & 0.321448887 & 0.27231454\end{array}$ $\begin{array}{llllllll}0.220116775 & 0.280717951 & 0.250081815 & 0.273147583 & 0.187244254 & 0.209143724 & 0.181057445 & 0.093256474\end{array}$ 


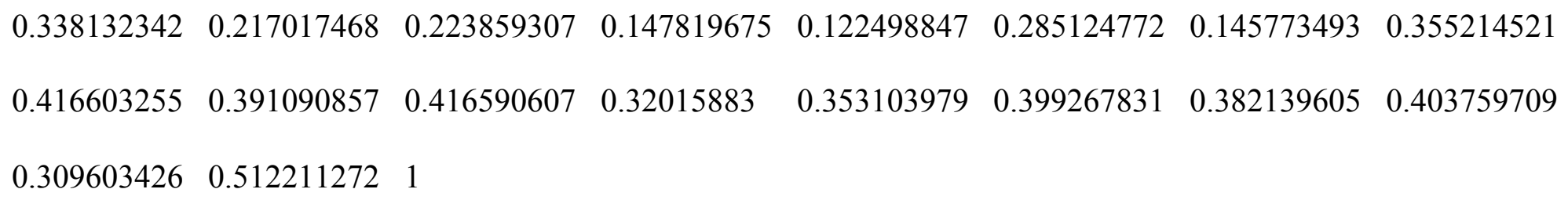

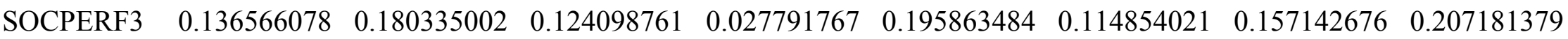

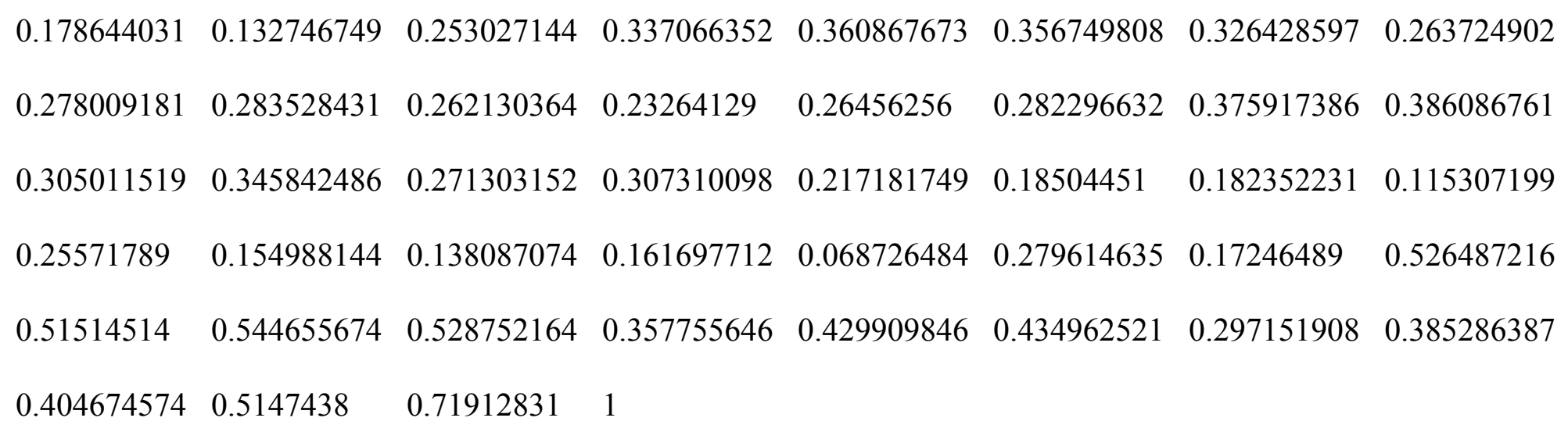

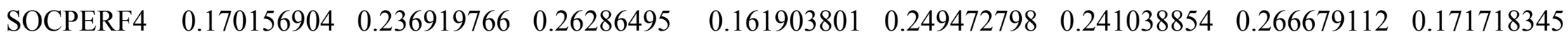

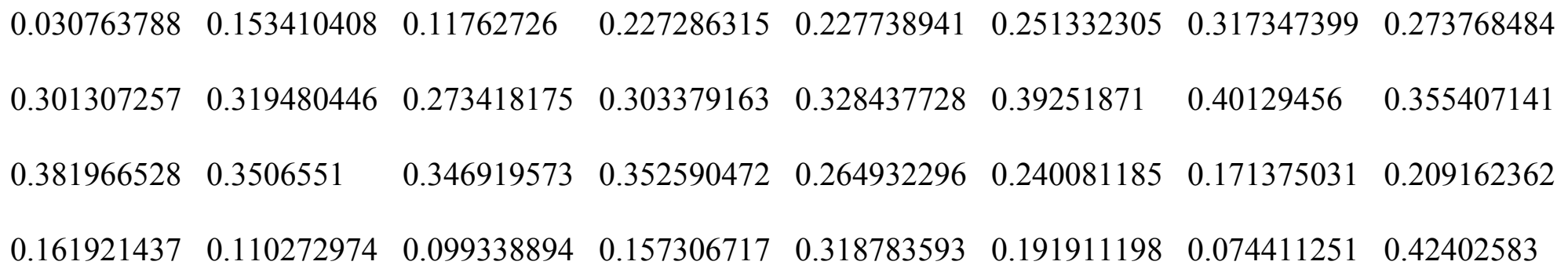


$\begin{array}{llllllll}0.333755163 & 0.40309017 & 0.388234892 & 0.462304856 & 0.42569318 & 0.457150951 & 0.269060945 & 0.352738687\end{array}$ $\begin{array}{llllll}0.451151507 & 0.419737566 & 0.397286011 & 0.496690299 & 1\end{array}$ 